UNIVERSIDADE DE SÃO PAULO
FACULDADE DE ECONOMIA, ADMINISTRAÇÃO E CONTABILIDADE
DEPARTAMENTO DE ECONOMIA

\title{
História do Debate do Cálculo Econômico Socialista
}

\author{
Fabio Barbieri
}

Orientador: Prof. Dr. Jorge. E. C. Soromenho

SÃO PAULO

2004 
Reitor da Universidade de São Paulo

Prof. Dr. Adolpho José Melfi

Diretor da Faculdade de Economia, Administração e Contabilidade

Prof. Dra. Maria Tereza Leme Fleury

Chefe do Departamento de Economia

Prof. Dr. Ricardo Abramovay 


\title{
História do Debate do Cálculo Econômico Socialista
}

\author{
Fabio Barbieri
}

Orientador: Prof. Dr. Jorge. E. C. Soromenho

Tese apresentada ao Departamento de Economia da Faculdade de Economia, Administração e Contabilidade da Universidade de São Paulo, como requisito parcial para a obtenção do Título de Doutor em Economia.

São Paulo

2004 


\section{FICHA CATALOGRÁFICA}

Elaborada pela Seção de Publicações e Divulgação do SBD/FEA/USP

Barbieri, Fabio

História do debate do cálculo econômico socialista /

Fabio Barbieri. -- São Paulo, 2004.

$284 \mathrm{f}$.

Tese (Doutorado) - Universidade de São Paulo, 2004

Bibliografia.

1. Economia - Teoria 2. História do pensamento econômico

3. Escola austríaca de economistas I. Universidade de São Paulo.

Faculdade de Economia, Administração e Contabilidade II. Título.

CDD - 330 
But planning is likely to be a more efficient method of reaching any chosen set of ends because reason is superior to instinct and knowledge to ignorance, and Professor Hayek must admit as much unless, indeed, he calls upon us to reject in despair the opportunities and responsibilities of full humanity. He can drive science out of economic life only by preferring instinct to reason and ignorance to knowledge. (Durbin, 1949:103)

The title of the present chapter, 'Between Instinct and Reason', is meant literally. I want to call attention to what does indeed lie between instinct and reason, and which on that account is often overlooked just because it is assumed that there is nothing between the two. That is, I am chiefly concerned with cultural and moral evolution, evolution of the extended order, which is, on the one hand ..., beyond instinct and often opposed to it, and which is, on the other hand ..., incapable of being created or designed by reason. (Hayek, 1988: 21)

But those who clamor for "conscious direction" - and who cannot believe that anything which has evolved without design ... should solve problems which we should not be able to solve consciously - should remember this: The problem is precisely how to extend the span of our utilization of resources beyond the span of the control of any one mind; and, therefore, how to dispense with the need of conscious control and how to provide inducements which will make the individuals do the desirable things without anyone having to tell them what to do. (Hayek, 1945:88) 


\section{Agradecimentos}

Gostaria de agradecer primeiramente ao meu orientador Prof. Dr. Jorge E. C. Soromenho pela inestimável ajuda e pelas sempre valiosas sugestões e críticas.

Agradeço também aos meus professores e colegas dos cursos de Mestrado e Doutorado em Economia do IPE, que contribuíram para minha formação e aos membros da comissão julgadora do meu exame de qualificação: Prof. Dr. José R. Chiappin e Prof. Dr. Eleutério Prado, pelos comentários a este trabalho.

Adicionalmente, devo à FIPE o financiamento dos dois primeiros anos de estudo e ao CNPq o ano e meio seguintes.

Por fim, agradeço a professora Regina Buongermino Pereira pela revisão do texto.

Dedico esta tese aos meus pais, que financiaram minha "adolescência tardia", de modo que pressões financeiras no início de minha pós-graduação não impedissem a sua continuidade, e à minha esposa, Yumi, pelas clássicas "horas de convivência subtraídas para que eu pudesse efetuar a pesquisa". 


\section{Resumo}

O propósito deste trabalho é estudar o Debate do Cálculo Econômico Socialista, desde a sua 'pré-história' a partir da Revolução Marginalista e o seu início em 1920 com o artigo de Ludwig von Mises até a moderna retomada do mesmo na década de noventa. Argumentaremos que a fonte do desacordo pode ser traçada nas diferentes percepções sobre a complexidade do problema alocativo. A desconsideração dessa complexidade por sua vez levou os economistas a usar a teoria microeconômica padrão para construir um novo sistema econômico, desconsiderando as assimetrias entre explicação e previsão/controle existentes na teoria econômica neoclássica. Em cada fase do debate, elementos importantes dos mercados reais, geralmente desconsiderados pela teoria econômica então prevalecente, foram utilizados para criticar as tentativas de solução do problema do cálculo. Em particular, a articulação de Hayek da abordagem austríaca de processo de mercado foi em parte fruto do debate e ainda é relevante para avaliar os méritos das propostas modernas de socialismo de mercado e o significado da teoria micro em geral. 


\begin{abstract}
The purpose of this work is to study the Socialist Economic Calculation Debate, from its 'prehistory' since the Marginalist Revolution and its beginning in 1920 with Ludwig von Mises' article to the modern reopening of the discussions in the 90's. We will argue that the source of the disagreement can be traced to the different perceptions about the complexity of the allocative problem. The neglect of this complexity in turn lead the economists to use the standard microeconomic theory to construct a new economic system, disregarding the asymmetries between explanation and prediction/control in neoclassical economic theory. At each phase of the debate, important elements of the real markets, usually disregarded by the economic theory prevailing in the moment, were used to criticize the attempts to find a solution to the calculation problem. Particularly, Hayek's articulation of the Austrian or market process approach to economic theory was in part fruit of this debate and is still relevant to evaluate the merits of the modern market socialist proposals and the significance of micro theory in general.
\end{abstract}




\section{Sumário}

1. INTRODUÇÃO: A HISTÓRIA DE UM DEBATE CENTENÁRIO......................................................... 10

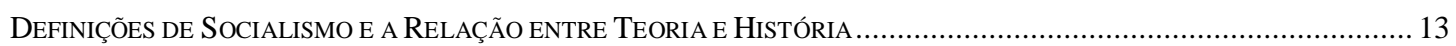

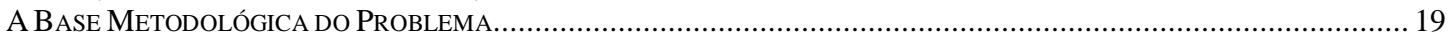

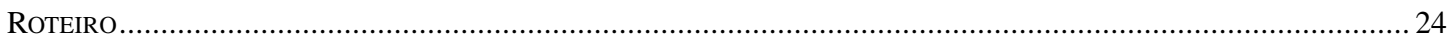

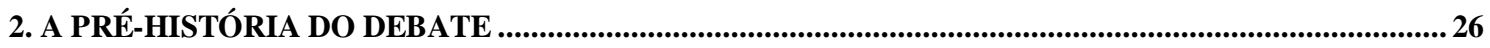

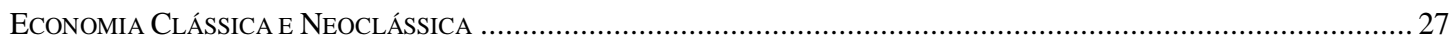

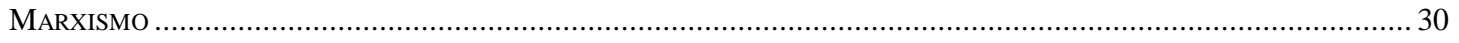

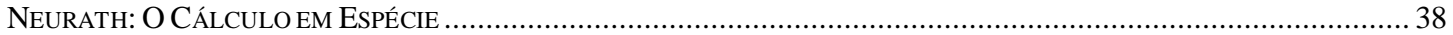

O Argumento de Similitude Entre Economias de Mercado e Socialistas............................................ 41

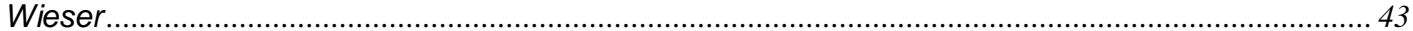

Böhm-Bawerk

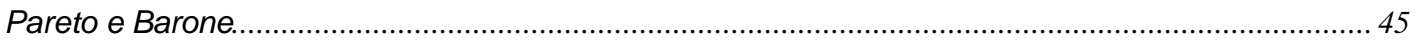

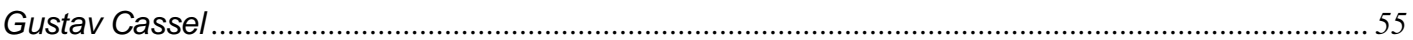

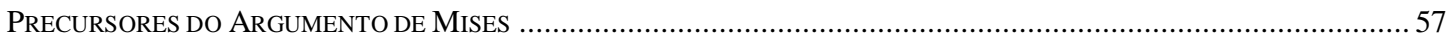

3. O ARGUMENTO DA IMPOSSIBILIDADE DO CÁLCULO ECONÔMICO SOCIALISTA.......................63

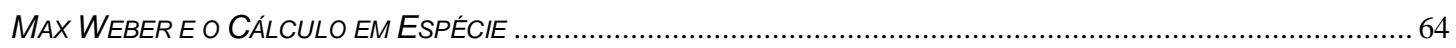

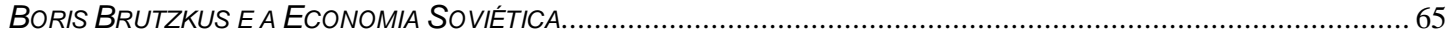

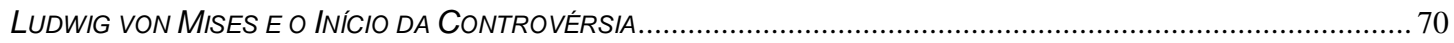

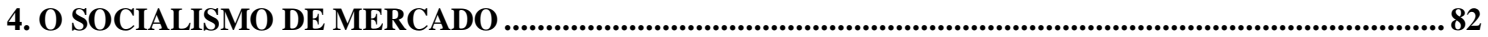

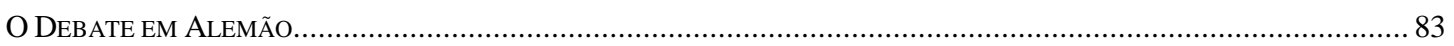

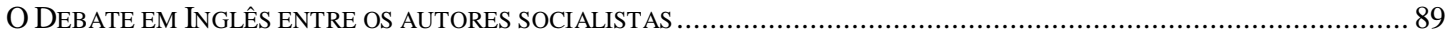

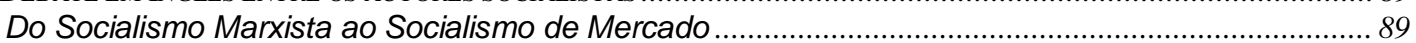

Teoria, Prática, Instituições e o Escopo da Teoria Econômica .............................................................. 93

As Propostas dos Socialistas de Mercado............................................................................................ 96

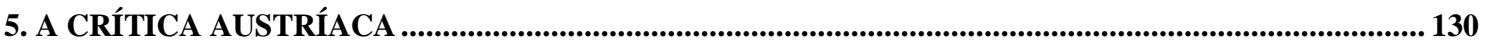

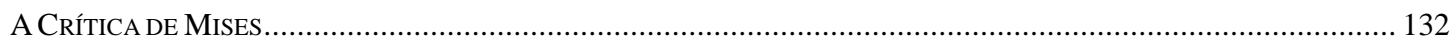

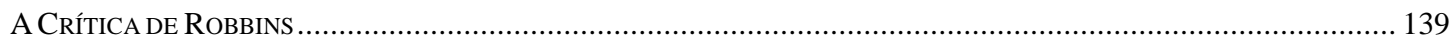

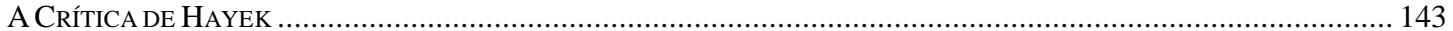

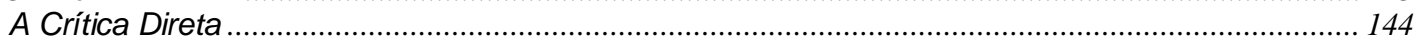

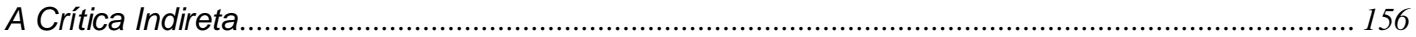

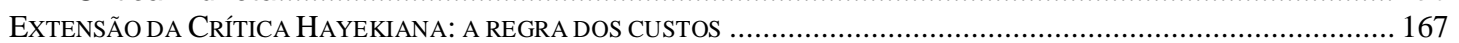

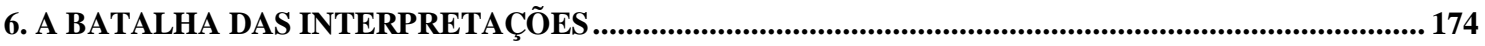

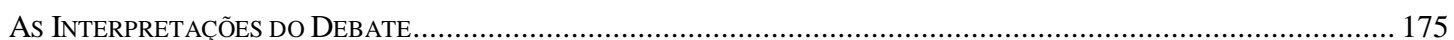

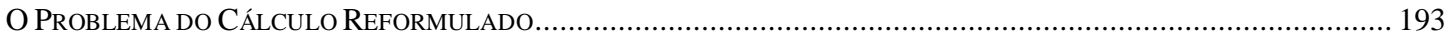

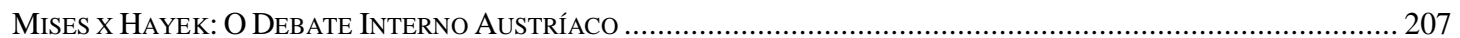

7. SOCIALISMO DE MERCADO MODERNO: INFORMAÇÃO E INCENTIVOS ..................................... 213

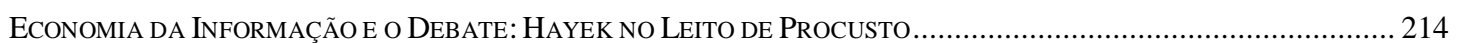

A Nova Geração de Modelos de Socialismo de MerCado.................................................................. 228

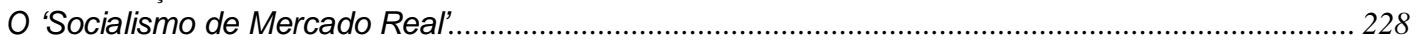

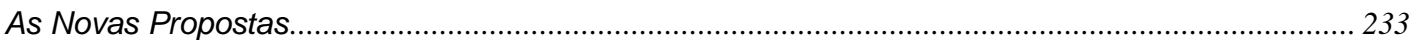

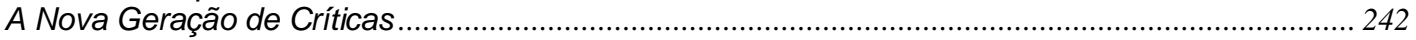

8. INFORMAÇÃO, CONHECIMENTO E COMPLEXIDADE DO PROBLEMA ECONÔMICO................. 252

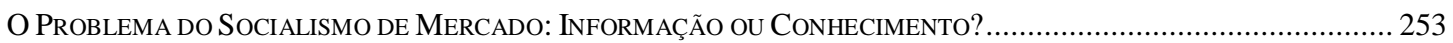

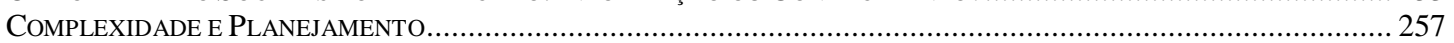

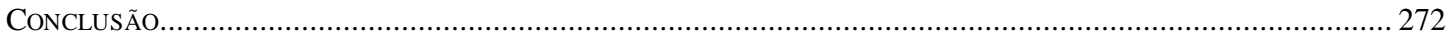

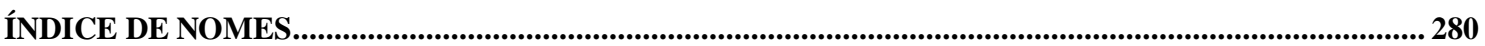

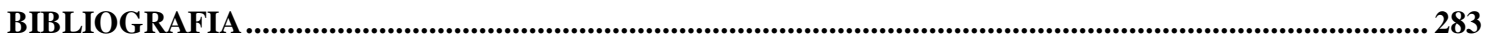




\section{Introdução: A História de um Debate Centenário}

Em 1920, na Áustria, em um período no qual o ideal socialista alcançava grande aceitação, o economista Ludwig von Mises publicou um artigo en que defendia a tese de que o socialismo não seria uma forma possível de organização social, a despeito do apoio que essa causa obtivesse, do ardor com que fosse desejado e da previsão marxista sobre sua inevitabilidade.

Para Mises, o socialismo marxista, que prometera trazer consigo a racionalidade para a esfera das atividades econômicas em substituição ao 'caos da produção capitalista', fracassaria justamente quando se investigasse à luz da teoria econômica como seria o funcionamento de uma economia socialista.

Mises notou que os autores marxistas pouco ou nada diziam sobre a natureza do sistema econômico socialista. A mesma observação foi feita pelo economista russo Boris Brutzkus, que simultaneamente formulou a crítica feita por Mises:

Scientific socialism, confining itself exclusively to a criticism of the capitalist economic order, has so far produced no theory for a socialist economic order. (Brutzkus, 1920:3)

Quando a análise econômica do socialismo fosse feita, chegaríamos então à conclusão de que ali não seria possível alocar os recursos escassos de forma racional. Segundo Mises, em qualquer sociedade, se os recursos forem escassos, a decisão sobre o emprego de um fator na produção de um bem deve sempre comparar a importância do recurso na produção desse bem com a sua importância em empregos alternativos. Em uma economia avançada, as formas como os bens podem se combinar nos processos produtivos são incontáveis, de modo que, sem um sistema de preços de mercado para que se possa comparar benefícios com custos - tarefa que o autor denomina 'cálculo econômico' - seria impossível escolher combinações economicamente viáveis. Como no socialismo não existiriam mercados nos quais preços fossem formados, o cálculo econômico seria impossível e estaríamos perdidos diante da complexidade do problema econômico. Em vez de racionalizar o processo produtivo, o socialismo traria o caos.

A tese de Mises é melhor resumida com as próprias palavras do autor:

Where there is no free market, there is no pricing mechanism; without a pricing mechanism, there is no economic calculation. (Mises, 1935:111) 
Desde a formulação dessa tese, os economistas socialistas têm buscado responder ao desafio de Mises, formulando modelos de socialismo que possam refutar o argumento da impossibilidade.

O conjunto de propostas de socialismo mais significativo foi formulado não por autores marxistas, mas sim por economistas neoclássicos, cujo programa de pesquisa reconhecia a importância do problema. Essas propostas procuravam resolvê-lo por meio da introdução no socialismo de alguma forma de sistema de preços, mesmo que fosse de forma simulada. A mais famosa dessas propostas foi sugerida pelo economista polonês Oskar Lange, em um artigo publicado em 1936-7, considerado o ponto culminante das discussões entre os economistas curiosamente denominados de 'socialistas de mercado'. Na versão final do modelo de Lange, as firmas estatais seriam instruídas a minimizar os custos médios e igualar os custos marginais aos preços enunciados centralmente. $\mathrm{O}$ planejador estabeleceria os preços que, por tentativas e erros, seriam alterados de forma a igualar oferta e demanda. O debate em torno desses modelos constitui o chamado Debate do Cálculo Econômico Socialista.

O objetivo desta tese é estudar tal debate. O estudo da controvérsia do cálculo se reveste de interesse por vários motivos. Em primeiro lugar, existe o interesse no objeto em si da discussão. Simpatizantes e opositores do socialismo, ambos devem levar a sério o argumento que afirma a impossibilidade de sua existência. Se correta a tese sobre a impossibilidade do socialismo, qualquer discussão sobre a desejabilidade se torna ociosa ou sobre a sua inevitabilidade incorreta. De forma mais geral, a discussão sobre a economia do socialismo feita no debate deve interessar a todos aqueles que investigam quais seriam as formas de organização social mais adequadas, ou seja, deve interessar a todos os cientistas sociais.

Em segundo lugar, o debate é importante para os economistas que se interessam pela evolução da teoria econômica e por questões metodológicas a respeito do significado da teoria que utilizam. Embora o debate propriamente dito se inicie em 1920, a discussão sobre como o socialismo lidaria com o problema alocativo sem um sistema de preços se estende por um período que se incia pelo menos desde 1850 até os dias de hoje. É curioso então estudar como o debate toma cursos diferentes conforme a teoria econômica avança e também como esta mesma deve parte desse avanço à própria controvérsia do cálculo. O debate passa pelo confronto entre as teorias clássica e neoclássica do valor, toma corpo com a maturação da teoria neoclássica, é parcialmente 
responsável pelo aprofundamento da cisão entre a Escola Neoclássica e a Escola Austríaca, se relaciona com a evolução da Teoria do Bem Estar e incorpora as contribuições posteriores da Escola de Escolha Pública e Teoria da Informação Assimétrica.

No debate, as teorias de equilíbrio geral e parcial foram utilizadas não para explicar o funcionamento dos mercados, mas sim para construir um novo sistema econômico. Isso, como veremos, dará origem a uma série de questões metodológicas sobre o significado e as limitações dessas teorias.

Finalmente, e em terceiro lugar, é interessante estudar a história da controvérsia por si mesma. Isso porque se trata de um dos debates mais interessantes da história da economia, no qual se envolveram alguns dos mais eminentes economistas do século vinte.

Dada a importância do debate, é de surpreender, mesmo entre os economistas, quão poucos são aqueles que já ouviram falar do mesmo. Adicionalmente, entre estes últimos, a maioria tem conhecimento de uma versão bastante distorcida. Enquanto nessa versão o argumento de um dos lados da controvérsia é totalmente descaracterizado, os historiadores modernos que a contestaram se preocuparam em recuperar o significado do argumento distorcido, deixando todavia de expor com cuidado os argumentos do outro lado. Por isso, é uma ambição do presente trabalho deixar os participantes falarem por si mesmos, de modo a apresentar uma narrativa que exponha todos os lados da questão. Isso, naturalmente, sem nos furtarmos de tomar posição sobre o mérito dos argumentos apresentados.

Outro intento que buscaremos no trabalho será a apresentação de uma história completa da controvérsia. Em vez de tratar apenas do núcleo do debate, ocorrido nas décadas de vinte e trinta do século vinte, procuraremos retomar com mais cuidado os seus antecedentes. Com efeito, o problema em questão já fora tratado em 1850 por Gossen, um dos precursores da Revolução Marginalista, e continuou sendo investigado por autores como Wieser, Cassel e Pareto, entre outros. Tampouco as discussões se encerram na década de trinta, quando ocorrem as principais tentativas de refutar a tese de Mises. Depois de um período de dormência, o debate é retomado na última década do século, e persiste até hoje. Este trabalho abarcará a fase moderna do debate, relacionando-a com as fases precedentes. 
Por último, formularemos uma interpretação do debate tendo como base uma particular abordagem sobre metodologia da ciência que explicitaremos ainda neste capítulo ${ }^{1}$. Antes disso, porém, devemos fazer uma série de observações a respeito da natureza do socialismo e também sobre a relação entre os fatos históricos a respeito do socialismo e a tese teórica debatida aqui.

\section{Definições de Socialismo e a Relação entre Teoria e História}

O pensamento marxista dominava o movimento socialista quando Mises escreveu seu artigo. Para essa tradição, não apenas os mercados, mas também os conceitos de valor, preço ou lucro desapareceriam no socialismo. Contrapondo-se a essa crença, a tese da impossibilidade pressupunha ausência de mercados. Como parte das tentativas posteriores de propor um modelo que refutasse Mises introduzia no socialismo algum elemento tirado das economias de mercado, sempre estiveram presentes dúvidas se aqueles modelos poderiam de fato ser considerados socialistas, o que nos leva a perguntar qual seria a natureza do socialismo.

Contudo, como nos ensina Popper, não existe algo mais fútil do que disputas em torno de definições. A menos que se acredite que exista uma definição correta do termo, incrustada em uma espécie de dicionário definitivo existente no mundo das idéias de Platão, as definições são apenas conceitos imperfeitos que, apesar de pretender capturar algo sobre entidades reais, dependem do referencial teórico e dos problemas com os quais o investigador se preocupa ${ }^{2}$.

Dessa maneira, apresentaremos algumas definições de socialismo dadas pelos participantes do debate, não com a intenção de encontrar a correta ou mesmo a melhor, mas sim com o propósito de determinar que características dos modelos propostos podem ser consideradas compatíveis ou não com a idéia de socialismo, ou seja, a fim de determinar se uma proposta pode ser vista como tentativa legítima de solução do problema do cálculo.

\footnotetext{
${ }^{1}$ Ver a seção mais adiante intitulada 'A Base Metodológica do Problema'.

${ }^{2}$ Não discutiremos aqui filosoficamente se existe uma realidade socialista objetiva à qual uma definição descritiva deva se aproximar de forma melhor possível. Isso só teria sentido se se pressupusesse que o socialismo de fato existe ou existirá. Mais isso é justamente o que se nega no debate. A tese de Mises implica que só podem existir definições em termos de propostas socialistas, já que para ele o socialismo em si não seria algo possível de existir.
} 
Uma proposta de socialismo que introduza mercados, por exemplo, será considerada ilegítima por aqueles socialistas marxistas que vêem no núcleo da idéia de socialismo a superação da produção de mercadorias, origem do que há de irracional no modo de produção capitalista. Para um socialista que define o sistema em termos da obtenção de igualdade, tal proposta pode ser vista como um meio legítimo. Ou ainda para outro que acredita que os mercados, especialmente os artificiais, podem ser totalmente controlados e usados como um instrumento de planejamento, o uso de mercados não implicaria em absoluto em perda de controle do processo produtivo ${ }^{3}$.

O socialismo pode ser então definido em relação aos fins almejados ou aos meios propostos para tal. No debate, Roemer (1994:11) e Weisskopf (1993:120) ilustram o primeiro tipo, definindo o socialismo em termos da busca de igualdade de oportunidades e direito à participação para todos os membros da sociedade. Esse tipo de definição é útil porque o conhecimento dos propósitos almejados nos ajuda a avaliar que proposta de socialismo se afina com o espírito desses objetivos. Contudo, é por demais ampla. Uma economia de mercado que por acaso gerasse uma distribuição igualitária deveria ser classificada como socialista?

A definição em termos dos meios, por sua vez, pode nos indicar que certos modelos que resolveriam o problema do cálculo não seriam considerados socialistas por outros participantes, já que negam por exemplo a abolição dos mercados. No debate, Flauerbaey (1993) propõe como solução uma sociedade com firmas administradas pelos trabalhadores, mas que competem em mercados. Além da rejeição marxista dessa proposta, o próprio Mises (1981) classificou uma proposta semelhante não como socialismta, mas sim 'sindicalista'.

Mises, assim como a maioria dos participantes do debate até a década de quarenta, definia o socialismo através da predominância da propriedade pública dos fatores produtivos. Isso pode ser visto em sua definição, feita em 1922:

All the means of production are in the exclusive control of the organized community. This and this alone is socialism. All other definitions are misleading. (Mises, 1981:211)

Essa definição foi razoavelmente aceita ao longo do debate. Isso pode ser verificado através de uma definição de Roemer, que, como dissemos, prefere algo mais relacionado aos fins últimos:

\footnotetext{
${ }^{3}$ No debate, a primeira postura será defendida por Dobb (1944), a segunda por Dickinson (1939) e a última por Lerner (1944).
} 
I therefore find it useful to define socialism not as a system in which there is, simply, public ownership, but as a system in which there are institutional guarantees that aggregate profits are distributed more or less equally in the population. (Roemer, 1993:89)

Além da propriedade, outro conceito chave relacionado ao socialismo é a noção de planejamento central. Embora a introdução parcial de mercados no socialismo enfraqueça o escopo relegado ao planejamento, ainda assim este ocupa um papel importante na percepção sobre o que viria a ser o socialismo. Isso pode ser visto na seguinte definição, talvez a mais completa, dada por Dickinson:

Socialism is an economic organization of society in which the material means of production are owned by the whole community and operated by organs representative of and responsible to the community according to a general economic plan, all members of the community being entitled to benefit from the results of such socialized planned production on the basis of equal rights. (Dickinson, 1949: 10)

Também para um dos opositores do socialismo, a abolição da propriedade privada implica em controle central:

[socialismo é un] Sistema de agresión institucional al livre ejercicio de la función empresarial en una determinada área social y que es ejercida por un órgano director que se encarga de las necesarias tareas de coordinación social en esa área. (De Soto, 1992:92)

A definição de De Soto se baseia na distinção liberal entre economias nas quais predomina a troca voluntária ou a atividade coercitiva, pertencendo o socialismo a este último tipo.

Por fim, resta notar que a maioria dos debatedores na década de trinta distinguia socialismo de comunismo nos seguintes termos:

A socialist economy in the classical sense is one that socializes production alone, as contrasted with communism, which socializes both production and consumption. (Lippincott, 1965:9)

Dados esses esclarecimentos a respeito dos fins e meios que os debatedores identificavam com o ideal do socialismo, iremos agora discutir em que medida os eventos históricos ocorridos nos países que se declaravam socialistas afetam as discussões teóricas do debate. O objetivo dessa discussão será afastar pretensas 'provas' ou 'refutações' empíricas das teses discutidas no debate e justificar por que este trabalho se limitará aos aspectos teóricos do problema.

Bergson (1948:448), seguido por Boettke (2000), sugere uma regra a ser observada pelos participantes do debate: teoria deve ser comparada com teoria e fato com fato. Não se pode comparar o modelo da competição perfeita com a economia soviética ou um modelo ideal de socialismo com as economias ocidentais presentes. Em ambos os casos, a idealização teórica obviamente vence a realidade. 
A adoção dessa regra, à primeira vista adequada, suscita no entanto uma série de dificuldades, derivadas da impossibilidade de se definir os 'fatos' de forma inequívoca. Os dados empíricos, como enfatizam autores como Weber ou Popper, são impregnados de teorias: não existem aqueles sem estas. Como participaram do debate economistas de diversas formações - marxistas, walrasianos, marshallianos, austríacos, teóricos da informação e escolha pública - a mesma realidade pode ser vista como 'fatos' diferentes por cada um deles, conforme o conjunto de teorias econômicas e sociológicas de cada um. O que faremos em seguida é mostrar como alguns fatos são vistos de forma diversa por defensores e críticos do socialismo, conforme alteramos os óculos teóricos empregados.

$\mathrm{Na}$ comparação entre teoria e realidade do socialismo e economias de mercado, temos de fato todas as combinações possíveis. A economia da União Soviética foi considerada socialista tanto por socialistas quanto por opositores do socialismo. Por outro lado, tanto opositores quanto defensores negaram que fosse de fato socialista. Adicionalmente, o experimento soviético foi tanto utilizado como evidência de que o socialismo seria impossível quanto para afirmar o contrário. Já quanto às economias ocidentais, os seus problemas podem ser vistos como inerentes ao capitalismo pelos socialistas ou tributáveis ao estatismo pelos liberais. Vejamos mais de perto algumas dessas posturas.

No debate do cálculo, Bergson (1948:447) cita a posição segundo a qual a existência da URSS refutaria a tese de Mises: o funcionamento dessa economia provaria que o socialismo e o planejamento central seriam possíveis.

Robbins, por outro lado, disputa a tese de que a URSS alocava recursos de forma adequada, sem enormes desperdícios de recursos. A experiência dos primeiros anos da revolução bolchevique, por sua vez, foi utilizada por Brutzkus (1935) como prova da tese da impossibilidade: a abolição do sistema de preços teria causado o caos econômico. Esse fracasso é por sua vez atribuído por Nove e outros aos distúrbios causados pela Primeira Guerra Mundial.

Depois da $\mathrm{NEP}^{4}$, o período dos planos qüinqüenais também foi invocado para contradizer empiricamente a tese de Mises. Michael Polanyi (2003:210), por outro lado, acredita que os planos anuais não envolviam planejamento em absoluto. Para ele, na realidade, o suposto plano seria um resumo sem significação de planos agregados

\footnotetext{
${ }^{4}$ NEP: Nova Política Econômica, período de relaxamento do controle econômico por parte do partido bolshevique. Sucedeu a chamada "Economia de Guerra", fase mais centralizadora do início do regime.
} 
travestidos de plano único (pág. 112). Seria como se no xadrez um chefe de equipe afirmasse: nosso plano é avançar 45 peões em uma casa, 20 bispos 3 casas na media, 15 torres 5 casas, e assim por diante, sem referência às posições do tabuleiro. No 'plano', agregados de produção são retirados de seus contextos econômicos e encarados como simples processos de mudança física (pág. 214).

Também alguns socialistas negam que a Rússia tenha passado por um experimento socialista, já que este, segundo as previsões de Marx, surgiria em economias avançadas e não rurais. A URSS seria então uma forma de capitalismo de estado.

Os processos de reforma na Iugoslávia e Hungria a partir da década de sessenta, por sua vez, foram ora vistos como um exemplo real dos modelos propostos no debate, que misturavam mercados com propriedade pública (Bergson, Drenowski), ora vistos apenas como um dos primeiros passos para o abandono do socialismo (Kornai).

Por sua vez, os problemas encontrados nas economias americana e européias foram considerados como inerentes ao capitalismo por Lange (1936-7), um economista influenciado pelo marxismo. Já Mises e Hayek, pertencentes a uma tradição liberal, não compartilham da visão sociológica marxista sobre a natureza do 'capitalismo'. Para eles, essas economias devem ser estudadas como economias mistas. Uma forma particular de intervenção não seria então inerente ao estado capitalista, mas dependente de fatores como a lógica do processo de intervenção e ideologia dos governos, que por sua vez não pode ser reduzida a interesses de classes da forma defendida pelo marxismo. Mises, por exemplo, formula uma teoria sobre a dinâmica do 'intervencionismo',5 para explicar o desempenho das economias modernas. Os problemas dessas economias são então atribuídos à forte intervenção do estado na economia e os méritos à esfera privada, da mesma forma que um estatista atribui os pontos positivos das economias mistas a programas governamentais e os fracassos ao mercado.

Poderíamos então modificar o conselho de Boettke, recomendando a comparação de teoria com realidade em cada um dos sistemas econômicos. Isso também não é simples em ciência social. As diferenças entre mercados livres e teoria da competição perfeita podem em graus diferentes ser atribuídas tanto a falhas de mercado, diante do que a realidade pode ser alterada para fazer jus aos padrões da teoria, ou a 'falhas de teoria',

\footnotetext{
${ }^{5}$ Ver Mises, L. Uma Crítica ao Intervencionismo e Ikeda (1997), para uma versão moderna dessa teoria.
} 
diante do que a teoria deve ser alterada para dar conta de explicar as complexidades dos mercados reais. As diferenças entre o 'socialismo real' e a teoria do planejamento podem também ser atribuídas a falhas de implantação dessa teoria, o que leva à conclusão de que o modelo deva ser implementado por outras pessoas ou partidos, ou ainda se deve esperar o momento histórico correto, ou a falhas de teoria, caso em que a evidência empírica mostraria a impossibilidade do planejamento.

Por fim, devemos invocar nessa discussão a distinção clássica difundida por Neville Keynes entre ciência normativa e positiva, a primeira descrevendo, sem juízos de valor, 'o que é' e a segunda indicando 'o que deveria ser' a partir de preceitos morais ou éticos e preferências políticas.

Drenovski (1961:342), com base nessa distinção, critica o irrealismo do modelo de ‘socialismo de mercado' de Lange na medida em que este não lembra em absoluto o socialismo real. A teoria econômica do socialismo deveria ser então mais positiva, relacionada à economia soviética e menos normativa, como nos trabalhos de Lange, Lerner e demais 'socialistas de mercado'.

Entretanto, a mencionada distinção, na nossa opinião, adiciona ainda mais confusão à questão. A inadequabilidade da distinção repousa em última análise na necessidade de separação, dentro da ciência positiva, entre aquilo 'que é' e aquilo 'que poderia ser' ${ }^{6}$. A construção de um modelo teórico de um socialismo ainda não existente em parte alguma, segundo essa nova ótica, não se classifica como ciência normativa, uma sugestão ética sobre como o mundo deveria ser e não é, mas sim como ciência positiva, a investigação de como poderia funcionar uma sociedade baseada em um conjunto alternativo de instituições.

A discussão sobre a relação entre teoria e prática é então complicada pela óbvia impossibilidade de se comparar a teoria com a realidade, dado que tal realidade ainda não existe, embora estejamos tratando de um problema da ciência positiva ${ }^{7}$. O problema do cálculo, aliás, consistiu em uma discussão teórica a respeito da possibilidade de existência na prática dessa realidade alternativa denominada 'socialismo'.

\footnotetext{
${ }^{6}$ Hayek (1982:16) percebe a necessidade dessa separação quando afirma que a ciência não deve se limitar a descrever apenas o existente, pois grande parte de seu interesse repousa justamente nos casos em que se possa especular sobre estados de coisas diversos dos atuais.

${ }^{7}$ Da mesma forma que um modelo sobre os efeitos do choque de um asteróide hipotético com a Terra não seria "física normativa".
} 
Discordamos então da crítica de Drenowski, que demanda que a investigação deva seguir em termos positivos conforme usualmente este termo é entendido. Steele (1991) concordaria com a nossa opinião, pois esposa em seu livro sobre a controvérsia do cálculo a causa do 'socialismo utópico', entendido não no sentido de Marx, mas sim como a tarefa intelectual de imaginar sistemas alternativos de funcionamento da sociedade.

Tudo isso foi dito com a intenção não de defender uma visão relativista em ciência social, mas para apontar que a questão é complexa e pouco afeita a comparações empíricas simplistas. Assim, os fatos não mostram necessariamente, de forma inequívoca, o fracasso do socialismo ou das economias ocidentais ou mesmo que uma terceira via seria a alternativa.

Por causa da diversidade de interpretações dos fatos, e pelo nosso interesse na história das teorias, nos limitaremos à controvérsia teórica, que aliás ocupou quase a totalidade das discussões no debate do cálculo. Faremos referência a argumentos empíricos somente naqueles pontos nos quais esses argumentos inspiraram novas contribuições teóricas aos modelos propostos na controvérsia.

\section{A Base Metodológica do Problema}

Como já mencinamos anteriormente, o estudo da controvérsia nos ajuda a compreender o significado da própria teoria econômica moderna. Isto porque importantes problemas relativos ao uso apropriado da teoria afloram quando analisamos os argumentos dos economistas que procuraram refutar a tese de Mises. A teoria neoclássica, concebida originalmente para explicar o funcionamento dos mercados, a partir do debate passou a ser utilizada para criar e controlar um sistema econômico alternativo ${ }^{8}$. No centro das discussões encontradas nesta tese estará a exploração do significado e da legitimidade do uso dos postulados da teoria e quando esta é utilizada nesse segundo modo.

A importância dessas questões, argumentaremos, dependerá da concepção que se tem sobre a complexidade do problema alocativo que Mises requer que seja resolvido no

\footnotetext{
${ }^{8}$ Utilizando a distinção positivo/normativo, Brus e Laski (1992:56) questionam de modo similar a utilidade da teoria neoclássica quando esta prescreve regras de ação em vez de apenas descrever os princípios de funcionamento dos mercados.
} 
socialismo. Isto porque, admitida a complexidade do problema, a simetria em uma teoria entre explicação por um lado e previsão e controle por outro se rompe ${ }^{9}$.

Para entendermos o significado dessa afirmação, devemos primeiramente investigar o que entendemos por complexidade e as conseqüências metodológicas do estudo dos fenômenos complexos. A melhor maneira de fazê-lo é através do exame de um artigo escrito por Hayek [1967] intitulado The Theory of Complex Phenomena. Visto que defendemos a tese de que o problema da complexidade está no centro da controvérsia do cálculo, não é de surpreender que Hayek, um dos participantes do debate, tenha se interessado por esse tema.

Nesse artigo, Hayek crê que quando passamos dos fenômenos físicos para os biológicos e desses para os mentais e sociais há um aumento de complexidade. O grau de complexidade, para Hayek (1967:25), se relaciona com o número mínimo de elementos de um fenômeno ou padrão necessário para descrevê-lo de forma satisfatória. Assim, as fórmulas da Física tipicamente envolvem poucas variáveis, e as previsões obtidas com tais fórmulas exibem grande precisão. Evidentemente, a composição de fenômenos físicos simples pode resultar em algo complexo. Os fenômenos biológicos e sociais, por outro lado, quase nunca são simples no sentido exposto ${ }^{10}$.

A diferença fundamental entre o estudo dos fenômenos simples e dos complexos residiria então no fato de que, nos primeiros, as relações entre os elementos individuais do fenômeno (ou padrão) estudado não importam na sua explicação, enquanto que as relações estruturais entre tais elementos são fundamentais para que possamos estudar os segundos.

Por exemplo, para explicar a temperatura de um gás contido em um recipiente precisamos saber apenas a velocidade média de suas moléculas, enquanto que para entender o funcionamento do cérebro precisamos apelar para a localização dos neurônios e suas relações com os demais. Para prever precisamente o comportamento do padrão complexo, seria necessária uma quantidade gigantesca de informações detalhadas sobre as interações entre seus elementos e não apenas o 'resumo' dessas informações, expresso na forma de dados estatísticos.

\footnotetext{
${ }^{9}$ Ver Blaug (1980:40) e Feijó (2003:37) para a apresentação da tese da simetria entre explicação e previsão no modelo hipotético-dedutivo.

${ }^{10}$ Popper, na Miséria do Historicismo, professa a crença oposta: os fenômenos humanos seriam mais simples porque, ao contrário dos fenômenos físicos, temos a vantagem de conhecer por introspecção a existência da ação proposital que guia os agentes.
} 
Podemos derivar dessas observações a conclusão de que para fenômenos simples existe uma simetria entre explicação e previsão: as fórmulas da Física e Química, suficientes para descrever certos fenômenos com precisão, quando alimentadas com dados do passado fornecem uma 'explicação' do ocorrido; quando alimentadas com dados presentes, fornecem uma 'previsão' precisa sobre o que ocorrerá no futuro. Para os fenômenos complexos, por outro lado, jamais poderíamos conhecer os dados com a riqueza de detalhes necessária para que possamos fazer previsões exatas para o futuro. Por outro lado, podemos olhar o passado e explicá-lo com a teoria, imaginando que determinados fatores não observados estavam presentes. Existe então uma assimetria entre explicação e previsão no que se refere a teorias sobre esses fenômenos.

$\mathrm{O}$ argumento desenvolvido no parágrafo anterior parece implicar que o teste de hipóteses sobre fenômenos complexos seria impossível. Hayek, no entanto, preserva no mencionado artigo uma postura popperiana ao indicar que, a partir de tais teorias, podemos fazer previsões de padrão (pattern predictions). Podemos ilustrar a idéia do autor com um exemplo: embora a meteorologia não possa afirmar que amanhã ao meiodia formar-se-á uma nuvem na forma de coelho, pode prever que sob tais e tais condições formar-se-ão cumulus nimbus, que apresentam uma série de características específicas. Hayek ilustra ainda o ponto com a teoria da evolução: embora esta não seja capaz de prever que conjunto de animais evoluirá em certa data futura, a teoria não é destituída de conteúdo empírico, pois existem certas previsões como por exemplo 'o corte de um membro em sucessivas gerações de uma espécie não resultará no nascimento de indivíduos sem tal membro'. Hayek conclui então que se deve buscar refutar as teorias, como quer Popper; no entanto, o aumento da complexidade do fenômeno reduz forçosamente o grau de falseabilidade das teorias.

O reconhecimento de que é impossível prever os detalhes de um padrão complexo por falta de conhecimento sobre os detalhes de sua estrutura também implica na impossibilidade de construir e controlar esse padrão de forma centralizada, conclusão essa que Hayek desenvolve ao longo de várias de suas outras obras ${ }^{11}$ :

We can never produce a crystal or a complex organic compound by placing the individual atoms in such a position that they will form the lattice of a crystal or the system based on benzol rings which make up an organic compound. But we can create the conditions in witch they will arrange themselves in such a manner. (Hayek, 1982:39-40)

\footnotetext{
${ }^{11}$ Ver por exemplo Hayek $(1982,1988)$.
} 
Estruturas altamente complexas emergem a partir da interação de seus elementos, que seguem regras cujo propósito, se houver, não inclui a obtenção da estrutura emergente. Hayek (e também Michael Polanyi) denomina essas estruturas de 'ordens espontâneas'. Embora nem todas as ordens espontâneas sejam complexas (Hayek, 1982:38), para que se obtenha um alto grau de complexidade é necessário transcender a capacidade cognitiva de um indivíduo ou grupo que tente planejar a estrutura em seus detalhes. Um dos princípios de organização dessas ordens espontâneas é o mecanismo de correção de erros dado pelo princípio de seleção natural na biologia ou o mecanismo de lucros e perdas nos mercados.

Voltamos agora à controvérsia do cálculo, informados pelas considerações sobre a natureza dos fenômenos complexos que tecemos acima. Se a alocação de recursos através dos mercados for de fato um exemplo desse tipo de ordem espontânea complexa a que nos referimos acima, o desafio de Mises requer uma resposta para o problema de substituir o mercado por um outro mecanismo capaz de lidar pelo menos com o mesmo grau de complexidade.

A resposta a Mises, entretanto, baseou-se na teoria neoclássica. Inspirada que é na mecânica e não na teoria da evolução, esta teoria trata os fenômenos complexos do mercado como fenômenos simples. Um produto simplório como, digamos, uma laranja, apresenta uma quantidade enorme de dimensões competitivas, como tipos, tamanhos, frescor, localização geográfica, serviços que acompanham o produto, entre outras características, características essas que levariam anos apenas para que fossem listadas.

A teoria econômica, no entanto, despreza essa variedade quando adota a hipótese de produtos homogêneos. As várias maneiras de produzir os bens, por outro lado, estão sob um constante processo de mudanças inovadoras. Na teoria, entretanto, temos um conjunto de opções técnicas estáveis e bem conhecidas, congeladas nas funções de produção. Uma curva de demanda ou oferta deixa então de fora, intencionalmente, as milhares de complicações que de fato impedem que tais curvas sejam relativamente estáveis ${ }^{12}$.

\footnotetext{
12 Tais curvas, embora não reflitam a complexidade do fenômeno em questão, podem ser utilizadas como um exemplo de padrão a que Hayek (1967) se refere: embora seja impossível preencher uma curva com elementos empíricos concretos, dadas a complexidade e a mutabilidade do fenômeno, a idéia apresenta algumas propriedades do padrão complexo denominado demanda. Watkins sugere o uso do termo 'teoria algébrica' para expressar a idéia. Keynes profere opinião semelhante em uma carta a Roy: "but it is of the essence of a model that one does not fill in real values for the variable functions. To do so would make it useless as a model". A idéia é captada ainda por Mises quando afirma que "não existem constantes no comportamento humano [como as constantes da Física]"
} 
Os defensores da teoria reagem a esse tipo de crítica lembrando que toda teoria é uma simplificação e que o mapa mais realista (e inútil) é aquele com escala 1:1. A isso devemos replicar que a crítica não é dirigida à simplificação por si mesma, mas sim ao uso indiscriminado de uma particular simplificação, independentemente da natureza do problema em pauta. Com tais simplificações, por exemplo, podemos explicar um enorme conjunto de fenômenos econômicos e até realizar uma série de 'previsões de padrão' do estilo 'uma geada, ceteris paribus, resultará na elevação do preço da laranja'. Porém, quando a mesma teoria é utilizada para controlar o funcionamento da economia, como é feito nos modelos de socialismo de mercado, estamos impondo a simplicidade do modelo à própria realidade.

Impor um preço único para 'a' laranja levando em conta a demanda e a oferta agregadas dos diversos tipos do produto levaria não a um equilíbrio eficiente, mas sim a uma série de excessos de demanda ou oferta em cada mercado desagregado, que só poderiam ser eliminados por ajustes no custo de fabricação, como diminuição da qualidade (do lado da oferta) e substituição do produto (do lado da demanda), ajustes esses que levam a uma diminuição de bem-estar quando comparamos com as escolhas em um mercado não restrito dessa maneira. A imposição de um imposto de Pigou, por sua vez, além de desconsiderar o problema discutido acima, tem que pressupor para o seu cálculo que os custos, as funções de produção e as demandas sejam não só estáveis como também conhecidas, em flagrante oposição à realidade.

Na controvérsia do cálculo ocorre precisamente essa transferência da simplicidade do modelo para a realidade. Os defensores dos mercados artificiais, como veremos ao longo do trabalho, tendem a esquecer que a teoria é uma simplificação, acreditando que a realidade é tão simples quanto a teoria a descreve. Por isso, a crítica não será dirigida sequer ao mérito do conjunto de hipóteses adotadas pela teoria neoclássica, mas sim ao seu uso inadequado, que não leva em conta as questões metodológicas discutidas acima: tendo em vista a complexidade do problema alocativo, a teoria é útil para descrever, em um plano altamente idealizado, o tipo de ajuste necessário para o funcionamento dos mercados, mas não para construr um sistema alocativo, como ao cristal da ilustração de Hayek mencionado anteriormente.

Tendo em vista isso, de um lado da controvérsia teremos um grupo de economistas que negam a natureza complexa dos fenômenos econômicos e evitam a todo custo a discussão de elementos dos mercados que ficam fora do que a teoria descreve e, do 
outro lado, economistas que apontam os elementos dos mercados reais que seriam essenciais para o seu funcionamento e que no entanto são descartados pela teoria. $\mathrm{O}$ estudo da controvérsia, deste modo, se reveste de vivo interesse na medida em que podemos aprender (ou lembrar) quais são os aspectos relevantes dos mercados que os economistas profissionais deixam de lado e que muitas vezes viciam as suas conclusões.

\section{Roteiro}

O presente trabalho é dividido da seguinte maneira. No segundo capítulo descrevemos a 'pré-história' do debate, que trata das primeiras aplicações da teoria neoclássica ao problema da economia socialista, desde Gossen em 1850 até os trabalhos de Wieser e Pareto, entre outros. Esses trabalhos estabelecem que a natureza do problema econômico - a escolha diante da escassez - seria a mesma em qualquer sociedade.

Em seguida, no capítulo 3, trataremos do início da controvérsia. Mises, Weber e Brutzkus afirmam simultaneamente que o socialismo seria impossível devido à incapacidade de resolver o problema alocativo na ausência de mercados. No capítulo 4, analisaremos a primeira geração de tentativas de refutar a tese de Mises. Estudaremos o debate em alemão que ocorreu na década de vinte e o debate em inglês da década de trinta, que versa sobre as propostas de 'socialismo de mercado'.

No capítulo seguinte, estudaremos as objeções que os economistas austríacos fizeram a esse tipo de solução, em especial a reação de Hayek às propostas de socialismo de mercado. Como sub-produto dessa crítica, veremos como tomou corpo a formação de um programa de pesquisa austríaco próprio, distinto do programa neoclássico tradicional.

No capítulo 6, estudaremos o período entre o final dessa fase do debate, em torno de 1940, até antes de sua retomada, em 1990. Esse período é rico em interpretações alternativas sobre quem teria 'ganho' o debate. No final desse capítulo retomaremos a discussão desenvolvida na seção acima, construindo a nossa própria avaliação da controvérsia.

No sétimo capítulo, veremos como os desenvolvimentos teóricos ocorridos na segunda metade do século vinte, em especial a economia da informação, deram origem à retomada do debate, com novos modelos de socialismo de mercado que procuram 
desenhar mecanismos de incentivos para lidar com o problema agente-principal no socialismo.

Finalmente, no oitavo capítulo, estudaremos outras contribuições contemporâneas ao debate que retomam a visão marxista sobre o problema. A discussão dessas contribuições nos levará de volta àquilo que identificamos como o ponto central da questão, a saber, a complexidade do problema alocativo. Concluiremos com uma avaliação geral do debate e especulações sobre que rumo poderá tomar no futuro. 


\section{A Pré-História do Debate}

Embora a controvérsia do cálculo tenha se iniciado com o artigo de Mises, vários outros autores discutiram antes dele as implicações da teoria neoclássica para a economia socialista. Essas discussões, naturalmente, abordam de uma forma ou outra as questões levantadas por Mises em seu artigo, algumas delas antecipando o argumento da impossibilidade, embora de forma menos desenvolvida ou contundente.

Neste capítulo traçaremos a 'pré-história' do debate, com o objetivo de situar o artigo de Mises na história intelectual do problema, de forma que possamos melhor entendê-lo. $\mathrm{O}$ texto de Mises, lido fora do contexto, foi de fato freqüentemente distorcido ou incompreendido pelos comentaristas.

Em primeiro lugar mencionaremos alguns elementos do pensamento socialista ao qual Mises dirigiu o seu ataque - o marxismo - enfatizando a diferença de natureza dos problemas econômicos tratados por um lado pela escola clássica, que guiou o pensamento socialista até então, e por outro pela escola neoclássica, que orienta o ataque de Mises.

Em seguida, já no contexto neoclássico, visitaremos os textos de autores que procuravam mostrar que a natureza do problema econômico fundamental tanto no socialismo quanto nas economias de mercado seria a mesma. Tal argumento, de 'similitude formal' entre socialismo e economias de mercado, foi exposto tanto pela tradição austríaca à qual se filia Mises quanto pela tradição walrasiana, que mais tarde dará suporte aos oponentes de Mises.

Finalmente, veremos os precursores do argumento de Mises, observando em que medida o anteciparam.

Naturalmente, não faremos menção a toda uma vasta literatura crítica ao socialismo anterior a Mises. Primeiramente porque, dado o seu volume, não seria humanamente possível. Em segundo lugar, porque a natureza da crítica de Mises ao socialismo não é comum nessa literatura, visto que a base teórica da crítica se firmou apenas em 1871 com a Revolução Marginalista. 


\section{Economia Clássica e Neoclássica}

A crítica de Mises foi dirigida principalmente contra o marxismo, a forma prevalecente de pensamento socialista no início do debate. Para que compreendamos o significado do seu argumento, devemos antes esboçar alguns elementos importantes da concepção marxista do socialismo e da sua origem na teoria econômica clássica ${ }^{1}$.

O desafio de Mises pode ser historicamente entendido como conseqüência natural da mudança de percepção sobre a natureza do problema fundamental da ciência econômica que ocorreu na Revolução Marginalista. Como a idéia do socialismo entre os economistas foi moldada durante o predomínio da escola clássica, os textos socialistas não tocam assim nos problemas econômicos só enfatizados pelos economistas neoclássicos. Mises simplesmente chama a atenção dos socialistas a esses problemas. Para que entendamos isso precisamos antes mostrar que problemas definem as duas tradições teóricas.

Segundo a caracterização feita por Hicks (1976), enquanto a preocupação fundamental da escola clássica era a plutologia - o estudo da produção e distribuição da riqueza, a escola neoclássica se ocupa da catalaxia - o estudo das trocas. As duas escolas, evidentemente, falam de produção e trocas:

There is of course no doubt that exchange is a basic feature of economic life, at least in a 'free', or what Marx would have called a 'capitalist' economy. By none of the classical economists would that have been denied. But while the classics looked at the economic system primarily from the production angle, the catallactists looked at it primarily from the side of exchange. It was possible, they found, to construct a 'vision' of economic life out of a theory of exchange, as the classics had done out of the social product. It was quite a different vision. (Hicks, 1978:212)

O que distingue as duas visões, então, será a natureza do problema fundamental tratado pelas duas tradições. Ao estudar os determinantes da produção agregada de riqueza de um país e de seu crescimento no longo prazo, os clássicos precisavam de uma medida de valor que reduzisse os bens heterogêneos a um denominador comum. O ponto de partida da análise, porém, era a produção.

Já para os economistas neoclássicos, que buscavam explicar a adequação de meios diversos aos fins almejados pelos agentes, o valor dos bens, dado pela importância

\footnotetext{
${ }^{1}$ Boettke (1998) observa com razão que o argumento de Mises só pode ser entendido tendo em vista a audiência a que se dirigia. A diferença fundamental entre as exposições do argumento do cálculo feitas por Mises e por Hayek está no fato de que enquanto o primeiro escrevia para autores marxistas, o segundo escrevia para economistas neoclássicos. A ignorância desse fato, como já aludimos, levou a distorções sobre o significado da crítica de Mises.
} 
desses bens para atingir os fins, guiava tanto as escolhas nas trocas de mercado quanto as escolhas sobre o que e como deve ser produzido (o que pode ser visto como troca com a natureza).

Embora na primeira teoria o sistema de preços oriente no curto prazo a alocação de recursos, no longo prazo os preços gravitam em torno dos custos de produção determinados em essência pela quantidade de trabalho empregada na produção dos bens. Para os economistas 'cataláticos', por outro lado, não é possível determinar esses custos de forma independente do sistema de preços, na medida em que as técnicas produtivas utilizadas (a proporção entre os fatores) dependem da importância dos usos alternativos dos recursos produtivos ${ }^{2}$. O custo de oportunidade do uso de um fator é visto como a utilidade marginal daquilo que se abdica quando se faz uma escolha. Dessa forma, quando um fator de produção passa a ser mais solicitado em um uso alternativo, o seu preço sobe e a continuação de seu uso na fabricação de um bem nas proporções usuais pode representar um desperdício alocativo, de forma que a proporção de fatores utilizados na fabricação deste bem pode ser alterada.

Para a catalaxia, portanto, não existem em uma economia técnicas produtivas determinadas a priori, independente do problema alocativo tal como este é visto pelos economistas neoclássicos. A escolha da proporção e quantidade de fatores, e portanto o custo de produção, depende de como varia ao longo do tempo a utilidade marginal desses fatores na produção de outros bens. Trata-se de uma escolha econômica, não uma escolha técnica.

De fato, no próprio ensaio que define a Economia como a ciência que "estuda o comportamento humano como uma relação entre fins e meios escassos que têm usos alternativos" (Robbins, 1932:15), podemos encontrar por parte do seu autor o contraste entre o problema econômico e o problema técnico. Enquanto que neste último escolhese os usos dos recursos tendo em vista fatores técnicos, no primeiro, devido a possibilidade de empregos alternativos dos recursos escassos, escolhe-se tendo em vista o custo de oportunidade. Robbins dedica considerável espaço de seu ensaio a criticar a confusão entre os dois problemas que ocorre quando se utiliza a definição antiga de

\footnotetext{
${ }^{2} \mathrm{O}$ contraste entre as duas visões pode ser encontrado em autores 'cataláticos' já no período clássico. Say (1983:275), por exemplo, ao criticar Ricardo, afirma que a demanda final por diversos produtos influi sobre o valor de um deles em particular, na medida em que altera o valor dos serviços produtivos e, portanto, o custos de produção. Por outro lado, Marshall, no período neoclássico, recupera a teoria ricardiana do valor no longo prazo.
} 
Economia como "a ciência da produção de riqueza material", que muitas vezes toma o problema econômico como técnico ${ }^{3}$.

Embora no período clássico a interpretação do problema econômico como visto por Robbins esteja presente, a ênfase na "ciência da produção" foi dominante. Adicionalmente, enquanto para os autores continentais, como Cantillon e Say, os empresários tinham a função fundamental de dirigir sob condições de incerteza os recursos para seus usos mais importantes, segundo suas concepções individuais sobre a realidade econômica vigente no futuro, entre os ingleses o desenvolvimento do sistema ricardiano, com sua abordagem macroeconômica e de longo prazo, obscureceu a necessidade de lidar com o problema alocativo.

As escolhas na área de produção, conseqüentemente, passaram a ser vistas como algo não problemático economicamente, tornando-se a produção uma questão puramente técnica. De fato, J.S. Mill (1996:259), ao anunciar a tese da separabilidade entre produção e distribuição, afirma que "as leis e as condições da produção da riqueza têm o caráter de verdades físicas". A produção dependeria assim do estoque de capital, da lei dos retornos decrescentes, da teoria da população, e assim por diante, mas não dos preços de mercado dos fatores produtivos, influenciados pela importância dos usos alternativos dos recursos.

Em resumo, o sistema de preços, entre os clássicos, não guia a produção de forma fundamental, mas apenas em ajustes no curto prazo. A discussão da produção antecede logicamente a discussão do valor e preço dos bens, que são explicados pelo custo da produção em termos de quantidade de trabalho empregada na mesma. Essas quantidades de trabalho e dos demais fatores que determinam o custo, por sua vez, são dados dos quais a análise parte. Com a revolução marginalista, porém, já que o problema principal passou a ser o estudo de como a capacidade produtiva deve se adequar às necessidades dos agentes, a determinação da composição dos fatores não mais era considerada como dada, vista como um problema técnico, mas sim como dependente do próprio sistema de preços, na medida em que as necessidades se manifestam nas demandas pelos bens alternativos e indiretamente na demanda pelos fatores produtivos.

\footnotetext{
${ }^{3}$ Robbins (1932:33) escreve, por exemplo, que: "For the influences determining the structure of production are not purely technical in nature." Ou ainda (pág. 36) "Economists are not interested in technique as such."
} 


\section{Marxismo}

A teoria do valor trabalho e a primazia da produção na análise econômica serão elementos da escola clássica herdados por Marx. Esses elementos, aliados aos demais componentes do sistema marxista, comporão uma visão do socialismo. Nos dedicaremos agora à tarefa de esboçar alguns poucos elementos dessa visão, não de forma a recompor o edifício teórico marxista, mas apenas selecionando alguns poucos aspectos com o propósito de construir o pano de fundo da crítica misesiana ao socialismo.

A crítica de Mises parte da observação que os autores marxistas apenas se limitaram a analisar o que eles chamavam de capitalismo, não explicitando no entanto em que consiste o socialismo ou como este resolveria o problema alocativo. Mises (1935:88) interpreta esse fato como uma proibição marxista de se analisar o funcionamento da futura economia socialista. Para os marxistas tal análise seria descartada como socialismo utópico.

Como é sabido, porém, podemos entender a ênfase na análise do capitalismo (e a falta de estudos sobre o socialismo) tendo em vista o método de análise empregado por Marx. Para este, a dialética materialista seria o modo verdadeiramente científico de análise econômica, método pelo qual estuda-se a evolução da sociedade movida pelo conflito entre classes sociais determinadas pelo modo de produção vigente em um período. O que se poderia inferir cientificamente por esse método seria o colapso do capitalismo e não a antecipação de detalhes do funcionamento do socialismo. As tentativas de construir o socialismo de forma experimental e isolada a partir de esquemas preestabelecidos são classificadas como utópicas e não científicas, pois ignoram a evolução das forças inexoráveis que levariam necessariamente à substituição do capitalismo pelo socialismo:

From that time forward Socialism was no longer an accidental discovery of this or that ingenious brain, but the necessary outcome of the struggle between two historically developed classes - the proletariat and the bourgeoisie. Its task was no longer to manufacture a system of society as perfect as possible, but to examine the historico-economic succession of events from which these classes and their antagonism had of necessity sprung, and to discover in the economic conditions thus created the means of ending the conflict. (Engels, 1914: 92)

A mudança de percepção sobre o problema fundamental da ciência econômica que ocorreu a partir da revolução marginalista, no entanto, convida os economistas socialistas a realizar algo próximo a um exercício em socialismo utópico, procurando 
imaginar o funcionamento do socialismo, com o intuito de explicar como uma sociedade socialista resolveria o problema da alocação de recursos escassos a fins alternativos.

Embora de fato tenhamos pouquíssimas observações nos escritos marxistas sobre como funcionaria uma economia socialista, podemos inferir algumas características dessa economia através da análise da crítica que os autores marxistas fizeram ao capitalismo. Os elementos do capitalismo criticados pelos marxistas, supõe-se, devem estar ausentes no socialismo. Podemos então esboçar um quadro do socialismo a partir das antíteses desses elementos ${ }^{4}$.

Uma das características do capitalismo mais criticadas por Marx é a 'anarquia da produção', ou seja, a falta de planejamento do processo produtivo. Os bens produzidos em cada firma assumem a forma de mercadorias e as relações entre os setores produtivos são governadas pelas forças atuantes no mecanismo de mercado que governa a troca entre mercadorias. A coerência do sistema está limitada aos mecanismos espontâneos de ajuste fornecidos pelos mercados. Desperdício e crises surgem como conseqüência natural da fragmentação das ações individuais competitivas. O processo produtivo foge assim do controle da $\operatorname{sociedade}^{5}$ e é por isso irracional. Um grande aumento de produtividade seria então esperado no comunismo, quando a anarquia da produção e seus desperdícios seriam substituídos pelo 'controle consciente' e, portanto, racional da produção.

Como a substituição da 'produção para a troca' pela 'produção para o uso' envolve a substituição dos mecanismos de ajuste de mercado pelo planejamento racional da produção, as instituições relacionadas ao mercado desaparecem. Não só a propriedade privada é abolida, mas também os mercados e a moeda são vistos como próprios do capitalismo e, portanto, dispensáveis no socialismo.

O fim da produção anárquica implica por sua vez na perda da utilidade dos conceitos usados pela Economia para tratar dos fenômenos de mercado. As categorias econômicas relacionadas à produção para a troca, como valor, preço, salários, capital e assim por

\footnotetext{
${ }^{4}$ Ver por exemplo Brutzkus (1920:6): "Although Marxism has produced no systematic theory for a socialist economy, it has nevertheless determined its outline." ou Lavoie (1985:30): "In many respects, where Das Kapital offers us a theoretical 'photograph' of capitalism, its 'negative' informs us about Marx's view of socialism."

${ }^{5}$ São as relações entre mercadorias que dominam as relações entre pessoas (fetichismo da mercadoria).
} 
diante perdem então o seu significado. Tem-se então a postura historicista que marca o pensamento marxista:

Therefore, economic categories, too, are the 'theoretical expression of historical relations of production, corresponding to a particular stage of development in material production. On no account are they eternal, as bourgeois scholarship maintains, which immortalizes them because it immortalizes the capitalist mode of production. (Bukharin, 1979:149)

Tais categorias só fariam sentido no sistema de produção de mercadorias. Sem mercadorias, termos como 'valor' perdem seu significado. No entanto, não se pode inferir a partir disso que a produção comunista goza de liberdade completa. Quais seriam as leis que limitam a produção e portanto que categorias substituiriam as noções de valor em uma economia sem mercadorias, porém, não é tratado pelos marxistas, pelas razões já discutidas anteriormente.

Contudo, devemos aqui aludir a um dos escritos de Marx que menciona alguns elementos do funcionamento do socialismo, a Crítica ao Programa de Gotha, que nos é importante pois é citado várias vezes ao longo do debate do cálculo. Nesse texto, Marx $(1938: 18)$ identifica uma fase de transformação do capitalismo em comunismo na qual o estado - visto como instrumento de dominação de classe - ainda não desaparece, assumindo a forma de uma ditadura do proletariado. Quanto ao comunismo em si, o autor identifica duas fases. Na primeira, a capacidade produtiva ainda está limitada pelo passado capitalista. Um mecanismo de distribuição de bens é então imaginado por Marx. Dada a quantidade de trabalho realizada por cada pessoa, deduz-se o necessário para investimento e manutenção do capital, além de deduções para financiar escolas, hospitais e atendimento aos incapacitados. Efetuados os descontos, emite-se um vale que pode ser trocado nos centros de distribuição por bens que representam quantidade de trabalho equivalente. Marx salienta que esses vales não são moeda, pois não circulam em mercados.

Para que o esquema seja implementado, deve-se levar em conta a 'duração e a intensidade' do trabalho de forma a se obter uma medida padrão da quantidade de trabalho (pág. 9). Já na segunda fase do comunismo, com o esperado aumento da produtividade, dissociam-se o consumo e a contribuição de cada membro da sociedade. O trabalho seria voluntário e as pessoas usufruiriam livremente dos bens produzidos, como podemos ver no dito: 'de cada um conforme sua capacidade, para cada um conforme suas necessidades' (pág. 10). 
Com a passagem dos anos, dada a possibilidade concreta de efetuar uma revolução socialista, a literatura marxista passa progressivamente a se ocupar das questões mais concretas concernentes à construção do socialismo e por conseguinte se aproxima dos problemas relacionados com o cálculo econômico. No The State and Revolution, escrito às vésperas da revolução bolchevista, Lenin trata das tarefas a serem realizadas a partir da revolução. A substituição da anarquia da produção pelo controle consciente assume explicitamente formas hierárquicas de organização. O sistema econômico, segundo uma famosa passagem (Lenin, 1920:52), deve ser organizado segundo os moldes do correio, como uma única firma obedecendo a um comando central e a um plano único.

Esse comando central deve ser efetuado por uma identidade concreta, o estado, que assume a forma de ditadura do proletariado. Lenin tem então que harmonizar essa idéia com a previsão marxista de desaparecimento do estado. Esse desaparecimento para Lenin ocorreria apenas na segunda fase do comunismo. Já na primeira fase, denominada por Lenin de socialismo, deveria haver um estado. Esse estado seria justificado pelas observações de Marx ao Programa de Gotha sobre o esquema de distribuição de bens da fase de transição do capitalismo para o comunismo:

To this extent, therefore, a form of State is still necessary, which, whilst maintaining the public ownership of the means of production, preserves the equality of labor and equality in the distribution of the products. (Lenin, 1920:99)

Estabelecida a necessidade de um estado e de um comando central, Lenin passa a tratar da estratégia a ser seguida após a tomada do poder, em um capítulo intitulado "Os Fundamentos Econômicos do Desaparecimento do Estado". Embora os 'fundamentos econômicos’ sejam na verdade discussões de estratégia política sobre a possibilidade de tomada do poder, Lenin menciona algo sobre a organização da produção:

\footnotetext{
With such an economic groundwork it is quite possible, immediately, within twenty-four hours, to pass to the overthrow of the capitalists and bureaucrats, and to replace them in the control of production and distribution, in the business of apportioning labour and products, by armed workers or the people in arms. The question of control and bookkeeping must not be confused with the question of scientifically educated staff of engineers.... Book-keeping and control - these are the chief things necessary for the smooth and correct functioning of the first phase of the communist society. ... The book-keeping and control necessary for this have been simplified by capitalism to the utmost, till they have become the extraordinarily simple operations of watching, recording, and issuing receipts, within the reach of anybody who can read rules. (Lenin, 1920:106)
}

Essas considerações estratégicas a respeito da conduta pós-revolução são reveladoras de como se via a condução do processo de produção. Para Lenin, o papel exercido pelos capitalistas na economia se limita a tarefas administrativas simples de controle e registro. Isso nos leva de volta às nossas observações sobre a natureza do problema econômico antes e depois da revolução marginalista. 
Se as decisões produtivas forem puramente técnicas e não dependentes da questão de como cada recurso produtivo pode ser realocado para atender necessidades mais urgentes, o processo produtivo pode visto como algo mais ou menos automático, independente da atividade empresarial que percebe oportunidades de lucro em tais realocações. Formados nessa visão de economia, os autores marxistas também privilegiam o estudo da produção sem considerar como a demanda orienta o processo produtivo. Como nota Brutzkus:

A characteristic feature of scientific socialism is its one-sided view of production, which it regards merely as a process of mechanical work. (Brutzkus, 1920:80)

De fato, percorrendo a literatura da época, poucas linhas são dedicadas à questão de saber como guiar a produção segundo as necessidades dos consumidores depois que o sistema de preços for abolido, o que revela que isto não era visto como um problema. Em um sistema produtivo 'anárquico', os empresários têm a função de imaginar como atender as necessidades dos consumidores e estimar as condições futuras da demanda e produção. Essa função é desconsiderada na análise marxista da produção capitalista, como ilustra a seguinte passagem de Engels:

All the social functions of the capitalist are now performed by salaried employees. The Capitalist has no further social function than that of pocketing dividends, tearing off coupons, and gambling on the Stock Exchange, where the different capitalist despoil one another of their capital. (Engels, 1914: 122)

A atividade empresarial, ignorada na análise do capitalismo, também não se faz necessária na primeira fase do socialismo. De fato, Bukharin lista os empresários como uma das classes parasíticas a serem combatidas:

The ruling proletariat, in the first phase of its supremacy, is up against 1 the parasitic strata (former landowners, investors of every sort and bourgeois entrepreneurs who had little to do with the production process), trade capitalists, speculators, stockbrokers, bankers; 2 ... (Bukharin, 1979:160, ênfase adicionada)

Nota-se que o que define parasitismo é a não relação com o processo físico de produção. Assim, a direção do processo produtivo, seja no capitalismo ou no socialismo, aparenta não apresentar problemas alocativos dignos de nota. O método dialético, de qualquer modo, privilegia o estudo das forças que conduzem a mudança e não a especulação a respeito de como conduzir a produção no socialismo.

Com a aproximação da revolução, contudo, o problema alocativo não pode ser ignorado, visto que a tarefa de construir o socialismo se faz concretamente presente. É interessante notar a mudança de atitude em relação ao problema nos escritos de alguns autores. Steele (1992:59-65), por exemplo, chama a atenção para a evolução do 
pensamento de Kautsky conforme o partido social democrata alemão se aproximava do poder. No Erfurt Program de 1892, Kautsky fala de temas marxistas clássicos, como substituição da produção para a troca pela produção para o uso. Entre esses temas reafirma a tese de que, como o capitalismo estaria condenado, de pouca utilidade seria investigar como seria organizado o socialismo, não tratando o texto da questão de como organizar a produção. Em 1902, instigado por Pierson ${ }^{6}$ a lidar com esse problema, Kautsky mostra como a substituição do capitalismo pelo socialismo seria uma empresa gradual, defendendo uma série de medidas reformistas na ordem capitalista herdada. $\mathrm{O}$ problema da organização da produção, no entanto, não é abordado. Já em 1922, em The Labour Revolution, Kautsky afirma que a transformação seria gradual, feita ao longo de décadas, sendo a produção organizada em linhas capitalistas. Moeda e preços não seriam abolidos. Para ele, "a criação de uma organização socialista não é um processo tão simples como pensávamos" ${ }^{7}$.

O mesmo exercício que Steele realiza com Kautsky na Alemanha pode ser repetido com Bukharin na Rússia. Em The Politics and Economics of the Trasition Period este autor aborda as questões do início do período socialista com o instrumental marxista tradicional. O autor parte da caracterização da economia capitalista. Uma economia baseada em mercadorias seria impessoal, estando sujeita à anarquia da produção, sendo portanto cega e irracional (pág. 59). O sistema não compõe uma 'unidade teleológica', visto que não é dirigido por um plano. A construção do comunismo, por outro lado, requereria controle consciente:

If the creation of capitalism was spontaneous, the building of communism is to a marked degree a conscious, i.e. organized process. (Bukharin, 1979:99)

O processo de superação da produção anárquica no período transitório seria feito segundo as tendências concentradoras já em marcha, ou seja, por meio do surgimento de elementos de organização que surgem no capitalismo financeiro (pág. 78), ou seja, pelo tipo de administração resultante da crescente concentração da indústria. A existência de firmas organizadas segundo controle consciente, para Bukharin, seria prova empírica da

\footnotetext{
${ }^{6}$ No prefácio de The Social Revolution, Kautsky conta que: "The purpose of the work shows for itself and needs no explanation. It had a special application for Holland in that shortly before my lectures, which took place on the 22d and 24th of April, 1902, the former minister Pierson had made an assertion in a public assemblage, and argued for it, that a proletarian revolution must, for certain necessary reasons, be avoided, my lectures form a direct answer to this. The Minister was, however, so friendly as to attend the second one, where he made industrious notes and did not offer a word against me". Na resposta, Pierson (1902) trata pela primeira vez do problema do cálculo econômico de forma sistemática. Mais adiante, neste mesmo capítulo, abordaremos a contribuição deste autor.

${ }^{7}$ Kautsky, K (1925) The Labour Revolution, pág. 143, citado em Steele (1992:64).
} 
possibilidade de construir o comunismo (pág. 96). Apesar de não discutir que essas "ilhas de planejamento" existem em um ambiente guiado por preços de mercado, nesse ponto podemos encontrar a única frase do livro que aborda o problema da alocação de recursos no socialismo: "Se existisse um sistema judicialmente controlado, então o trabalho seria alocado aos diferentes setores e firmas na proporção necessária" (pág. 124). O autor não discute, porém, como se chega a essas proporções necessárias, o que mais uma vez nos mostra que essa tarefa não seria especialmente problemática.

O sistema de preços, fundamental na determinação dessas proporções para a teoria neoclássica, é visto por Bukharin como mecanismo próprio da produção para a troca, tornando-se desnecessário na construção do comunismo:

Indeed, as soon as we take an organized social economy, which establishers the latter as an organized social economy, all the basic 'problems' of political economy disappear: problems of value, price, profit and so on. (Bukharin, 1979:57)

Isso ocorreria porque as leis anárquicas e cegas da Economia se aplicam apenas ao irracional modo de produção de mercadorias. São leis referentes ao equilíbrio econômico entre agentes fracamente interligados pelos mercados (pág. 152). Quando o processo de racionalização da produção cresce exponencialmente, as categorias da Economia desaparecem:

Consequently, value, as a category of the capitalist commodity system in its equilibrium, is least useful of all during the transition period, where commodity production to a considerable extent disappears and there is no equilibrium. (Bukharin, 1979:155)

Já em 1922, em The ABC of Communism, o problema alocativo passa a chamar a atenção de Bukharin. Entre as perguntas de 'imensa importância' (pág. 263) figuram questões como 'qual é o melhor e mais econômico meio de alocar reservas de matérias primas?' Como ligar um ramo produtivo com os demais? Como lidar com alocação e incentivo do trabalho? Ou ainda, como empregar avanços tecnológicos?

Para o autor, a solução para esses problemas se encontra na extensão do planejamento central. As dificuldades econômicas enfrentadas pelos bolchevistas, entre outras razões, se explicam pela falta de estatísticas para conduzir o planejamento. Esses dados seriam expressos não em termos monetários, mas em espécie, como mostra a seguinte passagem:

At the outset, the Soviet Power and its instruments had no accurate reports of what was going on. There was no list of undertakings; there were no tabulated statements of the supplies of raw materials, fuel, ad finished commodities; there was no account of the productive possibilities, no definite idea concerning how much the undertakings that were being nationalized were competent to produce. (Bukharin e Preobrazhesky, 1922:263) 
Ao mesmo tempo, a questão da alocação de recursos escassos, que é a origem do problema do cálculo econômico, se faz sentir na Rússia e é testemunhada pelo próprio Bukharin:

Owing to scarcity, we have often been compelled to close down some of the largest works (in the textile industry, for instance). Even today we owe to these causes the still persistent partial disorganization of production. The main trouble here, however, is not the lack of organization properly speaking, but the lack of material things requisite for production. (Bukharin e Preobrazhesky, 1922:270)

O fracasso em organizar a produção sem o auxílio do sistema de preços ocorrido nos primeiros anos da revolução resultou na reintrodução de mercados no período conhecido como N.E.P. Em um texto que procura explicar as medidas que representavam um recuo na adoção de uma economia planificada, Bukharin justifica o uso de categorias de uma economia de mercado, pelo menos na primeira fase do socialismo:

\footnotetext{
We can say, therefore, that if our former expectation concerning the development of a socialist order involved elimination of the market and the capitalist economy immediately following achievement of the dictatorship of the proletariat, together with the immediate introduction of a planned economy, them we were mistaken. These things will not happen immediately, but will result from a process of gradually squeezing out, overcoming, and reshaping a whole series of intermediate forms. We can say, therefore, that market relations, money, the bourse, banks, etc., play a very important role in this process. (Bukharin, 1982:595)
}

A reintrodução do sistema de preços e da propriedade, porém, é vista puramente como uma questão de incentivos, ou seja, como um método de extrair excedente da produção no campo para financiar a industrialização. Nesse sentido, o autor chega inclusive a citar Mises - "um dos mais esclarecidos críticos do comunismo" (Bukharin, 1982:593). O que Bukharin extrai do Socialism de Mises, contudo, não é a discussão do problema do cálculo, mas sim o reconhecimento que a política de expropriação da produção leva ao 'destrucionismo' e não à construção de uma economia progressiva. O fornecimento de incentivos seria, portanto, necessária no socialismo.

Podemos assim concluir que tanto Kautsky quanto Bukharin procuraram lidar com as consequiências advindas da ausência do cálculo econômico, não reconhecendo porém a formulação do problema em si.

Mais tarde, uma vez reconhecido o problema, alguns autores marxistas tentarão discutilo, propondo a quantidade de trabalho como unidade de medida para o cálculo econômico, como será visto no quarto capítulo. Outros, porém, procurarão defender a possibilidade de cálculo em espécie, que dispensaria o uso da noção de valor. 
Além do marxismo, o trabalho de Mises combaterá também a crença na possibilidade de cálculo em espécie. Por isso, dirigimos agora a nossa atenção para essa possibilidade.

\section{Neurath: O Cálculo em Espécie}

Uma das primeiras especulações sobre como organizar as atividades econômicas sem a utilização de mercados foi feita por autores que buscaram imaginar o socialismo como uma 'economia natural'. ${ }^{8}$ Nessa economia, o cálculo econômico seria feito em espécie, sem o auxílio de valores expressos em moeda. A produção seria organizada da mesma forma que um engenheiro organiza a produção em processos de transformação industriais.

Na Rússia, como relatam Brutzkus (1920:14) e Hoff (1981:72), Tschayanoff propõe o uso no socialismo de um método de comparação dos resultados das diversas firmas conforme estas se organizem de forma mais ou menos racional segundo um esquema de cálculo em espécie. Como relatam Brutzkus e Hoff, Tschayanoff, referindo-se à agricultura, afirma que, após considerações técnicas, a produção de 1000 'unidades de grão’ requereria 45 unidades de trabalho, 120 unidades de grãos estocadas, 11 unidades de terra e assim por diante. Cada uma dessas 'normas marginais de produtividade socialmente necessárias', que representam as quantidades de insumos que podem ser utilizadas na produção do bem, são comparadas com o que de fato se emprega de recursos na produção, dividindo-se uma magnitude pela outra. Temos assim uma série de proporções entre a norma e o utilizado de fato. A média dessas proporções para os diversos insumos é denominada 'efetividade do cultivo' do produto. Essa importância da produção do bem poderia ser comparada com a importância da produção de outros tipos de bens, multiplicando-se as efetividades por pesos que representam a importância de cada setor segundo a avaliação do planejador.

Além de Tschayanoff, o positivista lógico Otto Neurath escreveu em 1919 um livro Through War Economy to Economy in Kind (Neurath:1973) - propondo a adoção do cálculo em espécie. Tal livro será importante no debate, pois tanto Mises quanto Weber fazem referência a ele ao exporem o argumento sobre a impossibilidade do cálculo

\footnotetext{
${ }^{8}$ Foi hábito entre os economistas (Wieser e Pareto, por exemplo), antes de expor o funcionamento de uma economia monetária, utilizar o artifício de uma "economia natural", organizada sem o auxílio da moeda e livre dos fenômenos emergentes a partir de seu uso.
} 
socialista. Publicado ao mesmo tempo que o artigo de Mises, o texto de Weber é de fato organizado como uma crítica à proposta de cálculo em espécie de Neurath.

Em seu livro, Neurath argumenta que a experiência com a economia de guerra demostra na prática que se podem organizar as atividades econômicas de uma sociedade por meio do planejamento central, dispensando-se o uso do sistema de preços. Além disso, o autor aponta uma tendência histórica rumo à crescente planificação das economias, tendência essa relacionada à ocorrência das guerras.

É interessante notar que também autores liberais, como Bastiat, viam relações entre guerra e intervenção estatal. Não só as guerras aumentariam o tamanho do estado, mas também o protecionismo geraria antagonismos e guerras. Ao contrário desses autores, que lamentavam a relação entre guerra e estatismo, Neurath dá boas vindas aos períodos de guerra, pois os mesmos aprofundam o grau de planejamento central das economias, o que permite, sob o esforço unificado, que se desenvolvam de forma mais racional as aplicações das novas tecnologias e melhoras no sistema produtivo.

A fim de se preparar para o advento das economias administradas, o autor propõe a criação de uma nova teoria. De maneira historicista, Neurath nega a validade geral da economia (desenvolvida para períodos de paz), sugerindo em seu lugar o desenvolvimento de um novo campo de estudo: a ciência da economia de guerra. Tal ciência mostraria a superioridade das economias planejadas centralmente em relação às economias de mercado. Da mesma forma que Marx, Neurath associa as crises e o desemprego de fatores produtivos com o "caos da produção" descentralizada. A eficiência do sistema econômico seria grandemente aumentada através da moldagem consciente das atividades econômicas e suas interelações. Para Neurath, isto só pode ser obtido por meio do planejamento central. Uma economia 'socializada' necessariamente implicaria planejamento central e supressão do sistema monetário, peça fundamental do irracionalismo das economias de mercado. O planejamento substituiria o cálculo em termos de valores monetários pelo cálculo em espécie. De fato, para Neurath (1973:145), "any completely planned economy ultimately amounts to an economy in kind. To socialize therefore means to further an economy in kind. To hold on to the split and uncontrollable monetary order and at the same time to want to socialize is an inner contradiction".

A diferença marcante entre Marx e Neurath, no entanto, diz respeito ao método de estudar a economia futura. Enquanto o primeiro utiliza a dialética materialista, o 
segundo pretende se entregar à tarefa de imaginar e construir o futuro, como um engenheiro planeja um mecanismo. Em uma crítica velada ao pensamento marxista e ao método dialético, Neurath (1919:582) critica a condenação ao socialismo utópico, encorajando o desenho da nova ordem social.

Nesse aspecto Neurath, o positivista lógico, se encaixa perfeitamente na caracterização que Hayek (1979) faria mais tarde, em The Counter-Revolution of Science, do racionalismo construtivista, ou seja, a mentalidade presente na Escola Politécnica francesa de identificar o racionalismo com a aplicação centralizada e consciente dos métodos da engenharia, no caso, à tarefa de construir uma ordem social racional de cima para baixo:

A social engineering construction treats our whole society and above all our economy in a way similar to a giant concern. The social engineer who knows his work and wants to provide a construction that shall be usable for practical purposes as a fist lead, must pay equal heed to the psychological qualities of men, to their love of novelty, their ambition, attachment to tradition, willfulness, stupidity, in short everything peculiar to them and definitive of their social action within the framework of the economy, as does the engineer to the elasticity of iron, to the breaking point of copper, to the color of glass and to other similar factors. The levers and screws of the machinery of life are of a strange and subtle kind. But the difficulty of the task has never yet frightened a courageous thinker and man of action. (Neurath 1973:151)

Como seria então guiada a produção na sociedade imaginada por Neurath? As decisões parciais, baseadas em lucro, seriam substituídas pela comparação direta entre planos alternativos, formulados pelo 'Escritório Central de Medição em Espécie'. Esse órgão elaboraria, segundo o exemplo do autor, um plano que prevê ampliação da capacidade de geração de energia e melhoras na agricultura, enquanto um segundo plano daria conta das atividades econômicas sob a hipótese de que se investirá em canais e fornos. O Escritório Econômico Central e os representantes do povo devem então decidir o que preferem: mais agricultura e eletricidade ou mais importações e mais ferro. A comparação seria direta. "We shall simply have to determine production and consumption, distribution of shelter, food, clothing, education, work and effort, etc., in a similar way by direct consideration of the various possibilities" (1973:577). Isto não envolveria problemas, pois um general decide onde empregar seus recursos sem fazer uso de 'unidades de guerra', e os governos decidem entre a construção de hospitais e escolas sem fazer referência a 'unidades de educação ou saúde'.

Para elaborar os planos, o Escritório Central de Medição em Espécie teria que possuir conhecimento sobre as possibilidades de produção, consumo, movimentos de matérias primas e energia, quantidades de recursos utilizados em cada processo produtivo e assim por diante. Esse conhecimento seria adquirido por meio de "estatísticas 
universais" uniformes e abrangentes (a abrangência deveria ser mundial). Com a socialização da atividade produtiva, seriam reveladas também as informações mantidas em segredo pelas empresas que seguem a lógica da competição por lucros. Tudo seria 'transparente e controlável'. Aparece aqui pela primeira vez no debate o que será tema recorrente ao longo de todas as discussões: a crença de que o principal problema de coordenação de informações no mercado é fruto da tentativa deliberada de reter dados por parte de competidores atuando descentralizadamente ${ }^{9}$.

Finalmente, no sistema de Neurath, os lucros das firmas, como uma forma de incentivo, são substituídos por prêmios por produção maior, estabelecidos com o auxílio da ciência da administração. Nota-se aqui que, para o autor, os lucros refletem apenas incentivos, não tendo a função de alocação de recursos, como defendido pelos austríacos e neoclássicos.

\section{O Argumento de Similitude Entre Economias de Mercado e Socialistas}

A Revolução Marginalista, que trouxe consigo a substituição da plutologia pela catalaxia como foco analítico, abriu caminho para a crítica econômica ao socialismo, na medida em que a partir de então acreditava-se que as decisões produtivas, mesmo no longo prazo, não seriam independentes do sistema de preços. Os preços, além de estarem relacionados com a distribuição do produto, desempenham na teoria neoclássica o papel fundamental de guiar o que deve ser produzido, segundo as necessidades dos indivíduos e a escassez de recursos. Conforme estas se alteram, as relações técnicas de produção devem se adaptar.

Dessa maneira, na virada do século XIX para o XX os economistas começaram a criticar as idéias socialistas que pretendiam abolir o uso da moeda, indagando como seria então resolvido o problema da alocação no socialismo na ausência de um sistema de preços, já que no socialismo também existirão necessidades e recursos limitados para satisfazê-las.

O chamado 'argumento da similitude formal' entre socialismo e economias de mercado consistiu na observação por parte de alguns economistas neoclássicos de que também o

\footnotetext{
${ }^{9}$ No capítulo quatro veremos como esta crença é compartilhada pelos socialistas de mercado da década de trinta, em especial Dickinson. Essa crença tem a sua origem na concepção de Marx sobre a natureza competitiva dos mercados.
} 
socialismo, como qualquer forma de organização social, se depara com o problema alocativo. Se a terra, o capital, ou um bem qualquer forem escassos, afirma o argumento, pelo menos algo análogo à renda, juros e preços deve ser levado em conta pela comunidade socialista em suas escolhas. Os autores do argumento não discutem ou colocam em questão a possibilidade da solução desse problema no socialismo ${ }^{10}$, mas sim criticam a crença socialista de que categorias econômicas como moeda, preços, custos e lucros seriam próprias da forma contemporânea de organização econômica, descartáveis porém no socialismo.

$\mathrm{O}$ argumento talvez tenha sido o maior ataque que se fez ao credo historicista. A teoria econômica e suas categorias analíticas, vistas pelos socialistas como transitórias, dependentes da época e das instituições, invadem a análise do socialismo, pretendendo estabelecer a validade universal de seus conceitos.

O argumento de similitude formal foi enunciado por diversos autores neoclássicos. Repassando seus textos, podemos já identificar em suas análises as diferenças fundamentais entre as vertentes do neoclassicismo, que na época eram percebidas como pouco além de diferenças no estilo de exposição. Por um lado temos a apresentação verbal do argumento, realizada por Wieser e Böhm-Bawerk segundo a tradição austríaca. Pelo outro temos o argumento matemático desenvolvido por Pareto e pelo seu discípulo, o economista italiano Enrico Barone, na tradição walrasiana.

Essas diferenças, conforme veremos ao longo do nosso trabalho, gerarão interpretações opostas sobre como julgar a viabilidade do socialismo segundo a análise econômica neoclássica, além de catalisar o processo de diferenciação do programa de pesquisa austríaco.

$\mathrm{O}$ argumento de similitude formal teve um papel fundamental no desenvolvimento da controvérsia do cálculo econômico, em particular o texto de Barone, que, devido à falta de clareza do autor sobre o significado de seu argumento, gerou diferentes interpretações por parte dos oponentes no debate sobre a possibilidade ou não de se resolver o problema econômico do socialismo. Além da controvérsia, o artigo de Barone conterá boa parte das idéias desenvolvidas mais tarde pelos autores socialistas que procuraram oferecer uma resposta satisfatória ao desafio de Mises. Em seguida

\footnotetext{
${ }^{10}$ Apenas com o argumento de Mises temos a tese de que tal problema não possui solução.
} 
exporemos as diferentes versões do argumento para depois discutir as interpretações possíveis sobre seu significado.

\section{Wieser}

Entre os austríacos, o argumento da similitude entre economias de mercado e socialismo surge em livros de Wieser e Böhm-Bawerk, ambos publicados em 1889.

O argumento é tratado de forma mais sistemática no Natural Value de Wieser. Nesse livro, o autor procura desenvolver a teoria do valor e preços de Menger, em especial tratando do problema da imputação do valor dos insumos produtivos a partir do valor dos bens de consumo final. Diferentemente de Menger, e mais tarde de Mises e Hayek, Wieser constrói seus argumentos puramente em termos de equilíbrio, desconsiderando o subjetivismo e a análise de processo que caracterizam a escola austríaca.

Wieser discute a teoria do valor fazendo referência a uma imprecisa noção de equilíbrio baseada no conceito 'valor natural', definido pelo autor como "value as we should find it in a community at a high stage of development carrying on its economic life without price or exchange" (Wieser, 1889, livro 2, cap.1). A eliminação de preços e trocas tem como objetivo separar o valor "natural" de um bem, dado pela sua utilidade marginal, do valor de mercado, influenciado por outros fatores além da utilidade marginal:

The relation of natural value to exchange value is clear. Natural value is one element in the formation of exchange value. It does not, however, enter simply and thoroughly into exchange value. On the one side, it is disturbed by human imperfection, by error, fraud, force, chance; and on the other, by the present order of society, by the existence of private property, and by the differences between rich and poor, -- as a consequence of which latter a second element mingles itself in the formation of exchange value, namely, purchasing power. In natural value goods are estimated simply according to their marginal utility. (Wieser, 1889, livro 2, cap.1)

Wieser investiga então os fenômenos comumente ligados ao valor nas economias de mercado, indagando se esses mesmos fenômenos seriam "naturais" ou não no socialismo. Se existirem rendas ou juros naturais, por exemplo, o desprezo socialista por essas categorias não se sustentaria. Utilizando a nova teoria do valor, o autor encontra valor natural em toda ocasião na qual existem recursos úteis ${ }^{11}$, como terra e capital, para a obtenção de bens de consumo escassos. Como tais fatores continuam existindo no socialismo, seus valores seriam naturais. A única diferença para uma economia

\footnotetext{
${ }^{11}$ Atribui-se a Wieser a criação da expressão 'utilidade marginal'.
} 
coletivista seria que a renda e os juros vão para o estado, não para os proprietários privados. $\mathrm{O}$ autor enuncia então o argumento de similitude formal:

Even in a community or state whose economic affairs were ordered on communistic principles, goods would not cease to have value. Wants there would still be, there as elsewhere; the available means would still be insufficient for their full satisfaction; and the human heart would still cling to its possessions. All goods which were not free would be recognized as not only useful but valuable; they would rank in value according to the relation in which the available stocks stood to the demand; and that relation would express itself finally in the marginal utility. (Wieser, 1889: livro2, cap 6)

Embora os bens no socialismo tenham valor pelas mesmas razões do que nas economias de mercado, e os autores socialistas sejam criticados por Wieser por ignorarem esse fato, a possibilidade de resolver o problema de alocação de recursos sob o socialismo não é investigada:

Natural value is a neutral phenomenon, the examination of which, whatever may come of it, can prove nothing for and nothing against socialism. (Wieser, 1889: livro2, cap 7)

Essa opinião ressurgirá mais tarde nos escritos de Frank Knight e dos socialistas de mercado, como veremos no quarto capítulo.

\section{Böhm-Bawerk}

Foi Böhm-Bawerk, cunhado de Wieser, porém, o principal oponente do socialismo no final do séc. XIX. São conhecidos seus ataques no primeiro volume do Capital and Interest à teoria clássica do valor e em especial à teoria da exploração de Marx. Enquanto esta ligava o fenômeno dos juros à apropriação de parte do fruto do trabalho dos trabalhadores (mais-valia), Böhm- Bawerk procurava mostrar que, se os juros fossem um fenômeno explicado pela preferência temporal, a teoria da exploração marxista perderia sua base.

Contudo, é no segundo volume de seu livro - The Positive Theory of Capital - que o autor formula o argumento de similitude, em uma seção intitulada "Interest Under Socialism”. Enquanto Wieser enunciara o argumento de forma genérica, tratando de todos os preços, Böhm-Bawerk se limita aos juros, dado seu interesse pela teoria do capital. Nessa seção, o autor postula uma economia sem propriedade privada de terra e capital, com trabalhadores empregados pela sociedade e recebendo o fruto de seu trabalho.

Nessa economia, argumenta o autor, os juros não desaparecem, como afirma a teoria da exploração marxista, pois as causas verdadeiras do fenômeno ainda estariam presentes: 
os processos produtivos continuam a ocorrer no tempo e os bens presentes continuam sendo valorados de forma diferente do que os bens futuros, e a coletividade terá que levar em conta essa diferença. O trabalho, pago antes da obtenção da receita pela venda do bem final, deve ser descontado segundo a taxa de desconto temporal:

Under socialism it would be the economizing state itself which would apply - and indeed be forced to apply - as against its citizens the principle of interest, ,and the practice of exacting a deduction from the product of labor - a practice which today's socialist reviles as "exploitation." (BöhmBawerk, 1959, vol. 2:343)

Se os juros não fossem levados em conta, no cálculo econômico as necessidades presentes seriam sacrificadas em favor da maior produtividade dos processos de produção mais longos, que renderiam frutos apenas no futuro remoto.

Se os trabalhadores recebessem o fruto total do seu trabalho, exemplifica BöhmBawerk, um padeiro receberia $\$ 10$ por dia pelo seu trabalho presente, enquanto um operário de reflorestamento, plantando 100 mudas que daqui a 100 anos gerariam árvores que valeriam $\$ 50$ cada, deveria receber pelo mesmo dia de trabalho $\$ 5000$. Nesse caso, ninguém gostaria de trabalhar com panificação e a sociedade seria uma grande floresta. Se se abdica da liberdade de ocupação, tem-se uma sociedade marcada por privilégios, concedidos àqueles trabalhadores que operam em estágios produtivos mais afastados do consumo final. Finalmente, se os juros apreendidos pelo estado forem recolhidos centralmente e distribuídos uniformemente entre todos os trabalhadores, teremos uma equivalência formal com o que ocorre nas economias de mercado: os trabalhadores, além de seus salários, recebem juros como capitalistas, ou seja, como acionistas do capital que agora está centralizado nas mãos do estado. Embora a distribuição dos juros seja mais uniforme, o fenômeno dos juros permanece.

\section{Pareto e Barone}

Wieser e Böhm-Bawerk expuseram o argumento de similitude entre economias de mercado e economias socialistas em termos verbais, conforme a tradição austríaca. $\mathrm{Na}$ escola de Lausanne, por outro lado, surgiram contribuições semelhantes às dos austríacos, baseadas porém na teoria do equilíbrio geral (EG). Essas contribuições foram feitas por Pareto e mais tarde pelo economista italiano Enrico Barone. Este último pretendia provar rigorosamente, com a autoridade dos fatos observáveis e rigor matemático, o que os 'economistas literários' teriam apenas vislumbrado de forma 
confusa. Contudo, como já observamos, longe de constituírem apenas versões diferentes do mesmo argumento - uma verbal e outra matemática - os argumentos revelarão diferenças fundamentais entre a compreensão austríaca e walrasiana sobre o funcionamento dos mercados.

Conforme mencionamos no primeiro capítulo, enquanto a teoria do equilíbrio for utilizada para explicar certos aspectos gerais do funcionamento dos mercados, as diferenças entre as abordagens austríaca e neoclássica têm pouca importância. Contudo, quando a teoria passa a ser utilizada não apenas para explicar, mas para prever e construir um sistema econômico, as diferenças afloram. De fato, antes do debate, podemos dizer que a teoria do equilíbrio era utilizada para explicar como os mercados funcionam. Walras, no prefácio do Compêndio, conta que Beaulieu criticou a economia matemática, afirmando que esta não pode chegar a valores numéricos adequados para as variáveis da teoria, pois a adição de complicações ao modelo alteraria totalmente esses números. Walras, diante dessa crítica, afirmou que a teoria de equilíbrio seria aplicável apenas para explicar e não para prever os preços e quantidades reais:

A aplicação de que se trata absolutamente não consiste em prever, mas em explicar a variação dos preços de acordo com as variações da oferta e da demanda, sob o regime da livre concorrência. (Walras, 1983:4)

Essa interpretação original de Walras sobre a aplicabilidade da teoria de EG seria logo negligenciada pelos seus sucessores Pareto e Barone. Sem nenhuma discussão ou ressalva metodológica sobre essa questão, os dois autores passam a descrever um sistema de EG que representaria uma economia de mercado e afirmam que o "ministério da produção' de uma sociedade socialista deve também resolver o sistema de equações a fim de que a racionalidade econômica seja preservada nesse último sistema, já que o problema da alocação permaneceria no socialismo.

Passam, então, os autores a analisar as dificuldades que o dito ministério teria para resolver o problema na prática. O modelo de EG, que supomos ser um modelo explicativo, que capta apenas parte da realidade do funcionamento dos mercados, passa então a ser utilizado como um procedimento que se deve seguir para construir uma sociedade socialista.

A abordagem adotada por Pareto e Barone dará origem a diversas interpretações sobre o significado do argumento de similitude formal, interpretações essas que discutiremos no final desta sessão. Antes, porém, vamos analisar mais de perto os argumentos de Pareto e Barone. 
Pareto, tanto no Manual quanto no Curso, considera uma sociedade socialista cujo objetivo é proporcionar o máximo de "ofelimidade" 12 aos seus membros. Tal sociedade deve resolver tanto o problema da redistribuição de renda quanto o da produção. No tocante ao primeiro, a teoria do EG contempla realocações das dotações iniciais entre os membros da sociedade. Isso poderia ser feito pelo estado, segundo um critério qualquer. Supondo resolvido o problema da distribuição, que terá que levar em conta considerações éticas e comparações interpessoais de ofelimidade, o verdadeiro problema a ser resolvido no socialismo seria a determinação da produção de modo a cumprir o objetivo mencionado acima.

A solução é dada, para o autor, da mesma maneira que se determina o EG para uma sociedade baseada em competição livre. No Curso, Pareto esboça essa idéia, mostrando como as categorias econômicas surgem novamente no socialismo. Dada a regra de repartição de renda, a sociedade socialista pode permitir a existência de mercados de bens de consumo, surgindo um sistema de preços autênticos para esses bens. Alternativamente, pode proibir as trocas diretas, caso em que os preços, estabelecidos pelo governo, reapareceriam sob outro nome. Para maximizar a ofelimidade, o governo teria que atribuir aos bens de capital taxas equivalentes a preços, que com certeza não seriam transacionados livremente no socialismo. Esses preços refletiriam a necessidade, dada pelo objetivo de maximizar ofelimidade, de minimizar o sacrifício ou custo aos administrados.

Esses 'preços', afirma o autor, serão os mesmos que vigoram em uma economia de concorrência livre. Sugere Pareto que o Ministério da Produção seja dividido em duas seções: uma administrará o capital e o venderá à segunda com preços que obriguem esta segunda seção a economizar no emprego dos serviços dos capitais mais escassos. A segunda seção opera da mesma forma que empresários que transformam capital em produtos finais. $\mathrm{O}$ volume de capital, do mesmo modo, deve ser escolhido de forma a balancear o ganho de produtividade com maior poupança e o sacrifício do consumo presente.

\footnotetext{
${ }^{12}$ Pareto, no Corso (1896:10), descreve o termo utilizado para exprimir utilidade sob o ponto de vista estritamente subjetivo como: Ci varremo del termine ofelimità, dal greco $\omega \varphi \varepsilon \lambda \mu_{\mu} \zeta$, per esprimere il repporto di convenienza, che fa sí que uma cosa soddisfi um bisogno o un desiderio, legittimo o meno.
} 
Sugere o autor (Corso: vol.2:410) que o governo apresente para a população a opção de obter 100 quilos de alcachofra hoje ou 105 a partir do ano seguinte, mediante sacrifício da produção presente. A resposta da população será a base para calcular o equivalente a taxa de juros, que deve ser a mesma para toda a economia. A escolha de como combinar insumos na produção de cada bem também deve ser feita da mesma forma que em uma economia competitiva. Em resumo, nas palavras do próprio autor:

Riassumendo dunque, se un'organizzazione socialista, quale che sia, voul ottenere il massimo di ofelimità per la società, può operare solo sulla ripartizione, ch'essa muterà DIRETTAMENTE sotraendo agli uni quel che darà algi altri. La produzione dovrà essere organizzata esattamente como in un regíme de libera concorrenza e di appropriazione dei capitali. (Pareto, 1896: livro 3, cap 2, $\$ 1022: 412)$

Como vimos, no Curso Pareto se dedica ao problema teórico, desconsiderando as "insormontabili difficoltà pratiche che si oppongono alla realizzazione di questo sistema”. Já no Manual, o autor investiga em mais detalhes tais dificuldades:

\begin{abstract}
Para saber o que seriam certos fenômenos, tivemos que estudar sua manifestação; para saber o que seria equilíbrio econômico, tivemos que pesquisar como ele era determinado. Observamos, aliás, que essa determinação não tem, absolutamente, como finalidade chegar a um cálculo numérico dos preços. Façamos a hipótese mais favorável a tal cálculo; suponhamos que tenhamos triunfado sobre todas as dificuldades para chegar a conhecer os dados do problema e que conhecêssemos as ofelimidades de todas as mercadorias para cada indivíduo, todas as circunstâncias da produção das mercadorias etc. Tal hipótese já é absurda e, no entanto, ela ainda não nos fornece a possibilidade prática de resolver esse problema. Vimos que no caso de 100 indivíduos e de 700 mercadorias haveria 70699 condições ... portanto deveremos resolver um sistema de 70699 equações. Na prática isso ultrapassa o poder da análise algébrica e ultrapassaria mais ainda se se considerasse o número fabuloso de equações que daria uma população de 40 milhões de indivíduos e alguns milhares de mercadorias. Nesse caso, os papéis seriam trocados, e já não seriam as Matemáticas que viriam em auxílio da Economia Política, mas a Economia Política é que iria em auxílio das Matemáticas. Em outras palavras, se fosse possível conhecer verdadeiramente todas essas equações, o único meio acessível às forças humanas para resolvê-las seria observar a solução prática que o mercado fornece. (Pareto 1984:vol 1, cap3, pág. 126).
\end{abstract}

Assim, Pareto considera impossível na prática a solução do sistema de equações. Na argumentação do autor, o cálculo numérico de preços se mostra inviável não porque o modelo seja uma simplificação da realidade, mas porque não se tem acesso ao grande número de informações necessárias para calcular tais preços.

Após essas observações o autor reafirma a confiança na teoria:

Porém, se as condições que acabamos de enumerar não podem nos servir na prática para cálculos numéricos de quantidade e de preços, elas são o único meio, até aqui conhecido, para se chegar a uma noção da maneira como variam essas quantidades e esses preços ou, mais exatamente, de modo geral, para saber como se produz o equilíbrio econômico (Pareto 1984: vol 1, cap3, \$218: 126).

Quanto à superioridade de um sistema ou outro, Pareto afirma que (assumindo-se a possibilidade de resolver o problema no socialismo), embora o estado possa corrigir falhas alocativas encontradas em uma economia livre, o grande número de funcionários necessários para realizar os cálculos representaria um custo em termos de atividades 
produtivas. Tem-se assim uma indefinição sobre qual sistema seria superior, dado que não se sabe a priori qual custo seria maior. Muitas décadas depois, essa mesma opinião será formulada novamente por Stiglitz.

A idéia de aplicar o EG à solução do problema da produção no socialismo, esboçada por Pareto, foi desenvolvida em 1908 por Barone em seu artigo "Il Ministro della Produzione nello Stato Coletivista", traduzido para o inglês por Hayek e publicado como apêndice da coletânea de textos sobre o debate do cálculo editada por este autor. Dada a importância que esse artigo futuramente terá no debate ${ }^{13}$, dedicaremos algum espaço para descrever em mais detalhes os seus argumentos.

Barone constrói inicialmente um sistema de EG descritivo do 'regime individualista' e em seguida discute como este seria modificado em um 'regime coletivista'. Procedendo da forma usual na época, o autor lista quais são os dados do problema, quais são as variáveis a serem encontradas e verifica se o número destas últimas coincide com o número de equações do sistema. Caso coincidam, o sistema terá solução. Entre os dados do problema teríamos a definição de m produtos finais, representados por A, B, C, ... . Os bens de capital existentes na posse dos indivíduos são representados por S,T, ..., perfazendo n tipos de insumos, cujas quantidades de serviços consumidos totais são $\mathrm{Q}_{\mathrm{s}}$, $\mathrm{Q}_{\mathrm{t}}$ e assim por diante. Além disso, temos também a fabricação de novos bens de capital, n' deles, representados por $\mathrm{H}, \mathrm{K}, \ldots$ Finalmente, temos os coeficientes técnicos de produção (inicialmente considerados como fixos), dados por $a_{s}, a_{t}, \ldots, b_{s}, b_{t}, \ldots$, em que $a_{s}$ representa a quantidade de insumo $\mathrm{S}$ utilizado na produção de $\mathrm{A}$ e assim sucessivamente.

Entre as variáveis desconhecidas, temos as $\mathrm{m}$ quantidades totais demandadas $\mathrm{e}$ produzidas: $R_{a}, R_{b}, \ldots$ com os $m$ custos de produção $\pi \mathrm{a}, \pi \mathrm{b}, \ldots$ e os $\mathrm{m}-1$ preços $\mathrm{p}_{\mathrm{b}}, \mathrm{p}_{\mathrm{c}} \ldots$, (fixando o preço de A em uma unidade). De forma análoga temos as $\mathrm{n}$ quantidades totais de capital existentes $R_{s}, R_{t}, \ldots$ cujos serviços custam $p_{s}, p_{t}, \ldots$ e $n^{\prime}$ quantidades de capital novo, representadas por $\mathrm{R}_{\mathrm{h}}, \mathrm{R}_{\mathrm{k}}, \ldots$ com custos dados por $\pi_{\mathrm{h}}, \pi_{\mathrm{k}}, \ldots$. Além disso, temos a quantidade total de poupança, representada por E. No total teríamos $3 m+2 n+2 n^{\prime}$ variáveis, somando-se as variáveis listadas.

Quanto às equações, primeiramente Barone deriva as funções de demanda dos produtos (R's e E) em função dos preços da economia. Isso é feito a partir das restrições

\footnotetext{
${ }^{13}$ Lange afirma que o artigo de Barone teria refutado a tese de Mises antes que esta fosse formulada.
} 
orçamentárias individuais, que relacionam as quantidades gastas com os produtos $\left(\mathrm{r}_{\mathrm{a}}, \mathrm{r}_{\mathrm{b}}\right.$, ...) e o consumo de serviços $\left(\mathrm{r}_{\mathrm{s}}, \mathrm{r}_{\mathrm{t}, \ldots)}\right.$ ) com as dotações ( $\left.\mathrm{qs}, \mathrm{qt}, \ldots\right)$, de modo que as restrições orçamentárias são expressas por:

$p_{a} r_{a}+p_{b} r_{b}+\ldots+p_{s} r_{s}+p_{t} r_{t}+\ldots+e=p_{s} q_{s}+p_{t} q_{t}+\ldots$

Teríamos então $m+n+1$ equações de demanda, uma para cada bem, em função de todos os preços da economia $(R a=f(p), \ldots, R s(p), \ldots)$. Barone não utuiliza especificações de funções utilidade para derivar as demandas: estas seriam puramente fatos empíricos.

Além dessas expressões de demanda, temos uma série de equações de equilíbrio: primeiramente um sistema de $\mathrm{n}$ equações refletindo as 'necessidades físicas da produção', que mostra como o serviço total do capital é dividido entre os bens finais e serviços e manufatura de capital novo ${ }^{14}$ :

$$
\mathrm{Q}_{\mathrm{s}}=\mathrm{R}_{\mathrm{s}}+\mathrm{a}_{\mathrm{s}} \mathrm{R}_{\mathrm{a}}+\mathrm{b}_{\mathrm{s}} \mathrm{R}_{\mathrm{b}}+\ldots+\mathrm{h}_{\mathrm{s}} \mathrm{R}_{\mathrm{h}}+\mathrm{k}_{\mathrm{s}} \mathrm{R}_{\mathrm{k}}
$$

Em seguida temos uma equação que iguala poupança $(E)$ e investimento (fabricação de capital novo): $\mathrm{E}=\Pi_{\mathrm{h}} \mathrm{R}_{\mathrm{h}}+\Pi_{\mathrm{k}} \mathrm{Rk}+\ldots$ Um terceiro sistema de $\mathrm{m}+\mathrm{n}^{\prime}$ equações dá conta dos custos: $\pi_{\mathrm{a}}=\mathrm{a}_{\mathrm{s}} \mathrm{p}_{\mathrm{s}}+\mathrm{a}_{\mathrm{t}} \mathrm{p}_{\mathrm{t}}+\ldots, \ldots, \pi_{\mathrm{h}}=\mathrm{h}_{\mathrm{s}} \cdot \mathrm{p}_{\mathrm{s}}+\mathrm{h}_{\mathrm{t}} \mathrm{p}_{\mathrm{t}}+\ldots$ Finalmente, um quarto sistema de $m+n^{\prime}+1$ equações impõe a condição de lucro zero concorrencial para os m produtos e $n^{\prime}$ bens de capital fabricados: $1=\pi_{\mathrm{a}}, \mathrm{p}_{\mathrm{b}}=\pi_{\mathrm{b}}, \ldots, \mathrm{P}_{\mathrm{h}}=\prod_{\mathrm{h}} \mathrm{p}_{\mathrm{e}}, \ldots$, onde $\mathrm{p}_{\mathrm{e}}$ representa o preço do capital circulante novo, ou seja, a taxa de juros. Mostrando que uma das equações é combinação das demais, Barone conclui que o sistema é determinado, visto que teríamos $3 m+2 n+2 n^{\prime}$ equações independentes.

Como mencionamos, o autor trabalha inicialmente com coeficientes de produção fixos. Neste ponto, porém, Barone (1908:251) irá introduzir o que denomina 'variabilidade econômica dos coeficientes técnicos', que representa a variação da composição de insumos quando aumentamos a produção e minimizamos os custos de produção:

For it is evident - in the realistic case - that it is necessary to admit that, besides the technical relations between the technical coefficients, there are, for each entprepreneur, special economic relation, which are usually based either on the want of ability to discern and to put into action a plan which combines the technical coefficients to the greatest economic advantage, or on the impossibility of arranging that combination of maximum advantage because of the limitation on the available supply of some factor. Hence originates the transitory profit of various enterprises, even in static conditions. (Barone, 1935:252)

\footnotetext{
${ }^{14}$ Qs-Rs, o capital existente menos seus serviços consumidos, são devotados para a produção de bens e capital novo.
} 
Essa 'variabilidade econômica' será fundamental no julgamento do autor sobre a viabilidade de se resolver na prática o sistema de equações no socialismo. No seu modelo, todavia, Barone representa o problema por meio de algumas restrições entre os coeficientes. Assim, na produção de $\mathrm{B}$, teríamos $\mathrm{k}$ restrições , $\mathrm{k}<\mathrm{n}$, onde $\mathrm{n}$ é o número de coenficientes totais utilizados na produção. Essas restrições assumem a forma: $\mathrm{F}_{\theta}\left(\mathrm{b}_{\mathrm{s}} \mathrm{b}_{\mathrm{t}} \ldots \mathrm{Qb}\right)$. A partir da postulação dessas restrições, o autor considera solúvel o seu sistema de equações.

Estabelecido o sistema, o autor demostra que o equilíbrio é ótimo no sentido de Pareto, diferenciando $\mathrm{o}$ valor da produção total $\phi=\mathrm{R}_{\mathrm{a}}+\mathrm{p}_{\mathrm{b}} \mathrm{R}_{\mathrm{b}}+\ldots+\mathrm{p}_{\mathrm{s}} \mathrm{R}_{\mathrm{s}}+$ $p_{t} R_{t}+\ldots+1 / p_{e}\left(p_{h} R_{h}+p_{k} R_{k} \ldots\right)^{15}$ em relação a um aumento em um bem qualquer e notando que o aumento no valor do bem é anulado pelo aumento equivalente nos custos. $\mathrm{O}$ ótimo ocorre com $\Delta \phi=0$.

Dada a descrição do EG para uma economia individualista, Barone passa a discutir como o problema seria resolvido no socialismo, dado que o estado socialista deve procurar maximizar o bem estar de seus administrados. Neste, entre os recursos produtivos, temos $\ell$ bens $\mathrm{M}, \mathrm{N}, \ldots$ privados (possivelmente trabalho) e $\mathrm{n}$ - $\ell$ bens de posse do estado $\mathrm{S}, \mathrm{T}$, ...., n no total, como antes. No lugar de preços, temos 'razões de equivalência' entre bens: $1, \lambda_{b}, \ldots, \lambda_{m}, \lambda_{n}, \ldots, \lambda_{s}, \lambda_{t}, \ldots O$ produto social total é representado por $\mathrm{Q}_{\mathrm{s}} \lambda_{\mathrm{s}}+\mathrm{Q}_{\mathrm{t}} \lambda_{\mathrm{t}}+\ldots=\mathrm{X}$. Baseando-se em "critérios éticos e sociais", o estado distribui esse produto entre classes ou indivíduos segundo uma fração do bolo total: $\gamma \mathrm{X}$, sendo que $\Sigma \gamma=1$. As restrições individuais ficam: $1 . \mathrm{r}_{\mathrm{a}}+\lambda_{\mathrm{b}} \cdot \mathrm{r}_{\mathrm{b}}+\ldots+\lambda_{s} \mathrm{r}_{\mathrm{s}}+\lambda_{\mathrm{t}} \mathrm{r}_{\mathrm{t}}+$ $\ldots+\mathrm{e}=\lambda_{\mathrm{m}} \mathrm{q}_{\mathrm{m}}+\lambda_{\mathrm{n}} \mathrm{q}_{\mathrm{n}}+\ldots+\gamma \mathrm{X}$. O governo, 'depois de reflexão madura', impõe a si mesmo obediência a sua restrição orçamentária.

Estabelecido o sistema, a solução do mesmo se dá por processos interativos. Os juros, ou melhor, o 'prêmio pelo consumo adiado' é obtido por um mecanismo de tentativas e erros $^{16}$ : O estado sugere um valor e observa - não se explica como - qual seria o equivalente à poupança agregada e verifica se tal soma é suficiente para criar o novo capital de forma a aumentar a produtividade para honrar o prêmio proposto. Novamente, o autor não explica como isso pode ser feito.

\footnotetext{
${ }^{15}$ Esse último membro do produto total é igual a $\mathrm{E}$, a poupança total. 16 Let it choose at random a rate of premium for deferred consumption; let it hen see how much saving on the basis of this premium its people put freely at its disposition. Then let it find out if with this sum of saving it is possible to manufacture such a quantity of new capital that it will be able, in the future to put at the disposition of the people a quantity of products and consumable services so great that it can really give them the promised premium for deferred consumption. And by trial and error, raising and reducing the promised premium, it will eventually make its promise in terms which can be realized. (Barone, 1908: 268)
} 
Quanto ao resto do sistema, o estado parte do conjunto de coeficientes técnicos (fixos) pré-existentes. Escolhe aleatoriamente um conjunto de R's que obedecem as equações das necessidades físicas da produção. Anuncia, de forma arbitrária, um conjunto de equivalentes $\lambda$ (preços) e leva em conta as alterações na produção necessárias. Diante desses preços as pessoas escolhem as demandas $\mathbf{r}$ e as poupanças $\mathbf{e}$, valores esses que são agregados nos R’s e em E. Das infinitas soluções que atendem ao sistema de equações das necessidades físicas da produção, escolhe-se uma de tal forma que o aumento do valor total se reduza a zero: $\Sigma \Delta \theta=\Delta \mathrm{R}_{\mathrm{a}}+\lambda_{\mathrm{b}} \Delta \mathrm{R}_{\mathrm{b}}+\ldots+\lambda_{\mathrm{s}} \Delta \mathrm{R}_{\mathrm{s}}+\lambda \mathrm{t} \Delta \mathrm{R}_{\mathrm{t}}+\ldots+$ $\Delta_{\mathrm{h}} \Delta \mathrm{R}_{\mathrm{h}}+\Delta_{\mathrm{k}} \Delta \mathrm{R}_{\mathrm{k}}$, em que $\Delta_{\mathrm{h}}, \Delta_{\mathrm{k}}, \ldots$ representam a poupança necessária para a produção de unidades de $\mathrm{H}, \mathrm{K}, \ldots$ Enquanto $\Sigma \Delta \theta$ for positivo, devem-se alterar os coeficientes técnicos, até finalmente se obter $\Sigma \Delta \theta=0$.

No processo de busca do máximo, Barone nota que um aumento na quantidade de um produto final, digamos, $B$, deve ser levada adiante enquanto o seu valor $\lambda_{b} \Delta R_{b}$ for maior do que o custo $\left(\lambda_{s} b_{s}+\lambda t b_{t}+\ldots\right) \Delta R_{b}$, o que ocorre quando $\lambda_{b}=\lambda_{s} b_{s}+\lambda t b_{t} \ldots$, ou seja, quando o preço se igualar ao custo marginal de produção. Do mesmo modo, deve-se procurar minimizar o custo médio de produção. Assim, Barone expressa o argumento de similitude formal:

From what we have seen and demonstrated hitherto, it is obvious how fantastic those doctrines are which imagine that production in the collectivist régime would be ordered in a manner substantially different from that of "anarchistic" production.

If the Ministry of Production proposes to obtain the collective maximum - which it obviously must, whatever law of distribution may be adopted - all the economic categories of the old régime must reappear, though maybe with other names: prices, salaries, interest, rent, profit, saving, etc ... Not only that; ..., the same two fundamental conditions which characterize free competition reappear, and the maximum is more nearly attained the more perfectly they are realized. We refer, of course, to the conditions of minimum cost of production and the equalization of price to [marginal] cost of production. (Barone, 1935:289)

Depois de elaborar detalhes sobre o procedimento necessário para que o ministro da produção socialista resolva o sistema de equações, Barone traça alguns comentários, um tanto confusos, sobre a possibilidade prática de que essa solução prática ocorra. Tais comentários merecem citação na íntegra, já que o significado da contribuição de Barone irá receber interpretações opostas.

Many of the writers who have criticized collectivism have hesitated to use as evidence the practical difficulties in establishing on paper the various equivalents; but it seems they have not perceived what really are the difficulties - or more frankly, the impossibility - of solving such equations $a$ priori.

If, for a moment, we assume that the economic variability of the technical coefficients may be neglected and we take account of their technical variability only, it is not impossible to solve on 
paper the equations of the equilibrium, It would be a tremendous -a gigantic - work (work therefore taken from the productive services): but it is not an impossibility.

It is conceivable, in fact, that with a vast organization for this work it would be possible to collect the individual schedules for every given series of the various equivalents, including the premium for deferred consumption. Hence it is not inconceivable that with these schedules collected - always supposing the technical coefficients known and invariable - it would be possible by a paper calculation to find a series of equivalents, which would satisfy the equations expressing the physical necessities of production and the equalization of cost of production and the equivalents, which become the prices. There is no analytical difficulty about it: it is a problem of very simple linear equations. The difficulty arises rather from the very great number of individual and goods of which we must take account; but it is not inconceivable that, with still more arduous work, such difficulty could be overcome. (Barone, 1935:287)

Com coeficientes técnicos fixos, o sistema poderia ser resolvido. No entanto, o que tornaria inconcebível a solução do sistema para o autor é a 'variabilidade econômica dos coeficientes de produção’:

But it is frankly inconceivable that the economic determination of the technical coefficients can be made a priori, in such a way as to satisfy the condition of the minimum cost of production which is an essential condition for obtaining that maximum to which we have referred. This economic variability of the technical coefficients is certainly neglected by the collectivists, ... (Barone, 1908:287, ênfases no original).

A variabilidade ocorre porque estes coeficientes só podem ser obtidos pela experimentação de formas diferentes de combinar recursos que ocorre em cada firma. Nesse processo algumas firmas têm sucesso, outras fracassam e desaparecem. Barone critica, então, a idéia socialista de que seria possível organizar a priori, sem fazer uso do processo 'anárquico' de correção de erros a posteriori com o auxílio do sistema de preços. Este será um tema recorrente no debate: enquanto os autores socialistas partem de relações técnicas dadas (e fixas), os seus críticos insistirão que as técnicas escolhidas serão dependentes dos preços (custos de oportunidades).

Enquanto o começo dos comentários de Barone servirá para sustentar a tese de Lange de que um sistema de equações pode ser encontrado para se administrar uma economia socialista, o final dos comentários se assemelha à tese de Hayek sobre o caráter disperso do conhecimento e da impossibilidade de se utilizar o sistema de equações. Retornaremos a essas duas interpretações quando tratarmos das contribuições de Lange e Hayek. Neste ponto, contudo, vale a pena nos determos na análise da origem da ambigüidade do trabalho de Barone.

Barone (1908:246-7), revelando uma orientação positivista, se orgulhava do caráter científico de sua contribuição, desprezando conceitos 'metafísicos' como utilidade, grau final de utilidade (utilidade marginal) ou ainda curvas de indiferença, pretendendo basear sua contribuição na autenticidade de fatos simples como demanda, oferta e 
custos de produção. Além disso, o uso da matemática seria a única maneira conhecida de expor o argumento de forma breve, precisa e inequívoca. Assim, o autor dedica a maior parte de seu artigo à tarefa de construção de seu modelo e reserva pouquíssimo espaço para comentar o significado de seus resultados. Os poucos comentários ou procuram distinguir o caráter científico da sua contribuição dos 'canhestros argumentos' de outros autores, ou comentam de forma confusa, como reportamos acima, a possibilidade de resolver o sistema de equações na prática.

Desse modo, ironicamente, apesar do pretenso rigor, a falta de clareza do autor resultou em interpretações opostas sobre o argumento na sequiência do debate. Para Oskar Lange, Barone teria refutado o argumento de Mises antes deste ser enunciado, provando que o socialismo seria viável na teoria. A prova da possibilidade prática seria fornecida, como veremos, pela própria contribuição de Lange. Para Hayek, por outro lado, considera que o texto de Barone apresenta formalmente o argumento de similitude e mostra a impossibilidade de resolver o problema no socialismo (na prática e, portanto, na teoria).

$\mathrm{Na}$ verdade, a estranha dicotomia entre prova teórica e prova prática se relaciona com a tese da simetria entre previsão e explicação. Barone, como Pareto, ao sutilmente deixar de usar o modelo de EG apenas para explicar o funcionamento dos mercados e passar a utilizá-lo para investigar a possibilidade de construir um sistema de mercado artificial, deixa de discutir metodologicamente se existem elementos dos mercados reais que sejam importantes para o seu funcionamento e que no entanto não figuram no modelo de EG. Ao não discutir esta questão, fica a impressão que o modelo de EG contém os elementos suficientes para a explicação e portanto para a operação de um conjunto de mercados.

Essa peculiaridade da contribuição de Barone irá marcar sobremaneira o desenrolar do debate em língua inglesa na década de trinta, tanto pelos elementos em comum que apresenta com as principais tentativas de responder ao argumento da impossibilidade, quanto ao significado histórico que terá como etapa fundamental do debate. Comentaristas como Lavoie (1984) e de Soto (1992) identificam o interesse pelo texto de Barone com o início do desvio do debate em direção à análise puramente estática de equilíbrio. Esse desvio, para eles, tornaria boa parte da discussão posterior irrelevante sob o ponto de vista do argumento posto por Mises. 
Adicionalmente, não podemos deixar de enfatizar que a distinção entre as vertentes austríaca e walrasiana do argumento de similitude formal será fator preponderante no processo histórico de diferenciação dos paradigmas austríaco e neoclássico.

\section{Gustav Cassel}

Além dos autores já apresentados, também Gustav Cassel, em 1918, formula o argumento da similitude em The Theory of Social Economy. Será interessante rever esta outra versão do argumento, pois ela expõe de forma mais clara o que será na seqüência do debate a opinião neoclássica sobre a aplicabilidade da análise econômica de equilíbrio ao problema do socialismo.

Ao investigar como o problema da escolha diante da escassez é resolvido com o auxílio do sistema de preços, Cassel (1967, cap. 2) distingue entre 'economias de troca', caracterizadas pela liberdade de escolha de ocupação e de consumo, e economias comunistas, nas quais essas liberdades não existiriam. Para o autor, os princípios de economização descritos pela teoria seriam aplicáveis apenas ao primeiro tipo de sociedade.

O socialismo, por seu turno, deve ser classificado como 'economia de troca', pois além da direção central da atividade produtiva, nele pressupõem-se adicionalmente as liberdades de escolha de ocupação e consumo que definem as economias de troca. A teoria econômica, portanto, longe de se referir apenas a economias de mercado, abarca também a economia do socialismo:

It follows that the principle of pricing hold goods for every exchange economy, and are independent of the particular organization of production within the economy. ... These principles would remain unchanged in an exchange economy in which the State had assumed control of production and reserved to itself the ownership of the material factors of production. (Cassel, 1967:132)

A alocação de recursos escassos no socialismo seria feita da mesma forma em qualquer economia de troca, inclusive com o uso de moeda e preços. O raciocínio até aqui pouco difere do argumento tradicional de similitude formal. É importante salientar, porém, que para Cassel o estabelecimento de preços é consequiência direta da existência de economias de troca. Em outros termos, a essência do mecanismo de alocação via preços é derivada puramente do fato de haver trocas e não de outras características dos 
mercados reais, como propriedade privada ou competição. A análise econômica seria então igualmente aplicável ao socialismo:

The study of pricing under a typical socialistic system is from several points of view useful and profitable in economic theory. It shows absolutely clearly, in the first place, how untrue it is that free competition is a theoretically necessary condition of giving effect to the principle of cost, and of what universal importance the principle of cost is in the exchange economy. (Cassel, 1967:132-3)

A comparação entre economias presentes e socialistas seria então útil para testar a necessidade das instituições vigentes para o funcionamento de uma economia. Isto, em última análise, é o ponto central do debate do cálculo.

Cassel (1967:133), antes de abordar a questão de como funcionaria o socialismo, observa que não levará em conta as dificuldades práticas ou a desejabilidade de tal organização social, antecipando assim a distinção feita posteriormente pelos defensores do socialismo entre o problema teórico e o problema prático da organização econômica socialista.

Quanto ao socialismo propriamente dito, observa o autor que o uso da moeda será necessário para alocar os recursos, e a presença dos vales (vouchers) imaginados pelos socialistas como esquema distributivo na primeira fase do comunismo desempenharia o papel de moeda. Ao contrário de Marx e mais tarde Mises, que consideravam que tais vales não são equivalentes à moeda em economias de mercado, Cassel afirma que esse seria o caso, visto que os vales são meios de pagamento.

No socialismo, as rendas dos indivíduos - derivadas apenas dos salários - seriam alocadas aos bens de consumo segundo preços estabelecidos pelo estado. Tais preços deveriam ser fixos segundo o 'princípio da escassez', da mesma forma como ocorre nos mercados, pois a alteração dos preços é a única forma de compatibilizar a demanda com a produção. Os preços dos bens de produção, da mesma forma, devem ser estabelecidos segundo o mesmo princípio, visto que a demanda por fatores é derivada da demanda por produtos finais e deve ser limitada pela escassez dos recursos existentes.

Como Barone, Cassel descreve, no capítulo 3 de seu livro, o mecanismo de funcionamento dos preços em termos da teoria de EG. Cassel mostra como, dadas as demandas, os coeficientes de produção e as quantidades de recursos, derivam-se as quantidades de bens e preços de equilíbrio, por meio de equações que a) igualam o preço ao custo (competição), b) relacionam a demanda aos preços e renda e c) relacionam os fatores com a produção. A obtenção de uma solução matemática para 
esse conjunto de equações mais tarde inspirará uma das primeiras tentativas de responder ao argumento de Mises por meio da teoria de $\mathrm{EG}^{17}$.

\section{Precursores do Argumento de Mises}

Além das discussões sobre a similitude formal, que mais tarde influenciarão os autores dos dois lados do debate, é interessante mencionar o trabalho de alguns autores que, embora não tenham despertado interesse como o texto de Mises, anteciparam os argumentos deste último em vários aspectos.

Desde o ressurgimento do interesse pelo debate do cálculo, vários autores contemporâneos têm buscado precursores de Mises. Entre eles, Stiebler (1999) resgata a contribuição de Adolphe Thiers no livro intitulado De la Propriété (1848). Depois de listar diversas justificações para a existência da propriedade privada, Thiers discute a ausência da mesma no socialismo. Ao criticar uma proposta de organização socialista de Luis Blanc, segundo a qual os preços seriam fixos para evitar concorrência e a propriedade das firmas seria transferida para cooperativas de trabalhadores, com capital fornecido pelo estado, Thiers menciona o problema do cálculo. Ao argumentar em favor do sistema de preços, o autor antecipa Mises ao apontar a complexidade da tarefa alocativa diante de uma gigantesca quantidade de escolhas. Como, questiona o autor, se poderia saber se "existem algodão, tecido ou aço o suficiente?" Para Thiers, existiria apenas uma base para controlar o volume de produção; a saber, o preço, "porque é impossível em uma sociedade de 20,30, 40 ou 80 milhões de pessoas saber se há comida, vestuário ou habitação ou não. Existe apenas um método para julgar a questão que é chamada aumento ou diminuição dos preços". (Thiers, citado em Stiebler, 1999:45).

Richard Ebeling (1993), por sua vez, lista vários autores que anteciparam o argumento de Mises ${ }^{18}$. Da mesma forma que outros historiadores do debate, Ebeling afirma que a maioria das críticas ao socialismo anteriores a Mises tratava apenas da falta de liberdade sob planejamento e da falta de incentivos ao trabalho. Os autores estudados por Ebeling, por outro lado, questionaram a capacidade de uma economia socialista alocar recursos

\footnotetext{
${ }^{17}$ Ver no capítulo 4 a contribuição de Kläre Tisch.

${ }^{18}$ The Quintessence of Socialism (1874) de A. Schäffle, Collectivism (1885) de P.L. Beaulieu, Socialism: old and new (1891) de W. Graham, Socialism: Its Theoretical Basis and Practical Application (1890) de V. Cathrein e A Study of Socialism (1915) de B. Edler.
} 
racionalmente, dado que no socialismo não existiriam mercados e portanto sistema de preços que ajudem a guiar a produção. Todos eles discutiram as dificuldades de se tentar calcular o valor dos bens em termos de horas de trabalho, tanto em relação à capacidade de ajustar demanda e oferta utilizando valores expressos em termos de custos objetivos, quanto à tarefa de determinar na prática a quantidade de trabalho socialmente necessária empregada nos bens.

Ebeling nota que, por comungarem a noção clássica de competição vista como rivalidade entre empresários, esses autores antecipam vários aspectos da crítica austríaca ao socialismo que será estudada no quinto capítulo, como por exemplo o caráter disperso do conhecimento dos agentes econômicos ou a visão do mercado como um processo de descoberta dos fundamentos da economia, já que não seria legítimo pressupor que o tal conhecimento fosse conhecido de início. Beaulieu, por exemplo, antecipa Hayek ao salientar que o sistema de preços permite uma economia de informações que, na ausência de mercados, deveriam ser coletadas na sua totalidade pelo órgão de planejamento central: o empresário, por outro lado, altera seus planos de produção conforme os preços se alterem, sem que conheça os detalhes sobre as mudanças na demanda e oferta de outras firmas.

Quanto ao processo rival de competição, de forma condizente com a nossa própria opinião sobre o debate exposta no sexto capítulo, Beaulieu discorre sobre o papel que a multiplicidade de opiniões entre agentes econômicos exerce no funcionamento do mercado. Este autor nota que "even the most perfect statistics can do no more then supply information, which has then to be interpreted, and interpretations are certain to vary widely." (citado em Ebeling,1993:72). Na ausência do processo espontâneo de correção de erros dado pelo sistema de preços, continua Beaulieu, a salvaguarda contra o desastre econômico dependeria da infalibilidade do conhecimento do planejador central. Graham, por sua vez, critica a falta de flexibilidade das decisões de investimento sob um órgão decisório centralizado, pois nesse caso a aprovação de um projeto deveria ser unânime, ao contrário das economias descentralizadas, nas quais tal unanimidade não seria necessária, já que se deve convencer apenas alguns investidores para que um projeto seja financiado.

Finalmente, entre os predecessores do argumento da impossibilidade do socialismo, o próprio Mises (1981:117) nota que Gossen, um dos precursores da Revolução Marginalista, menciona o problema do cálculo em seu livro, escrito em 1853. Gossen, 
depois de investigar as "leis" que regem o funcionamento das economias de mercado, contesta a crença socialista de que a abolição da propriedade privada traria progresso para a humanidade. Através de alguns exemplos históricos, Gossen afirma que tal progresso ocorre justamente na medida em que se avança na proteção da propriedade privada. A defesa teórica desse argumento é feita, inicialmente, na mesma linha dos críticos do socialismo anteriores ao debate do cálculo, ou seja, em termos de incentivos. Já que os indivíduos se dedicam a atividades não diretamente relacionadas à satisfação de suas próprias necessidades (devido à divisão do trabalho), o incentivo à aquisição de propriedade seria necessário para induzir os agentes a se dedicar à tarefa de criar valor para a sociedade por meio de seu trabalho. Removido esse incentivo, cessaria ou diminuiria a dedicação, visto que o trabalho em geral envolve desutilidade. Criados em um ambiente marcado pela propriedade privada, por outro lado, os indivíduos desenvolveriam uma ética de trabalho. Abolindo-se a propriedade, manter-se-ia por algum tempo o comportamento trabalhador devido à formação anterior. No entanto, tal comportamento tenderia a desaparecer:

Hence, specifically, the removal of the institution of private property would result in the most undesirable consequences. Although these consequences may be hardly noticeable at first, with the passage of time they would become increasingly serious. (Gossen, 1983:253)

Antecipando desenvolvimentos modernos do debate ${ }^{19}$, o autor revela sua descrença na eficácia de mecanismos de incentivos alternativos que possam ser desenhados pelos planejadores:

But while with some individuals other incentives would guarantee perfect substitutes for the loss of the property, in the overwhelming number of cases these incentives, just because they are substitutes, would be less adequate. (Gossen, 1983:254)

Veremos como no final do século vinte o debate se volta para a questão de desenho de mecanismos de incentivos por parte dos teóricos socialistas, mecanismos esses rejeitados pelos seus opositores, sob o argumento de que tais mecanismos não dão conta de substituir de forma adequada os sistemas de incentivos sob regime de propriedade privada.

Depois de argumentar em termos de incentivos, Gossen menciona rapidamente, como um ponto adicional, o que será mais tarde o núcleo do argumento do cálculo econômico proposto por Mises:

... the cause of suffering of the working class is not to be found in the established property relations; thus this suffering cannot be corrected by the abolition of the institution of private property.

\footnotetext{
${ }^{19}$ Ver o capítulo 7.
} 
Moreover, only with the establishment of private property can the yardstick be found for the determination of the optimal quantity of each commodity to be produced under given circumstances. This follows from the previously found laws of pleasure and the related rise and fall in the value of any commodity (with the decrease or increase of its quantity) and the manner by which prices are determined. Consequently, the central authority - projected by the communist - for the purpose of allocating the different types of labour and their rewards would soon find that it has set itself a task that far excess the powers of any individual. (Gossen, 1983:254, ênfase no original)

Essa citação contém vários aspectos desenvolvidos mais tarde no debate, como a relação entre propriedade privada e possibilidade de cálculo econômico postulada por Mises e o argumento do conhecimento limitado proposto por Mises e Hayek.

Finalmente, entre os precursores, uma das principais contribuições ao problema anteriores a Mises foi feita em um artigo publicado em 1902 na revista The Economist holandesa, escrito por Nicolaas Pierson. Esse artigo tem como objetivo criticar a desconsideração do problema da alocação de recursos por parte dos autores socialistas. Como vimos há pouco, o principal alvo das críticas de Pierson foi Kautsky, em sua tentativa de expor os funcionamentos da economia socialista.

Embora creditado como um dos precursores do argumento da impossibilidade do cálculo econômico $^{20}$, talvez por estar contido na coletânea original de Hayek (1935), o argumento de Pierson deve ser classificado como argumento de similitude formal na interpretação austríaca. De fato, no texto o autor coloca o problema econômico a ser resolvido pelo socialismo, idêntico ao problema encontrado por qualquer sociedade, abstendo-se todavia de julgar a possibilidade de sua solução sob o socialismo: "as to whether socialism can be carried into practice I shall not decide here." (1902:43).

O problema identificado por Pierson, “o problema do valor”, se contrapõe à crença prevalecente de que no socialismo não haveria o fenômeno do valor e a determinação da produção seria um problema puramente técnico, logicamente independente do uso de preços de mercado..

Diante dessa crença, o autor passa a dar exemplos de escolhas econômicas que exigiriam a comparação de alternativas através de seus valores expressos em preços, em especial no campo do comércio internacional. Pierson pergunta, por exemplo, quem deveria embarcar a mercadoria primeiro, no caso de uma troca entre dois países? Ou seja, quem faria o investimento inicial, esperando pela contrapartida do outro país? A resposta depende da importância que o novo capital tem em cada uso alternativo nos dois países. Os países devem investir em navios próprios ou pagar frete de navios

\footnotetext{
${ }^{20}$ Ver, por exemplo, Steele (1981:11).
} 
estrangeiros? Pierson aponta que esses problemas, e outros mais complexos, são resolvidos automaticamente nos mercados através da lucratividade comparada dos investimentos, solução essa que vai além de questões técnicas. O autor passa a descrever os inúmeros ajustes que ocorrem na produção e comércio quando existe uma quebra de safra de grãos, através da alteração do valor dos bens. Como, pergunta o autor, seriam nesse caso determinadas as quantidades trocadas?

Depois desses exemplos, Pierson aponta os problemas com o cálculo em termos de horas de trabalho. Além da heterogeneidade do trabalho, cada país tentaria explorar o outro alegando horas de trabalho arbitrárias para a produção de cada bem. O comércio internacional deveria então ser pautado, mesmo no socialismo, pelos princípios (1) da liberdade de trocar ou não trocar mediante as condições oferecidas e (2) troca na base de 'serviços equivalentes', que, dada a crítica anterior ao cálculo em horas de trabalho, parece significar trocas segundo preços de mercado. Para Pierson (1902:69), esses dois pontos não seriam contrários aos princípios do socialismo. Mas, na medida em que seus defensores põem em questão o uso da moeda, o mesmo fazem com os preços e os fenômenos do valor, cujos problemas também devem ser resolvidos no socialismo.

Além do comércio internacional, o problema do valor surge internamente. Como medir a renda a ser alocada para cada indivíduo sem moeda, já que não faz sentido somar quantidades de produtos diferentes? E como distribuir os bens produzidos aos cidadãos? Não adianta listar as necessidades médias das famílias conforme suas composições, como sugerira Engels, pois, devido à diversidade humana, sempre surgirão exceções e necessidades insatisfeitas. Se um bem se tornar mais escasso, como substituir o processo de alocação que hoje é feito via aumentos de preços? Preços fixos ou cupons por produtos não são capazes de resolver esse problema, e nesse caso surgiria o comércio entre cupons, a preços diversos das taxas de troca oficiais:

Thus the commercial principle, which such a society sought in vain to abolish, comes once more into the foreground. ... The phenomenon of value can no more be suppressed than the force of gravity. What is scarce and useful has value. (1902:75)

Nota-se pela leitura se seu texto que Pierson se aproxima mais do argumento de similitude formal na sua versão austríaca, para o qual os preços são fundamentais na alocação de recursos diante de mudanças constantes, e não do argumento walrasiano centrado em preços de equilíbrio. Essa diferença, que aqui passa despercebida, tomará contornos mais nítidos no debate a partir da década de trinta. Relacionado a esse ponto, Pierson nota que a comparação do valor dos bens em termos de seus preços de mercado 
é apenas uma estimativa. Para bens públicos, por exemplo, nota o autor que não existem preços de mercado. Mas nesses casos, o que seria uma exceção em uma economia de mercado seria a regra em um socialismo sem moeda.

O trabalho de nenhum dos autores estudados acima foi capaz de acender a discussão sobre a possibilidade do cálculo econômico no socialismo. Os expositores do argumento de similitude formal apenas colocaram um problema, não desafiando diretamente a viabilidade do socialismo. Os trabalhos de Pareto e Barone, entre estes, além de ambíguos no seu significado, eram abstratos demais para serem capazes na época de despertar interesse entre os socialistas. Já os precursores do argumento da impossibilidade não trataram do assunto de forma sistemática. Entre os autores apresentados, apenas Böhm-Bawerk e Pierson se envolveram em debates com defensores do socialismo.

O mais importante, talvez, tenha sido o momento histórico. Embora a influência do socialismo fosse crescente, não tinha atingido ainda o seu ápice como no séc. XX, tanto intelectualmente quanto em tentativas práticas de implementá-lo em larga escala. Por outro lado, o processo de difusão e dominância da teoria neoclássica não se completara ainda. Apenas com a publicação do trabalho de Mises teremos reunidas tanto as condições históricas quanto a existência de um autor com qualificação teórica e estilo incisivo para lançar um desafio capaz de iniciar o debate do cálculo. 


\section{O Argumento da Impossibilidade do Cálculo Econômico Socialista}

Em 1920, pouco depois da revolução russa e em um período de grande influência das idéias socialistas, tanto entre políticos quanto na academia, três autores escreveram críticas à viabilidade do socialismo em termos econômicos. Entre essas críticas, o artigo de Ludwig von Mises é tido como o texto que iniciou o debate sobre a possibilidade do cálculo econômico socialista. Contudo, no mesmo ano Max Weber e Boris Brutzkus publicaram textos com a mesma crítica, que não chamaram a mesma atenção que o artigo de Mises.

O texto de Brutzkus, escrito em russo, não chegou à comunidade acadêmica ocidental. Weber, por sua vez, coloca a crítica em um pequeno trecho de sua volumosa obraprima, que não é um tratado sobre teoria econômica pura. Apenas o trabalho de Mises chamou a atenção dos economistas. Em primeiro lugar, por ser já um influente teórico em 1920. Em segundo lugar, escreveu na Áustria, um dos principais focos de influência política do socialismo. Em terceiro lugar, suas idéias influenciaram tanto Robbins quanto Hayek, que as difundiram na academia inglesa a partir da London School of Economics. Em último lugar, e o mais importante, dentre os três autores Mises foi o principal herdeiro de uma tradição teórica - austríaca - que, por suas peculiaridades, fornecerá uma opinião única sobre a relevância da teoria neoclássica para a discussão do socialismo. De fato, os trabalhos de Pareto e Barone revelavam a neutralidade da tradição walrasiana no que diz respeito à possibilidade do socialismo, neutralidade essa que também caracterizará a vertente marshalliana.

A natureza e as peculiaridades de cada uma das três críticas à possibilidade do cálculo econômico no socialismo poderão ser vistas neste capítulo, que trata do início do debate propriamente dito. 


\section{Max Weber e o Cálculo em Espécie}

Na segunda década do séc. XX, o sociólogo Max Weber desenvolveu, de forma independente dos outros dois autores, a crítica econômica ao socialismo, no segundo capítulo da sua obra prima Economia e Sociedade. Embora tenha sido influenciado pela Escola Austríaca, e Mises em particular ${ }^{1}$, Weber afirma (1997:82) que seu livro já estava sendo impresso quando foi publicado o artigo de Mises.

Ao contrário de Brutzkus, que publicou um livro sobre o assunto e Mises, que publicou inicialmente um artigo e depois um livro, Weber dedica apenas uma pequena parte de um capítulo ao problema. Talvez por isso a argumentação do autor é a menos clara e sistemática das três. Contudo, a essência do argumento está claramente presente. Nesse capítulo, que trata de definições de categorias sociológicas na Economia, Weber afirma que uma economia com 'socialização plena' precisa encontrar um sistema apropriado de cálculo se pretende construir uma sociedade planificada de forma racional. Por outro lado, a forma suprema de racionalidade, em termos de gestão econômica, é obtida na presença do cálculo em dinheiro nos mercados livres. Portanto, a possibilidade de planificação 'científica' da produção em uma economia natural (sem moeda) é posta em dúvida.

A argumentação do autor é estruturada como uma crítica ao cálculo em espécie proposto por Neurath:

Él cálculo natural como fundamento de una calculabilidad de las explotaciones... encuentra sus límites de racionalidad en el problema de la imputación,... El cálculo natural para los fines de una gestión económica permanente y racional de los medios de producción tendría que encontrar 'indices de valor' para cada uno de los distintos objetos, los cuales tendrían que asumir la función de los 'precios de balance' en la contabilidad moderna. (Weber 1997:78)

O cálculo em espécie é limitado a poucos casos simples, como por exemplo quando se compara em uma economia primitiva a produção de bens agrícolas qualitativamente semelhantes. Nessas sociedades a tradição pauta em grande medida as decisões econômicas. Weber, como os outros dois autores, enfatizará que a necessidade de cálculo monetário deriva da complexidade das decisões alocativas. Dessa forma, quando tivermos diversas classes de bens de produção, cada qual com múltiplos usos, apenas poderemos estimar a importância de cada insumo para a produção de cada bem por meio da comparação dos 'preços efetivos' formados no mercado.

\footnotetext{
${ }^{1}$ Economia e Sociedade de Weber possui referências a Theory of Money and Credit de Mises, obra esta que contém os elementos da crítica misesiana ao planejamento sem moeda.
} 
Com o cálculo em espécie, seria impossível determinar, por exemplo, a localização mais econômica de uma indústria ou saber se vale mais a pena empregar mão-de-obra e materiais na produção de um bem localmente ou adquiri-lo através da troca.

Weber ataca em seguida o argumento de Neurath segundo o qual a experiência com a economia de guerra teria demostrado a viabilidade da economia natural. Neste caso, afirma Weber, temos apenas um fim, o esforço de guerra. O problema de alocação de recursos se torna aqui puramente técnico: todos os meios são alocados para o único fim inequívoco. O suprimento das necessidades futuras, do mesmo modo, é ignorado nessas ocasiões, podendo haver esgotamento de recursos. O problema econômico surge, em época de paz, quando temos inúmeros fins disputando os recursos escassos. Uma economia sem moeda, fazendo uso do cálculo em espécie, jamais seria capaz de viabilizar uma sociedade populosa e complexa, com seus inúmeros bens qualitativamente diferentes. O cálculo monetário, por sua vez, embora muito superior ao cálculo natural, apresenta várias limitações, como a falta de preços de mercado para certos bens, a atribuição de custos para a produção de múltiplos bens em uma firma ou a existência de cartéis ou monopólios.

\section{Boris Brutzkus e a Economia Soviética}

Entre os três autores, a crítica de Brutzkus se destaca pelo casamento do argumento teórico com a ilustração histórica. Como bem observa Hayek no prefácio do livro de Brutzkus, este, como russo e economista que vivenciou a revolução, se qualifica como poucos a examinar as conseqüências de uma economia organizada sem o uso da moeda, como ocorreu na Rússia logo após a tomada do poder pelos bolchevistas.

Brutzkus conta que em 1921, durante a NEP, existiu um pequeno período de relativa tolerância em relação à literatura não comunista e assim ele decidiu publicar seu artigo, intitulado "The Doctrines of Marxism in the Light of the Russian Revolution" na revista The Economist russa. O texto foi publicado com apenas alguns parágrafos censurados. No ano seguinte, com o recrudescimento da censura, o autor foi preso e deportado, juntamente com a diretoria do jornal:

"Learned ideologists", he [Trotsky] wrote in the Pravda, "are not at present dangerous to the Republic, but external or internal complications might arise which would oblige us to have these ideologists shot. Better let them go abroad therefore.” (Brutzkus, 1920:xvii) 
Em seu artigo, que consiste na primeira parte ${ }^{2}$ do livro Economic Planning in Soviet Russia, editado em 1935 por Hayek juntamente com a coletânea deste último sobre o socialismo, Brutzkus atribui o fracasso do período posteriormente denominado 'economia de guerra' à ausência de cálculo econômico em termos monetários:

I put forward my contention that the system of Marxian communism, as then conceived, was - quite apart from the conditions produced by the war - intrinsically unsound and must inevitably break down. (Brutzkus, 1920: xv)

Para provar sua tese, Brutzkus coloca o problema primeiramente em termos teóricos e o ilustra com o caso da Rússia. Em termos teóricos, tanto em uma economia natural quanto em uma economia capitalista ou socialista, os resultados de uma ação devem ser comparados com os custos. Enquanto na primeira, devido à simplicidade da tarefa, seja possível compará-los diretamente, na segunda a tarefa é realizada pelo sistema de seleção do mercado, que promove ou elimina os empresários conforme ocorram lucros ou prejuízos. Os empresários, movidos pelo incentivo dos lucros, direcionam a produção guiados pelo sistema de preços, o que permite que sejam feitas estimativas de custos e rendimentos em termos monetários.

No socialismo, por outro lado, inexiste esse sistema de incentivos. O cálculo econômico seria então mais importante no socialismo do que no capitalismo, visto que a ausência do mecanismo automático de seleção do mercado no primeiro impõe a realização de estimativas mais precisas do que aquelas feitas pelos empresários no segundo. Isto ocorre porque o fracasso dos administradores socialistas não cairia sobre estes, mas sobre a população. Se um empresário de uma economia de mercado administra uma firma sem consideração pelo cálculo, ou ele acerta por acaso ou ele mesmo perde o capital investido, suportando o prejuízo. Já no socialismo, estimativas incorretas dos benefícios e custos de uma ação resultam em desperdícios em termos econômicos que são sentidos pela população sem que seus administradores sejam afetados. Isso seria exatamente o que estaria ocorrendo na Rússia: a 'atrofia do cálculo econômico' nas grandes empresas russas impusera enormes custos em termos de organização do sistema econômico sem que os administradores precisassem se preocupar com o problema. Brutzkus compara a situação a uma ferida que não dói, não sendo por isso menos prejudicial à saúde.

\footnotetext{
${ }^{2} \mathrm{Na}$ segunda parte do livro, escrito no exílio na Alemanha, o autor analisa sob o ponto de vista econômico os períodos de NEP e o primeiro plano qüinqüenal.
} 
Produtos são feitos, sem dúvida, mas ninguém é capaz de calcular os custos. Ausente a possibilidade de contabilidade de custos em termos monetários, o governo precisa controlar as empresas por outros meios. Explica-se assim o surgimento do gigantesco aparato de supervisão e controle, que progressivamente consome os recursos do setor produtivo. Esse sistema de controle, porém, além de consumir recursos preciosos, estaria fadado ao fracasso, pois seria incapaz de realizar a tarefa levada a cabo pelo sistema de preços. Um sistema de controle baseado no cálculo em espécie, como aquele sugerido por Tschayanoff, sofre pelo caráter hipotético e arbitrário das unidades utilizadas nas fórmulas deste autor. Como converter, pergunta o autor, os diversos tipos de insumo a uma unidade comum a ser empregada nas fórmulas que relacionam insumos com produtos? O socialismo deve então buscar outra forma, mais eficaz, de avaliar os benefícios e custos dos empreendimentos de forma econômica. Ausente essa forma, o cálculo econômico seria impossível:

Without evaluation any rational economic conduct, under whatever kind of economic system, is impossible. (Brutzkus, 1920: 15)

A alternativa mais óbvia para substituir o rublo seria basear as avaliações expressas em moedas por avaliações advindas do cálculo de horas de trabalho empregadas na produção dos bens, já que esta é a base do valor para o socialismo marxista. Para Brutzkus, o decreto soviético que estabeleceu a obrigatoriedade do cálculo em horas de trabalho nunca foi posto em prática, dada a impossibilidade de se saber a priori a quantidade de trabalho socialmente necessária para a produção dos bens. Seria concebível realizar médias para firmas já existentes se estas operassem em condições idênticas, como por exemplo mesma quantidade e tipo de capital. Em uma situação complexa, no entanto, não há como reduzir as diferentes quantidades de trabalho a um denominador comum.

Brutzkus ilustra então a inaplicabilidade do cálculo em horas de trabalho a partir de exemplos de alterações nos dados da economia, como quando ocorrem mudanças nos processos produtivos e preferências. Depois de mostrar como somente a noção de valor baseado em utilidade da teoria neoclássica pode explicar o valor dos bens nesses casos, Brutzkus conclui que apenas em uma economia estacionária existe uma relação completa entre custos e preços. Em uma economia real, no entanto, não há como utilizar o valor em termos de horas de trabalho para realizar o cálculo econômico. 
Um socialismo descentralizado seria possível se houvesse cálculo em espécie ou em horas de trabalho. Descartadas essas hipóteses, Brutzkus investiga então a possibilidade de organizar o socialismo segundo um plano central:

But if it is impossible to operate socialism from the bottom upwards by means of suitable economic calculation, it is sought to direct it from the top downwards by means of a unitary economic plan based upon statistical data. (Brutzkus, 1920: 31)

O processo de formação de preços no capitalismo, nota Brutzkus, é um processo espontâneo. "Aqueles que fazem parte não baseiam suas ações em nenhuma teoria, e raramente utilizam cálculos estatísticos." (Brutzkus.1920:34) Embora o sistema de cálculo econômico em termos de moeda apresente defeitos, como crises periódicas, tem-se um sistema de coordenação que funciona. O planejamento central, por outro lado, procura superar a anarquia da produção através do controle consciente expresso em planos. Como seria então feito esse controle visto que "o Conselho Econômico Supremo não mais possui o barômetro sensível fornecido pelos preços de mercado"? (Brutzkus, 1920:37). Sem um mecanismo de coordenação descentralizado, o órgão de planejamento requer uma quantidade gigantesca de informações, que seriam expressas por estatísticas:

... since the socialist state lacks the mechanism of the market prices, it must needs possess an enormous and unusually perfect statistical apparatus, an apparatus witch embraces every aspect of social life, and which functions elastically and uninterruptedly, so that it may respond to every chance in social life. (Brutzkus, 1920:38).

Essas informações, contudo, não podem ser obtidas. As necessidades da população, por exemplo, não podem ser estabelecidas a priori. Quando os primeiros autores socialistas escreveram, a pobreza era extrema e talvez fosse possível julgar centralmente as necessidades da população ${ }^{3}$.

Com o crescimento econômico, mesmo os mais pobres escolhem e manifestam preferências por bens diversos. Sem o auxílio do sistema de preços, porém, não se pode estabelecer relações de demanda. As condições de produção, da mesma maneira, não se sujeitam a cálculos pré-concebidos. Sem o sistema de preços, conclui-se, não se pode dirigir a produção para atender as necessidades dos cidadãos.

\footnotetext{
${ }^{3}$ A crença na relativa simplicidade do problema alocativo pode ser ilustrada pela seguinte afirmação de Engels: "In communist society it will be easy to be informed about both production and consumption. Since we know how much, on the average, a person needs, it is easy to calculate how much is needed by a given number of individuals, and since production is no longer in the hands of private producers but in those of the community and its administrative bodies, it is a trifling matter to regulate production according to needs". (Engels, citado em Steele, 1991:25)
} 
Esse fato tem como conseqüência que as decisões econômicas dependem em última análise das avaliações subjetivas dos oficiais, o que resulta em decisões baseadas em critérios políticos. A economia cederia lugar à política: os fundos são desperdiçados em projetos sem justificação econômica porque atendem a objetivos dos governantes, como teria mostrado o caso russo. Mesmo quando este não for o caso, o sistema de coordenação dos diferentes setores industriais por meio das juntas governamentais (Glavki) não seria capaz se substituir o sistema de coordenação via preços:

And who can doubt that the Astrakhan fisheries are Russia's most important source of supply of fish? Yet the fishers failed to obtain nets. Thus millions of pound of fish have been lost simply because the homeworkers of Nizhni-Novgorod, who have always made the nets, were not supplied with the necessary materials. (Brutzkus, 1920:47)

Para Brutzkus, os setores que funcionam adequadamente manteriam a vitalidade devido ao contato com alguma forma de mercado e obtenção de recursos por conta própria e não através dos favores do estado por meio dos Glavki.

Além do argumento do cálculo, Brutzkus procura mostrar como a ausência de liberdade econômica em uma economia centralizada afetaria o funcionamento da mesma. Em primeiro lugar, haveria a falta de liberdade e de incentivos que levam os empresários a inovar. Da mesma forma que Schumpeter, o autor distingue inovação de invenção, relacionando o progresso econômico com a primeira noção. O ideal socialista de igualdade tenderia a inibir tal atividade. Teríamos no socialismo a predominância do conservadorismo e indolência (pág. 69). Em segundo lugar, o socialismo traria a falta de liberdade de consumo. Assumindo um sistema de preços fixos, o autor considera que apenas a flutuação ininterrupta de preços seria capaz de trazer o equilíbrio entre as quantidades produzidas e desejadas. Além disso, tocando no que seria um dos temas principais do Caminho da Servidão de Hayek, Brutzkus relaciona o controle dos meios de produção com o controle dos fins. Na imprensa, por exemplo, o controle dos meios impressos pelo estado implica na falta de liberdade de publicações que contrariem a ideologia oficial. Em terceiro lugar, a falta de mercados de trabalho implicaria na organização coercitiva do trabalho entre as diversas atividades.

Finalmente, na conclusão de seu artigo, Brutzkus argumenta que o fracasso em termos econômicos dos primeiros anos do regime bolchevista na Rússia tem como explicação principal não a guerra, mas a ausência de cálculo econômico. A Rússia, em seu vasto território, produz em abundância meios de subsistência e matérias primas, podendo facilmente produzir internamente as poucas que são importadas. Como seria então 
possível que o bloqueio da guerra causasse tantos problemas econômicos para um país quase economicamente autárquico, em comparação com os outros países envolvidos na guerra? Para Brutzkus, a Rússia seria o país no qual a implementação do socialismo de forma isolada teria as maiores chances de sucesso. A renúncia do socialismo no período de NEP seria explicada pela ausência de cálculo econômico e não pela guerra:

On the contrary, Russian experience bears out in the clearest manner our basic conclusion - namely, that the principle of socialism is not creative, that it leads the economic life of society not to fruition but to ruin. (Brutzkus, 1920:94)

\section{Ludwig von Mises e o Início da Controvérsia}

Do trio de autores que em 1920 contestaram a possibilidade de se alocar recursos racionalmente no socialismo, Mises foi sem dúvida o mais importante. Afinal, o artigo deste autor - "Economic Calculation in the Socialist Commonwealth" - foi responsável pelo início do debate, provocando o surgimento de várias tentativas, tanto em alemão quanto em inglês, de negar a tese da impossibilidade do cálculo econômico.

Como mencionamos no primeiro capítulo, a maioria dessas tentativas, em especial na Inglaterra, foi feita não por autores marxistas, mas sim por economistas formados no referencial teórico neoclássico. Até então, o argumento do cálculo parecia contrapor a teoria clássica à neoclássica. Tanto Pierson quanto Brutzkus criticaram a teoria do valor trabalho e expuseram o argumento do cálculo segundo a nova teoria do valor. Os textos desses autores, porém, não mencionavam as diferenças entre as correntes do neoclassicismo. Brutzkus (1935:25), por exemplo, menciona em seu trabalho a "moderna economia de Walras, Jevons e Menger". Ao tratar da economia do socialismo, apenas Barone considera necessário distinguir a sua contribuição baseada na teoria de EG das contribuições menos rigorosas dos 'economistas literários'. Ainda assim, a diferença entre elas seria apenas de estilo e rigor.

Com o debate em torno da tese de Mises, entretanto, as diferenças afloram. Dessa forma, o artigo de Mises nos é importante não apenas pelo fato de iniciar o debate, mas também porque permitiu que se pusessem em evidência as diferenças teóricas entre as diversas abordagens que compunham a escola neoclássica, uma vez que um mesmo problema - o problema do socialismo - levaria a conclusões completamente diferentes 
conforme tratado por cada uma dessas tradições. Com efeito, o estudo do desenrolar do debate mostrará como, sob o efeito do debate do cálculo econômico, os elementos característicos da abordagem austríaca ficaram mais nítidos e se desenvolveram em direções diferentes daquelas tomadas pela tradição neoclássica que viria a dominar o cenário intelectual. Por isso, ao analisar a contribuição de Mises ao debate, procuraremos salientar desde já os elementos tipicamente austríacos de seu argumento.

O artigo de Mises, publicado em alemão, em 1920, no Archiv für Sozialwissenchaften, aparece de forma modificada e ampliada dois anos depois como parte integrante do livro Socialism: an Economic and Socialogical Analysis, traduzido para o inglês em 1936. Embora o livro seja uma análise ampla das questões relacionadas com o socialismo, nos limitaremos ao artigo e àquelas partes do livro dedicadas à questão do cálculo que complementam o artigo.

Como nota Boettke (2001), o artigo de Mises é uma crítica dirigida a uma audiência marxista e não neoclássica ${ }^{4}$. De fato, o autor inicia seu artigo observando que embora as idéias socialistas estejam se tornando dominantes, seus proponentes se recusam a investigar a natureza dos problemas econômicos que surgiriam no socialismo ${ }^{5}$, sob a influência do método dialético. Mesmo se o socialismo fosse considerado inevitável, ainda assim essa investigação deveria ser feita pelos socialistas, pois, como nota Steele (2000) a tese de Mises, se correta, tornaria a própria análise de Marx 'utópica'.

Ao analisar os problemas econômicos do socialismo, Mises disputa a tese de que a produção fetichística baseada em trocas monetárias resulta em uma economia mais irracional do que sob o socialismo. Mises, herdeiro dos ensinamentos de Menger sobre valor e respeitado como especialista em moeda desde a publicação do seu primeiro livro nessa área ${ }^{6}$, procura inverter a conclusão marxista, afirmando que a supressão da moeda, do sistema de preços e das trocas nos mercados traz consigo a incapacidade de determinar o valor das infinitas alternativas de ação possíveis em uma economia

\footnotetext{
${ }^{4}$ Deve-se notar que o autor freqüentemente emprega termos tipicos do marxismo, como 'anarquia da produção' ou 'meios de produção'.

${ }^{5} \mathrm{O}$ autor escreve em tom provocativo: Economics, as such, figures all to sparsely in the glamorous pictures painted by the Utopians. They invariably explain how, in the cloud-cuckoo lands of their fancy, roast pigeons will in some way fly into the mouths of the comrades, but they omit to show how this miracle is to take place. (Mises, 1935:88) e mais adiante: they [the socialists] are for ever drawing up programmes of the path to Socialism and not of Socialism itself. (122)

${ }^{6}$ Hortwitz $(1996,1998)$ busca as origens da crítica ao socialismo no The Theory of Money and Credit (1912), o primeiro livro de Mises.
} 
complexa, representando assim justamente a abolição da economia racional, não o seu advento:

Thus in the socialist commonwealth every economic change becomes an undertaking whose success can be neither appraised in advance nor later retrospectively determined. There is only groping in the dark. Socialism is the abolition of rational economy. (Mises, 1935:110)

Para chegar a esta conclusão, Mises terá que mostrar a) qual é a natureza do problema econômico a ser resolvido em qualquer sociedade, b) como esse problema é resolvido em economias de mercado e c) como as poucas características descritivas do socialismo imaginadas por seus defensores impossibilitam que o problema seja ali resolvido ${ }^{7}$.

Quanto ao primeiro ponto, Mises (1922:95-98) parte da identificação do problema econômico básico, o estudo da ação racional. A exposição do problema é feita nos moldes do subjetivismo mengeriano. A ação econômica ocorre apenas quando há a percepção de um estado de coisas insatisfatório que possa ser alterado pela ação. Quando os recursos materiais e o tempo não são suficientes para satisfazer todas as necessidades, os homens agem de forma a economizar recursos. Na seção do artigo intitulada 'A Natureza do Cálculo Econômico', Mises explica a lógica das escolhas a serem feitas pelos agentes quando há escassez. Ao escolher entre duas alternativas, fazse um julgamento de valor sobre a importância das necessidades que seriam satisfeitas.

Mises enfatiza em várias ocasiões que as escolhas na esfera da produção não são meramente técnicas, como em um grande problema de engenharia, mas sim escolhas econômicas, que comparam a importância de um bem com a importância do que se abdicou com a escolha, o seu custo de oportunidade. Os bens são valorizados conforme possam satisfazer as necessidades de forma direta (bens de primeira ordem ou bens de consumo) ou de forma indireta (bens de ordem superior ou bens de produção), segundo a nomenclatura de Menger.

A valoração desses últimos, por sua vez, leva em conta a complexidade dos métodos de produção, presente na teoria austríaca do capital. Em uma economia simples, a valoração dos relativamente poucos bens de ordem superior não é problemática. Um fazendeiro em isolamento, ao escolher entre utilizar a terra para pasto ou para campo de caça, avalia diretamente a importância de cada bem de produção na obtenção dos bens finais. Já em uma economia avançada, com a aumento do uso de métodos indiretos (roundabout, na terminologia de Böhm-Bawerk) de produção, não se consegue julgar

\footnotetext{
${ }^{7}$ A nossa exposição do artigo segue a ordem indicada acima e não a sequêencia original do artigo.
} 
diretamente o valor das alternativas empregadas, devido à duração dos processos produtivos e a diversidade de vias alternativas de ação. A escolha entre obter mais energia por meio da construção de uma usina hidroelétrica ou uma termoelétrica deve por isso se basear em um processo de avaliação mais sofisticado.

Esse processo requer o uso de uma unidade pela qual se pode expressar o valor das diferentes alternativas, a fim de compará-las. O valor de uso subjetivo não pode ser utilizado como unidade, visto que o processo de valoração apenas ordena as alternativas. Resta então o valor objetivo de troca - o preço - como medida viável de comparação. O sistema de cálculo econômico baseado nos preços, além de possibilitar a redução do valor dos bens transacionáveis a uma unidade comum, o dinheiro, apresenta como vantagem a possibilidade de basear o cálculo na avaliação de todos os participantes do comércio. Dessa forma, o cálculo econômico monetário permite o controle sobre os usos mais apropriados para os bens, visto que os agentes podem avaliar a importância de sua atividade através da comparação do benefício gerado com o custo dos recursos empregados, expressos em termos de receitas e custos monetários.

Temos assim a explicação de como o problema do cálculo é resolvido em economias de mercado. Para Mises, o cálculo econômico em termos monetários possibilita a comparação do valor de alternativas de ação em uma economia desenvolvida, comparação essa que não seria possível sem o auxílio do sistema de preços. O autor argumentará que o cálculo econômico só é possível se baseado na formação de preços de mercado e não que a alocação de recursos é ótima quando se usa o sistema de preços, como muitas vezes é interpretado o seu argumento. De fato, logo depois de explicar como o cálculo baseado no sistema de preços permite a avaliação do valor das diversas vias de ação, Mises (1935:99-100) aponta os limites desse sistema de cálculo. O próprio valor da moeda se altera ao longo do tempo, mesmo em um sistema monetário relativamente estável. Além disso, ficam fora da avaliação aqueles bens que possuem utilidade mas não são trocados em mercados, pois nesses casos não se formam preços. Mises vai além e afirma que o cálculo monetário só tem sentido na esfera das trocas econômicas. Extensões de seu uso, como a agregação da produção e riqueza (como é feito no cálculo do PIB) ou o uso do que chamamos modernamente de preços sombra seriam ilegítimas.

As limitações, contudo, não inviabilizam o cálculo econômico. A moeda pode ser relativamente estável no curto prazo e grande parte dos bens não comercializáveis são 
bens de primeira ordem (consumo final), sujeitos à avaliação direta. Respeitadas as limitações, o cálculo monetário permite estender a avaliação àqueles bens de ordem superior (bens de produção) em uma economia desenvolvida.

Surge aqui um elemento chave da visão de mundo austríaca que mais tarde ocupará o centro das atenções de Hayek - a complexidade do problema econômico da escolha quando levamos em conta as infinitas possibilidades de ação e suas inter-relações possíveis. Os bens de produção têm inúmeros usos e são empregados de forma complementar e em seqüências temporais específicas para cada um desses usos. Assim, para Mises (pág. 101), o cálculo monetário "nos fornece um guia através da opressiva plenitude das potencialidades econômicas". A complexidade das alternativas sujeitas à escolha só pode ser contornada por um mecanismo que prescinde da onisciência dos agentes, como aquele fornecido pela moeda ao possibilitar o cálculo econômico:

Moreover, the mind of one man alone - be it never so cunning, is too weak to grasp the importance of any single one among the countlessly many goods of a higher order. No single man can ever master all the possibilities of production, innumerable as they are, as to be in a position to make straightway evident judgments of value without the aid of some system of computation. The distribution among a number of individuals of administrative control over economic goods in a community of men who take part in the labour of producing them, and who are economically interested in them, entails a kind of intellectual division of labour, which would not be possible without some system of calculating production and without economy. (Mises, 1935:102)

Encontramos aqui o que será a base do argumento que Hayek usará contra a possibilidade do cálculo econômico no socialismo em uma fase posterior do debate: a limitação do conhecimento humano diante da complexidade do problema econômico impede que este seja resolvido de forma direta, sem o auxílio do sistema de preços. O planejamento central seria inviável por não contar com o mecanismo automático de correção de erros dado pela contabilidade de lucros e prejuízos, mecanismo esse que dispensa a necessidade de agentes ou planejadores oniscientes.

Exposta a natureza do problema econômico, e como este é resolvido nos mercados com o auxílio do cálculo econômico em termos monetários, veremos agora como Mises trata da possibilidade de resolução do problema no socialismo. Para isso, devemos primeiramente mencionar o que Mises entende por socialismo, já que várias tentativas de solução do problema do cálculo feitas ao longo do debate não seriam consideradas socialistas em absoluto pelo autor. Como vimos na introdução deste trabalho, Mises 
(1935:89) define socialismo como uma sociedade na qual 'todos os meios de produção são propriedade da comunidade ${ }^{8}$.

A definição se centra nos bens de capital pois esses têm papel fundamental tanto na explicação marxista da exploração quanto na explicação austríaca do valor desses bens na teoria do capital. Assim, a ênfase do texto recairá na possibilidade de formação de preços de bens de capital. Por outro lado, o aspecto mais importante a ser notado na definição é a alusão à propriedade, entendida pelo autor como o poder de dispor do uso de um bem. A noção de propriedade será fundamental na seqüência do debate, pois enquanto para Mises o funcionamento dos mercados depende de forma crucial da existência da propriedade privada, para seus críticos neoclássicos da década de trinta, a possibilidade de funcionamento de um mercado será dissociada e não dependerá de forma significativa da definição de direitos de propriedade. Nesse aspecto, curiosamente, a postura de Mises se afasta do neoclassicismo e se aproxima de Marx, para quem as instituições que acompanham os mercados são inerentes ao sistema de produção de mercadorias ${ }^{9}$.

A definição de socialismo de Mises deixa de lado os objetivos finais almejados pelos seus proponentes, como igualdade de renda, em favor da identificação do meio pelo qual se perseguem esses objetivos. Identifica-se aqui a essência do socialismo na abolição da propriedade privada. Essa idéia pode ser notada na tipologia que Mises (1922, caps. 15 e 16) constrói de formas de socialismo e pseudo-socialismo. No primeiro grupo, o autor reúne os movimentos políticos prevalecentes na época que propõem a supressão da propriedade privada, entre os quais o socialismo militarista, cristão, estatista, defensor do planejamento central e socialismo de guildas ${ }^{10}$. No segundo grupo estão movimentos que abraçam idéias socialistas mas não pretendem abolir a propriedade privada, entre os quais o solidarismo, o socialismo agrário, a divisão dos lucros entre trabalhadores, socialismo parcial ou sindicalismo. Entre estas formas, será importante enfatizarmos a última, que comporta aqueles grupos que defendem a distribuição da propriedade para os trabalhadores das indústrias nas quais atuam:

\footnotetext{
${ }^{8}$ Do mesmo modo, em Socialism (pág. 211), podemos ler: 'The essence of socialism is this: All the means of production are in the exclusive control of the organized community. This and this alone is Socialism.' ${ }^{9}$ Ver Lavoie (1985, cap. 2).

${ }^{10}$ No socialismo de guildas cada setor industrial é administrado pelos trabalhadores daquele setor. As decisões intersetoriais são debatidas e decididas através de órgãos políticos mais amplos.
} 
Every measure witch takes the ownership of all the means of production from entrepreneurs, capitalists and landlords without transferring it to the whole of the citizens of the economic area is to be regarded as syndicalism (Mises, 1922:240)

A noção de sindicalismo diferenciada do socialismo será importante porque várias das tentativas de responder ao argumento de Mises proporão formas de organização social vistas por este como sindicalismo e não socialismo.

Definido o socialismo, vejamos então como este sistema poderia enfrentar o problema do cálculo, na opinião de Mises. Se os bens de capital são propriedades da 'comunidade', e propriedade significa poder de decisão sobre o seu uso, a propriedade só pode ser exercida no socialismo por meio de um órgão representativo da comunidade, seja esse eleito democraticamente ou funcionando como uma ditadura do proletariado. Tal órgão terá que decidir tanto a maneira como os bens de consumo são distribuídos quanto a forma pela qual se realizam as escolhas na produção.

Embora o primeiro problema não seja essencial para a tese do autor, algum espaço é dedicado a ele. Mises imagina um sistema de cupons que dão direito a cada pessoa a uma certa quantidade de bens. Como as preferências variam por indivíduo, surgirá oportunidade de ganhos de troca, já que cada um de fato tem o direito de uso propriedade - do vale. No exemplo "politicamente incorreto" do autor, as pessoas sem cultura estariam dispostas a trocar seus acessos a concertos por formas mais facilmente compreensíveis de entretenimento, como entradas para cinema.

Com a propriedade restrita aos bens de consumo, a comunidade socialista poderia permitir o uso da moeda, com o propósito de estender as oportunidades de ganho por meio da troca indireta. Embora a moeda funcione como meio de troca, a sua importância seria aqui reduzida, visto que as trocas se restringem aos bens de consumo final. Se os cupons de fumo forem distribuídos de forma diferente por pessoa em termos de 'vales- cigarros' ou 'vales- charutos', o órgão diretor não poderá ignorar o preço relativo dos dois bens, senão os cupons não terão o mesmo valor para cada um. Surge então a dificuldade de ajustar a produção segundo as preferências reveladas em tais preços. Até este ponto Mises pressupõe uma quantidade fixa de bens a ser distribuída. Se houver liberdade de escolha, surgirão excessos de oferta e demanda pelos bens.

Esse problema não seria cogitado pelos adeptos da teoria do valor trabalho, para os quais um esquema de cupons análogo ao proposto por Marx na análise do Programa de Gotha seria viável. Descontando-se um imposto para lidar com os gastos públicos, emitem-se cupons equivalentes às horas de trabalho despendidas pelos trabalhadores, 
que por sua vez os trocariam pelos bens que desejassem e que custassem a mesma quantia de trabalho. Tal esquema, contudo, não seria viável na opinião de Mises, pois a) o trabalho não é homogêneo e b) a teoria do valor trabalho não dá conta de forma satisfatória do valor dos recursos naturais escassos. Quanto ao primeiro ponto, a redução dos diversos tipos de trabalho a um denominador comum ou o cálculo da quantidade de trabalho 'socialmente necessária' para a produção de um bem apelam para os preços e práticas adotadas nos mercados de fatores, valores esses não disponíveis no socialismo, já que tais mercados são abolidos. Quanto ao segundo ponto, o valor dos recursos escassos só é levado em conta de forma indireta, na medida em que um recurso que se torna mais escasso requer geralmente mais trabalho para sua obtenção.

Chegamos assim ao núcleo do problema do cálculo: a avaliação dos bens de capital em um sistema produtivo avançado. Mises critica a opinião de Engels ${ }^{11}$ segundo a qual a quantidade de trabalho socialmente necessária pode ser observada diretamente, sendo revelada pela experiência diária e observação da quantidade de insumos utilizada na produção de cada bem. Em contraste, para Mises, levando-se em conta a complexidade inerente ao processo temporal de produção descrito pela teoria austríaca do capital, as decisões de produção que devem ser tomadas em uma comunidade socialista não são simples:

There will be hundreds and thousands of factories in operation. Very few of these will be producing wares ready for use; in the majority of cases what will be manufactured will be unfinished goods and production-goods. All these concerns are inter-related. Every goods will go through a whole series of stages before it is ready for use. In the ceaseless toil and moil of this process, however, the administration will be without any means of testing their bearings. (Mises, 1935:106)

Cada via alternativa de ação deve ser comparada com seu custo. Em uma economia de mercado, a decisão de construir ou não uma estrada e que rota esta deve seguir (pág. 106) é feita em termos monetários, comparando-se os benefícios da construção da estrada - a redução no custo do transporte - com os seus custos - o valor dos recursos empregados, passíveis de uso alternativo. O cálculo desses benefícios e custos não pode ser feito em espécie, pois é impossível somar ganhos e custos em termos de quantidades físicas de recursos diferentes.

Barradas as alternativas de cálculo em espécie ou em horas de trabalho, resta apenas o cálculo monetário. Contudo esta possibilidade, para Mises, não está disponível no socialismo, pois os preços são formados nas transações de mercado e não havendo

\footnotetext{
${ }^{11}$ F. Engels, Dührings Umwälzung des Wissenschaft, citado em Mises (1935:112).
} 
mercados para bens de capital, preços não se formam e o cálculo econômico não seria então possível (pág. 111).

Para Mises, o funcionamento dos mercados depende de forma crucial da existência de propriedade privada. Não poderia então haver mercados para bens de capital no socialismo, já que aí não existe propriedade privada para esse tipo de bens. Trocas entre departamentos estatais no socialismo não seriam equivalentes a trocas em um mercado autêntico. Para Mises, assim como para Marx, trocas em mercados e socialização da produção são incompatíveis ${ }^{12}$. Mercados implicam em 'anarquia da produção' e não controle consciente:

Exchange relations between production-goods can only be established on the basis of private ownership of the means of production. When the 'coal syndicate' provides the 'iron syndicate' with coal, no price can be formed, except when both syndicates are the owners of the means of production employed in their business. This would not be socialization but workers' capitalism and syndicalism. (Mises 1935:112)

A formação de preços seria fruto da interação entre empresários que competem pela obtenção de lucros. A possibilidade de decidir o emprego dos bens de produção segundo o julgamento de cada um sobre a alternativa mais lucrativa a seguir e o incentivo gerado pela possibilidade desse ganho geram os comportamentos que resultam na competição de mercado.

Deve-se notar que Mises utiliza o termo 'formação de preços'. Com isso o autor quer se referir ao processo competitivo, no qual os preços refletem a avaliação subjetiva de todos os indivíduos participantes do mercado, avaliações essas motivadas pelo desejo de ganho. Assim, para Mises, a formação de preços genuínos nos mercados dependeria do incentivo ao lucro e das possibilidades de ação relacionados com a propriedade privada.

Depois de expor o problema do cálculo, Mises (1935, parte 4) aprofunda a questão dos incentivos no socialismo. Para o autor, esse problema se relaciona diretamente com o problema do cálculo, na medida em que a livre iniciativa importa ou não para o funcionamento de um mercado competitivo. Contudo, para Mises, essa questão seria subsidiária, pois mesmo que se obtenha todo o incentivo necessário no socialismo, ainda assim a ausência do cálculo torna impossível medir desempenhos. Por outro lado, o pensamento socialista, ao tratar da socialização, ignora os problemas de incentivo, pois parte da hipótese de que não há possibilidade de haver conflito entre os interesses

\footnotetext{
${ }^{12}$ Em Socialism (pág. 119), Mises escreve: 'the market is thus the focal point of the capitalist order of society, it is the essence of capitalism. Only under capitalism, therefore, it possible; it cannot be artificially "imitated under socialism".
} 
individuais e os coletivos em uma sociedade sem classes. Na verdade, porém, quando os ganhos individuais representam uma fração do produto total, cada um estará mais interessado no esforço da maioria do que no seu próprio ${ }^{13}$.

De qualquer forma, ao se enfrentar o problema, descobre-se que, com a socialização dos meios de produção, desaparece o interesse material dos administradores pelos lucros das firmas, o que, segundo o autor, explicaria o fracasso das experiências de nacionalização de indústrias. Esse fracasso não pode ser remediado pela adoção de práticas administrativas mais comerciais ou mesmo pela contratação de empresários para gerir empresas públicas, pois o tipo de administração eficiente não depende de características pessoais, mas sim da pressão competitiva gerada pela busca de lucros, eliminada no socialismo:

It is not a knowledge of bookkeeping, of business organization, or of the style of commercial correspondence, or even a dispensation from a commercial high-school, which makes the merchant, but his characteristic position in the production process, which allows of the identification of the firm's and his own interests. (Mises 1935:121)

A alusão ao controle (bookkeeping) é uma referência, explicitamente feita algumas páginas mais adiante, à idéia de Lenin de que as atividades comerciais se reduzem a poucas técnicas administrativas. Para Mises, ao contrário, a propriedade privada geraria o interesse pelo lucro e daria origem ao comportamento que mais tarde, no desenvolvimento das teorias do autor, será identificado com a atividade empresarial.

Até aqui, podemos verificar pela leitura do artigo que a crítica de Mises é dirigida a uma platéia marxista. Quando abordamos a relação entre funcionamento dos mercados e a existência de propriedade privada, contudo, começam a surgir diferenças entre a abordagem austríaca e a neoclássica, diferenças essas que se manifestarão na interpretação e uso que se faz da teoria de equilíbrio de mercado. Essas diferenças, implícitas no artigo, se tornam mais claras em Socialism. Veremos agora alguns trechos desse livro que mostram tais diferenças.

A própria organização dos capítulos do livro já mostra a nova preocupação com o uso da noção de equilíbrio. Os capítulos 8 e 10 são intitulados respectivamente 'A Comunidade Socialista sob Condições Estacionárias' e 'Socialismo sob Condições Dinâmicas'. No primeiro deles, Mises expõe a noção de equilíbrio e opina sobre a sua utilidade. O equilíbrio é imaginado como um estado econômico estacionário, em que em cada período se repetem as ações tomadas no anterior, visto que não ocorrem mudanças.

\footnotetext{
${ }^{13}$ Para uma abordagem moderna desta questão, ver Olson, M. The Logic of Collective Action.
} 
Essas ações refletem as opções mais econômicas para o emprego dos fatores de produção.

Para Mises (1981:142), assumir uma economia estacionária descrita acima seria apenas um expediente teórico e não uma tentativa de descrever a realidade, pois nesta sempre ocorrem mudanças. Para entender a mudança econômica, imagina-se antes, como um passo intermediário, um estado de coisas no qual a mudança não ocorre.

No capítulo 10, Mises afirma que uma economia socialista também estará sujeita a mudanças. A partir disso procurará mostrar que a noção de equilíbrio estacionário não seria suficiente para lidar com o cálculo econômico diante dessas mudanças. No capítulo, Mises lista várias fontes de mudanças que terão que ser enfrentadas no socialismo: na a) natureza, b) população, c) quantidade e qualidade de bens de capital, d) técnicas de produção, e) organização do trabalho e f) demanda.

Visto que sempre ocorrem mudanças, qualquer ação envolve inovação. Mesmo a repetição, por ser feita em um ambiente cambiante, consiste em uma inovação. De qualquer modo, o socialismo pretende trazer progresso, que implica mudanças. Em qualquer economia em que ocorram mudanças, o futuro é incerto ${ }^{14}$. Conseqüientemente, para Mises, toda ação é especulativa e não faz sentido portanto distinguir entre ação produtiva e especulativa, como seria comum entre autores socialistas. O problema do cálculo, por sua vez, diria respeito a como se lida com o futuro incerto. Em sociedades baseadas em propriedade privada, seria o mecanismo de lucros e perdas que informa o sucesso ou fracasso da ação empresarial e guia a alocação de recursos. No socialismo, sem a ferramenta do cálculo, o sucesso dependeria da onisciência do planejador.

As diferenças salientadas aqui entre as visões de Mises e a da maioria da profissão sobre o funcionamento dos mercados ficarão mais nítidas com a publicação na década de trinta das propostas neoclássicas de conciliar mercados com socialismo que serão vistas no próximo capítulo. Em 1936 Mises adiciona ao Socialism uma seção criticando diretamente as propostas dos socialistas neoclássicos. Adiamos então até o quinto capítulo a discussão da reação de Mises a esses desenvolvimentos.

\footnotetext{
${ }^{14}$ Contraste com a visão de alguns autores socialistas, conforme veremos no próximo capítulo, que argumentam que a maior parte da incerteza advém da competição, na medida em que os empresários ocultam seus planos aos demais. Suprimida a competição (no sentido usual, não técnico, do termo), desapareceria a principal fonte de incerteza.
} 
O argumento da impossibilidade do cálculo econômico exposto neste capítulo, desenvolvido por Weber, Brutzkus e Mises, estabeleceu uma nova fase na investigação teórica do socialismo. A transição do programa de pesquisa clássico para o neoclássico trouxe consigo uma nova compreensão sobre o funcionamento dos mercados e o papel destes na alocação de recursos. De fato, um dos pontos em comum na crítica dos três autores estudados neste capítulo é a ênfase na complexidade do problema econômico e na negação da tese de que este possa ser reduzido a um problema de escolha meramente técnico.

Segundo os autores, o grau de complexidade das atividades econômicas que resultou do desenvolvimento dos mercados deveria ser ampliado ou pelo menos preservado se o socialismo pretende superar o nível de bem estar das sociedades existentes. Os três autores estudados neste capítulo convidam então os defensores do socialismo a mostrar como isso seria possível na ausência de mercados, isto é, perguntam como seria possível obter pelo menos o mesmo grau de coordenação possibilitado pelos mercados, dado que o conhecimento de qualquer pessoa ou comitê está aquém daquele requerido pelo planejamento central. Sem planejamento central, como obter então no socialismo a 'divisão intelectual do trabalho' descrita por Mises?

Os autores socialistas que procuraram resolver essas questões foram não marxistas, mas economistas neoclássicos. Tal fato era de se esperar, dado que estes últimos compartilham com Mises os pressupostos teóricos básicos da teoria econômica moderna, aceitando assim naturalmente a existência do problema do cálculo.

O que se observou, contudo, não foi um debate interno a um programa de pesquisa único. De fato, os defensores neoclássicos do socialismo, conhecidos como 'socialistas de mercado', debateram entre si formas alternativas de resolver o problema do cálculo sob a luz das tradições walrasiana e marshalliana, ignorando porém os elementos distintamente austríacos do argumento de Mises. O debate entre os socialistas de mercado, como veremos em seguida, girará assim em torno do estabelecimento de um equilíbrio estático no socialismo e ignorará a ênfase misesiana à necesssidade de adaptação à mudança. $\mathrm{O}$ contraste entre o desafio de Mises e a resposta dos socialistas de mercado marcará então o processo de diferenciação dos programas de pesquisa neoclássico e austríaco. 


\section{O Socialismo de Mercado}

A publicação do artigo de Mises em 1920 teve como consequiência o surgimento de diversos trabalhos cujo propósito foi refutar a tese da impossibilidade do cálculo econômico. Nesses textos os defensores do socialismo buscaram construir e propor esquemas sobre o funcionamento de uma economia socialista que possibilitassem a alocação dos recursos de forma econômica.

O primeiro conjunto de respostas ao desafio de Mises foi feito ainda na década de vinte, por autores austríacos e alemães. Essas respostas, juntamente com as réplicas de Mises (1923, 1928), constituem o debate em alemão sobre o cálculo. As propostas de operacionalização do socialismo discutidas nessa fase são geralmente baseadas da defesa de associações e monopólios setoriais. Embora as propostas de solução do problema feitas na década seguinte já apareçam aqui de forma embrionária, a maioria das propostas em alemão não reflete a dominância da teoria neoclássica que caracterizará o debate pouco depois.

$\mathrm{Na}$ década de trinta o debate ressurge, agora em inglês. Nessa fase, a defesa do socialismo será feita por autores filiados à teoria neoclássica e politicamente será mais próximo do fabianismo inglês, que favorece a conciliação de ideais socialistas com a democracia inglesa. Nesse debate surgiram as principais tentativas de construir um modelo de funcionamento do socialismo que ficou conhecido como socialismo de mercado e que buscava conciliar mecanismos de mercado com a abolição da propriedade privada dos bens de capital.

Neste capítulo procuraremos rever as principais tentativas de solução do problema do cálculo que surgiram ao longo desses debates. Em primeiro lugar visitaremos as propostas em alemão e as respostas que Mises deu a elas, para em seguida abordarmos o debate em inglês entre os autores que defendiam a viabilidade do socialismo. Terminaremos o capítulo estudando a crítica que Dobb fez ao socialismo de mercado e a reação a esta crítica. As respostas de Mises e Hayek, além de outras críticas ao socialismo de mercado, serão vistas no capítulo seguinte. 


\section{O Debate em Alemão}

Vários autores publicaram trabalhos em alemão que contestaram a tese de Mises. As soluções ao problema do cálculo defendidas nesses trabalhos foram por sua vez criticadas por Mises em 1923 e mais tarde em $1928^{1}$. Como tais autores não alcançaram a fama que Mises alcançou, a maioria desses trabalhos ficou sem tradução para o inglês e os originais em alemão são difíceis de encontrar. En inglês, além de um artigo de Chaloupek (1990), que investiga o debate na Áustria, as referências às contribuições em alemão são feitas pelos seus críticos, como o próprio Mises, Halm ou Hoff, sendo que este último autor publicou em 1938 o primeiro livro dedicado à história do debate. Assim, infelizmente, nos limitaremos apenas a classificar as contribuições dos autores e mencionar em linhas gerais a natureza de suas contribuições e das críticas as suas propostas, correndo o risco de ignorar aspectos importantes de suas contribuições, negligenciados por seus críticos.

Hoff (1981:204), seguindo Hayek, classifica as respostas ao desafio de Mises ao longo do debate do cálculo em cinco categorias: em primeiro lugar temos propostas de cálculo em termos naturais (em espécie), em seguida propostas baseadas na teoria do valor trabalho, em terceiro lugar as soluções matemáticas (que envolvem método experimental), em quarto lugar a recomendação do cálculo baseado em considerações de custos marginais e, finalmente, as tentativas de introdução da competição no socialismo. Essa tipologia nos será útil para classificarmos as principais propostas feitas em alemão.

Antes da publicação do artigo de Mises, a proposta mais concreta sobre o funcionamento do socialismo foi a defesa de Neurath do cálculo em espécie. Em 1925 Neurath publica outro texto reafirmando a possibilidade do cálculo natural e que seria possível comparar diretamente a importância de dois conjuntos diferentes de bens sem uso de moeda ${ }^{2}$. Mises [1928], reagindo novamente à sugestão de cálculo em espécie, nota que, além de Neurath, não existem outros defensores dessa idéia ${ }^{3}$. Como os demais críticos, Mises reafirma a impossibilidade de se basear o cálculo econômico em comparações de quantidades de bens heterogêneos. A possibilidade de se avaliar

\footnotetext{
${ }^{1}$ Os dois artigos foram traduzidos para o inglês. Ver Mises, 2002.

${ }^{2}$ Neurath, O. (1925) Wirtschaftsplan und Naturalrechnung. (Planejamento Econômico e Cálculo Natural) Berlim: E. Laubsche.

${ }^{3}$ Entre os críticos socialistas do cálculo natural se encontram Kautsky, Bukharin, Strumilin e Varga.
} 
diretamente dois conjuntos de bens tal como sugerido por Neurath - possibilidade essa que não é negada por Mises - não diz nada a favor da possibilidade de basear o cálculo econômico no que diz respeito aos bens de produção em comparações diretas.

Essa opinião é compartilhada por autores socialistas que buscarão então uma alternativa ao cálculo em espécie. Uma alternativa foi proposta por Otto Leichter ${ }^{4}$, que, segundo Chaloupek (1990), escreveu o primeiro livro dedicado a responder a tese de Mises. Em seu livro, Leichter de fato concorda com Mises que a alocação racional dos recursos requer a comparação de esforços e resultados. Os defensores do cálculo em espécie tratariam apenas da comparação de bens finais. Os bens de produção, por sua vez, não seriam comparáveis por esse método.

A proposta de Leichter de como o cálculo do valor de todos os bens seria feito no socialismo se encaixa no tipo 2 mencionado acima: o cálculo, para ele, seria feito tendo como unidade contábil a quantidade de horas de trabalho empregadas na produção, que serve também de base para o esquema de distribuição baseado em vales. Os salários seriam ajustados pela habilidade e intensidade do trabalho feito ${ }^{5}$.

Mises [1923], ao criticar essa proposta, afirma que Leichter procura negar as objeções por ele levantadas contra essa solução; a saber, a impossibilidade de reduzir o trabalho a um denominador comum e falta de consideração pelo valor dos fatores materiais de produção. Para Leichter a comparação entre diversos tipos de trabalhos pode ser feita diretamente, levando-se em conta critérios como a importância do trabalho, o esforço ou a perícia requerida. A fixação de salários nos mercados, além disso, seria feita com base em negociações e não faz referência aos determinantes das condições de demanda e oferta por trabalho. A crença na necessidade de preços para a tomada de decisões é denominada por Leichter 'fetichismo de mercado'.

Por sua vez, Mises (2002:363) pergunta qual dos diversos critérios propostos de comparação entre diferentes trabalhos deveria ser levado em conta no cálculo de salários. Conforme o critério arbitrariamente escolhido, teríamos avaliações contrárias. Quanto ao segundo ponto, Mises procura mostrar como os mecanismos de mercado sempre atuam na determinação de preços e salários. A existência de escassez ou

\footnotetext{
${ }^{4}$ Leichter, O. (1923) Die Wirtshaftsrechnung in der sozialistischen Gesselschaft (Cálculo Econômico na Sociedade Socialista). Marxstudien, vol. 5, No.1.

${ }^{5}$ Ver Chaloupek, 1990.
} 
abundância de um fator influencia de forma indireta - não perceptível na observação do processo de barganha - a capacidade de negociação de salários.

Além das propostas de Neurath e Leichter, temos também no debate em alemão soluções mais próximas ao socialismo de mercado inglês, que admite a existência de preços. Tais soluções foram propostas por Karl Polanyi e Eduard Heimann, que publicaram trabalhos que procuravam basear a organização do socialismo em cartéis setoriais. A partir da interação entre mesmos, estabelecer-se-iam preços, o que tornaria possível a direção racional da produção.

Em 1923 Karl Polanyi publica um artigo intitulado "Contabilidade Socialista"6, no qual procura imaginar o funcionamento de uma economia socialista descentralizada ainda em transição. O planejamento central estrito, por sua vez, seria impossível:

We admit out-of-hand that we regard the solution of the problem of calculation in a centrally directed economy as impossible. (Polanyi, citado em Hoff, 1981:243)

Em sua proposta, a propriedade dos bens de produção pertence à Comuna, organismo político que representa os interesses mais gerais da sociedade e é estabelecido por eleições. A condução da produção, no entanto, é responsabilidade das Associações de Produtores, cujos membros são eleitos pelos trabalhadores de cada setor produtivo. A união das associações formaria o Congresso das Associações de Produtores. Tanto esse congresso quanto a Comuna têm funções legislativas e executivas. As decisões resultam na interação entre esses dois organismos, que levariam em consideração não apenas as questões relevantes à eficiência econômica mas também os interesses mais amplos da sociedade.

A crítica que Mises [1923] faz a proposta de Polanyi diz respeito à forma vaga como se definem direitos de propriedade. No esquema proposto, conflitos inevitavelmente surgiriam entre as duas organizações. Nada é dito sobre como tais disputas seriam resolvidas. Se a propriedade de fato fosse da comuna, teríamos planejamento central, caso em que o próprio Polanyi afirma que não se pode resolver o problema do cálculo. Se a propriedade e o poder de decisão fosem das associações de produção, teríamos não uma forma de socialismo, mas sim de sindicalismo.

Na opinião de Mises, a proposta de Polanyi seria uma forma de socialismo de guildas e, como todas as propostas deste último tipo, peca pelo seu caráter vago. Hoff (1981:243)

\footnotetext{
${ }^{6}$ Polanyi, K. (1923) Sozialistische Rechnungslegung. Archiv für Sozialwissenschaft und Sozialpolitik, Vol. 49.
} 
comunga dessa opinião. Para este autor, Polanyi não é claro a respeito de como se formam os preços em sua proposta. Ao mesmo tempo em que Polanyi afirma que haverá 'toda forma de formação de preços', nega na mesma página que esta seja uma hipótese admissível. Apesar de imcompleta, é importante notar que a proposta de Polanyi admite preços e almeja contemplar uma forma relativamente descentralizada de socialismo.

Da mesma forma que Polanyi, Heimann apresenta em $1922^{7}$ uma proposta de socialismo que pretende utilizar preços de mercado e introduzir competição, além de fugir do centralismo estrito, embora haja ainda planejamento central. Buscando introduzir um tipo de competição 'pacífica', Heimann substitui o planejamento central por monopólios setoriais. Segundo Halm (1935:191), Heimann acredita que desde que os monopólios possuam pessoal próprio, com ideais e interesses materiais diversos, a competição entre eles surgirá. A produção seria guiada não por planejamento central baseado em cálculo natural, mas sim pelo cálculo monetário. Os gerentes dos monopólios seriam instruídos a fixar preços segundo os custos de produção, evitando-se a exploração de ganhos de monopólio. A valoração dos bens de produção seria feita tendo em vista que existe uma conexão entre os preços dos bens finais e dos bens intermediários, sendo que os preços dos primeiros são transmitidos aos segundos ${ }^{8}$ (Halm, 1935:181).

A proposta de Heimann foi alvo de críticas de diversos autores. Entre estes, Mises afirma que Heimann é vago ao tentar conciliar planejamento central (identificado por ele com a consolidação da produção em monopólios setoriais) com o funcionamento de unidades independentes. Para Mises, o planejamento central seria incompatível com unidades funcionais independentes. $\mathrm{O}$ órgão de planejamento central poderia estabelecer preços contábeis arbitrários, porém, estes não refletiriam as valorações subjetivas de todos os agentes envolvidos em mercados reais (Mises, 2002:258). O cálculo fundado em preços baseados nos custos, por sua vez, resultaria em argumento circular quando estes são entendidos no sentido austríaco de custos de oportunidade, já que custo de

\footnotetext{
${ }^{7}$ Heimann, E. (1922) Mehrwert und Gemeinwirtschaft, Dritische und positive Beiträge zur Theorie des Sozialismus (Mais-valia e a economia coletiva, contribuições críticas e positivas à teoria do socialismo, Berlim: Hans R Engelman).

8 "As soon as real competition reigns on the market for consumer goods, the resulting structure of prices immediately spreads throughout all stages of production, provided the price relationships emerge in the same competitive way on each market and are independent of the influence of the parties on the producers' side of the market." (Heimann, 1922, citado em Mises, 2002:359)
} 
oportunidade é igual a importância subjetiva da alternativa preterida em uma escolha. Os custos seriam equivalentes ao valor apenas no equilíbrio em uma economia estática.

É justamente em relação ao funcionamento dos mercados em um ambiente real (não estático) que Mises concentrará suas observações. Não poderá haver competição de fato, como supõe Heimann, se o órgão de planejamento central estabelecer uma área exclusiva de atuação para cada monopólio. A competição não se resume em atos de compra e vendaque possam ocorrer ${ }^{9}$, mas depende da propriedade privada:

Competition only exists whenever everyone produces what seems to him to offer the prospect for the greatest profit. I have attempted to show that only private ownership of the means of production corresponds to such situations. (Mises, 2002:359).

Halm (1935) também analisa a proposta de Heimann, tecendo várias críticas a ela. Como Mises, Halm chama a atenção para os elementos típicos da competição real (rivalidade empresarial) em contraste com a 'competição pacífica' imaginada por Heimann. Além disso, também como Mises, Halm acredita que o processo de imputação do valor dos bens finais para os bens intermediários exigiria avaliação direta de cada um destes últimos, pois cada insumo é usado em vários processos produtivos em proporções variáveis, não sendo possível inferir diretamente seu valor. De qualquer forma, mesmo considerando os custos de produção dados, os órgãos de fiscalização nunca poderiam saber se os monopólios setoriais estariam seguindo a regra de fixar preços em termos dos custos, pois em uma economia real o surgimento de lucros poderia tanto significar exploração monopolística quanto resultado de administração eficiente que gerou um lucro extraordinário. Este último ponto será muito importante na crítica às propostas mais avançadas de socialismo de mercado que abordaremos em breve.

Semelhante às propostas de Polanyi e Heimann, temos ainda uma solução baseada em monopólios feita por Jakob Marschak ${ }^{10}$. Segundo Hoff (1981:244), a proposta de Marschak é uma forma de socialismo de guildas que na verdade deve ser classificada como sindicalismo, devido ao alto grau de independência dos monopólios, o que resulta em propriedade privada de seus recursos. O sindicalismo, para Marschak, permitiria a resolução do problema dos incentivos:

\footnotetext{
${ }^{9}$ Compare esta opinião de Mises com Cassel, para o qual a formação de preços se refere apenas a atos de compra e venda, não dependendo das relações de propriedade.

${ }^{10}$ Marschak, J. (1923) Wirtschaftsrechnung und Gemeinwirtschaft. Zur Misesschen These von der Unmöglichkeit sozialistischer Wirtschaftsrechnung (Cálculo Econômico e a Economia Socialista. A respeito da tese misesiana sobre a impossibilidade do cálculo econômico socialista). Archiv für Sozialwissenschaft und Sozialpolitik, Vol. 51.
} 
Syndicalism is a system that demands the least departure from the contemporary type of economically egoistic man. Within the syndicates there is a far-reaching homogeneity of economic interests and in the scales of enjoyment and labour-sacrifice. (Marschak, citado em Hoff, 1981:245)

A estratégia de defesa do socialismo feita por Marschak consiste em criticar as imperfeições da fixação de preços nos monopólios capitalistas. Mises [1928], comentando essa estratégia, compara Marschak a Marx, na medida em que ambos se limitaram a criticar o capitalismo. Apontar imperfeições dos monopólios nos mercados não seria argumento em favor da possibilidade de realizar cálculo econômico no socialismo. Além disso, Mises assinala que sua crítica original não contesta em absoluto a possibilidade de cálculo econômico no sindicalismo.

Por último, alguns anos mais tarde, temos propostas que podemos classificar como 'soluções matemáticas', feitas já em termos da teoria de equilíbrio geral por Herbert Zassenhaus e Kläre Tisch, esta última em sua tese de doutoramento que foi orientada por Schumpeter ${ }^{11}$. Essas propostas se inspiram nos trabalhos de Barone e Cassel, segundo a interpretação que os primeiros autores deram ao argumento destes últimos.

O significado do argumento de similitude formal feitos por Barone e Cassel pode ser objeto de disputa. Ou o argumento é interpretado como se utilizando do conceito de equilíbrio com o propósito de mostrar a complexidade do problema a ser tratado pelo socialismo e não para descrever o funcionamento dos processos de mercado reais, como quer Hayek, ou pode ser interpretado como baseado em uma teoria que mostra de forma suficiente o funcionamento das economias e que não pode ser replicado artificialmente apenas por motivos práticos da dificuldade de coleta de dados, como quer Lange. De qualquer forma que se possa interpretar o argumento, e no espírito da segunda interpretação, Tisch e Zassenhaus utilizaram os textos de Barone e Cassel como base de suas propostas para se construir de fato um mecanismo que substitua a formação de preços nos mercados.

A alocação de recursos no socialismo poderia ser feita tendo como base preços para bens de consumo e de produção. Estes últimos poderiam ser derivados a partir das equações que descrevem o equilíbrio competitivo. Tanto Barone quanto Cassel mostraram como a partir dos dados se chega aos preços de equilíbrio. Para que isso seja feito, é necessário o conhecimento dos fundamentos da economia: demandas,

${ }^{11}$ Zassenhaus, H. (1934) Über die ökonomische Theory der Planwirtschaft (Sobre a Teoria do Planejamento Econômico) Viena: Zeitschrift für Nationalökonomie.

Tisch, K. (1932) Wirtschaftsrechnung und Vertelung im zentralistisch organisierten sozialistischen Gemeinwesen. Wuppertal - Elberfeld. 
coeficientes técnicos (e sua variabilidade) e as dotações de recursos. Esse conhecimento, para os defensores da solução matemática, poderia ser obtido pelo órgão responsável pela direção da produção no socialismo $^{12}$. A enorme quantidade de informação estaria disponível centralmente por meio da coleta de dados e de tratamento estatístico dos mesmos:

Naturally an enormous statistical apparatus will be needed to deal with production and the technical coefficients, but this can all be worked out by subordinates and need not burden the 'mind' of the Director of Industry. (Tisch, citada em Hoff, 1981:206)

Surge assim na Alemanha o embrião da resposta dada ao argumento de Mises que será desenvolvido no debate em língua inglesa, e que culminará na proposta de socialismo de mercado feita por Oskar Lange, que procura contornar os problemas de coleta e processamento de informação patentes na solução matemática. Abordaremos agora os modelos propostos no debate em inglês.

\section{O Debate em Inglês entre os autores socialistas}

\section{Do Socialismo Marxista ao Socialismo de Mercado}

A partir de 1929 e ao longo da década de trinta, surgiram diversos artigos publicados em inglês que contestavam a tese de Mises e que procuravam mostrar como a administração da produção poderia ser realizada no socialismo. A característica comum a todos esses artigos é o fato de que seus autores basearam suas propostas na teoria neoclássica. Assim, a mesma teoria que havia sido utilizada para criticar a teoria clássica do valor e formular a tese de Mises foi então utilizada não só para mostrar que o socialismo seria viável mas também para defender a superioridade desta forma de organização social sobre as economias de mercado.

As diversas vertentes da teoria neoclássica foram utilizadas nessa empresa. A abordagem de equilíbrio geral foi utilizada por Taylor (1929), Dickinson (1933) e Lange (1936-7) para propor esquemas socialistas que substituem os mercados por um

\footnotetext{
${ }^{12}$ Em Hoff (1981), temos a seguinte afirmação de Zassenhaus (pág. 210): “And we have assumed certain technical conditions, along with static conditions, we may conclude that the Ministry of Production knows them as well." ou a citação de Tisch (pág. 206) de que se pode chegar aos preços "when only certain data are known to one, and one takes into consideration the prerequisites of equilibrium (prices and cost, supply and demand)".
} 
sistema artificial de preços. As abordagens austríaca e marshalliana, por sua vez, foram utilizadas por Durbin (1936) e Lerner (1937) para propor economias socialistas nas quais se permitiriam mercados em que os participantes seriam firmas estatais, cuja atuação seria determinada por regras ditadas centralmente. Em ambos os casos, a incorporação no socialismo de um sistema de preços (real ou artificial) justifica a classificação das propostas como 'socialismo de mercado'.

Entre os defensores do socialismo de mercado, o debate gira em torno da formulação de um sistema adequado de instruções ditadas às firmas por um organismo de planejamento central que garantam uma alocação econômica dos recursos. Entre os seus oponentes, procura-se discutir a inadequabiliade da teoria de equilíbrio neoclássica para lidar com o problema econômico, tanto por autores marxistas, como Dobb (1933), quanto por autores 'austríacos', como Hayek e Robbins. Antes de entrarmos no conteúdo dos debates, porém, será interessante dedicar algum espaço para relatar o contexto intelectual no qual as propostas do socialismo de mercado estão inseridas.

A visão de mundo dos socialistas de mercado, em larga medida, se baseia não exclusivamente no marxismo mas sim no socialismo fabiano e nas crenças do partido trabalhista inglês. De fato, boa parte do debate ocorre entre economistas da London School of Economics (Lerner, Durbin), fundada por membros da Fabian Society, como o casal Webb. Durbin, um dos participantes do debate, foi durante a guerra assistente pessoal de Clement Attlee, mais tarde eleito primeiro ministro pelo Partido Trabalhista $^{13}$. Na esfera teórica, os autores são influenciados tanto pela teoria neoclássica quanto pelo keynesianismo que acabara de surgir. Além da substituição do marxismo pela teoria neoclássica como ferramenta teórica - o que muda significativamente a natureza da análise e a forma como se enxerga uma futura sociedade socialista - algumas crenças marxistas são rejeitadas pelos socialistas de mercado.

Um dos aspectos do socialismo inglês é a rejeição da ditadura do proletariado em favor da democracia parlamentar inglesa. Durbin (1940, 1949), por exemplo, critica vigorosamente a idéia da ditadura (condenando inclusive os métodos totalitários na Rússia) em favor do socialismo democrático. Por outro lado, dedicou também um ensaio (Durbin, 1949) à tarefa de criticar a tese de Hayek, desenvolvida em $O$ Caminho

\footnotetext{
${ }^{13}$ O prefácio de um livro de Durbin (1949) foi escrito por Attlee. Ver também o livro escrito pela filha de Durbin, Elisabeth Durbin, que descreve o clima intelectual existente entre os socialistas ingleses.
} 
da Servidão, segundo a qual os métodos socialistas levariam necessariamente à supressão da democracia e da liberdade.

Da mesma forma, na primeira página do Economics of Control, Lerner nos conta que "o objetivo fundamental do socialismo não é a abolição da propriedade privada, mas a extensão da democracia". O seu ideal de socialismo - a economia controlada - poderia utilizar-se tanto de setores estatizados como de mercados livres, conforme esses sejam em cada caso julgados como os meios mais adequados para atender o fim de maximizar o bem-estar social. Ou seja, não se adere à propriedade privada ou ao 'coletivismo puro' como princípios, mas sim, de forma pragmática, como meios alternativos aos objetivos do governo (pág.5).

Mesmo Lange, mais distante do socialismo inglês e mais voltado ao planejamento central no qual não são permitidos mercados para bens de capital, defende a existência de um sistema de preços - ainda que em larga medida artificial - na operacionalização do socialismo.

A adoção da teoria neoclássica implicaria na aceitação do argumento de similitude formal e na necessidade de levar em conta as categorias econômicas antes rejeitadas pelos socialistas. Por isso, para os socialistas de mercado, o planejamento tem que ser conciliado com a existência de preços:

... it must follow that there is no formal or logical contradiction between planning and pricing. It is perfectly possible for a centralized authority to order a price system to appear and to follow the guidance it necessarily gives. There is no necessary connection between the form of the authority by which decisions are taken and principles according to which the decision are made. (Durbin, 1949:48)

Sempre que o funcionamento dos mercados garanta uma alocação ótima de bens, como sob condições de competição perfeita, o Estado socialista poderia permitir que houvesse mercados ou poderia ordenar que as empresas atuassem como se fossem competidoras. Uma das tarefas do estado socialista seria então corrigir as falhas que desviariam os mercados da obtenção de equilíbrios socialmente desejáveis.

Apesar das diferenças em relação às formas mais usuais de socialismo, por outro lado podemos encontrar aqui elementos comuns ao ideário socialista em geral, em especial no que se refere aos fins almejados com a sua adoção. Lerner (1944:3), por exemplo, identifica três problemas com a ordem social existente que deveriam ser resolvidos pelo socialismo: garantia de emprego, destruição do poder de monopólio e a obtenção de uma distribuição de renda igualitária. Da mesma forma, Durbin (1949), em um artigo 
intitulado "The Case for Socialism", identifica os principais problemas da Inglaterra a serem resolvidos pelo socialismo: a desigualdade econômica (renda) e a desigualdade social (desigualdade de oportunidades), além de, de forma curiosa, o vandalismo e falta de imaginação (conservadorismo) do povo inglês!

Todos esses problemas poderiam ser tratados com o auxílio da teoria econômica. Afinal, na teoria neoclássica, a riqueza é determinada pela posse de recursos produtivos e realocações de dotações que resultassem em distribuições eqüitativas e em um novo equilíbrio eficiente.

Como os marxistas, os socialistas de mercado também consideravam que o grau de concentração estava crescendo. Os ganhos monopolísticos daí resultantes poderiam também ser eliminados através de ordens que proibissem a cobrança de preços acima dos custos.

Finalmente, a obtenção de um equilíbrio estático organizado pelo estado eliminaria os desperdícios advindos do 'caos da produção' atomizada:

I believe that that the substitution of conscious foresight for the instinctive adjustments of the competitive system, and the establishment of social authority in place of the search for private monopolistic control, will bring into existence a better balanced and a more securely progressive economy. (Durbin, 1949:21)

Embora a alocação de recursos nas firmas existentes seja feita via sistema de preços, imitando-se o comportamento ideal das firmas da teoria da competição, os defensores do socialismo de mercado defendem alguma forma de planejamento central na determinação dos investimentos ou na coordenação intersetorial das indústrias. Isto é justificado pela maior capacidade que teria o Estado de enxergar o processo econômico como um todo, em comparação com a miopia dos agentes isolados atuando em interesse próprio:

A central authority, because it is central - because that is to say it can survey the whole industrial field - can see things no individual producer can ever see and give weight to considerations that cannot play any part in the calculations of men engaged in competing with one another. The general officers on the hill must be able to see more than the ensign in the line of battle. (Durbin, 1949:51) 


\section{Teoria, Prática, Instituições e o Escopo da Teoria Econômica}

A defesa do socialismo contra o argumento de Mises, sendo feita em termos da teoria marginalista, naturalmente refletiu o estágio de desenvolvimento em que o programa de pesquisa neoclássico se encontrava na década de trinta do século vinte. Os textos dos socialistas de mercado abordavam apenas os problemas econômicos que eram tratáveis (ou levados em consideração) pela teoria naquele instante, relegando os demais aspectos concernentes à economia do socialismo a outras disciplinas, como a psicologia e a sociologia.

Por isso, as análises dos socialistas de mercado centram sua atenção no estabelecimento de um equilíbrio estático de mercado no socialismo, obtido a partir de curvas de custo objetivamente dadas, derivadas a partir de preços cujo processo de formação não dependia substancialmente de hipóteses comportamentais sobre a ação fora do equilíbrio ou da existência de um determinado conjunto de instituições. Qualquer questão sobre comportamentos ou sistema de incentivos era relegada à uma esfera 'prática', que não diz respeito ao economista teórico. Pode-se dizer que a teoria neoclássica, nas mãos dos socialistas de mercado, operava em um estrito vácuo institucional.

A restrição dos problemas tratados, além de refletir o estágio de desenvolvimento da teoria, tinha também valor estratégico no debate, pois deixou de fora as questões que poderiam inviabilizar as soluções propostas ao problema, em especial aquelas questões que surgem quando se estuda não apenas o equilíbrio de mercado, mas também o processo competitivo anterior à obtenção desse equilíbrio. A desconsideração desse tipo de problema marcará então o processo de diferenciação da tradição austríaca da teoria neoclássica em geral, dando origem a dois programas de pesquisa distintos, que podem ser considerados tanto complementares quanto concorrentes, dependendo do problema analisado.

Desde a formação do socialismo de mercado, porém, questões como aquelas levantadas pela escola de Escolha Pública sobre comportamento dos funcionários do governo sob arranjos institucionais diferentes ou as discussões correlatas sobre oportunismo do neoinstitucionalismo passaram a ser consideradas. Por outro lado, a própria teoria neoclássica passou a lidar com o desenho de mecanismos de incentivos na medida em que incorporou a análise da informação assimétrica. Assim, apenas décadas mais tarde 
os modernos descendentes dos socialistas de mercados passaram a discutir essas questões, informados pelos novos desenvolvimentos teóricos, discussões essas que resultaram em uma nova geração de modelos de socialismo de mercado, que serão vistas no capítulo sete.

Na década de trinta, porém, quais problemas eram considerados legítimos (pertencentes ao escopo da teoria econômica) pelos primeiros socialistas de mercado pode ser bem ilustrado por um curioso artigo de Frank Knight (1936) sobre a economia do socialismo. Para o autor, a Economia não tem nada a dizer sobre a viabilidade do socialismo a não ser mostrar a natureza idêntica do problema econômico a ser resolvido em qualquer sociedade (similitude formal):

This means - and this is the main point to be made in the present paper - that the problems of collectivism are not problems of economic theory, but political problems, and that the economic theorist, as such, has little or nothing to say about them. (Knight, 1936:256)

Essa conclusão é derivada da percepção que o autor tem do escopo da ciência econômica. Curiosamente, a posição metodológica de Knight é semelhante à de Mises. Para Knight (1936:257), o conhecimento econômico consiste em proposições - válidas a priori - sobre a lógica da escolha. Da mesma forma que Mises, o autor considera que a ação humana diante da escassez implica nos conceitos de escolha, valoração, custos de oportunidade, risco, e assim por diante. O conteúdo dessas escolhas, ou seja, os propósitos individuais e as condições sob as quais tais escolhas são feitas, são objetos da história, fugindo ao conhecimento certo que a teoria econômica a priori fornece ${ }^{14}$.

Portanto, tudo o que se pode falar como economistas a respeito do socialismo é que o estado tem que considerar preferências, está sujeito à escassez de recursos, terá que calcular custos de oportunidade, comparando-os com a importância de cada via de ação alternativa e fazer escolhas.

No socialismo, apenas 'as condições dadas seriam diferentes' (Knight, 1936:255). Dados os fins da atividade econômica, a quantidade de recursos e as tecnologias, e admitindo que haja escolha do consumidor, que este receba uma renda monetária a ser gasta como queira em bens com preços determinados, e assumindo ainda uma 'burocracia administrativa honesta e competente', 'o estabelecimento do coletivismo não apresentaria nenhum problema econômico sério' (pág. 259).

\footnotetext{
${ }^{14}$ Compare com Theory and History de Mises (1957).
} 
Tanto para Mises quanto para Knight, o problema econômico é definido da mesma forma. Para o primeiro autor, contudo, a inexistência da instituição da propriedade privada impede o cálculo do custo de uma ação em um sistema econômico desenvolvido. Para o segundo, no entanto, a apresentação do argumento de similitude formal feito acima refutaria o argumento de Mises, equivalendo a uma prova da possibilidade do socialismo (pág. 263). Knight afirma que no socialismo seria necessário estabelecer preços de fatores de acordo com a produtividade marginal (pág. 262) e que os preços seriam fixados sob o mesmo princípio do que sob 'competição individualista' (pág. 260). Qualquer outra alternativa fugiria à competência do economista. Nenhuma palavra é dita sobre como tais preços poderiam ser estabelecidos ${ }^{15}$.

Em poucos termos, o argumento do artigo de Knight pode ser resumido na seguinte proposição: "O problema econômico é o mesmo em qualquer sociedade, portanto, a sua solução no socialismo existe" ${ }^{\text {. }}$. Esse argumento só seria válido se se admitisse de partida a possibilidade de existência do socialismo. Mas isso é precisamente o que se quer provar. $\mathrm{O}$ argumento, logicamente falho, e que aparece de uma forma ou outra na obra de todos os socialistas de mercado, choca um intérprete como Steele:

Consider a proposed society in which all industrial decisions are made by a single monk, consulting the I Ching. This monk wears a saffron robe and subsists on a macrobiotic diet. Is such an industrial order feasible and efficient? According to the argument, it must be so, or, if it is unfeasible or inefficient, this must be for non-theoretical or 'practical' reasons, about witch economists cannot pronounce. The economic theory of production applies to all societies, no matter how they are structured, so it applies to our monk-governed society. Therefore, economics allows us to say nothing about any possible difficulties that might ensue from entrusting the allocation of all resources to our enlightened monk. (Steele, 1992:112)

Um argumento dessa natureza, especialmente vindo de um autor importante como Knight, pode ter sua origem explicada pelo que dissemos sobre o estágio da evolução da teoria. A descrição do equilíbrio competitivo e de suas propriedades alocativas resume o escopo legítimo da teoria econômica no momento. O funcionamento dos mercados, a forma como operariam, não apresentaria grandes dificuldades em qualquer arranjo institucional. Como já vimos quando estudamos Cassel, os preços, para Knight, são estabelecidos de forma 'quase mecânica' através da interação das escolhas dos agentes (Knight, 1936:258).

\footnotetext{
15 "...the prices must be such as will clear the market of available supplies; a fairly successful effort must be made to set them at this point, or the system will break down in chaos". (Knight, 1936: 259).

${ }^{16}$ Na mesma linha, Lange (1936-37:55) acusa Mises de adotar uma posição historicista, já que, segundo a interpretação langeana do argumento deste autor, o princípio econômico da escolha seria então aplicável apenas em sociedades com propriedade privada.
} 
A teoria se limitava a descrever o estado final de equilíbrio competitivo. $O$ processo pelo qual se chega a esse equilíbrio, não contemplado pela teoria, é assim negligenciado quando se discute a replicação dos mercados no socialismo. Depositava-se assim a confiança no poder explicativo da teoria: esta dava conta da essência dos fenômenos de mercado, não ficando de fora da teoria aspectos relevantes que possam ser necessários para que os mercados funcionem.

Entre os socialistas de mercado Lange acreditava que a teoria de equilíbrio geral descreve satisfatoriamente como ocorre a competição nos mercados reais. Em uma aceitação por implicação da tese da simetria, não haveria problemas então para controlar os mercados.

Somente mais tarde no debate, com a elaboração do argumento de Mises por Hayek e pelo próprio Mises, o processo de formação de preços deixará de ser não problemático e a importância das instituições que permitem que tal processo ocorra voltará a ocupar um papel central.

\section{As Propostas dos Socialistas de Mercado}

Estudaremos agora as tentativas de solução do problema do cálculo propostas pelos socialistas de mercado. A evolução do socialismo de mercado, como argumentaremos, refletirá a progressiva preocupação com aqueles problemas que Knight exclui do escopo da teoria econômica. O resultado dessa preocupação será uma progressão dos modelos, desde a aplicação mais ingênua e literal da teoria do EG ao problema alocativo até a reintrodução de cada vez mais elementos retirados dos mercados reais.

O primeiro trabalho em inglês relevante para o socialismo de mercado foi a palestra presidencial da American Economic Association de 1928 proferida por Fred M. Taylor, publicada no ano seguinte na American Economic Review. Embora sua proposta de cálculo econômico seja bem incompleta, nela surgem pela primeira vez elementos utilizados mais tarde por Oskar Lange, como o método de tentativas e erros para a determinação de preços.

No artigo, Taylor procurava resolver o problema da determinação de quais bens deveriam ser produzidos a partir dos recursos existentes em uma sociedade socialista. $\mathrm{O}$ 
autor entende que toda atividade produtiva no socialismo seria feita pelo estado segundo um plano que a guiasse. A solução adequada do problema não deveria ser diferente daquela adotada no capitalismo, no qual a demanda guia o que deve ser produzido. Dessa maneira, Taylor recomenda o seguinte procedimento a ser seguido: “(1) o estado deveria assegurar aos cidadãos uma dada renda monetária e (2) o estado autorizaria o cidadão a gastar aquela renda como queira na compra de mercadorias produzidas pelo estado - um procedimento que virtualmente autorizaria o cidadão a ditar precisamente que mercadorias as autoridades econômicas do estado deveriam produzir" (Taylor,1929: $1)$.

Como Wieser, Taylor considera que a distribuição 'socialmente correta' da renda (cuja forma não é discutida) garantiria que a disposição a pagar dos agentes refletiria a 'importância social' do bem. A utilidade marginal do bem deve ser comparada com seu custo de oportunidade. Este é calculado monetariamente através dos preços dos bens, fixados centralmente. Os preços seriam estabelecidos no nível em que cubram os custos de produção, dados pela soma do valor dos recursos primários (terra, matérias primas, trabalho) utilizados na produção. Os custos refletiriam a subtração do emprego dos recursos primários em outros usos. Novamente ecoando Wieser, esse esquema garantiria que o valor dos recursos primário seria 'imputado de traz para frente' a partir do valor dos bens de consumo final.

Tayor não discute o valor dos bens intermediários, embora possamos presumir que estes sejam computados pelo mesmo procedimento, até ser reduzido aos preços dos fatores primários. Não discute, além disso, a possibilidade de existirem diversas tecnologias para a produção de um bem, o que resultaria em custos diferentes conforme os fatores sejam substituídos.

Entretanto, o ponto crucial do esquema - que será utilizado mais tarde por Lange - é a forma de determinação dos preços dos fatores primários. Estes seriam computados em tabelas denominadas 'tabelas de valoração de fatores' (pág. 4) e seriam sujeitos a alterações segundo um processo de tentativas e erros. O procedimento a ser seguido pelas autoridades econômicas seria dado por 5 passos (pág. 7):

(1) estabelecem-se os preços dos fatores de produção em níveis que se acredita que sejam adequados;

(2) as funções administrativas seriam realizadas como se esses preços fossem absolutamente corretos; 
(3) observar-se-iam resultados que indicassem que alguns dos valores provisórios estariam incorretos;

(4) os preços tabelados seriam corrigidos para cima ou para baixo conforme o tipo de erro detectado, e, finalmente;

(5) os passos (1) a (4) seriam repetidos até que desaparecessem as divergências.

No passo (3), se o preço de um fator fosse muito alto, as autoridades seriam muito econômicas no seu uso e muito pródigas se o inverso ocorresse. Isto tudo seria notado quando, no final do 'período produtivo', houvesse sobra ou falta no estoque do produto. Através desse método de correção, poder-se-ia estabelecer valorações corretas dos bens produzidos, resolvendo-se o problema do cálculo no socialismo.

No início do artigo, Taylor afirma que pretende fornecer um guia 'bastante específico' para a administração da produção no socialismo. Contudo, várias outras questões - além das já mencionadas - surgem a respeito de sua proposta que não são tratadas pelo autor. Pouco se discute, por exemplo, sobre o mercado de bens de consumo final. Neste, os preços são fixados pelos custos. Como se detectam alterações na demanda, visto que os preços são fixos e somos informados apenas como os administradores da produção reagem a variações nos custos da produção? Pressupõe-se que os administradores conheçam as curvas de demanda e os fatores que as alteram? Tais demandas são estabelecidas por pesquisas junto aos consumidores ou se supõe que excessos de demanda podem ser medidos por meio das pessoas que se dispõem a enfrentar filas? Ou, digamos, poderíamos perguntar como a disposição a pagar indicaria o que deve ser produzido quando temos apenas um ofertante de cada bem? Nessa situação, um bem essencial com qualidade baixa seria bastante demandado de qualquer modo. E assim poderíamos continuar com diversas outras perguntas dessa natureza.

Quanto ao processo de correção por tentativas e erros, somos informados no começo do texto (pág. 2) que o problema do estabelecimento dos preços deve ser resolvido antes que o plano de produção possa ser seguido. Ao enunciar os passos para o processo de correção, contudo, ficamos com a impressão de que os erros são detectados durante o processo produtivo, visto que os estoques são checados no final do 'período contábil'. Fica então a dúvida se o processo de correção seria mental, ex ante, ou real, após as trocas. A primeira hipótese suscitaria questões sobre como prever a priori os efeitos do estabelecimento de uma série de preços, que nos leva a questões sobre conhecimento e informação tratadas mais adiante no debate por Hayek. A segunda hipótese requer discussão sobre os custos de operar com preços errados até que se chegue ao equilíbrio 
e a frequiência com que os preços deveriam ser ajustados, questões estas também discutidas por Hayek ${ }^{17}$. Nos dois casos, deve-se investigar como um desequilíbrio em um setor altera o estoque nos demais setores. Esta última questão, por sua vez, será tratada no contexto da teoria do equilíbrio geral por Dickinson e Lange.

Embora incompleta, a proposta de Taylor é importante devido ao fato de que sua idéia de usar preços estabelecidos centralmente e sujeitos a um processo de correção será incorporada no modelo de Lange e será aceita por Dickinson. A este último autor caberá o próximo passo no desenvolvimento dos modelos de socialismo de mercado, refinando o esquema proposto por Taylor. A proposta de Dickinson, semelhante à de Tisch, será conhecida como a "solução matemática" ao problema do cálculo.

Ao contrário de Taylor, que não menciona nenhum autor em seu trabalho, Dickinson (1933) pretende com sua proposta refutar o argumento de Mises. Sua solução do problema do cálculo consiste em afirmar que o estado socialista deveria proceder da mesma forma como os agentes privados competitivos atuam segundo a descrição da teoria do equilíbrio geral. Assim, o estado socialista poderia não só replicar a racionalidade das alocações dos mercados reais mas também melhorá-la, na medida em que consiguisse replicar de forma mais fiel do que os mercados reais o estado de coisas descrito pela teoria.

Dickinson imagina uma comunidade socialista com propriedade privada de bens de consumo (adquiridos em mercados com o uso de moeda) e livre escolha de ocupação, com o salário pago para o trabalhador como parte da renda individual. Como no modelo de Barone, outra parte seria dada por uma parcela do 'fundo social', a somatória dos rendimentos a serem distribuídos pelo estado fora o pagamento de salários. Os bens de produção, por sua vez, seriam propriedade estatal. A produção seria dividida em duas áreas: a de bens vendidos à população pelas 'agências de venda' (consumo individualizado) e de bens dados gratuitamente (consumo socializado). A produção seria realizada por o que Dickinson, algo contraditoriamente, chama de 'hierarquia de corporações autônomas' (pág. 239). Tais corporações seriam agrupadas em trustes conforme afinidade técnica ou mercadológica e os trustes seriam agrupados por indústrias. O conjunto das indústrias seria inspecionado pelo 'Conselho Econômico Supremo' (SEC).

\footnotetext{
${ }^{17}$ Essas ambigüidades estarão presentes também no texto de Lange e serão alvo de crítica por parte de Hayek.
} 
As relações entre agentes nessa economia envolvem compras e vendas a preços dados, como acredita que ocorra nas economias de mercado. Embora superficialmente imite mercados existentes, a economia socialista dispensa elementos como segredos industriais e desconhecimento dos planos de ação dos demais agentes. Esses segredos seriam fruto da rivalidade que marca a competição real:

Although the forms of capitalistic organization are maintained, there is one fundamental difference in that there is fullest publication of output, costs, sales, stocks, and other relevant statistical data. All enterprises work as it were within glass walls. (Dickinson, 1933:239)

Como nota Steele (1992:150) ao comentar Marx, é característica comum a todas as formas do pensamento socialista a crença de que uma visão clara do processo produtivo só não é obtida devido à presença da propriedade privada ${ }^{18}$, como também tivemos a oportunidade de assinalar na seção anterior.

Para Dickinson, a publicação de estatísticas econômicas tornaria possível aproximar mais a realidade do ideal descrito pela teoria. Curvas objetivas de demanda e custo, antes utilizadas para explicar o funcionamento dos mercados sem necessariamente supor a sua existência na realidade, são agora passíveis de vir à tona no socialismo por meio de estimações econométricas, viáveis em uma economia transparente:

Under capitalism, demand schedules are apt to exist in the real of faith rather then in that of works, but within the glass walls of the socialistic economy they would become much easier to draw up. (Dickinson, 1933:240)

Com base nas curvas estimadas, pode-se estabelecer matematicamente um conjunto de preços que coordene as atividades no mercado e resultem em uma alocação econômica dos bens. As curvas de demanda por bens de consumo final, por exemplo, seriam obtidas pelo departamento estatístico das agências de venda na medida em que se observa a demanda a preços diferentes. Estes são alterados pelas agências com o propósito de regular o estoque existente do bem. Em termos práticos, os bens relacionados poderiam ser agrupados para facilitar a estimação da demanda. As firmas produtoras teriam assim conhecimento da demanda por seus produtos e por sua vez demandariam bens de ordem superior (bens de produção) até se chegar aos fatores primários. Os preços destes seriam fixados pelo SEC de forma a garantir o pleno

\footnotetext{
${ }^{18}$ Por exemplo, na página 245, Dickinson escreve: "the ignorance of economic opportunities would be eliminated by the publicity of a planned economy.". Durbin (1949:50), na mesma linha, afirma: "To begin with, a centrally controlled economy will be an economy with open eyes. It is the essence of an unplanned and competitive arrangement of industry that the persons who take decisions about output and investment should be blind".
} 
emprego do fator, supondo que sua quantidade seja dada. Teríamos assim curvas de demanda pelos fatores.

Quanto ao fator trabalho, o salário deve refletir o valor de seu produto marginal. Com isso chega-se a um dos dilemas dos socialistas de mercado: ou tem-se igualdade de renda, dada por fração do fundo social e se abdica da livre escolha de ocupação, ou preserva-se esta e perde-se a igualdade de rendas. As rendas, segundo a teoria, devem refletir as diferenças de valor da produtividade marginal do trabalho. Dickinson resolve a questão afirmando que no socialismo o acesso livre à educação reduziria as diferenças de renda obtidas pelo trabalho. De qualquer modo, pagando-se salários conforme a produtividade ou não, Dickinson acredita que se pode avaliar contabilmente o valor de cada tipo de trabalho para fins de cálculo tanto quando existem diferenças de salário ou não.

Dados os preços dos fatores, Dickinson propõe então que as firmas aumentem ou diminuam a produção conforme haja lucros ou prejuízos. Além disso, os fatores são substituídos conforme variem seus preços. Ao contrário de Taylor, que defende explicitamente um mecanismo de tentativas e erros, Dickinson (pág. 241) apenas menciona que os preços podem ser obtidos por 'sucessivas aproximações'. A solução de equilíbrio, entretanto, poderia ser obtida matematicamente com base nos dados estatísticos obtidos, não sendo necessário que se apele para o estabelecimento de preços em mercados.

Para que seja possível a determinação matemática dos preços e quantidades de equilíbrio de um dado conjunto de produtos e uma dada quantidade de fatores primários, Dickinson afirma que o SEC necessitaria 4 tipos de funções: funções de demanda em função do preço, funções de produção, igualdades entre custo e preço e funções de demanda por fatores. Poder-se-ia então resolver um sistema de equações simultâneas, ou, já que o autor acredita que apenas pequenas variações em termos de um equilíbrio pré-estabelecido sejam necessárias, usa-se cálculo de variações marginais.

Quanto ao ritmo de crescimento, as firmas poderiam traçar planos alternativos caso os juros fossem $5,4,3, \ldots$ por cento e teríamos uma demanda agregada pelo SEC por capital em função dos juros. Dada uma taxa de juros escolhida, e portanto determinado o investimento, o SEC pode utilizar a poupança necessária a partir do fundo social; ou, dada a quantidade de investimento desejada, determina-se a taxa de juros necessária para arrecadar poupança equivalente. Aos juros deve ser acrescido um prêmio por risco. 
Enquanto no capitalismo este montante é fixado através de palpites, no socialismo o SEC deverá adotar procedimentos estatísticos baseados nas distribuições de frequiência de vendas e preços.

Finalmente, o comércio internacional com outros países obedeceria ao princípio das vantagens comparativas, levando-se em conta porém os custos sociais de uma importação, podendo haver proteção quando os custos de adaptação forem maiores do que os ganhos ou quando se protege uma indústria nascente.

Com a solução matemática ao problema do cálculo, Dickinson conclui não só que o socialismo seria capaz de calcular custos, mas também que seria superior nessa tarefa. Mencionando Pigou, Dickinson acredita que o estado poderia corrigir as discrepâncias entre custos e benefícios privados e sociais, como aqueles derivados da presença de externalidades, e eliminar desperdícios de recursos devido à ignorância, duplicação de esforços e falta de padronização.

Fundamentalmente, em Dickinson temos a crença de que os problemas econômicos seriam resolvidos fazendo uma nova realidade imitar a teoria que pretendia descrever uma realidade anterior:

Capitalist society, with its deviations from equilibrium due to inequalities in individual income, to competition, to monopoly, and to mutual ignorance of entrepreneurs concerning other entrepreneur's activities is a very imperfect approximation to the economic ideal. The beautiful systems of economic equilibrium described by Böhm-Bawerk, Wieser, Marshall and Cassel are not descriptions of society as it is but prophetic visions of a socialist economy of the future. (Dickinson, 1933:247) ${ }^{19}$

Embora almeje que a realidade imite a teoria, Dickinson tacitamente reconhece a possibilidade de que na prática seu esquema não seja factível. De fato, o autor inicia e conclui o artigo afirmando que pretende refutar o argumento de Mises "pelo menos em teoria" (pág. 238). Caberá a Lange traçar claramente a distinção entre prova teórica e prática, desenvolvendo a proposta de Dickinson no sentido de contornar as objeções que foram levantadas contra ela por Hayek e Robbins.

Em 1935 Hayek publica a coletânea intitulada Collectivist Economic Planning, contendo traduções dos trabalhos de Pierson, Mises, Halm e Barone, além de dois artigos do próprio Hayek. No seu segundo artigo, Hayek classifica e critica as propostas de solução do problema do cálculo existentes até então. Entre as críticas - que serão estudadas no próximo capítulo - Hayek aponta alguns problemas com a solução

\footnotetext{
${ }^{19}$ Afirmação semelhante pode ser encontrada em Lange (1936-7, parte 2:127): "The actual capitalist system is much better described by the analysis of Mrs. Robinson and of Professor Chamberlin, than by that of Walras and Marshall. But the work of the latter two will be more useful in solving the problems of a socialist system."
} 
matemática: além de se concentrar indevidamente no estabelecimento de um equilíbrio estático, a solução matemática requereria que o órgão planejador obtivesse uma quantidade extraordinária de informações sobre os consumidores, firmas e disponibilidade de recursos, informações essas que se tornariam irrelevantes assim que fossem obtidas, pois a realidade econômica estaria em constante mutação.

Com o objetivo de contraditar essa última crítica, Lange (1936-7) publica um artigo em duas partes no qual procura fundir a solução de Dickinson com o mecanismo de estabelecimento de preços por tentativas e erros de Taylor, oferecendo assim uma prova 'prática' da possibilidade do cálculo econômico socialista. Segundo Lange (1936-7: 56), Hayek, ao apontar problemas com a operacionalização da solução matemática e admitir que esta não é impossível no sentido de ser contraditória logicamente, teria recuado para uma segunda linha de defesa em relação ao argumento de Mises, defendendo apenas a impossibilidade prática do socialismo.

Já Mises, ironiza Lange, mereceria uma estátua no saguão do Ministério da Socialização ou no Órgão de Planejamento Central (Central Planning Board - CPB) pelo mérito de chamar a atenção dos socialistas para o problema do cálculo ${ }^{20}$ por meio de sua polêmica sobre a impossibilidade. Os alunos de um curso de dialética visitariam a estátua para ter um exemplo de como mesmo o mais ferrenho opositor do socialismo teria servido à sua causa.

O erro do argumento de Mises, segundo Lange, consiste em confundir preços de mercado com preços no sentido mais amplo de "termos nos quais alternativas são oferecidas" ${ }^{21}$. Relações de troca ditadas centralmente, quando usadas como parâmetros que norteiam as escolhas das firmas socialistas, seriam capazes de guiar a produção. Assim, apenas no segundo sentido preços seriam necessários para o cálculo. Dadas as preferências dos consumidores, as quantidades de recursos e as funções de produção, é possível estabelecer preços paramétricos que resolvam o problema.

O artigo de Lange é estruturado da seguinte forma: na primeira parte descreve-se inicialmente, com o auxílio da teoria do equilíbrio geral, como o problema do cálculo seria resolvido nos 'mercados competitivos'. Em seguida investiga-se como a obtenção do equilíbrio via leiloeiro walrasiano poderia ser duplicada no socialismo sob a

\footnotetext{
${ }^{20}$ Steele (1992) devolve a ironia, notando que a inexistência do CPB é um tributo maior a Mises do que seria a estátua.

${ }^{21}$ A distinção é retirada do The Common Sense of Political Economy de Philip Wicksteed.
} 
coordenação do CPB. Na segunda parte do artigo, defende-se a superioridade do socialismo e discutem-se problemas da transição.

Ao discutir os 'mercados competitivos', Lange não distingue entre o comportamento das firmas em mercados competitivos reais daquele descrito pela teoria da competição perfeita, fundindo a realidade com sua descrição teórica. Assim como em Dickinson, o trabalho de Lange reflete a confiança que os primeiros socialistas de mercado tinham sobre a capacidade explicativa da teoria neoclássica. Ao colapsar todos os aspectos do funcionamento dos mercados reais na descrição teórica da obtenção de preços de equilíbrio entre oferta e demanda, conclui-se que tal equilíbrio pode ser facilmente duplicado no socialismo através do estabelecimento por tentativas e erros de preços fixados centralmente. Vejamos como o argumento é construído.

Lange (1936-7:57) aponta três tipos de condições necessárias para se estabelecer o equilíbrio em um mercado competitivo (com livre entrada e número grande de agentes):

(A) condições subjetivas - os consumidores maximizam utilidade escolhendo bens de forma a igualar a utilidade marginal de uma unidade monetária em todos os usos; as firmas, ao maximizarem lucros, minimizam custos, o que implica em (a) escolha da combinação de fatores mais barata e (b) escolha da escala de produção de forma a igualar o preço ao custo marginal (decorrente da maximização de lucros) e ao custo médio (fruto da livre entrada); os proprietários de capital, trabalho e recursos naturais maximizam sua renda vendendo seus recursos;

(B) condições objetivas - os preços são determinados de forma a igualar demanda e oferta de cada bem;

(C) condições que expressão as instituiçõos - a renda de cada agente consiste na receita de venda de seus recursos.

Quanto às condições subjetivas, sob competição, os preços são "parâmetros que determinam o comportamento dos indivíduos" (Lange, 1936-7: 59). Os indivíduos reagem então passivamente a variações nos preços. Dados os preços de todos os bens, as demandas e ofertas são determinadas. A solução teórica do problema seria então dada pelas condições objetivas que igualam demanda e oferta para um certo vetor de preços, dada a renda de cada agente. Já na realidade, a solução seria obtida por tentativas e erros. Dados preços aleatórios, as condições subjetivas determinam demanda e oferta. 
Caso não sejam idênticas, "a competição dos compradores e vendedores irá alterar os preços" (pág. 59, grifo nosso) ${ }^{22}$. Na prática, porém, utilizam-se preços históricos.

Vejamos agora como esse mecanismo, visto como representativo do funcionamento dos mercados, poderia ser replicado no socialismo. Inicialmente Lange pressupõe liberdade de escolha de consumo e ocupação e propriedade pública dos bens de capital. Só existiriam mercados reais para bens de consumo e trabalho. Os preços destes bens seriam então preços de mercado, no sentido de existir de fato trocas de bens por somas de dinheiro, enquanto os preços dos bens de capital seriam apenas entidades contábeis, parâmetros que devem ser levados em conta nas decisões alocativas das firmas. Dado um conjunto de preços, as 'condições subjetivas do equilíbrio' determinam o comportamento dos agentes. Excessos de demanda e oferta indicariam que correções deveriam ser realizadas nos preços até que se obtenha a 'condição objetiva do equilíbrio', igualando-se demanda e oferta.

Quanto às condições subjetivas propriamente ditas, os consumidores teriam suas demandas determinadas pelos preços dos bens e pela renda. Os trabalhadores buscariam o emprego que oferte o maior salário e os proprietários de recursos os vendem para as firmas que possam 'responder por esses preços', segundo as instruções ditadas pelo CPB. Em vez de atuarem de forma a maximizar lucros, como descreve a teoria, as firmas seriam instruídas pelo CPB a seguir duas regras:

One rule must impose on each production plant the choice of the combination of factors of production and the scale of output which minimizes the average cost of production. The output of the whole industry must be determined by the rule to produce exactly as much of a commodity, no more no less, than can be sold to consumers or 'accounted for' to other industries at a price which equals the average cost of production. (Lange, 1936-7:62)

A primeira regra, que substitui a maximização dos lucros, faz com que os fatores sejam escolhidos de forma a igualar o produto marginal de uma unidade monetária gasta com qualquer insumo. A segunda regra substitui a livre entrada, garantindo que o preço seja igualado ao custo médio.

Adicionalmente, Lange afirma que a primeira regra garante que o preço seja igual ao custo marginal (pág. 62). Porém, se além das quantidades de insumos, a firma escolhe ao mesmo tempo o nível de produção que minimiza custos, o preço seria igual ao custo marginal apenas no equilíbrio competitivo. Se a firma seguir a primeira regra proposta,

\footnotetext{
${ }^{22}$ É interessante notar que Lange não menciona nem o leiloeiro walrasiano nem os empresários como responsáveis pela alteração de preços.
} 
não precisaria observar o preço do produto, mas apenas dos fatores, para escolher a quantidade que minimiza custos médios, de forma que, fora do equilíbrio de longo prazo, ou a firma escolhe a quantidade de forma a igualar o preço ao custo marginal ou ignora o preço do produto e produz no ponto de custo médio mínimo ${ }^{23}$.

De qualquer modo, os preços - estabelecidos nos mercados no caso de bens de consumo e trabalho, ou fixados pelo CPB no caso de bens de produção - determinariam o comportamento dos agentes. Lange procura assim reproduzir a característica de preços paramétricos que acredita existir em mercados competitivos ${ }^{24}$. Já que haveria centralização no socialismo, a possibilidade de ganhos de monopólio seria excluída pela imposição dos preços paramétricos como uma regra. "Outro tipo de contabilidade não seria tolerada" (pág. 63).

Determinado o comportamento dos agentes, que reagem aos preços paramétricos, o $\mathrm{CPB}$ estabeleceria o conjunto de preços que levaria os agentes a fazer escolhas compatíveis entre si. Ao implementar no socialismo o procedimento descrito por Walras, Lange acredita que as funções do mercado seriam então desempenhadas pelo CPB:

Our study of the determination of equilibrium prices in a socialist economy has shown that the process of price determination is quite analogous to that in a competitive market. The Central Planning Board performs the functions of the market. It establishes the rules for combining factors of production and choosing the scale of output of a plant, for determining the output of an industry, for the allocation of resources, and for the parametric use of prices in accounting. Finally, it fixes the prices so as to balance the quantity supplies and the demanded of each commodity. It follows that a substitution of planning for the functions of the market is quite possible and workable. (Lange, 1936-7:65, ênfase adicionada)

Dada a solução geral, dois problemas são discutidos pelo autor nos mercados de trabalho e capital. Quanto ao primeiro, Lange se depara com um dos problemas principais enfrentados por todos os socialistas de mercado, que já mencionamos quando discutimos a proposta de Dickinson: a remuneração deve refletir o valor do serviço e ao mesmo tempo devem-se eliminar diferenças de renda. Lange soluciona o problema recomendando que o dividendo social (fruto da renda dos demais fatores além do trabalho) deva ser proporcional ao salário, a fim de não distorcer a alocação ótima do trabalho. Esta alocação ótima é obtida de modo que o valor do fruto do trabalho em

\footnotetext{
${ }^{23}$ Como veremos mais adiante, Lerner irá criticar as regras propostas por Lange. Entretanto, é curioso observar que essa inconsistência não foi discutida por Lerner, sempre ácido em suas críticas as regras propostas.

${ }^{24}$ Lange (1936-7: 63, grifo nosso) afirma: "For purposes of accounting prices must be treated as constant, as they are treated by entrepreneurs on a competitive market."
} 
diversos empregos - igual ao salário - seja proporcional às desutilidades marginais dos mesmos.

Quanto ao segundo problema, a determinação dos juros, Lange afirma que no curto prazo este seria determinado de modo a igualar a demanda de capital à quantidade fixa de capital disponível. No longo prazo, ou o CPB escolhe arbitrariamente uma quantidade de poupança antes da distribuição do dividendo social - o que envolve perda de bem estar, devido ao fato de que os agentes têm sua capacidade de fazer escolhas intertemporais reduzida - ou permite que os consumidores escolham, o que não seria compatível com princípios socialistas. Defendendo a primeira alternativa, Lange afirma que a perda de bem estar seria mais do que compensada pelos demais ganhos do socialismo.

Além do socialismo, também no comunismo (definido pela ausência da escolha de consumo e trabalho) seria possível resolver o problema do cálculo. No comunismo, as preferências do governo substituem as dos consumidores, e as mesmas regras ditadas às firmas seriam válidas, sendo que neste caso elas garantiriam a consistência das ações do governo, mas não a satisfação das vontades dos consumidores.

Dada a solução teórica do problema do cálculo descrita acima, vejamos como Lange imagina que esta possa ser determinada na prática com o auxílio do mecanismo de tentativas e erros proposto por Taylor. O CPB parte de um conjunto aleatório de preços, que por sua vez determina as ofertas e demandas dos agentes. Excessos de demanda ou oferta levariam a aumentos ou reduções de preços, respectivamente, até que se obtenha o equilíbrio. Partindo-se de preços dados historicamente, Lange acredita que apenas algumas alterações relativamente pequenas seriam feitas ao longo do tempo.

Esse mecanismo, segundo Lange, seria o mesmo existente nos mercados competitivos. Pretende-se com a adoção desse mecanismo contornar a objeção levantada por Hayek e Robbins de que seria necessário que o CPB obtenha informações sobre as curvas de demanda e oferta. Os consumidores e administradores das firmas tomariam decisões descentralizadas, sem a necessidade de resolver centenas de milhares de equações. Bastaria que se observassem as quantidades demandadas e ofertadas.

Embora sem dúvida a proposta de Lange represente uma redução da quantidade de informações requeridas pelo CPB em comparação com a proposta de Dickinson, a viabilidade prática da primeira pressupõe a discussão do volume restante de informação 
que o modelo requer. Mas, como em Taylor, poucos detalhes são fornecidos sobre o funcionamento do mecanismo de correção, as mesmas ambigüidades que lá surgiram reaparecem aqui, bem como os mesmos problemas, como por exemplo sobre diferenças de qualidade e tipos de bens ou frequiência de reajustes de preços. Enquanto na página 62 somos informados de que os preços dos bens de consumo são determinados nos mercados (o que levanta questões como o que garantiria que o preço de um produto arbitrariamente definido seja único ou constante), a página 66 mostra que os consumidores tomam decisões baseadas em preços ditados centralmente pelo processo de tentativas e erros. No caso de bens de consumo serem sujeitos ao processo de tentativas e erros anterior às trocas, como computar a demanda? Os consumidores teriam que responder um questionário informando a demanda por, digamos, dezenas de milhares de produtos a cada preço proposto? Teriam que estabelecer suas escolhas de uma vez só? Como lidar com contingências? Esse questionário seria mensal ou anual? Por outro lado, se o método for por observação de um processo de tentativas e erros real, como computar excessos de demanda? Pelo tamanho das filas? As mesmas questões valeriam para os produtores. Se, por outro lado, os preços forem estabelecidos em mercados reais, como computá-los no tempo e espaço, lidando com sua variabilidade? Como estas, várias outras questões poderiam ser levantadas para que se possa discutir a viabilidade do esquema proposto.

Lange crê, contudo, que não há motivo para que um processo de tentativas e erros semelhante àquele existente nos mercados não funcione no socialismo. $\mathrm{Na}$ verdade $\mathrm{o}$ mecanismo no socialismo deveria funcionar bem melhor, atingindo o equilíbrio com um menor número de interações, visto que o $\mathrm{CPB}$ possui conhecimento mais amplo sobre todos os aspectos da economia do que os agentes privados. Reaparece aqui a hipótese das 'paredes de vidro' de Dickinson que Lange inicialmente procurava contornar.

A pressuposição do conhecimento superior da realidade econômica por parte dos governantes socialistas se manifesta de forma mais enfática na segunda parte do artigo, que é pouco comentada. Nessa segunda parte, Lange defende a superioridade do socialismo, se posiciona a favor do tratamento de choque e contra o gradualismo como política de transição e finalmente, baseado em citações de Marx e Kautsky, defende de forma pouco convincente a tese de que os socialistas sempre reconheceram o problema do cálculo. Concentrar-nos-emos apenas no primeiro ponto. 
Lange (1936-7:123), à maneira neoclássica, afirma que a existência da competição forçaria os empresários a se comportar como se fossem administradores socialistas cujas decisões são consistentes e cuja interação resulta em uma alocação eficiente. Disso se derivaria o valor da competição para o economista. Contudo, apesar de que as regras alocativas sejam as mesmas nos dois sistemas, a superioridade do socialismo sobre o capitalismo deve ser buscada nas diferenças entre os dois sistemas.

Em primeiro lugar, o capitalismo falharia em termos de avaliações de bem estar econômico devido à má distribuição de renda, que faz com que a disposição a pagar não reflita a urgência das necessidades. Esta última relação ocorreria apenas se a utilidade marginal da renda fosse constante, o que se obtém de forma aproximada (e admitindo comparação interpessoal de utilidade) com igualdade de renda (ajustada pela desutilidade marginal do trabalho) no socialismo. Em segundo lugar, o socialismo teria condições de levar em conta todos os custos - privados ou não - de uma decisão, utilizando o mecanismo de taxação proposto por Pigou. Em terceiro lugar, no socialismo não ocorreriam ciclos econômicos, justamente porque o governo levaria em conta todas as alternativas. Assim, o fechamento de uma indústria, ao levar a uma contração cumulativa da demanda, pode resultar em custos elevados que não são considerados no capitalismo. No socialismo, os erros existem, porém seriam localizados e poderiam ser corrigidos. Em quarto lugar, os desvios do capitalismo do ideal da competição perfeita, como a existência de monopólios e competição monopolística, argumentariam fortemente em favor do socialismo. Em quinto lugar, embora tenha-se a desvantagem do estabelecimento de uma taxa arbitrária de juros no socialismo, Lange aponta para a existência no capitalismo do paradoxo da poupança proposto por Keynes, além de defender que a poupança depende da irracional distribuição de renda no capitalismo.

Em compensação, uma das possíveis desvantagens do socialismo seria o perigo da ineficiência na administração da produção por parte dos funcionários públicos, em comparação com a atuação dos empresários. O socialismo seria sujeito não a falta de critérios alocativos, mas sim ao perigo da burocratização. Depois de expô-lo, Lange minimiza o problema, notando que tal perigo não seria maior do que aquele existente nas grades corporações atuais. De qualquer modo, como em todo socialista de mercado, essa questão estaria fora do escopo da teoria econômica, devendo ser tratada por outro tipo de cientista social. 
Essa demarcação dos problemas tratáveis pela ciência econômica, porém, não impede Lange de fazer uma incursão no campo que o autor exclui da análise econômica para levantar ainda mais um argumento a favor do socialismo. Com a crescente monopolização, o processo de adoção de inovações no capitalismo diminui, pois enquanto por um lado a inovação confere lucros temporários, por outro destrói o valor do capital antigo. Como os monopolistas têm interesse em preservar o valor de seu capital, o progresso é combatido e por isso retardado. O capitalismo, quando marcado pela competição, exerceu papel progressivo na evolução social. Caberia agora ao estado socialista organizar o investimento de forma a eliminar a influência retrógrada dos monopólios. As políticas restricionistas e intervencionistas resultariam da luta dos monopólios para manter o valor de seu capital. No socialismo, a abolição da propriedade levaria ao final da atividade que hoje denominaríamos de rent-seeking ${ }^{25}$.

Até recentemente, o artigo de Lange passou para a história como a resposta definitiva ao desafio de Mises e, como tal, foi considerado o trabalho representativo do pensamento dos socialistas de mercado. Na verdade, o trabalho de Lange foi o ápice de uma linha de propostas que inclui os trabalhos de Taylor e Dickinson. Essa linha é classificada como socialista de mercado por reconhecer a necessidade de entidades análogas a preços de mercados. Contudo, em tais propostas os mercados de capital geralmente não existem na realidade; os preços são fixados centralmente.

Tendo isso em mente, Steele (1992) considera estranho que o texto de Lange, que procura substituir os mercados, seja considerado representativo do socialismo de mercado. De fato, tendo em vista o desenvolvimento posterior das discussões, observase que os mercados reais serão de fato incorporados nos modelos, como é feito no trabalho de Durbin que examinaremos em seguida. Por isso, a proposta deste último autor, desenvolvida ao mesmo tempo em que a de Lange, deveria ser objeto de mais estudo, embora não tenha até aqui chamado a atenção ou causado tanta polêmica como a de Lange. Voltar-nos-emos agora para essa segunda classe de propostas de socialismo de mercado baseado em mercados reais.

\footnotetext{
${ }^{25}$ Lange não discute, contudo, como a substituição dos monopólios por um único monopólio estatal impediria o surgimento de rent-seeking. Lerner (1944:4), por sua vez, também acredita que a busca de privilégios cessará no socialismo: "The uncontrolled economy may be likened to an automobile without a driver but in which many passengers keep reaching over to the steering wheel to give it a twist while complicated regulations prescribe the order and degree to which they may turn the wheel so as to prevent them from fighting each other about it. The controlled economy has a driver, so these regulations are unnecessary."
} 
Se por um lado o socialismo de Lange almeja implementar na realidade o mundo abstrato da teoria do equilíbrio geral, por outro a solução de Durbin ao problema do cálculo é menos abstrata, construída por um economista mais prático, membro ativo do Partido Trabalhista inglês. Desse modo, Durbin (1936) procurará refutar a tese de Mises através da elaboração de uma proposta mais prática do que aquela feita por Dickinson ou Lange.

Apesar de seu pragmatismo, Durbin acredita, como a maioria dos autores que estamos abordando, que o objeto de pesquisa de um economista deve se limitar à descrição do equilíbrio. Dessa maneira, temos poucas informações sobre as instituições que fazem parte de sua proposta de socialismo. Sabemos que o autor supõe planejamento central, possivelmente encarregado de coordenar as indústrias, planejar os rumos do crescimento e cuidar da distribuição, como em Lange. Como na proposta deste, a administração da produção - área para a qual seria relevante o problema do cálculo - é feita por entidades públicas que seguem regras estabelecidas pelo órgão de planejamento. Tais entidades seriam 'trustes', possivelmente setoriais, como nas propostas de Heimann e K. Polanyi. Cada truste consiste em um monopólio (Durbin, 1936:680). Ao contrário de Lange, porém, além de mercados de bens de consumo, existem mercados 'livres' de bens de produção, com compras, vendas e preços descentralizados.

Embora sejam monopólios, os trustes são instruídos a atuar de forma competitiva: "Let us suppose that the Central Authority has instructed all Trusts to compete with each other in the market for the mobile factors of production - land, unspecialized labour and new capital". (Durbin, 1936:680) Com isso, pretende-se que a produção seja ajustada às necessidades dos consumidores da mesma forma que em competição perfeita.

Como garantir então que a economia baseada nos trustes estatizados replique os resultados desejáveis da competição perfeita? A solução deveria ser buscada: a) no método de Marshall de igualar preço a custo marginal e médio, ou b) no método de Böhm-Bawerk de igualar o valor do produto marginal de cada fator em cada uso alternativo ou ainda c) no método de equações de Walras.

Durbin pretende encontrar em alguma dessas descrições teóricas dos mercados um conjunto de regras de atuação para as firmas que possa ser adotado pela autoridade econômica socialista: 
The three forms of the theory of value arrive at the same positive conclusion - that perfect competition secures the right distribution of resources. Do any or all or none of them provide a rule of procedure for the Planned Economy? (Durbin, 1936:677, ênfase adicionada)

Como Lange, Durbin parece acreditar que os pressupostos comportamentais postulados pela teoria, como maximização de lucros e minimização de custos, são de fato regras seguidas de forma literal pelas firmas nos mercados. Se as firmas existentes seguem as regras descritas pela teoria, as firmas socialistas poderiam ser instruídas a seguir um conjunto de regras da mesma natureza.

O procedimento sugerido pelo método walrasiano, adotado por Dickinson, é descartado por Durbin. O autor aceita os argumentos de Hayek e Robbins sobre a impossibilidade prática da solução matemática. Para Durbin, entretanto, seria 'quase certo' que o segundo método, o de Böhm-Bawerk, seria aplicável à solução do problema do cálculo. Os trustes socializados, atuando em mercados, seriam instruídos pela 'Autoridade Central' a seguir duas regras (Durbin, 1936:678):

(a) que as firmas calculem o produto marginal dos fatores móveis em sua produção ${ }^{26}$;

(b) que os recursos móveis sejam sempre movidos ao emprego de maior produtividade.

Se as regras fossem seguidas, a alocação de recursos seria idêntica àquela obtida sob competição perfeita.

Tal solução, sob o ponto de vista teórico do economista, seria suficiente. Como o autor acredita que as firmas de fato calculam produtos marginais e atuam conforme as regras descritas pela teoria, não haveria diferenças substanciais entre o comportamento das firmas nos dois sistemas. Tanto no capitalismo quanto no socialismo, as firmas teriam dificuldades técnicas para calcular produtos marginais. Questionar a possibilidade de que as firmas sigam as regras, como faz Hayek, seria 'dogmatismo teórico'. Estes problemas não seriam do tipo "que o professor de teoria econômica seja competente para discutir". Tais problemas, pelo contrário, seriam objeto de "análise sociológica e principalmente psicológica" (Durbin, 1936:678).

Como homem prático que é, Durbin não se contenta com a solução acima. O mesmo tipo de preocupação com o seguimento das normas, rejeitada pelo autor como 'dogmatismo teórico', o leva a elaborar mais o conjunto de regras. O valor da produtividade marginal, aponta ele, seria apenas uma estimativa, sujeita a erros. Tanto a

\footnotetext{
${ }^{26}$ Fica evidente pela página seguinte do artigo que o autor está se referindo, naturalmente, ao valor da produtividade marginal dos fatores.
} 
estimação da produtividade física, que envolve reorganização da produção, quanto o seu valor monetário, que envolve estimativa de curvas de demanda, são sujeitas a erro. A solução baseada no segundo método deve então ser verificada pela análise de custos do primeiro método, o de Marshall.

Durbin então se dedica ao problema da escolha do tamanho de uma planta, dado que o truste, como monopolista, deve atender todo o mercado, e a Autoridade Central deve portanto ditar regras que impeçam que surja exploração de ganhos monopolísticos, já que a curva de receita marginal é declinante para um mercado como um todo.

Como os trustes competem no mercado de fatores não específicos, obtemos para tais fatores preços que refletem o valor de seus produtos marginais. Baseado nesses preços, para cada tamanho de planta, o truste deve estimar os custos (totais e médios) fixos (overhead cost), incluindo lucros normais, e os custos variáveis (prime cost). A soma dos custos fixos e variáveis médios gera a curva de custo médio total em forma de U. Teríamos assim uma família de curvas, para os diversos tipos de plantas.

O truste deveria então estimar a curva de demanda pelo seu produto. A planta a ser escolhida seria então aquela cuja curva de custo médio cruza a curva de demanda no ponto de mínimo da primeira, como mostra a figura ao lado. Teríamos, assim, que o preço do produto seria igual ao custo médio de longo prazo.

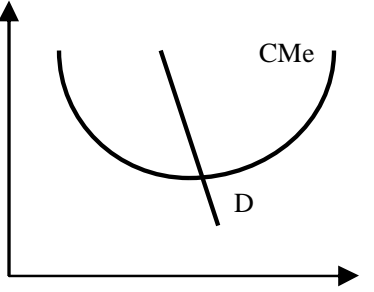

Durbin (1936:682,n.r.) rejeita uma solução que adotara anteriormente. Nesta solução, os trustes deveriam produzir a maior quantidade possível que gere lucros normais. Esta solução, para o autor, seria equivalente a construir uma planta cujo lucro máximo seja o lucro normal ${ }^{27}$.

Estudada a solução de equilíbrio, Durbin busca ir além da preocupação essencialmente estática de Lange, procurando investigar o comportamento das firmas diante de mudanças na demanda, preços de fatores, preço do capital fixo ou na tecnologia. Não só esses fatores variam, mas também podem ser estimados incorretamente pelas firmas. Em ambos os casos, as firmas devem mudar seu comportamento. Durbin procura assim fazer frente as críticas dos opositores do socialismo de mercado, que, como veremos no próximo capítulo, enfatizarão o aspecto dinâmico de adaptabilidade a mudanças dos

\footnotetext{
${ }^{27}$ Ver mais adiante a crítica que Lerner faz a essas soluções de Durbin.
} 
mercados. A resposta de Durbin, entretanto, será feita em termos de alguns exercícios de estática comparativa frente a algumas mudanças esporádicas.

Vejamos apenas como lidar com variações na demanda. Em primeiro lugar, a demanda pelo bem produzido pelo truste pode crescer. Esta mudança não apresentaria dificuldade, pois a decisão de aumentar a produção através do emprego de mais capital nas plantas existentes ou através da construção de nova planta pode ser feita tendo como critério o menor custo adicional. O problema seria mais complexo se a demanda diminuísse, visto que o capital fixo, agora redundante, já estaria aplicado na produção. Neste caso, duas vias de ação seriam possíveis: ou a firma maximiza lucros no curto prazo, reduzindo a produção para obter o maior lucro possível (já que o lucro normal não pode ser obtido) e no longo prazo ajusta-se o montante de capital fixo, ou a firma mantém o capital e é instruída a produzir até que a receita marginal cubra o custo marginal, o que seria teoricamente correto, já que o capital específico já aplicado não tem custo de oportunidade (bygones are bygones). O prejuízo incorrido neste segundo caso seria compensado pelos lucros existentes nos outros trustes, desde que todas as indústrias sejam estatais, para que a compensação seja possível.

Entre essas opções, Durbin prefere a primeira, por duas razões. Em primeiro lugar, quando o capital deprecia, os custos do capital fixo passariam a ser levados em conta no cálculo do custo marginal. Mas, se não for possível distinguir entre custo variável de produção e manutenção do capital, como seria o caso de uma linha ferroviária que substitui continuamente seu capital, digamos, $10 \%$ ao ano, o nível de capital excessivo seria mantido indefinidamente, pois não se pode estabelecer o custo marginal verdadeiro. Em segundo lugar, a primeira alternativa - a maximização de lucros - seria mais simples, pois evitaria os impostos e subsídios necessários para viabilizar a segunda, visto que algumas firmas teriam lucro enquanto outras prejuízo.

Vale a pena reproduzir a longa regra de Durbin, que a considera simples:

In the second place, the fist set of instructions issued has the great practical advantage of simplicity. The Central Authority simply says to its local representatives: "Here is a plant. Whenever output you make, make it a the lowest possible total cost. Make the largest output you can consistent with earning normal profit on the cost of replacing your plant. When, through a change in market conditions, you cannot earn normal profit at all, then earn the biggest profit you can (i.e. produce at the point where marginal revenue is equal to marginal cost other than profit). When you cannot earn normal profit, you will be producing less than the capacity for which the plant was built, and you must then consider what smaller plant would, working to capacity, produce a lower output and earn normal profit. In the fullness of time that plant must be built. (Durbin, 1936:686) 
As outras alterações nos fundamentos da economia ou seriam análogas às variações na demanda, ou não ofereceriam problemas teóricos. Durbin conclui então o conjunto de regras que devem ser seguidas pelos trustes socialistas.

Dado então o conjunto de regras sugeridas acima, Durbin pretende ter oferecido uma prova teórica da possibilidade do socialismo, refutando a tese de Mises e ao mesmo tempo oferecendo uma solução mais prática do que a solução matemática.

Tanto o socialismo de mercado 'artificial' de Dickinson e Lange quanto o 'real' de Durbin foram alvo de críticas feitas por Abba Lerner sob o ponto de vista do programa de pesquisa neoclássico. Embora seja o mais ácido crítico dos trabalhos de Dickinson, Lange e Durbin, Lerner é um defensor do socialismo, acreditando que, apesar dos defeitos, os trabalhos dos três autores mencionados refutam a tese da impossibilidade do cálculo econômico. A discordância de Lerner se refere ao tipo de regras que as firmas socializadas deveriam seguir.

Lerner, o mais sofisticado economista envolvido nesse debate, não constrói então um modelo próprio de funcionamento do socialismo, limitando-se a corrigir os defeitos analíticos das regras dos demais autores. Essa postura é coerente com a sua crença na irrelevância das questões institucionais para a teoria econômica. De fato, entre os autores estudados, Lerner é o que mais fielmente se aproxima da posição de Frank Knight discutida anteriormente, sempre condenando Durbin quando este faz incursões 'sociológicas' ${ }^{28}$.

A principal crítica de Lerner a Lange e Durbin consiste em notar que estes últimos buscaram replicar no socialismo o modelo de competição perfeita, quando na verdade deveriam almejar diretamente uma alocação de recursos socialmente ótima (Lerner, 1936-37, 1937). A solução competitiva seria ótima apenas se as irrealistas précondições do modelo competitivo estivessem presentes. Deve-se supor, por exemplo, que a demanda seja atendida por um número grande de plantas operando em tamanho ótimo (custo médio mínimo) e que a escala ótima de produção não tenha uma tendência a crescer ao longo do tempo (Lerner, 1936-7:75). Quando as condições para a competição perfeita não estiverem presentes, o que sempre ocorre, erroneamente buscase imitar um meio e não o fim da maximização do bem estar.

\footnotetext{
${ }^{28}$ Ver, por exemplo, Lerner (1937:267 n.r.).
} 
Quando o caso competitivo ocorrer, o preço será igual ao custo médio e ao custo marginal, no longo e no curto prazo. A alocação correta de recursos da economia, porém, exige apenas que o preço seja igual ao custo de oportunidade marginal ${ }^{29}$ :

If we so order the economic activity of the society that no commodity is produced unless its importance is greater than that of the alternative that is sacrificed, we shall have completely achieved the ideal that the economic calculus of a socialist state sets before itself. (Lerner, 1937:253)

Quando as condições competitivas estiverem ausentes, a regra $\mathrm{p}=\mathrm{CMg}$ continua representando o desejável em termos de bem estar. Exigir que se iguale o preço ao custo médio mínimo seria apenas copiar um acidente do modelo, não o seu aspecto desejável.

Este é o ponto principal da crítica que Lerner (1936-7) faz ao artigo de Lange ${ }^{30}$ : este último estaria buscando replicar o modelo competitivo como um fim, e não como um meio. As duas regras de Lange exigem de fato que as firmas minimizem o custo médio de produção, sendo a primeira dirigida aos administradores de cada planta e a segunda não se sabe a quem é dirigida. Cumprir esta última regra poderia ser tanto a função do responsável pelo setor ou ser um convite à entrada e saída de firmas quando houver oportunidade de lucros.

As regras corretas a serem seguidas pelas firmas no socialismo, na opinião de Lerner (1936-7:76), seriam:

(1) Todo produtor deve produzir o que quer que esteja produzindo ao menor custo total.

(2) Um produtor produzirá qualquer quantidade ou qualquer aumento de produção que possa ser vendido por um preço igual ou maior do que o custo marginal daquela produção ou aumento de produção (ou algum múltiplo do custo marginal fixo para todos pelo Ministro da Produção, visto que proporcionalidade é tudo que se necessita).

Na resposta às críticas, Lange (1936-7b) aceita o ponto de Lerner, afirmando porém que a confusão foi devida à falta de clareza por sua parte sobre o que seria uma norma a ser seguida a todo instante e o que seria fruto da obtenção do equilíbrio. As regras são então reformuladas por Lange (1936-7b:143) e podem ser resumidas da seguinte forma:

\footnotetext{
29 Igualar o preço ao custo marginal equivale, em termos dos insumos, a escolher as quantidades dos fatores até que o produto marginal de cada fator multiplicado pelo preço do produto seja igual ao preço do fator.

${ }^{30}$ Entre as críticas menos centrais, Lerner (1936-7:73) mostra que o fundo social deve ser independente do nível de salário, não uma porcentagem deste, como afirma Lange, se se pretende não distorcer a alocação de trabalho. Lange (1936-7b) aceita este argumento de Lerner.
} 
(1) as firmas devem produzir até que o preço seja igual ao custo marginal, mesmo que haja prejuízo;

(2) os administradores setoriais aumentam ou diminuem o número de firmas de modo que o preço se iguale ao custo médio. Quando o preço for superior ao custo médio o setor é expandido e vice-versa.

Lange reconhece que a aplicação da segunda regra envolve dificuldades quando o tamanho de cada planta é tal que apenas poucas delas sejam necessárias para atender a demanda total. Por sua vez, essas dificuldades serão justamente o foco da crítica que Lerner (1937) faz à proposta de Durbin no debate travado entre os dois autores, debate ao qual nos voltaremos agora.

A discussão é bastante interessante porque envolve por um lado um autor interessado na solução de problemas práticos da implementação do socialismo pelo Partido Trabalhista Inglês e, por outro, um autor preocupado com o rigor teórico na discussão da alocação ótima no mesmo regime, e que considera as questões práticas que preocupam o primeiro como externas ao campo de investigação do economista. A discussão entre os dois envolve considerar se os problemas práticos levantados por Durbin implicariam em dificuldades na adoção das regras teoricamente corretas defendidas por Lerner. Em termos mais concretos, os dois autores debaterão sobre a relevância da regra do custo médio.

Do mesmo modo que na crítica à proposta de Lange, Lerner (1937) também critica Durbin por adotar como modelo a teoria da competição perfeita e não o princípio correto de produzir bens cujo valor supere o custo de oportunidade marginal.

Em sua interpretação, Lerner identifica no trabalho de Durbin duas regras. Uma delas, sugerida pelo segundo método (marginal ou 'austríaco'), recomenda que se iguale a receita marginal ao custo marginal de produção, ou seja, recomenda que se maximizem lucros. Esta regra é denominada Regra Dois. Se os pré-requisitos da competição perfeita não estiverem presentes, no entanto, a Regra Dois deve ser subordinada a outra regra, sugerida pelo primeiro método (marshalliano), denominada então de Regra Um. Tal regra recomenda que o preço seja igualado ao custo médio.

Lerner considera que, além de incompatíveis em certos casos, as regras não garantem que o preço seja igualado ao custo marginal. Se houver competição, a regra dois implica na obediência da regra um, que se torna redundante. Quando a regra um se aplica, 
apenas substitui-se um sintoma da competição perfeita por outro, sem que ocorra a equalização do valor ao custo marginal. Mesmo se as duas regras forem aplicáveis, como no equilíbrio em competição monopolística, não segue que o preço seja igual ao custo marginal.

Lerner então investiga como as duas regras aparecem (e se relacionam com o princípio do custo marginal) na discussão de Durbin sobre como proceder diante de queda na demanda.

Como vimos há pouco, Durbin (1936:686) recomenda que a firma obtenha lucro normal e quando isso não for possível, maximize lucros igualando receita marginal com custo marginal, até que no longo prazo se ajuste o tamanho da planta.

Lerner (1937:260) identifica nessa instrução a Regra Um $(\mathrm{p}=\mathrm{CMe})$ no primeiro caso (quando lucro normal for possível) e Regra Dois $(\mathrm{RMg}=\mathrm{CMg}$ ) no segundo (quando não for possível). Para Lerner, a justificativa da adoção da primeira regra deve se basear em uma condenação implícita dos lucros como uma indicação de ganhos de monopólio, mesmo que esse lucro seja obtido pelo estado, crenças essas que não se justificariam.

A critica à segunda regra, entretanto, oferece uma dificuldade de interpretação advinda da falta de clareza do texto de Lerner. Este parece mostrar que a regra levaria, além do erro alocativo inicial, causado pela existência de equipamento grande diante de uma queda da demanda, a que a sociedade seja punida ainda mais ao se recusar a usar o equipamento já instalado fruto daquele erro. De fato, no curto prazo, a regra $\mathrm{RMg}=$ $\mathrm{CMg}$ levaria a uma redução da quantidade em relação à regra $\mathrm{p}=\mathrm{CMg}$, através da obtenção de ganho de monopólio com o intuito de maximizar lucros.

Contudo, Lerner (pág. 260) afirma que a segunda regra sugere que os recursos não utilizados indicam a necessidade de não repor o capital ou ainda ironiza sugerindo que os recursos deveriam então ser destruídos, se a regra de Durbin for adotada. Ora, as instruções de Durbin deixam claro que o abandono do equipamento por um menor seria efetuado apenas no longo prazo e não no curto prazo. Concluímos então que ou esta crítica de Lerner é uma distorção do que defende Durbin ou o primeiro autor acredita que a redução do nível de produção implica reduzir a quantidade de capital aplicada quando utiliza o termo reposição do capital no curto prazo.

No longo prazo, o critério de Durbin de escolher a planta cuja curva de custo médio corta a demanda no seu ponto de mínimo é também criticado. A proposta de Durbin é 
representada por Lerner no clássico diagrama de custos médios de longo e curto prazo. Devido à complexidade da figura original (pág. 261), reproduzimos em seguida uma ampliação da metade direita da curva de custo de longo prazo desenhada por Lerner, acrescentando cores para facilitar a identificação das curvas de curto prazo.

No diagrama, as curvas de custo médio são desenhadas com linhas cheias, com seus mínimos indicados por pequenos círculos, e os custos marginais por linhas tracejadas. As curvas de longo prazo são negras e as de curto prazo são coloridas, cada cor representando um tamanho de planta. A curva de demanda de mercado corta a curva de custo médio de longo prazo no ponto A.

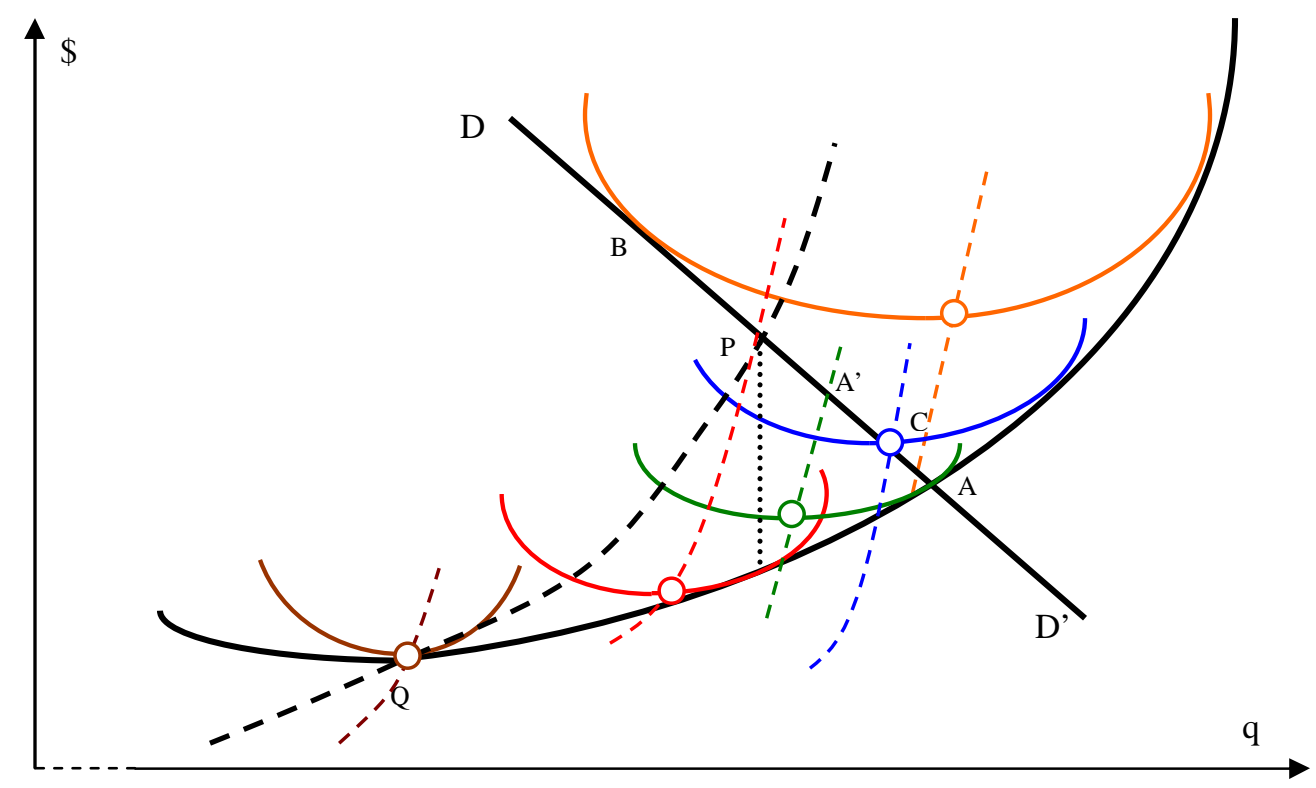

A planta azul, escolhida por Durbin, tem custo médio mínimo em $\mathrm{C}$, no cruzamento desta com a curva de demanda. A regra rejeitada por Durbin, de maximizar a produção consistente com lucros normais, é mostrada em A, na planta verde. Durbin erroneamente crê, aponta Lerner, que esta solução seria equivalente a construir a planta cujo lucro máximo seria o lucro normal. Esta outra solução é mostrada em laranja no ponto B.

Todas essas soluções, para Lerner, são errôneas. Em primeiro lugar, a solução em C não atende as regras de curto prazo de Durbin, pois apenas na solução B uma redução na demanda implica que não se pode mais obter lucros normais. A solução C não é de lucro máximo, portanto poder-se-ia reduzir a demanda e mesmo assim obter lucros 
normais. Além disso, e mais importante, a solução seria incorreta, pois em C o custo médio é maior no curto do que no longo prazo, o que indica que outras plantas poderiam fabricar essa quantidade a custo menor.

A planta verde seria incorreta porque o preço está abaixo do custo marginal de longo prazo, indicando que a planta é muito grande. Caso seja construída esta planta, a solução correta seria em A', em que o preço seria igual ao custo marginal no curto prazo, e não em A. Da mesma forma, a planta laranja também é muito grande e a solução correta nesse caso seria B' (não indicada na figura), em que $\mathrm{p}=\mathrm{CMg}$ de curto prazo.

A solução correta, aponta Lerner, seria no ponto $\mathrm{P}$, utilizando-se a planta vermelha. Neste ponto os custos marginais de curto e longo prazo coincidem e são iguais ao preço, como requer a alocação ótima de recursos. Nesse ponto também os custos médios de longo e curto prazo são os mesmos. Apenas se a curva de demanda cortasse a curva de custo médio no ponto Q (marrom) a solução A seria correta. Se houvesse retorno constante de escala, o que implica em curva de custo médio de longo prazo horizontal, todas as propostas seriam corretas, idênticas ao ponto Q.

Quanto à transição do curto para o longo prazo, Lerner afirma que o princípio do custo marginal também seria o bastante. Quando pequenas partes de uma planta velha são substituídas, deve-se considerar o benefício marginal e o custo marginal da substituição. Quando a vida útil do equipamento se aproxima do fim, o benefício de trocar tais peças diminui na margem, enquanto os custos sobem, até que a alternativa de manter o capital antigo se torne mais custosa do que trocá-lo e então a troca é feita. Lerner conclui que não é necessário em caso algum se desviar da regra do custo marginal.

Lerner aponta que a regra correta a ser seguida no socialismo seria encontrada no texto de Durbin, que admite que o preço deveria cobrir o custo marginal quando parte do capital for fixo e não tiver custo de oportunidade. Porém, como mencionamos acima, Durbin não aceita esse princípio por razões práticas. Lerner irá então (pág. 258-9) criticar as razões práticas apontadas. Entre elas, afirma que o problema de subsidiar indústrias deficitárias sob a regra do custo marginal é um problema de transição, não de alocação correta de recursos. Dever-se-ia então buscar uma transição rápida para o socialismo para evitar o problema. Quanto à dificuldade de separar custos variáveis (prime costs) da manutenção do capital, Lerner afirma que se um décimo da malha ferroviária tivesse que ser substituída todo ano, este seria um custo variável de produção 
e não de manutenção. Se tal custo não é coberto pelo preço, a ferrovia deveria ser abandonada.

A crítica de Lerner foi objeto de uma resposta por parte de Durbin (1937). Enquanto a crítica à escolha da planta adequada do diagrama é aceita, a crítica à regra de maximizar lucros no curto prazo não. Durbin afirma que Lerner não só teria distorcido o seu argumento, mas também não teria sido capaz de responder as questões práticas levantadas por ele.

Quanto à distorção de suas idéias, Durbin protesta contra a surpreendente afirmação de Lerner de que o primeiro autor não foi capaz de distinguir entre teoria descritiva e sugestão de uma técnica de administração derivada dessa teoria, já que o ponto do trabalho é justamente encontrar um procedimento prático a ser seguido a partir da teoria.

Quanto às questões práticas, afirma Durbin, Lerner teria preferido ajustar a realidade às suas categorias a lidar com os problemas concretos ${ }^{31}$. Ao admitir que a dificuldade de financiar os prejuízos das firmas estatais operando segundo a regra do custo marginal requer transição rápida para o socialismo, Lerner admite que suas regras são inaplicáveis e os fatos deveriam então se adaptar à teoria.

A utilidade da regra de maximização de lucros quando a demanda cai, esclarece Durbin, é derivada da importância de se manter a independência financeira das unidades produtivas:

I may be mistaken, or I may be unduly influenced by the ideas and practices of a capitalist society, but it seems improbable to me that mere cost figures - representing no actual funds - will be taken very seriously. It seems unlikely that particular interest will be taken in receipts and costs if industries can make "loses" and finance them for long periods by drawing on the "profits" of other concerns. Financial independence is surely and invaluable incentive to, and the comparison between costs an invaluable measure of, managerial efficiency. (Durbin, 1937:581)

A partir disso Durbin conclui que quando a demanda é atendida por uma única firma ou quando os custos se alteram com o volume produzido, haveria um conflito entre o realizável na prática e o desejável teoricamente.

A fim de defender exceções à regra do custo marginal, Durbin é relutantemente levado pelas preocupações práticas a fazer uso de um argumento sobre incentivos, assunto excluído das discussões por todos os socialistas de mercado do período. Desse modo, depois de defender a independência financeira das firmas, Durbin (1937:581) interrompe a discussão notando que o argumento "levaria a um mundo de pura

\footnotetext{
${ }^{31}$ Por isso Durbin (1937:581) rotula Lerner de armchair extremist.
} 
psicologia - de ciência profética - um paraíso inatingível para o mero teórico da Economia".

As razões para o suposto desvio da regra do custo marginal são criticadas por Lerner (1938) na sua réplica à resposta de Durbin. Além de retomar a discussão sobre o financiamento de firmas deficitárias e sobre a possibilidade de distinguir o custo marginal da manutenção do capital, Lerner atacará a preocupação de Durbin com a independência financeira.

Em primeiro lugar, a eficiência administrativa poderia ser feita por comparação de custos de firmas diferentes produzindo o mesmo bem ${ }^{32}$. Em segundo lugar, o argumento trazido pela incursão psicológica de Durbin só seria relevante no capitalismo e no comunismo russo, pois a renda do capitalista e do stakhanovista $^{33}$ depende do seu desempenho. No socialismo, no qual os valores monetários são apenas expedientes contábeis, essa "estranha dificuldade psicológica desapareceria”. Entretanto, Lerner não discute como seriam então os incentivos que substituiriam os ganhos materiais. $\mathrm{O}$ argumento de Lerner torna ainda menos claro que tipo de socialismo o autor tem em mente, já que tanto no modelo de Lange quanto no de Durbin o trabalho é de fato atraído para os salários mais altos e portanto não são meramente contábeis.

De qualquer modo, embora discuta ele mesmo incentivos no capitalismo e na Rússia, quando menciona capitalistas e stakanovistas, Lerner condena a discussão dessas mesmas questões no socialismo, como esboçara fazer Durbin:

To agree that managers will not manage prudently unless they manage with their own money is to agree with von Mises that socialism is impossible. (Lerner, 1928:75)

Lerner conclui sua réplica observando que mesmo que a regra do custo médio seja mais fácil de seguir do que a do custo marginal, não segue que deva ser implementada, pois só a segunda garante alocação ótima de recursos. O argumento de Durbin seria análogo à piada do menino que respondeu em um exame: "não sei quais foram os efeitos sociais da Revolução Francesa, mas os seguintes foram os reis da Inglaterra...”

\footnotetext{
${ }^{32}$ Lerner não mostra, porém, por que várias firmas de um setor, operando sem a pressão para evitar prejuízos, não apresentariam todas elas custos acima do que se espera em um ambiente competitivo real, o que se relaciona com o conceito de ineficiência-X.

33 Stakhanovistas eram indivíduos entusiastas que ultrapassavam as quotas de produção impostas como metas na Rússia.
} 
Embora tenha sido um dos principais críticos dos trabalhos de Lange e Durbin, Lerner chamará para si a tarefa de defender o socialismo de mercado quando este sofreu um ataque externo, de Maurice Dobb, que criticou o artigo de Dickinson sob um ponto de vista marxista. Concluiremos essa fase do debate com o estudo da controvérsia entre Lerner e Dobb. Por ser uma crítica externa, a controvérsia entre os dois autores permite salientar algumas diferenças e semelhanças entre os três programas de pesquisa envolvidos no debate ${ }^{34}$.

A crítica de Dobb (1933) ao socialismo de mercado, dirigido contra o trabalho de Dickinson, protesta contra a tentativa deste último de combinar o socialismo com um sistema de preços. Tal tentativa seria derivada da crença de que o problema econômico a ser resolvido tanto no capitalismo quanto no socialismo seria o mesmo, crença essa compartilhada com Mises e Brutzkus. Essa crença, afirma Dobb, refletiria a desconsideração dos economistas pela importância das instituições:

To the economist the rise and fall of institutions are a secondary affair. A change of property-rights and of class relationships may profoundly concern the social psychologist or the creator of ethical systems, but they will alter the form of "the economic problem" hardly at all. (Dobb, 1933:588)

Enquanto para Mises as diferenças institucionais impedem a solução do problema no socialismo, e para os socialistas de mercado as instituições são irrelevantes no que diz respeito à existência de uma solução, para Dobb considerações institucionais levam à negação do problema em si, o que leva à rejeição das 'categorias da teoria econômica' e sua aplicabilidade ao socialismo.

O artigo de Dobb é composto, porém, não da discussão sobre como a existência de um outro conjunto de instituições afeta o problema da escolha sob escassez ${ }^{35}$, mas sim de uma lista de objeções ao núcleo da teoria do valor neoclássica, na tentativa de invalidar a aplicação desta teoria à análise do socialismo.

Em primeiro lugar Dobb critica as bases normativas da teoria neoclássica, se estas existirem, e também a ausência dessas bases normativas, se estas não existirem. Inicialmente Dobb lembra a pretensa base hedonista da teoria do valor. Em seguida, mostra como, com o trabalho metodológico de Robbins (1932), a teoria pretendeu se distanciar de qualquer pressuposto normativo, consistindo apenas de uma relação formal entre meios e fins, quaisquer que sejam estes. Neste caso, a teoria do valor seria uma

\footnotetext{
${ }^{34}$ Ver na conclusão do último capítulo o diagrama que sumariza, no que diz respeito ao debate, as diferenças e semelhanças entre marxistas, austríacos e neoclássicos.
} 
teoria puramente definidora de equilíbrios, e não haveria como julgar a desejabilidade de qualquer um dos equilíbrios possíveis nem tampouco se esses são mais ou menos econômicos (Dobb, 1933:590). Ao recusar a se posicionar em relação a fins, o máximo definido pelo equilíbrio seria destituído de sentido. No entanto, a fim de poder realizar comparações na prática, o economista apela secretamente a um pressuposto valorativo, o que o leva novamente à postura hedonista que pretendia evitar:

The crucial assumption is as simple as it is questionable: it amounts to the sacredness of consumers' preferences. (Dobb, 1933:591)

Dobb ataca então a importância de se almejar o atendimento das necessidades do consumidor e a capacidade dos mercados de fazê-lo. Tanto a 'democracia econômica' quanto a 'democracia parlamentar' - caras ao socialismo de mercado - seriam fruto da herança burguesa do séc. XIX. A primeira seria, no entanto, viciada pela publicidade e a segunda, pelos magnatas da imprensa. A primeira, além disso, é sujeita a voto múltiplo, dada a inequalidade de renda.

A tentativa de Dickinson de replicar o mecanismo de mercado no socialismo, adicionalmente, enfrentaria um dilema, semelhante ao que já apontamos anteriormente: não se pode abolir o voto múltiplo sem absoluta igualdade de renda, e se esta for levada adiante, as avaliações de mercado no que se refere a custos perdem o sentido, já que diversos tipos de trabalho devem ter custos (salários) diferentes. Como consumidores são também produtores, ou as necessidades ou os custos serão expressas nos preços. "Mr. Dickinson cannot have it both ways" (Dobb, 1933:592).

Além disso, já que a escolha do consumidor é tão maleável pela publicidade no capitalismo, por que seria então sábia no socialismo, de forma a merecer ser atendida por um mecanismo como o de mercado? Se não for sábia, por que então atendê-la?

O cálculo econômico no socialismo, contudo, requereria tanto a expressão de uma escala de valores quanto de custos, além de uma contabilidade central ${ }^{36}$. Esse cálculo, contudo, não precisa ser baseado nas escalas de valores expressas nos mercados, pois este método seria inferior a outras escalas possíveis. Embora não detalhe uma

\footnotetext{
${ }^{35}$ Dobb repete no último parágrafo do artigo a noção marxista de que as leis econômicas do socialismo não podem ser discutidas antes do seu advento.

${ }^{36}$ Dobb (pág. 594) admite indiretamente, portanto, que afinal o problema econômico não se alterou no socialismo.
} 
alternativa, Dobb acredita que a alocação direta de recursos como educação, parques, pesquisa e outros bens não precisa ser feita com base em cálculos muito complexos ${ }^{37}$.

Dobb conclui seu artigo mostrando como princípios derivados da teoria de equilíbrio, como igualar rendimentos na margem, não têm aplicação direta no socialismo. Dobb (1933:596) critica brevemente a aplicação de tais princípios na análise de investimentos no mundo real, que por definição envolve mudanças tanto nos custos quanto nas demandas:

To apply dogmatically the postulates of a static equilibrium to such a continually moving situation would seem a particularly barren feat of abstraction. (Dobb, 1933:596)

Esse tipo de crítica, como veremos no próximo capítulo, será retomado na resposta austríaca aos modelos de socialismo de mercado.

Outro desvio das normas da teoria de equilíbrio seria ilustrado por um exemplo sugerido a Dobb por Sraffa, no qual seria adequada a aplicação de várias taxas de juros diferentes a projetos diferentes, o que viola o princípio marginalista. Para Dobb, o acúmulo de capital levaria a uma redução da taxa de juros no futuro, redução essa que não seria levada em conta pelos empresários. Assim, na medida em que os dirigentes de uma economia planificada possam prever esses acontecimentos, seria adequado em certas indústrias aplicar taxas de desconto inferiores, a fim de que se construam agora plantas viáveis só em dez ou vinte anos. Teríamos assim uma menor obsolescência e uma vida útil maior para as plantas. Seria como uma pessoa que em 5 anos ficará rica e poderá construir um palácio. Como não sabe o futuro, ela construirá uma casa agora, que se tornará inútil mais tarde. Se pudesse prever o futuro, valeria a pena morar em uma choupana e usar o dinheiro da casa para construir as fundações do palácio agora.

A diferença entre o capitalismo e o socialismo seria ainda ilustrada por outro exemplo: um cão persegue seu dono, que anda de bicicleta em uma rota perpendicular à posição do animal. Se guiado por reflexo, o cão irá sempre correr em direção à posição corrente do dono, descrevendo uma curva, ao passo que, se pudesse calcular, percorreria uma linha reta até a posição final do dono.

\footnotetext{
${ }^{37}$ Aparece assim a crença, que vimos no segundo capítulo, de que a alocação de recursos não seria problemática, crença esta que levou Mises a mostrar justamente como a complexidade do problema alocativo exige cálculo monetário. Ver também a crítica no início do capítulo ao trabalho de $\mathrm{O}$. Neurath.
} 
Lerner (1934-5a) tomou para si a tarefa de defender Dickinson contra os argumentos de Dobb. Embora apresente uma série de defeitos (Lerner lista vários deles), a tentativa de Dickinson de adaptar o mercado ao socialismo é defendida com vigor. A principal crítica de Dobb - de que o máximo defendido pelos 'economistas de equilíbrio' implica em juízo de valor em favor das opiniões maleáveis dos consumidores - é contestada de vários modos.

Em primeiro lugar, Lerner esclarece que o máximo se refere a melhoras paretianas, o que não implica julgamentos de valor sobre fins alternativos. Em segundo lugar, o artigo de Dobb implica em uma visão paternalista e autoritária, visto que a alternativa à democracia do mercado, com todos os seus defeitos, é o prevalecimento da opinião de uma elite governante (ou quiçá a do próprio Dobb, ironiza Lerner). Finalmente, mesmo que o ordenamento de preferências do governo prevalecesse, isto não mudaria em nada a natureza do problema. As categorias da ciência econômica e os mercados ainda assim seriam necessários para a alocação dos recursos segundo esse ordenamento:

\footnotetext{
Whether it is the consumer himself or whether it is somebody else who decides what is good for him, the same problem remains. All that happens is that the place of the consumer is taken by the other person or body who does the choosing for him. In the formal analysis this person or body now is the consumer. Without the pricing system that Mr. Dickinson, and once Mr. Dobb, were seeking to develop it is impossible for an economic system of any complexity to function with any reasonable degree of efficiency. All Mr. Dobb's arguments and illustrations to the contrary are erroneous or irrelevant. (Lerner, 1934-5a:55)
}

Quanto à crítica sugerida por Sraffa, Lerner aponta que o princípio marginal não teria sido invalidado em absoluto: ou a choupana é menos confortável do que a casa, e neste caso estaríamos diante de poupanças diferentes ou, se forem igualmente confortáveis, a diferença é apenas de poder de previsão. Se os mercados competitivos apresentassem o mesmo grau de previsão do que o socialismo, as taxas de juros para empréstimos de longo prazo diminuiriam e a casa não seria construída. Nota-se aqui que Lerner, como os demais socialistas de mercado, compartilha a crença marxista de que a eliminação do caos da produção resultaria em transparência e portanto no maior conhecimento sobre a realidade do mercado (as paredes de vidro de Dickinson). Lerner não critica assim o pressuposto de onisciência, inclusive dos eventos futuros, implicado no argumento. Desse modo, a tarefa de elaborar a crítica mais evidente aos exemplos da casa e da rota do cachorro caberá a Hayek, como veremos no próximo capítulo.

A resposta de Lerner, embora contenha argumentos teóricos significativos, representa um ponto baixo do debate em termos de ética acadêmica. Além das críticas às idéias, Lerner especula também sobre as motivações de Dobb por trás da rejeição do sistema de 
preços. Dobb seria um daqueles intelectuais que depositam toda a esperança de salvação da humanidade no governo soviético, que em sua administração burocrática despreza as massas em favor da tutelagem esclarecida da burocracia. Ao criticar o sistema de preços, Dobb esposaria idéias autoritárias. As idéias de Mises deveriam então ser tratadas pela OGPU, não pelo Gosplan. Quanto às idéias deste último autor, Lerner as distorce afirmando que Mises considera o mecanismo de preços perfeito ${ }^{38}$. Depois de classificar as posições de Mises e Dobb como dogmáticas, Lerner conclui ele mesmo com uma frase de cunho dogmático:

Authoritarianism objects to any pricing. Intransigent Liberalism objects to any amendments to the Liberal machine. But why need we take any notice of both? (Lerner,1934-5a:55-6, ênfase adicionada)

O ponto a que Lerner não acha necessário prestar atenção é a tese, esposada implicitamente tanto por Mises quanto por Dobb, de que não se pode satisfatoriamente replicar apenas alguns aspectos do funcionamento dos mercados. Lerner, por outro lado, crê que o mercado pode ser adaptado no socialismo, importando-se apenas alguns de seus aspectos, ou equivalentemente, como vimos, que os aspectos essenciais do funcionamento dos mercados são independentes das instituições.

Na resposta, Dobb (1934-5) se recusa a comentar a interpretação de suas intenções. Por outro lado, ao responder as críticas aos seus argumentos, Dobb deixa um pouco mais clara a natureza de suas objeções.

Dobb inicialmente critica o formalismo da postura de Lerner. Para Dobb (1934-5, 144146), as leis econômicas do capitalismo e do socialismo são diversas não no sentido formal, algébrico, mas sim no que se refere as diferenças do mundo real. No argumento de Lerner, não fica clara para Dobb a distinção entre o plano formal e o plano real, no qual instituições concretas estão presentes e métodos concretos de resolver os problemas teóricos são defendidos ou criticados. Embora Lerner argumente sempre no plano formal, ele deriva (ilegitimamente, na opinião de Dobb) conclusões sobre o segundo plano. Aparece aqui novamente a distinção entre teoria e prática tão presente no socialismo de mercado.

\footnotetext{
${ }^{38}$ Como pudemos observar ao longo deste trabalho, nenhum economista que expôs o problema do cálculo defendeu essa opinião. Entre os problemas com o sistema de preços, foram apontados a falta de mercadoso completos (Mises, Weber), o problema com a oferta de bens públicos (Pierson), a ineficiência dos monopólios e oligopólios (Weber), as dificuldades de separar o produto marginal de cada fator em um processo produtivo (Weber), a presença de crises macroeconômicas (Brutzkus) e as alterações no valor da moeda (Mises). Apesar disso, a opinião de Lerner é corrente na literatura primária e secundária.
} 
$\mathrm{Na}$ nossa interpretação, para Dobb a defesa da adoção de mercados no socialismo implicaria em defender a existência de todos os aspectos dos mercados reais, com suas instituições existentes, já que não se podem separar os dois planos.

Nos demais esclarecimentos Dobb critica a democracia do mercado defendida por Dickinson e Lerner, deixando claras mais uma vez algumas diferenças entre os programas de pesquisa envolvidos. Em primeiro lugar Dobb reafirma, de forma mais explícita, sua crença na relativa simplicidade da tarefa alocativa:

Mr. Lerner's view of the situation seems to be at the same time too simple and too complex. Too complex because I believe he overestimates the complexity of satisfactorily arriving at what people need by processes of judgment and inference, apart from the directives of a pricing system, in the case of a very large range of commodities - a range within which I should include nearly all basic necessities and probably the majority of the simpler comforts of life. (Dobb, 1934:147)

Em segundo lugar, atender a demanda dos consumidores não pode ser identificado com democracia. A visão de Lerner seria muito simples porque existem formas alternativas além do autoritarismo ou a 'democracia do mercado'. A prescrição de uma receita médica seria democrática ou autoritária? Métodos alternativos, além disso, poderiam ser utilizados para acessar a demanda, como cooperativas de consumidores ou questionários.

A preocupação com 'dar aos consumidores o que eles querem', além da ambigüidade sobre o que isto significaria, faria parte da 'perniciosa influência da economia subjetiva' (pág. 149). As leis da economia socialista, sejam lá quais forem, deverão lembrar as leis da escola clássica, com relações objetivas entre eventos que determinam ações individuais. $\mathrm{O}$ plano consciente adotado pela comunidade socialista deveria se adaptar a essas leis.

Na réplica final, Lerner (1934-35b), diante da afirmação de Dobb de que a adequação entre meios e fins seria simples, repete a idéia misesiana de que o uso de cálculo econômico através de mercados é necessário diante da complexidade da tarefa, já que existirão "milhares de produtos e milhares de fatores, sendo combinados em milhares de maneiras diferentes em milhões de unidades produtivas diferentes, nas quais as realocações de fatores podem ser do tipo mais complicado' (Lerner, 1934-5b:153). Nesse cenário, não existiriam técnicos capazes de dominar todos esses elementos complexos, de forma que se possa alocar os recursos sem o auxílio dos preços de mercado. 
As propostas de socialismo de mercado, que surgiram primeiramente na década de vinte em alemão e depois desenvolvidas em inglês na década de trinta, tinham como objetivo refutar o argumento de Mises de que a racionalidade na produção requereria propriedade privada dos meios de produção. Os seus proponentes, contudo, admitiram a impossibilidade do cálculo econômico na ausência de um sistema de preços, na medida em que, como economistas neoclássicos, compartilhavam do problema fundamental desse programa de pesquisa, que relaciona a atividade econômica com as escolhas diante da escassez e que tais escolhas seriam por demais complexas em uma economia desenvolvida.

As respostas ao argumento da impossibilidade do cálculo econômico, dessa maneira, empregaram como ferramenta a própria teoria neoclássica que embasou o ataque inicial. Buscaram-se, então, os elementos da teoria dos preços, até então utilizados para descrever como nos mercados se resolve o problema da escolha, que pudessem ser utilizados na tarefa de construir racionalmente um sistema econômico dirigido pelo estado, sistema esse que não dependesse da existência da propriedade privada.

Independente do sucesso dessa estratégia, a tentativa de 'transplantar' o sistema de preços para um novo ambiente institucional em que ele possa ser controlado suscita as interessantes questões metodológicas e teóricas que colocamos no primeiro capítulo, em especial aquelas relacionadas à complexidade do problema econômico e à assimetria entre explicação e controle.

Essas questões estarão presentes na estratégia adotada pelos críticos do socialismo de mercado em suas tentativas de refutar as respostas ao argumento da impossibilidade, como veremos no capítulo seguinte. 


\section{A Crítica Austríaca}

A importância do problema colocado por Mises foi reconhecida pelos socialistas de mercado: o socialismo precisa de um método para alocar os recursos da sociedade segundo as preferências dos agentes. $\mathrm{O}$ argumento da impossibilidade do cálculo, por sua vez, foi contestado através da sugestão de um sistema de preços artificial (Dickinson e Lange) ou mesmo real, fruto da competição entre monopólios estatais (Durbin). Nos dois casos, o transplante do sistema de preços das economias de mercado para o socialismo foi requerido com a finalidade de se encontrar uma alocação de recursos de equilíbrio que apresente as propriedades de optimalidade descritas pela teoria neoclássica. Apenas os elementos descritivos dos mercados reais considerados essenciais por tal teoria foram replicados no transplante, filtrando-se os demais aspectos não contemplados pela descrição teórica do equilíbrio competitivo.

Dessa maneira, como nota Lavoie (1985) ou De Soto (1992), e fica claro pela leitura do capítulo anterior, o debate, que no desafio original de Mises tratava da alocação de recursos em condições de contínua mudança, na mão dos socialistas de mercado sofreu um desvio para a discussão da possibilidade de implementar na prática algo equivalente a uma economia em equilíbrio estático.

A tentativa de responder ao argumento do cálculo via socialismo de mercado determinou então as estratégias seguidas pelos dois lados da controvérsia. No processo de filtragem dos aspectos do mercado a serem preservados, os socialistas de mercado buscaram limitar o campo de problemas econômicos que devam ser tratados na discussão, estratégia esta perfeitamente ilustrada pela relegação feita por Lerner dos demais problemas aos campos da psicologia ou sociologia. Por outro lado, os críticos irão salientar elementos dos mercados que consideram essenciais para o funcionamento do sistema de preços e que no entanto não estejam contemplados no modelo teórico de equilíbrio utilizado pelos socialistas de mercado. Para estes, se tais elementos não forem duplicados no socialismo, o 'transplante' pretendido fracassará.

As reações de Mises, Robbins, Hayek e outros autores às propostas de socialismo de mercado, como veremos neste capítulo, explorarão justamente esses elementos ignorados pela teoria de equilíbrio. Em especial, a descrição de um estado de equilíbrio ignora o processo em que consiste a atividade competitiva dos agentes fora do 
equilíbrio, antes que este seja alcançado. Ao explicar um aspecto do funcionamento dos mercados, a saber, como as oportunidades de ganho na alocação de recursos seriam esgotadas, a teoria legitimamente abstrai do processo competitivo do qual o equilíbrio é conseqüência. Ao tentar replicar artificialmente os mercados, contudo, tal abstração se tornaria ilegítima, já que os outros elementos ausentes no modelo, como as considerações sobrea a atividade competitiva fora do equilíbrio, seriam imprescindíveis para o funcionamento desses mercados. As contribuições ao debate dos autores austríacos podem ser vistas como aspectos diferentes da mesma estratégia, que explora as assimetrias entre explicação e previsão/controle na teoria econômica ignoradas nas propostas dos socialistas de mercado.

Além da importância para a própria questão discutida - a economia do socialismo - a resposta austríaca ao socialismo de mercado será interessante em termos teóricos na medida em que, ao explorar as referidas assimetrias, Mises e Hayek levantam problemas que ampliam o entendimento teórico sobre o funcionamento dos mercados, problemas estes que fazem parte do núcleo do programa de pesquisa austríaco moderno ${ }^{1}$. De fato, como já mencionamos, o debate do cálculo marca o processo de diferenciação entre as tradições neoclássica e austríaca. Os temas levantados no debate tornarão explícitas as diferenças entre a compreensão do fenômeno econômico das duas escolas que eram apenas latentes quando contrastamos Wieser com Barone.

A resposta austríaca, entretanto, não irá expor claramente as diferenças de abordagem entre as duas tradições e em seguida contextualizar o problema do cálculo em termos dessas diferenças, visto que o processo de diferenciação estava justamente ocorrendo naquele período e em grande medida graças ao próprio desenrolar da controvérsia do cálculo. O que temos na resposta austríaca é um estranhamento do emprego neoclássico da noção de equilíbrio no contexto do debate, seguido de críticas a diferentes aspectos dos modelos desenvolvidos e seus pressupostos e apenas depois teremos, da parte de Hayek, uma exposição mais fundamental das diferenças teóricas aludidas. Será importante, então, situar no tempo ${ }^{2}$ cada uma das críticas, visto que estas ocorrem durante, depois e mesmo antes das contribuições vistas no capítulo anterior ${ }^{3}$, e por

\footnotetext{
${ }^{1}$ Uma definição do programa de pesquisa austríaco moderno e o seu contraste com o programa neoclássico pode ser encontrada em minha dissertação de mestrado. Ver Barbieri, 2001, capítulo 1.

${ }^{2}$ Ver linha do tempo do debate na conclusão do último capítulo.

3 Ao contrário do debate interno ali revisto, temos poucas trocas diretas entre defensores e críticos do socialismo de mercado, o que possibilitou que dividíssemos as suas contribuições em capítulos distintos.
} 
conseguinte cada uma delas enfatiza os modelos que eram publicados em cada data específica.

Para facilitar a análise, porém, a nossa exposição não seguirá a ordem cronológica, mas será dividida por autor. Em primeiro lugar visitaremos as reações de Mises ao uso do conceito de equilíbrio no socialismo de mercado. Na seqüência veremos as objeções de Robbins, que além de reafirmar as críticas de Mises, acrescenta algumas outras dúvidas sobre a viabilidade das propostas. Depois disso, discutiremos a participação de Hayek no debate e sua crítica ao uso do conceito de equilíbrio que resultou dessa crítica. Concluiremos o capítulo discutindo uma variante da crítica de Hayek utilizada por Thierlby e Wieseman para questionar a praticabilidade da adoção do critério do custo marginal defendida por Lerner.

\section{A Crítica de Mises}

Mises e Hayek podem ser considerados os maiores opositores do socialismo no século vinte. Escreveram extensamente sobre o tema ao longo de suas carreiras, criticando inúmeros aspectos da doutrina socialista. Porém, do grande volume de artigos e livros que lidam direta ou indiretamente com a questão, teremos que nos limitar aqueles mais diretamente ligados à controvérsia do cálculo. No que diz respeito a Mises, nos concentraremos em três trabalhos: uma seção sobre 'mercados artificiais' incluída em 1936 na primeira edição inglesa de Socialism; um artigo publicado em 1938, voltado ao significado da economia matemática para o debate do cálculo e um capítulo de sua obra mais importante, Ação Humana, publicada em inglês em 1949. Os três textos, embora escritos em datas distintas, refletem a mesma atitude em relação ao socialismo de mercado e serão por isso vistos em conjunto.

Em Ação Humana, Mises (1949:703) classifica as respostas ao seu desafio em seis categorias: 1 o cálculo natural; 2. o cálculo em horas de trabalho; 3 . O cálculo baseado em unidades de utilidade; 4. os quase-mercados (nos quais competem firmas estatais); 5. a solução matemática e 6. o método de tentativas e erros. Dispensando rapidamente as três primeiras, discutidas no debate em alemão, Mises se concentra nas três últimas, relevantes para o debate em inglês. Veremos agora como Mises lida com essas propostas. 
No artigo de 1938, reagindo a afirmação de Lange de que Robbins e Hayek teriam apresentado apenas objeções práticas à solução matemática, Mises enfatiza o caráter teórico de sua crítica, dirigida contra o que seria um uso ilegítimo do conceito de equilíbrio. Ao argumento 'prático’ que chamou a atenção de Lange, Mises (2000:27) apenas acrescenta que o número de equações a serem resolvidas na solução matemática seria muito maior do que o imaginado quando, por exemplo, se adicionam ao problema as questões de localização, já que os bens estão distribuídos espacialmente na economia. Entretanto, a crítica principal à solução matemática, presente tanto no livro de 1949 quanto no artigo de 1938, retoma a posição do autor sobre o papel do conceito de equilíbrio exposto anteriormente em Socialism. Nos dois textos, Mises (2000:29; 1949:701-2) assevera que a noção de equilíbrio ${ }^{4}$, concebida como um estado de coisas no qual toda mudança cessa e os agentes repetem continuamente as ações que maximizam a satisfação das necessidades, é apenas um instrumento teórico, necessário para o entendimento da mudança, e não uma realidade objetiva:

The state of equilibrium which our equations describe is a purely imaginary state of equilibrium. It is merely a hypothetical, though indispensable, tool of analysis which has no counterpart in reality. (Mises, 2000:29)

Embora necessária para o entendimento do funcionamento dos mercados, a noção de equilíbrio seria inútil como guia prático para a ação e para a obtenção na realidade desse estado imaginário. A justificativa dada por Mises a essa afirmação se relaciona ao problema da assimetria entre explicação e previsão que mencionamos há pouco e discutimos no primeiro capítulo. As explicações da Física, para Mises, são capazes de gerar previsões sobre o futuro porque é possível achar relações empíricas constantes entre variáveis quantitativas. Nas ciências humanas, por outro lado, não existiriam relações constantes entre variáveis. O uso da estatística seria relevante para a história econômica apenas. A substituição da 'economia qualitativa' pela 'economia quantitativa' teria gerado a ilusão de que se é capaz de, a partir de informações sobre o passado, gerar relações quantitativas válidas para o futuro que sirvam como guia para a ação.

A origem desse indeterminismo, da inconstância das relações, seria dada por considerações sobre o conhecimento dos agentes econômicos. Para que se possa usar a solução matemática para estabelecer um equilíbrio no futuro, a partir de uma situação de

\footnotetext{
${ }^{4}$ Mises emprega a expressão evenly rotating economy - ERE - para se referir a sua concepção de equilíbrio.
} 
desequilíbrio, as equações teriam que conter informações sobre a demanda futura dos agentes, o que evidentemente não pode ser feito ${ }^{5}$. Mesmo o conhecimento sobre as demandas presentes, afirma Mises, não está disponível - conhece-se no máximo um ponto, a interseção entre demanda e oferta, e não as curvas de demanda completas ${ }^{6}$.

O argumento é desenvolvido no capítulo 26 de Ação Humana. Para se atingir um equilíbrio na data $D_{n}$ a partir de uma data inicial $D_{0}$, seria necessário o conhecimento em $\mathrm{D}_{\mathrm{o}}$ da quantidade de recursos naturais, bens de capital e preferências prevalecentes em $D_{n}$, enquanto o que se dispõe são informações sobre tais variáveis apenas em $D_{0}$. Seria logicamente impossível assumir que os dados são os mesmos nas duas datas, mesmo que não ocorra nenhuma mudança externa nos dados relevantes para o equilíbrio final. Isto ocorre porque o próprio processo de obtenção do equilíbrio ao longo do tempo consiste em mudanças nos dados (a menos que se assuma que o equilíbrio sempre exista desde o início). As formas assumidas pelos bens de capital, herdadas do passado, são continuamente alteradas durante o caminho rumo ao equilíbrio, alterando a forma do problema alocativo a cada instante ${ }^{7,8}$. Note que a derivação lógica do autor revela a herança austríaca do mesmo: qualquer fenômeno de mercado é visto sempre em uma sucessão temporal.

Os agentes econômicos, continua Mises, não necessitariam então de informações sobre o estado final de equilíbrio, mas sim sobre o método mais apropriado de transformar em sucessivas etapas os bens de capital de $\mathrm{D}_{\mathrm{o}}$ até $\mathrm{D}_{\mathrm{n}}$, tarefa esta que não obteria auxílio algum das equações de equilíbrio da economia matemática.

Em contraste com a atenção exclusiva dos economistas à descrição das propriedades do estado de equilíbrio, Mises enfatiza o processo de transformação envolvido na atividade econômica. Podemos identificar nesse ponto a preocupação com o processo de mercado que marcará o programa de pesquisa austríaco:

Economic calculation, which is essential to the economic system, does not, however, require that we should know this hypothetical situation which can certainly never be reached in the actual economic system. What is necessary for the direction of the economy is only the knowledge of the next step

\footnotetext{
${ }^{5}$ Ver o prefácio de A Miséria do Historicismo de Popper, no qual este autor mostra que logicamente não se pode ter hoje o conhecimento futuro.

${ }^{6}$ A fim de avaliar essa afirmação a luz de técnicas de estimação modernas, não se deve confundir o problema de Mises, que estuda movimentos fora do equilíbrio com o exercício de estática comparativa entre equilíbrios pressuposto por tais técnicas.

${ }^{7}$ Utilizando um exemplo de Lachmann, prédios que foram desenhados como teatros viram cinema e mais tarde igrejas.

${ }^{8}$ Modelos de otimização dinâmica, nos quais a trajetória é estabelecida desde o início, não lidam com a passagem do tempo real, pois excluem a possibilidade de surgimento de novidades durante o trajeto.
} 
which is required to be taken in the economic system. It is necessary to find out which of all the conceivable changes can, in the given conditions, secure the fullest satisfaction of wants from the standpoint of the preferences of the consumer or of the dictator. For this purpose the equations which describe the final equilibrium position are quite inappropriate. They say absolutely nothing about the path witch the economic system has to follow in order finally to reach the equilibrium. (Mises, 2000:30)

Para Mises, o que guiaria as decisões individuais em cada etapa do processo de mercado, com o auxílio do sistema de preços, seria a atividade empresarial. Ao contrário da concepção estática do mercado adotada nas propostas de socialismo de mercado, Mises acredita que toda ação humana, já que voltada para o futuro, ocorre necessariamente em um ambiente de incerteza e portanto é inerentemente especulativa ${ }^{9}$. Os empresários tomam decisões em cada etapa do processo de mercado tendo como base suas avaliações (appraisements) e antecipações sobre as condições futuras (Mises, 1949:700). O problema com a solução matemática é que nessa concepção da atividade econômica, 'os preços dos bens de produção seriam determinados pela interseção de duas curvas, não pela ação humana' (pág. 702). Em vez de, como nos mercados reais, haver um processo de teste das antecipações especulativas sobre as condições futuras por parte do diretor da economia socialista, este último basearia suas ações na solução de equações que dependem do conhecimento de variáveis futuras (Mises, 2000:31).

A menção à atividade empresarial nos leva à próxima categoria de resposta ao desafio do cálculo, denominada por Mises de 'quase mercado'. Por quase mercado Mises se refere a tentativa de introdução da competição no socialismo. Mises critica esse tipo de solução tanto em Ação Humana quanto em uma seção adicionada a primeira edição inglesa de Socialism publicada em 1936. Essa seção (cap. 6, seção 4) faz referência a jovens socialistas que pretendem resolver o problema do cálculo pela implementação de 'mercados artificiais'. Mises se refere à tradição oral inglesa de socialismo de mercado, cujas principais propostas foram publicadas no mesmo ano de 1936. Nos dois livros, Mises tem em mente um modelo de socialismo próximo à concepção de Durbin, embora não mencione em Ação Humana o texto já disponível deste último autor.

Em relação a esse tipo de proposta, Mises (1949:706) primeiramente observa que a tentativa de preservar a competição representaria a rendição dos socialistas ao argumento do cálculo, já que o objetivo do socialismo antes deste era justamente a substituição da competição e da anarquia da produção pela organização consciente da produção. 
O modelo proposto, por seu turno, seria fruto de uma compreensão errônea sobre o funcionamento dos mercados. Aqueles que propõem a implementação de mercados artificiais acreditam que, mesmo com a abolição da propriedade privada, os administradores das empresas comunistas poderiam ser instruídos a atuar 'como se' fossem capitalistas, mas com o lucro sendo atribuído à sociedade como um todo. Acreditam adicionalmente que a separação entre os acionistas e a administração das empresas em economias de mercado seria prova da viabilidade dessas propostas, já que se os administradores podem trabalhar para os capitalistas, também o fariam para os dirigentes socialistas.

No artigo de 1920 Mises responde a esse argumento de passagem, afirmando que no longo prazo os administradores atuam no interesse dos proprietários. Em Socialism, por outro lado, o autor desenvolve a crítica em termos da necessidade da propriedade privada para a existência da atividade empresarial, em especial nos mercado de capitais. A formação dos preços de mercado dos bens de capital dependeria para o autor da 'incessante busca por parte de capitalistas e empresários de maximizar seus lucros por meio da satisfação dos desejos dos consumidores’ (Mises, 1981:119), busca essa que por sua vez dependeria da propriedade privada, ou poder de dispor dos bens de produção.

O funcionamento do mercado, dessa maneira, não pode ser entendido apenas como um conjunto de atos de vendas e compras ${ }^{10}$, mas como um processo posto em marcha pela atividade empresarial, que se manifesta também nos mercados financeiros:

It follows that it is a fundamental deficiency of all these socialistic constructions which invoke the 'artificial market' and artificial competition as a way out of the problem of economic calculation, that they rest on the belief that the market for factors of production is affected only by producers buying and selling commodities. It is not possible to eliminate from such markets the influence of the supply of capital from the capitalist and the demand for capital by the entrepreneurs, without destroying the mechanism itself. (Mises 1981:121)

No parágrafo seguinte a esse, Mises afirma que o problema do cálculo não está relacionado apenas às questões rotineiras de administração de firmas, mas sim com a atividade dos empresários e capitalistas, que consiste em decidir, sob condições de incerteza, quais são os melhores empregos do capital, criando, expandindo, contraindo ou fechando firmas. Também em Ação Humana Mises (pág.707) chama a atenção para o papel dos mercados de capital na alocação de recursos. A direção da produção de

\footnotetext{
${ }^{9}$ Para o autor, ação implica em incerteza, pois não há sentido em agir para mudar algo cujo estado futuro já esteja determinado.

${ }^{10}$ Lembre-se de que esta era a posição explicitamente defendida por Cassel.
} 
forma econômica seria fundamentalmente determinada pela atividade empresarial, especulativa por natureza, e que consiste em compras ou vendas de títulos, ações e outras operações de crédito, além das decisões de abrir, fechar ou alterar o tamanho de firmas.

Para Mises(1949:708), essas transações são a essência dos mercados. Se a atividade especulativa dos empresários for eliminada nos mercados artificiais, o fragmento que sobra não funciona como mercado. Não seria possível então agir 'como se' a competição existisse. Não se pode 'brincar' (to play) de especulação e investimento, pois especuladores e investidores reais expõem a sua 'riqueza e fortuna' em suas escolhas. Sem propriedade privada, os agentes seriam meramente administradores, não empresários.

Para o autor, o problema do cálculo seria um problema de economias reais, sujeitas a contínua mudança - que requerem a atividade empresarial - e não um problema referente a um 'sistema econômico estacionário'. A preocupação exclusiva com o equilíbrio, por sua vez, explicaria para Mises (1981:122) a ênfase dos economistas na atividade meramente administrativa, em detrimento da atividade empresarial. Desse modo, a crítica feita anteriormente à concepção da economia de Lenin é repetida contra os economistas neoclássicos centrados exclusivamente no estudo das propriedades de equilíbrio:

The cardinal fallacy implied in this and all kindred proposals is that they looks at the economic problem from the perspective of the subaltern clerk whose intellectual horizon does not extend beyond subordinate tasks. They consider the structure of industrial production and the allocation of capital to the various branches and productive aggregates as rigid, and do not take in account the necessity of altering this structure in order to adjust it to changes in conditions. (Mises, 1949:707)

A desconsideração da atividade empresarial em favor da concepção meramente administrativa, patente quando percorremos a literatura do socialismo de mercado, pode ser ilustrada por uma passagem específica citada no capítulo anterior, na qual Lerner (1938:75) afirma que "Concordar que os administradores não irão administrar prudentemente a menos que administrem com seu próprio dinheiro é concordar com Mises que o socialismo é impossível".

Por outro lado, as questões relacionadas à atividade empresarial, como a alocação de capital entre indústrias, não merecem muito espaço nos esquemas propostos pelos socialistas de mercado. A única observação que podemos encontrar a respeito da questão, tanto em Dickinson quanto em Lange, Durbin ou mesmo Lerner, é que a 
coordenação central das indústrias seria facilitada pela maior disponibilidade de informações sob as 'paredes de vidro' do socialismo, observação que efetivametne ignora a complexidade do problema.

Falta-nos comentar a sexta categoria de soluções, por tentativas e erros. Assim como fez com as demais propostas, Mises não cita autores e modelos nominalmente. Esperaríamos comentários a respeito de algum modelo de ajuste de preços análogo àquele primeiramente imaginado por Taylor e posteriormente desenvolvido por Lange. Entretanto, Mises não cita tais autores nem descreve que tipo de solução por tentativa e erros tem em mente em sua crítica. Em vez disso, apenas discute as condições necessárias para que um processo de tentativas e erros funcione, não analisando se tais condições estariam ausentes no modelo de tentativas e erros proposto pelos socialistas de mercado.

O método de tentativas e erros, para Mises (1949:704) só seria aplicável se a solução correta fosse identificável por meios independentes do próprio método, isto é, por um método independente de avaliação subjetiva. A multiplicação de dois números pode ser buscada por tentativas e erros, mas o único critério de avaliação do sucesso seria através das próprias regras da aritmética. Nos mercados, o mecanismo de lucros e perdas fornece um critério externo de seleção, independente da avaliação pessoal dos participantes do mercado.

O que necessitaria ser feito em seguida seria então discutir se o critério sugerido pelo modelo de Lange - a avaliação de excessos de demanda ou oferta de um bem - seria ou não um critério externo de seleção de alternativas adequado. Esta questão será analisada no último capítulo quando introduzirmos a distinção entre seleção natural e seleção artificial. Ali, esta crítica de Mises ocupará papel central na nossa própria avaliação do debate. 


\section{A Crítica de Robbins}

Lionel Robbins, chefe do departamento de economia da London School of Economics, foi bastante influenciado pela Escola Austríaca, em especial por Mises e Hayek. Seu conhecimento de alemão permitiu que se inteirasse da controvérsia do cálculo antes que Hayek publicasse em inglês sua coletânea sobre o debate em 1935. É deste ano a sua primeira crítica à solução matemática e à solução via competição entre monopólios estatais, crítica essa que aparece no capítulo 7 de seu The Great Depression, uma interpretação da crise de 1929 sob a ótica da teoria austríaca do ciclo. Dois anos mais tarde, Robbins retoma as críticas no capítulo 8 de Economic Planning and International Order.

Em ambos os capítulos, o objetivo principal de Robbins é expor o argumento do cálculo, e apenas subsidiariamente criticar as tentativas de resolvê-lo até então. Nas suas objeções a essas tentativas, Robbins repete as críticas que Mises faz em Socialism ao uso do conceito de equilíbrio e contesta, ao mesmo tempo que Hayek, a viabilidade de se implementar na prática um esquema como o desenvolvido por Dickinson. Esta última objeção, como vimos, foi levada em conta por Lange e Durbin, que procuraram contorná-la na elaboração de seus modelos de socialismo de mercado.

Ao expor a solução matemática, Robbins (1935:151;1937:201) distingue entre a resolução do problema do cálculo 'no papel' e 'na prática', distinção fundamental para a interpretação langeana do problema. Para Robbins, enquanto no primeiro caso seria concebível a solução de um conjunto de equações, considerações sobre o que seria necessário para fazê-lo mostram a sua impossibilidade prática:

It would necessitate the drawing up of millions of equations on the basis of millions of statistical tables based on many more millions of individual computations. By the time the equations were solved, the information on which they were based would have become obsolete and they would need to be calculated anew. (Robbins, 1935:151)

Não apenas a resolução das equações, mas também a obtenção das informações necessárias para isso inviabilizariam a solução matemática. Robbins (1937:201-3) argumenta que se podem formar opiniões errôneas sobre a questão quando o problema do cálculo é simplificado. Por exemplo, quando a quantidade de alternativas de combinação de insumos para a fabricação de um bem qualquer for enorme, como de fato ocorre em uma economia desenvolvida, não há um método simples de computar custos. Ou se levam em conta 'no papel' todas as alternativas - uma impossibilidade - 
ou se apela para a sua determinação no mercado. Essa crítica de Robbins repete exatamente aquela feita anteriormente por Pareto: a única forma de conhecer esses dados seria pela observação dos mercados reais.

Após apontar para as dificuldades práticas, Robbins também chama a atenção para aqueles elementos existentes nos mercados que ficaram fora da descrição teórica do equilíbrio. Como Mises, Robbins (1935:152-3) salienta o caráter empresarial da atividade competitiva. As atividades produtivas seriam feitas tendo em vista a comparação entre receitas e custos futuros esperados pelos empresários. Tais expectativas são por sua vez baseadas no conhecimento particular de cada empresário sobre os mercados envolvidos na produção de cada bem. Os preços dos bens de capital, em particular, apenas tendem a refletir o seu valor por serem fruto do processo da competição dos empresários pelo seu uso. Além de mercados para bens de consumo, seria então necessária a existência no socialismo de mercados genuínos para bens intermediários, em especial capital novo. A descentralização necessária para a existência desses mercados, entretanto, seria contrária à idéia de planejamento central.

O exposto acima leva Robbins a considerar a possibilidade de existirem mercados para bens de capital no socialismo, como nas propostas de Heimann e Durbin. Em primeiro lugar, Robbins (1937:206-7) imagina o esquema de monopólios setoriais maximizadores de lucros. Para Robbins, esse tipo de organização tenderia a preservar o status quo, pois privilegia a prosperidade de cada indústria em si e não a distribuição de recursos entre as diferentes indústrias. Além disso, as negociações entre os monopólios bilaterais resultam em preços indeterminados entre os preços de reserva de cada parte. Se houvesse fixação de preços, por outro lado, estes seriam fixados em níveis arbitrários e não competitivos.

Deve-se lembrar que para Durbin tal problema não surge, pois os preços seriam fixos tendo em vista as curvas de custos razoavelmente conhecidas, formadas a partir da aquisição de fatores primários para os quais haveria preços competitivos determinados. No entanto, podemos imaginar que para Robbins, que pensa mais em termos austríacos do que marshallianos, os custos não são dados e portanto a fixação de preços depende do poder de barganha de cada monopólio setorial em relações de troca verticais, já que um longo processo temporal de produção liga os fatores originais ao produto final.

Em seguida, Robbins (1935:153-4; 1937:208) abandona a hipótese dos monopólios e discute os 'mercados fictícios', nos quais haveria firmas menores competindo entre si 
em cada mercado. A reação de Robbins a essa proposta é análoga à de Mises. Da mesma forma que este, Robbins nota que tal proposta representa o abandono do planejamento central em favor do 'caos da produção' descentralizada. Critica também o caráter estático e simplista (Robbins, 1935:153) da concepção teórica que informa a sugestão de que os administradores socialistas devam simular a competição, ou 'brincar de competição' nos termos usados tanto por Robbins quanto por Mises. Essa simulação não seria possível na proposta de socialismo em questão, pois qualquer economia real está sujeita a mudanças contínuas nas preferências, nas tecnologias e na disponibilidade de capital e trabalho. Robbins reafirma aqui que sob tais condições não basta que os administradores socialistas compram e vendam nos mercados de fatores e produtos. A competição real requer que os empresários tenham liberdade de mudar o uso do capital conforme suas expectativas, o que não se supõe que ocorra no socialismo segundo seus proponentes.

Além de chamar a atenção para a atividade empresarial e os mercados de capital, Robbins acrescenta objeções relativas à natureza da conduta de funcionários do estado, em contraste com a atividade de empresários. Como não existe propriedade privada no socialismo, afirma Robbins (1937:209), o risco dos empreendimentos recai não sobre os funcionários do estado, mas sim sobre a população como um todo. Conseqüentemente, a administração desses empreendimentos deve ser necessariamente burocrática em sua natureza, visto que o funcionário público não pode ter poder arbitrário, mas deve responder ao controle político central. A sua administração deve então seguir normas formais de conduta e manter registros ${ }^{11}$.

O problema estaria portanto na própria natureza da atividade burocrática inerente à ausência de propriedade privada, e não na falta de capacidade ou dedicação de um servidor público, como querem alguns críticos da burocracia e como interpretam o argumento autores como Lerner. O problema dos incentivos, central em fase posterior do debate, é assim irrelevante para Robbins. O que importa é a capacidade de duplicar o comportamento empresarial. Quanto a isso, embora não seja inconcebível, o autor considera improvável que um funcionário público seja livre para mudar o ramo de uma firma ou fechar uma fábrica em uma localidade e abrir outra noutro lugar. Sem essa

\footnotetext{
11 Mises elabora as diferenças entre a administração burocrática e empresarial nas mesmas linhas que Robbins em Burocracy (Mises, 1993).
} 
liberdade, entretanto, a simulação da competição só seria reproduzida em um irreal mundo estático:

But if this is not so, then the competitive system is not re-created. For it is the essence of capitalist competition in a changing world that there should be a continual reinvestment of capital in new forms and combinations. ... Under static conditions, it is easy enough to conceive of a fictitious competition which might very well sustain an efficiency which might wane under complete centralization. But the main function of the price system is dynamic; and it is difficult to see how dynamic competition can be effectively re-created by any decentralization which stops short of institutions incompatible with central ownership. (Robbins, 1937:211)

Além do problema da administração burocrática, Robbins discute também a relação entre as decisões econômicas e políticas e como estas últimas impossibilitariam a criação de mercados competitivos no socialismo. Tomando como exemplo o comércio internacional, mesmo que o ideal sob o ponto de vista econômico seja simular o comércio livre, Robbins acredita que o mais provável seja que o estado abandone o livre comércio em favor do protecionismo (restricionismo, nos termos do autor). Preservar o valor de um investimento local protegendo-o da competição externa seria o modo mais provável de lidar com as pressões políticas dos produtores.

É interessante contrastar a opinião exposta acima com a posição de Lange e Lerner. Lembremos que Lange utilizou um exemplo semelhante- a tentativa não econômica de preservar o valor de um investimento (por meio de restrição à inovação) - como um defeito das economias de mercado a ser corrigido pela nacionalização da indústria. Vimos também que Lerner acredita que os interesses particulares desapareceriam no socialismo, pois neste a renda individual não dependeria do sucesso dos empreendimentos. O uso do mesmo argumento por Robbins e Lange para fins diametralmente opostos pode ser explicado por uma diferença entre as doutrinas marxista e liberal. Enquanto para a primeira os interesses de classe explicam a batalha por privilégios legais, e portanto o desaparecimento das classes eliminaria a pressão por privilégios, para a segunda é a existência de um estado interventor no sistema econômico que explica e gera a busca por privilégios. Em outros termos, para a primeira os interesses de classe geram a atividade de rent-seeking e para a segunda a possibilidade de se dedicar à atividade de rent-seeking dá origem a classes com interesses antagônicos. Sempre que o estado for além do estabelecimento de regras impessoais de conduta e regular a atividade econômica, surgirão 'classes' que lutam por privilégios legais ${ }^{12}$.

\footnotetext{
${ }^{12}$ Esse argumento é desenvolvido, por exemplo, em A Lei de Bastiat.
} 
Enquanto para Lerner e Lange o socialismo acabaria com o rent-seeking, para Robbins a sua adoção significaria a própria substituição da competição econômica pela competição política:

The ideal socialist policy would be equivalent to free trade adjustment. The actual policy would be equivalent to something worse than high protectionism. (Robbins, 1935:158)

A contribuição de Robbins ao debate refina assim a posição de Mises, chamando a atenção para a existência de competição genuína, inclusive nos mercados de capital e acrescenta observações semelhantes às da escola de escolha pública, observações essas que serão retomadas em estágios posteriores do debate.

\section{A Crítica de Hayek}

Enquanto Mises fora o principal crítico da economia do socialismo na fase alemã do debate, Hayek assume esse papel na fase inglesa do mesmo. Pela iniciativa de Robbins, Hayek migra para a Inglaterra e assume um posto na London School of Economics, depois de lá expor uma série de palestras sobre sua teoria dos ciclos econômicos. Nesse país, nota que o debate sobre o cálculo não tivera impacto. Edita então em 1935 o livro Colectivist Economic Planning, que contém a tradução para o inglês dos trabalhos de Pierson, Mises, Halm e Barone, além dos capítulos inicial e final escritos pelo próprio Hayek.

No primeiro capítulo do livro em questão, Hayek introduz o problema e escreve a primeira história do debate do cálculo. No último, critica tanto a solução matemática, que era a proposta mais importante que surgira até o momento, quanto a idéia da reintrodução da competição no socialismo, cujas propostas concretas não haviam ainda sido publicadas. Cinco anos mais tarde, publica um artigo no qual examina a solução por tentativas e erros contida no artigo de Lange e adotada por Dickinson em The Economics of Socialism.

Estes trabalhos constituem a crítica direta de Hayek ao socialismo de mercado. Embora tenha assumido para si a liderança do ataque ao socialismo no debate em inglês, a crítica de Hayek é inicialmente a menos clara em relação à exposição das diferenças analíticas entre a abordagem austríaca e neoclássica em comparação com as críticas de Mises e Robbins. Estes deixaram bem clara a diferença entre competição no modelo estático e no mundo real, esta última exigindo atividade empresarial especulativa e mercados de 
capital. Hayek, embora baseando suas críticas na mesma tradição austríaca, faz poucas referências diretas às diferenças de abordagem, sendo menos claro sobre os fundamentos de suas objeções. Tal estratégia resultou na interpretação de que sua contribuição ao debate consistiu em objeções meramente práticas à viabilidade do socialismo de mercado.

Kirzner (1992) acredita que isso ocorreu porque o processo de conscientização por parte dos economistas austríacos de que trabalhavam em um programa de pesquisa próprio, distinto do neoclássico, ocorreu justamente a partir do debate do cálculo. Assim, a crítica inicial de Hayek soou como uma crítica interna ao programa neoclássico. Alternativamente, Hayek poderia ter considerado que uma crítica interna seria mais efetiva.

A crítica aos pressupostos teóricos adotados pelo socialismo de mercado, contudo, aparecerá em uma série de artigos que Hayek escreveu a partir de 1937, nos quais o autor discute o significado dos conceitos de equilíbrio e competição. Esses artigos estão entre as mais importantes contribuições do autor à teoria econômica, sendo fundamentais para o desenvolvimento da abordagem austríaca moderna. Embora claramente relacionados ao debate, tais artigos não fazem referências diretas ao mesmo ${ }^{13}$. Esses artigos constituem o que chamaremos de resposta indireta de Hayek ao socialismo de mercado. Concentrar-nos-emos agora no que denominamos resposta direta para em seguida estudar a resposta indireta.

\section{A Crítica Direta}

Escrevendo em 1935, Hayek dá atenção especial no capítulo final do Collectivist Economic Planning à solução matemática, já que esta era a principal proposta publicada em inglês até então. Tal solução, nota Hayek (1935b:207), procura mostrar que sob o pressuposto de total conhecimento dos dados, as equações que descrevem o equilíbrio dos mercados podem ser usadas para se determinar as quantidades de bens que devem ser produzidas. Como Robbins, Hayek afirma que tal solução não é logicamente impossível no sentido de ser contraditória. Entretanto, disso não segue que o método

\footnotetext{
${ }^{13}$ Ao criticar o modelo de Lange, Hayek (1940) faz uma única referência explícita a um desses artigos, o de 1937.
} 
proposto seja de fato uma solução ao problema do cálculo. A falsa inferência da possibilidade do cálculo a partir do argumento de similitude formal mostraria, para Hayek, a incompreensão da natureza do problema. Porém, em vez de discutir, como fizeram Mises e Robbins, o que considera a verdadeira natureza do problema, ou seja, mostrar em que sentido a teoria neoclássica não seria capaz de explicar as ações dos agentes fora do equilíbrio em um ambiente sujeito a contínua mudança, Hayek passa abruptamente a listar algumas dificuldades de implementação da solução proposta. Embora essas dificuldades reflitam a opinião austríaca do autor sobre o que consiste a natureza do problema, foram interpretadas por Lange como meras dificuldades práticas de implementação de uma solução teoricamente correta.

Hayek procura mostrar a inviabilidade da solução através da discussão sobre a quantidade de informações que seria necessário coletar e processar para que se resolvesse o problema alocativo. A estratégia do autor é então apontar para a complexidade dessa tarefa; para o número enorme de aspectos que deveriam ser levados em conta na solução. A adoção de um sistema de equações tratáveis computacionalmente, mas que ignorasse tais aspectos, resultaria em uma solução inferior àquela obtida pela competição real na medida em que esta última inclua esses aspectos.

Para que a solução matemática seja válida, entretanto, os dados e cálculos não precisam ser exatos, mas sim gerar um estado de coisas pelo menos comparável à competição real. Assim, desde o início, Hayek se preocupa com o desempenho comparativo de dois conjuntos de instituições admitidamente falhos e não com a avaliação destes em comparação com um ideal inatingível de optimalidade de Pareto, como ocorre com os participantes neoclássicos do debate, em especial em fases posteriores do mesmo.

A solução matemática, para que gerasse algo que se aproxime da competição real, requereria a coleta de dados detalhada sobre a disponibilidade de recursos, tecnologias e preferências. Quanto à primeira categoria, Hayek afirma que os diferentes bens não podem ser agregados por classes de bens fisicamente semelhantes. A alocação econômica de recursos e o sucesso dos empreendimentos dependem, para o autor, do acúmulo de pequenas economias que são feitas todo o tempo, que dependem de particularidades sobre cada bem de produção concreto, como sua localização ou seu grau de uso. A administração central, para que pudesse alocar os recursos de forma satisfatória, não poderia se utilizar de diretrizes gerais, mas teria que levar em conta 
cada detalhe administrativo em cada empresa a fim de decidir o melhor uso dos recursos.

Os membros do órgão de planejamento central devem também concentrar todo o conhecimento técnico existente. A hipótese teórica de que o conhecimento é dado, quando aplicada à explicação do equilíbrio competitivo, não implica que o conhecimento sobre as melhores técnicas é dado centralmente, mas que em cada ponto do mercado temos indivíduos que possuem tal conhecimento, indivíduos esses selecionados pelo processo competitivo. Porém, sob planejamento central, ausente tal mecanismo seletivo do mercado, a escolha dos métodos técnicos mais apropriados só pode ser feita se o órgão planejador levar em conta em seus cálculos todo o conhecimento disponível. Isso, por sua vez, seria impossível. Além da dificuldade prática mais evidente em coletar esses dados caso existam, Hayek (1935b:210) afirma que boa parte desse conhecimento é tácita, consistindo em técnicas inconscientes de decisão diante de novas situações, e que portanto não são passíveis de objetivação na forma de dados a serem transmitidos ao órgão planejador. Note-se que o argumento deste parágrafo também ilustra a afirmação de Mises de que a solução por um processo de tentativas e erros deve pressupor um critério externo de seleção.

Em terceiro lugar, o órgão planejador deve possuir informações sobre as preferências dos indivíduos. Deve-se saber não apenas a variação da demanda com o preço do bem, mas também as demandas de todos os bens sob qualquer combinação de preços dos demais bens. Os cálculos devem ainda levar em conta que tais dados, se coletados no passado, não seriam válidos para o futuro, visto que os gostos se alteram a cada instante.

Finalmente, superada a 'mera dificuldade estatística', como ironiza o autor, resta a dificuldade de processar os dados. À maneira de Pareto, Hayek afirma que centenas de milhares de equações devam ser resolvidas. Tal resolução deveria ainda ser repetida a cada instante e comunicada aos executores dos planos. Isso deve ser feito não para atingir sempre um estado de equilíbrio ótimo, mas porque, comparando-se com os mercados reais, enquanto nestes últimos temos um sistema de reação contínua a pequenas mudanças (mesmo que incompletas), que no conjunto determinam o grau de economia do sistema, no esquema proposto o cálculo deveria ser feito continuamente se este pretende considerar as mesmas mudanças nos fundamentos da economia.

Embora escrito em 1935, anterior ao trabalho de Lange, o trabalho de Hayek discute o método de solução das equações por tentativas e erros, visto que este já aparece no 
artigo de Taylor. Hayek (1935b:213-4) levanta duas objeções à idéia proposta por Taylor. Em primeiro lugar, nega que os preços herdados do capitalismo possam ser utilizados como ponto de partida para o procedimento, visto que as mudanças de um sistema para outro seriam significativas. Em segundo lugar, cada mudança em um preço requereria alterações em centenas de outros preços, alterações essas cujas magnitudes dependem de inúmeros outros fatores. Bastaria imaginar as dificuldades da fixação central no preço de um único bem no capitalismo para imaginar os problemas com a fixação de todos os preços no socialismo. Por essas razões, o método de tentativas e erros não funcionaria como substituto para a solução matemática:

To imagine that all this adjustment could be brought about by successive orders by the central authority when the necessity is noticed, and that then every price if fixed and changed until some degree of equilibrium is obtained is certainly an absurd idea. That prices may be fixed on the basis of a total view of the situation is at least conceivable, although utterly impracticable; but to base authoritative price-fixing on the observation of a small section of the economic system is a task which cannot be rationally executed under any circumstances. An attempt in this direction will either have to be made on the lines of the mathematical solution discussed before, or else entirely abandoned. (Hayek, 1935b:214)

Ajustes em um "pequeno fragmento do sistema econômico", ou seja, ajustes de poucos preços por vez, depende da hipótese de que a economia já esteja próxima ao equilíbrio geral.

É curioso notar que, enquanto para Lange a crítica hayekiana da solução matemática representa o abandono da tese da impossibilidade teórica em favor da impossibilidade prática, refutada por sua vez pelo seu método de tentativas e erros, para Hayek a solução matemática seria concebível teoricamente e a solução por tentativas e erros seria por sua vez incorreta, mesmo teoricamente.

Depois de criticar a posição de Dobb de forma análoga às críticas de Lerner à mesma proposta, Hayek examina no mesmo texto a sugestão de introdução de mercados reais no socialismo ${ }^{14}$. Escrita em 1935, a crítica de Hayek foi publicada um ano antes da proposta de Durbin. Hayek baseia sua crítica tanto no conhecimento das soluções competitivas que surgiram no debate em alemão quanto nas discussões orais que o autor afirma que ocorriam no debate em inglês no momento. Discute então em primeiro lugar a economia socialista organizada em torno de monopólios setoriais atuando de forma a maximizar lucros e em seguida examina o caso em que as firmas são instruídas a cobrar um preço que cubra os custos. Finalmente, investiga a competição entre firmas na mesma indústria.

\footnotetext{
${ }^{14}$ Os quase mercado ou mercados artificiais de Mises ou os mercados fictícios de Robbins.
} 
No primeiro caso, Hayek afirma, da mesma maneira que Robbins, que as transações entre monopólios não resultam em equilíbrios determinados, nos quais os recursos tenderiam ao seu uso mais adequado, mas sim em instabilidade de preços entre os preços de reserva e também exploração dos consumidores pelos monopolistas.

Mais interessante, porém, é o segundo caso. Hayek (1935b:226) procura mostrar que a instrução para que as firmas estabeleçam os preços de forma que estes cubram os custos marginais não consiste em um critério claro a respeito do que as firmas devam fazer.

Aqui o autor pela primeira vez em seu texto deixa um pouco mais nítidas as diferenças entre as vertentes austríaca e marshalliana da teoria neoclássica. A magnitude dos custos, na interpretação austríaca, só tem sentido preciso em um ambiente de equilíbrio competitivo estático. Contudo, na vida real, na qual ocorrem mudanças incessantes e os fatores de produção são frutos de processos que não se repetem, o que os torna específicos, o valor dos recursos (o seu custo de oportunidade) não têm necessariamente relação direta com os custos monetários de fato incorridos na sua produção. Os custos verdadeiros, para Hayek, se relacionam com a expectativa dos agentes a respeito do valor dos serviços alternativos que tais recursos possam prover no futuro. Na tradição austríaca, custos não são entidades determinadas objetivamente, mas são custos de oportunidade subjetivos, baseados nas expectativas individuais, que por sua vez são calcadas no conhecimento particular de cada agente sobre as circunstâncias que o cercam. Por isso, fora do equilíbrio competitivo, a instrução que dita às firmas a cobrança de preços que cubram os custos não consiste em uma regra que determina a conduta das firmas socialistas.

Mais tarde, no que chamamos a crítica indireta de Hayek, teremos uma explicação mais acabada de como as decisões baseadas em conhecimento particular e falível dos agentes se relacionam com as alternativas reais deixadas para trás quando tais agentes interagem nos mercados. Ou, em outros termos, como os custos de oportunidade subjetivos são modificados no processo de obtenção de um equilíbrio. Na crítica à solução competitiva, porém, Hayek já intui que não se pode pressupor o conhecimento dos custos antes que o próprio processo competitivo ocorra:

To make a monopolist charge the price that would rule under competition, or a price that is equal to the necessary cost, is impossible, because the competitive or necessary cost cannot be known unless there is competition. (Hayek,1935b:229)

Devido ao fato de que as idéias do autor estavam em processo de desenvolvimento, o exemplo que ele elabora para ilustrar seu ponto não foi capaz de deixar claras as 
diferenças entre as posturas austríaca e marshaliana mencionadas acima. Nesse exemplo, Hayek (1935b:227) considera um bem de capital durável que não será reposto quando depreciar totalmente e que não pode ser usado fora da indústria monopolizada, não tendo portanto preço de mercado. Neste caso, a decisão sobre a intensidade de seu uso presente envolve não só o custo de diminuir a produção futura, quando o recurso se desgastar, mas também a sua substituição no futuro por outro recurso, que por sua vez tem usos alternativos. Ainda que de forma indireta, o uso do recurso implica na existência de custos, não derivados do seu preço de mercado, que não existe, mas sim relacionados com o preço do produto final. $\mathrm{O}$ valor ou custo de oportunidade do recurso só será estimado se for permitida a competição real ou potencial entre as diversas maneiras de fabricar o bem, o que influenciará o valor do recurso.

As observações de Hayek são de interesse especial para Durbin. Quando este propõe no ano seguinte a sua versão de socialismo de mercado baseado em monopólios setoriais, faz referências diretas às objeções aqui levantadas (Durbin, 1936:688-690) ${ }^{15}$. O exame da reação de Durbin será interessante, pois ilustra como os argumentos austríacos no debate foram em geral interpretados de forma marshaliana. Em primeiro lugar, com o exercício de estática comparativa (alterações na demanda e na tecnologia) que desenvolve no seu artigo, visto no capítulo anterior, Durbin crê que teria respondido à objeção de Hayek de que o socialismo de mercado se preocupa exclusivamente com condições estáticas. Com a crítica indireta de Hayek, porém, veremos que a objeção original não se refere à estática comparativa, mas sim às ações dos indivíduos fora do equilíbrio, ações essas de que consiste o processo de mercado.

Durbin critica também o exemplo dado por Hayek, mencionado há pouco, cuja intenção era mostrar que os custos não são objetivamente determináveis fora do equilíbrio. Enquanto este autor acredita que a situação descrita no exemplo representa a indeterminação dos custos na maioria das situações reais (fora do equilíbrio competitivo), Durbin, pensando em termos estritamente marshalianos, ou seja, em termos de equilíbrio competitivo, ignora a questão da subjetividade dos custos, afirmando em sua crítica que não existem casos significativos nos quais não se possa estabelecer um preço de um fator de forma independente. $\mathrm{O}$ único caso em que isso ocorreria seria um recurso ao mesmo tempo específico e eterno (Durbin,1936:689). Se o

\footnotetext{
${ }^{15}$ Como já vimos, Durbin aceita os argumentos de Robbins e Hayek contra a solução matemática, walrasiana, mas procura encontrar nas outras abordagens neoclássicas 'regras de procedimento' a serem ditadas às firmas nacionalizadas, regras essas que Hayek considera inexistentes no artigo em foco.
} 
recurso específico no curto prazo depreciar, afirma Durbin, a quota de depreciação converteria o recurso em um fator não específico. A objeção de Hayek dependeria então, ironiza Durbin, da relevância de bens como um túnel escavado em rocha sólida. Mesmo assim, a falta de preço seria irrelevante, visto que neste caso o uso é determinado, não podendo ocorrer distorções alocativas. Então, para gerar problemas alocativos, teríamos que ter um conjunto de túneis ligando dois pontos escavados na rocha com produtividades diferentes, para que a intensidade do uso de cada um, combinada com fatores complementares, se torne inadequada na ausência de preços dos fatores específicos.

Lerner, influenciado em sua formação pela tradição austríaca, chama a atenção de Durbin (em sua crítica de 1937 à proposta deste último) para o verdadeiro significado do ponto de Hayek. Além de criticar a idéia de que a existência de cotas de depreciação resolva o problema no curto prazo, e chamar a atenção para o fato de que o exemplo de Hayek trata justamente de um bem que deprecia e não algo eterno, Lerner mostra que a objeção de Hayek consiste na afirmação de que a decisão sobre o uso do recurso deve se basear na estimativa sobre as alternativas sacrificadas, que não podem ser estabelecidas objetivamente. Lerner, como Hayek, reconhece a natureza subjetiva dos custos. A diferença entre os dois consiste no seguinte: enquanto para o segundo, como veremos na próxima seção, o estudo do processo de mercado fora do equilíbrio diz algo sobre como estas expectativas convergem ou não a um valor mais acurado, que reflete as verdadeiras alternativas disponíveis nos mercados, para o primeiro esse tipo de análise foge à competência do economista:

The question is then the sociological one, whether the Socialist Trust is able to estimate this future value more accurately or less accurately than the competitive owner of the hired instrument, and here we leave pure economic theory. (Lerner, 1937:269)

O tipo de objeção levantada por Hayek consistirá precisamente em uma reavaliação de quais problemas a teoria econômica deva tratar, e a proposta de incorporar na disciplina o estudo do processo de aprendizado no mercado marcará a definição do programa de pesquisa austríaco, que, como bem indica Kirzner, se delineia precisamente no debate do cálculo.

Voltamos agora ao terceiro tipo de solução competitiva examinada por Hayek. Devido aos problemas apontados com as propostas de mercados monopolistas, o autor considera que a competição só será efetiva se for reintroduzida em sua totalidade. Examina assim a possibilidade de várias firmas competirem entre si em cada indústria. As objeções 
levantadas contra essa proposta se assemelham àquelas feitas por Mises e Robbins, embora sejam postas de forma menos clara que estes últimos. Enquanto estes claramente indicaram a importância da propriedade privada e a necessidade de mercados financeiros para que os mercados possam funcionar adequadamente, Hayek lista alguns problemas com a alocação do capital que são na verdade derivados da ausência de tais instituições.

O aspecto que Hayek acrescenta à análise diz respeito à observação de que a reintrodução da competição, que à primeira vista elimina a necessidade de planejamento central, na verdade implica em um papel tão ativo para o órgão central quanto nas outras versões de socialismo de mercado: as decisões sobre a alocação do capital entre empreendimentos, se econômicas, devem levar em conta os detalhes específicos da administração de cada firma, visto que não existem mercados de capitais nos quais tais decisões são fruto da competição entre empresários. O órgão de planejamento deve então conhecer todos esses detalhes para que possa alocar os recursos de forma econômica.

Entre as diferentes versões do socialismo de mercado, apenas a solução matemática havia sido publicada até 1935. A crítica de Hayek a esta proposta se baseia então naturalmente na contribuição de Dickinson. Já as críticas às propostas de introdução no socialismo de mercados reais, monopolistas ou competitivos, e a proposta de implementar a solução matemática por um mecanismo de tentativas e erros foram feitas sem que o autor pudesse se referir a esquemas concretos publicados em revistas acadêmicas, com a exceção do artigo de Taylor, que menciona brevemente esta última proposta. Cinco anos mais tarde, em 1940, quando as propostas já haviam sido publicadas, Hayek voltou a criticar, agora em um artigo, aquela que se tornou a mais conhecida entre elas, a solução por tentativas e erros de Lange.

O artigo de Hayek [1940] examina o método de tentativas e erros contido tanto no artigo original de Lange, reimpresso juntamente com o artigo de Taylor (Limpicott, 1938), quanto no livro de Dickinson [1939], que adere à proposta de Lange. Por ser publicado em 1940, quando as idéias do autor já estavam mais desenvolvidas, o artigo de Hayek contrasta de forma mais nítida as diferenças entre a concepção tradicional da competição subjacente à proposta de Lange e a sua própria, derivada da concepção austríaca. 
Antes de listar suas objeções à proposta de Lange, Hayek (1940:126-7) comenta sobre o significado desta e a interpretação do debate dada pelo seu autor. Para Hayek, da mesma maneira que para Mises e Robbins, a proposta de basear a alocação de recursos em um sistema de preços representa um recuo em relação à posição socialista original defensora do planejamento central. Adicionalmente, o argumento de similitude formal teria mostrado originalmente que a afirmação de que as categorias da Economia não se aplicariam em outras sociedades seria infundada. Porém, Lange, ao utilizar o argumento de similitude como prova da possibilidade teórica do socialismo, teria então encoberto o próprio recuo socialista criando confusão sobre a questão.

Na verdade a confusão, como temos defendido, advém da assimetria entre explicação e previsão/controle no uso da teoria neoclássica. O argumento de Mises, para Hayek, não se refere ao problema de saber se as categorias da economia devam ou não ser levadas em conta, questão esta reconhecida desde Wieser, mas sim se uma solução real pode ser encontrada sem o uso de mercados. Enquanto o argumento de Mises dirigido contra os primeiros socialistas poderia ser classificado como um argumento de impossibilidade lógica do socialismo, pois estes não reconheciam o argumento de similitude, o argumento de Hayek dirigido contra os socialistas de mercado tem outra natureza, visto que Lange aceita o argumento da similitude e procura então simular os mercados. Não seria justa, então, continua Hayek (1940:127), a afirmação langeana de que ele próprio e Robbins teriam recuado para uma segunda linha de defesa, abandonando o argumento original de Mises. A crítica de Hayek contra a proposta de Lange não será portanto dirigida contra aspectos lógicos da teoria neoclássica, mas sim sobre a relevância dessa teoria para responder o problema em discussão.

Isso nos leva a ver como Hayek explicita de maneira mais clara, como tinham feito Mises e Robbins, as diferenças entre as posturas austríaca e walrasiana sobre a real natureza do problema do cálculo, diferenças essas relativas à capacidade de adaptação a mudanças contínuas. Não seria logicamente impossível, afirma Hayek (1940:131) conceber a solução matemática funcionando se o problema fosse encontrar uma solução de equilíbrio em um mundo com dados constantes e no qual um conjunto de preços poderia prevalecer fixo por longos períodos. Nesse mundo, um órgão de planejamento central "onisciente e onipresente", como o descreve Dickinson (1939), não teria dificuldades em encontrar uma solução por meio do esquema proposto. 
Embora concebível, tal método não oferece uma solução para o problema real do cálculo, em um mundo que requer adaptação a mudanças contínuas. As soluções de Lange e Dickinson, para Hayek, não abordam o problema real devido 'à excessiva preocupação com problemas da teoria pura de equilíbrio estacionário’:

The practical problem is not whether a particular method would eventually lead to a hypothetical equilibrium, but which method will secure the more rapid and complete adjustment to the daily changing conditions in different places and different industries. (Hayek, 1940:131-2)

Como Lerner, Hayek critica a preocupação de Lange e Dickinson em replicar a teoria da competição perfeita, embora por motivos diferentes: grande parte dos bens de capital, por exemplo, são contratados sob encomenda; em cada transação mudam os compradores e vendedores. Nesse contexto, não tem sentido a fixação central de preços de forma a igualar demanda e oferta. Para que o órgão de planejamento central ${ }^{16}$ possa fixar o preço, teria que conhecer os detalhes de cada situação particular e assim substituir os empresários, o que nos leva de volta aos mesmos problemas da solução matemática original.

No restante de seu artigo, Hayek ilustra vários problemas com a solução de Lange, a maioria deles derivados da observação de que a solução por tentativas e erros se preocupa com a competição perfeita em um ambiente estático e não com a competição real.

A preocupação com a teoria estática se revela, por exemplo, na ambigüidade dos autores em relação à frequiência dos ajustes de preços. Ora afirma-se que as mudanças de preços seriam anunciadas no final de períodos pré-estabelecidos, ora afirma-se que as mudanças seriam feitas quando necessário. A falta de precisão sobre o assunto advém da crença de que uma vez estabelecido o equilíbrio, poucas alterações deveriam ser feitas. A afirmação de Dickinson (pág. 100-103) de que mudanças seriam feitas apenas na presença de grandes mudanças nos gostos ou grandes inovações técnicas é citada por Hayek (pág. 135) como prova da falta de compreensão sobre a verdadeira função do mecanismo de preços, advinda da preocupação com o equilíbrio. Para Hayek, em contraste, as mudanças de preços seriam necessárias a todo instante, de forma a haver adaptação ao contínuo fluxo de mudanças.

É interessante lembrar que também Lange acusa seus oponentes de falta de compreensão da teoria quando analisa o argumento de Barone como prova teórica da

\footnotetext{
${ }^{16}$ Em vez do CPB (órgão de planejamento central) de Lange, Hayek utiliza o SEC (conselho econômico supremo) de Dickinson em seu texto.
} 
possibilidade do cálculo socialista. A acusação mútua de incompreensão da teoria revela de forma nítida as diferenças entre as bases teóricas dos dois autores, diferenças essas que tomavam forma no debate.

Para Hayek, a fixação de preços em intervalos descontínuos traria como conseqüência uma menor adaptabilidade da economia, em comparação com um sistema de preços real. Em primeiro lugar, as mudanças ocorreriam com atraso, visto que devem ocorrer apenas quando os administradores locais reportarem as alterações centralmente e o SEC processar os dados e enviar as instruções de volta. Em segundo lugar, o mecanismo não daria conta da complexidade do problema alocativo real, pois os bens seriam agrupados em categorias uniformes. As especificidades referentes ao local, tempo e diferenças de qualidade de cada bem não teriam, portanto, expressão nos cálculos do SEC e as oportunidades de ganho derivadas dessas diferenças seriam desconsideradas.

Hayek critica também as instruções ditadas às firmas pelo modelo, de forma semelhante à crítica feita em 1935 aos mercados artificiais. Para Hayek as regras não seriam seguidas e isso não ocorreria por falta de incentivos. Hayek assume explicitamente que os administradores socialistas sejam tão motivados quanto os empresários. O problema com as regras consiste em que elas não podem de fato ser seguidas. A instrução de minimizar custos médios e produzir de forma a igualar preço a custo marginal indica que os autores da proposta acreditam que as curvas de custo são dadas objetivamente. Para Hayek, a descoberta de qual é o custo mínimo de produção é feita justamente com o auxílio da competição de preços, excluída do modelo. A redução dos custos é feita precisamente por indivíduos que crêem que conhecem métodos mais baratos e têm a possibilidade de arriscar e reduzir o preço cobrado pelos outros empresários, em um teste de sua hipótese:

What is forgotten here is that the method which under given conditions is the cheapest is a thing which has to be discovered, and to be discovered anew sometimes almost from day to day, by the entrepreneur, and that, in spite of the strong inducement, it is by no means regularly the established entrepreneurs, the man in charge of the existing plant, who will discover what is the best method. (Hayek, 1940:139)

Quando o preço é fixado centralmente, por outro lado, cada melhora dependeria de convencer o SEC de que o novo método proposto é viável, o que pode ser feito apenas se este assumir para si as funções do empresário e investigar os detalhes do empreendimento em questão. 
Novamente, Hayek mostra que o sistema de Lange, aparentemente descentralizado, se escrutinado a fundo resulta em um sistema centralizado, sujeito à crítica de que a capacidade de obter e processar informações de um órgão central é limitada ${ }^{17}$.

Outros problemas com a fixação periódica de preços paramétricos surgem quando se examina a economia fora do equilíbrio. Um administrador que se comporta como tomador de preços seria incapaz de seguir as instruções: se, pergunta Hayek, a regra de expandir a produção de forma a igualar custo marginal ao preço requeresse o uso de uma quantidade maior de um recurso, e o administrador não fosse capaz de oferecer um preço maior para atrair esse recurso, a produção deveria parar ou a regra deveria ser cumprida de forma não econômica por meio do uso de substitutos inferiores?

Hayek se espanta com a afirmação de Lange de que os administradores devam tratar os preços como constantes da mesma forma como o fazem nos mercados competitivos. Se os administradores sabem que os preços terão que variar, devem eles ignorar esse conhecimento? Ou se puderem agir, poderiam tirar vantagem do atraso do reajuste, estocando um recurso antes que o preço suba?

Os custos marginais, por sua vez, não são entidades conhecidas de antemão, mas variam, por exemplo, com a data em que se realizam as aquisições de recursos e com as expectativas dos preços futuros. Essa indeterminação dos custos implica que as responsabilidades devam ser apuradas por meio de auditorias que precisam investigar os cálculos de cada empreendimento, incluindo as vias alternativas de ação, a fim de que se constate que à luz do conhecimento existente em cada período as decisões foram acertadas, o que levaria à pior forma de burocracia (Hayek, 1940:141). Novamente, o SEC não se limita a observar estoques ou faltas, mas deve conhecer os detalhes do funcionamento da economia.

Finalmente, como Mises e Robbins, Hayek considera a maior fraqueza do modelo o tratamento dado à alocação do capital sem o uso de mercados genuínos. Nesse ponto as propostas de Lange e Dickinson teriam se tornado menos definidas e não ofereceriam uma resposta adequada sobre como, sem propriedade privada e mercados de capital, a alocação pode ser feita sem pressupor omnisciência por parte do SEC. Como procurou mostrar várias vezes ao longo do artigo, Hayek crê que para que os esquemas aparentemente descentralizados de alocação de recursos propostos sejam efetivos, o

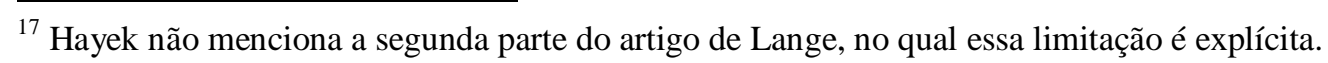


SEC deve ser capaz de verificar e repetir todos os cálculos dos empresários. Assim, inconscientemente os autores acabam por apelar para a onisciência e onipresença dos planejadores. Os esquemas propostos seriam portanto sujeitos à mesma crítica que Hayek faz a todas as propostas de socialismo de mercado - o planejamento central não é viável porque a complexidade do problema econômico, diante da inevitável limitação do conhecimento humano, só pode ser tratado de forma descentralizada:

I have tried to show on another occasion, it is the main merit of real competition that through it use is made of knowledge divided between many persons, which, if it were to be used in a centrally directed economy, would have all to enter the single plan. (Hayek, 1940:144)

Hayek se refere aqui ao seu artigo Economics and Knowledge, que inaugura uma série de trabalhos explicitando as diferenças que surgiram no debate entre as concepções austríaca e neoclássica a respeito do significado da competição. A esses trabalhos, que denominamos crítica indireta ao socialismo de mercado, nos voltamos agora.

\section{A Crítica Indireta}

$\mathrm{Na}$ crítica direta ao socialismo de mercado, como já notamos algumas vezes, Hayek falha em deixar claras as diferenças entre sua abordagem teórica austríaca e a abordagem neoclássica tradicional que informa seus oponentes, já que essas diferenças estavam vindo à tona justamente naquele momento. Essas diferenças, no entanto, serão explicitadas e desenvolvidas em artigos publicados a partir da data de seu envolvimento no debate (Hayek, 1937, 1945, 1946, 1976).

Embora claramente influenciados pelo debate, esses artigos praticamente não fazem referências explícitas aos socialistas de mercado. Podemos imaginar duas razões para tal. Em primeiro lugar, Hayek cultivava a elegância intelectual, evitando nas controvérsias sempre que possível o confronto pessoal em favor do confronto de idéias. Adicionalmente, a importância do mencionado conjunto de artigos não se limita à questão do cálculo econômico socialista, sendo relevante para questões de regulação, antitruste e todos os problemas relacionados ao significado da competição em geral. Esses artigos, além disso, são extremamente importantes para o desenvolvimento do programa de pesquisa austríaco que ocorreu a partir da década de oitenta do século vinte. A nossa tarefa a partir de agora será identificar nos referidos artigos os temas relacionados ao debate. 
No primeiro e mais fundamental desses artigos - Economics and Knowledge [1937] Hayek argumenta que a descrição do estado de equilíbrio não consiste em uma explicação suficiente dos fenômenos de mercado. Tal descrição, denominada por Mises de 'pura lógica da escolha', consiste somente de derivações de resultados obtidos a partir do conhecimento dos dados do problema no qual a escolha se faz necessária. Isso seria um exercício lógico, sem conteúdo empírico. Uma explicação adequada dos fenômenos de mercado, por outro lado, não deveria se limitar a pressupor tal conhecimento dos dados, mas explicar como esse conhecimento é obtido pelos agentes.

Embora não faça referências a Lange, podemos inferir que a argumentação de Hayek se relaciona ao uso da teoria de equilíbrio feito por aquele autor ${ }^{18}$. Como podemos lembrar, no modelo de Lange, conhecidos os dados (given the data) sobre os fundamentos da economia, pode-se derivar um vetor de preços de equilíbrio. No artigo em questão, por seu turno, Hayek critica a prática de se assumir tal conhecimento como dado de antemão, mencionando inclusive o uso do pleonasmo ‘data given' empregado por Lange ${ }^{19}$.

Hayek conduz sua crítica investigando a relação entre a noção de equilíbrio e a natureza dos 'dados'. Considerando-se primeiramente um indivíduo isolado, pode-se afirmar que as suas ações estão em equilíbrio (serão consistentes entre si) se fizerem parte de um mesmo plano de ação. Nesse equilíbrio, a lógica da escolha chega à conclusão de que as utilidades marginais se igualam aos custos marginais e os fatores têm o mesmo retorno em cada uso alternativo. Aqui, os 'dados' são puramente subjetivos; as crenças individuais (mesmo incorretas) sobre a realidade pautam as ações. A sucessão de ações no tempo implica na existência de um equilíbrio enquanto não houver mudanças no conhecimento do agente e o plano for executado conforme previsto. Se as antecipações se mostrarem incorretas, o conhecimento se alterará e o equilíbrio será desfeito.

Quando passamos para o caso no qual interagem várias pessoas, podemos definir de forma análoga a existência de equilíbrio se as ações de todos no período são execuções de seus planos. Para que isso ocorra os agentes precisam ter as mesmas expectativas sobre a realidade externa e os planos devem ser compatíveis entre si, ou seja, as ações dos demais agentes, derivadas de seus planos, são exatamente aquelas esperadas por

\footnotetext{
${ }^{18} \mathrm{E}$ também, naturalmente, do uso do conceito de equilíbrio encontrado nas críticas que Hayek recebeu em relação a sua teoria de ciclos.

${ }^{19}$ Décadas mais tarde, em um artigo dedicado à interpretação dominante sobre sua controvérsia com Lange, Hayek (1984) criticará explicitamente o uso de Lange do referido pleonasmo.
} 
cada agente, fazendo parte do conjunto de 'dados' deste. Então, para Hayek, o equilíbrio, visto como compatibilidade de planos executados ao longo do tempo, é identificado com a previsão correta sobre eventos que dependem tanto de dados externos, referentes a objetos físicos, quanto de ações dos demais agentes. Visto dessa maneira, o conhecimento perfeito seria a característica definidora, e não um dos requisitos, do equilíbrio competitivo.

Hayek aponta então um problema na transição da análise do indivíduo isolado para a interação entre vários deles, problema esse derivado das restritivas condições para que o equilíbrio acima definido ocorra. Prever corretamente o estado de objetos materiais e ao mesmo tempo o comportamento de agentes que por sua vez tentam fazer o mesmo tipo de previsão aumenta sobremaneira a complexidade da tarefa de coordenar as ações individuais. Conseqüentemente, não podemos mais considerar os dados como puramente subjetivos e portanto a análise econômica não pode mais seguir em bases puramente tautológicas. Isso ocorre devido ao fato de que os dados subjetivos de cada agente não se identificam automaticamente como a realidade subjacente, objetiva ${ }^{20}$. Neste caso o conhecimento dos agentes será apenas conjectural.

Na teoria neoclássica tal problema seria contornado pela suposição de que os mesmos 'dados' são dados para todos os agentes. O conceito de 'dado' teria então sofrido uma (não discutida) mudança de significado. As ambigüidades geradas pela mudança de significado surgem, por exemplo, no uso do pleonasmo langeano 'data given' ou na falta de clareza sobre se 'dado' significa conhecimento objetivo, supostamente conhecido pelo economista, ou se significa conhecimento subjetivo dos agentes e nesse caso se esse conhecimento é o mesmo para todos os agentes.

O ponto central da crítica de Hayek consiste na afirmação de que os economistas simplesmente assumem a correspondência entre dados subjetivos e realidade objetiva, ignorando o processo de mercado que explicaria como essa correspondência é obtida. Se a teoria econômica pretende oferecer explicações reais sobre o funcionamento dos mercados que não sejam meras petições de princípio, deve-se estudar o processo pelo qual as expectativas se tornam corretas e se obtém um equilíbrio. Se isso fosse feito, a economia deixaria de ser um ramo da lógica (a lógica da escolha) e ganharia um

\footnotetext{
${ }^{20}$ No próximo artigo analisado, Hayek (1945:91) afirma que "Any approach, such as that of much mathematical economics with its simultaneous equations, which in effect starts from the assumption that people's knowledge corresponds with the objective facts of the situation, systematically leaves out what is our main task to explain."
} 
elemento empírico: Hayek considera que a existência de coordenação nos mercados é uma regularidade empírica que deva ser explicada com a ajuda de uma teoria sobre o aprendizado dos agentes, teoria essa que poderia ser corroborada ou refutada, pelo menos em princípio.

Deve-se salientar que com isso Hayek não propõe que se observem empiricamente processos de aprendizados reais, mas sim que se investigue a natureza desses processos de aprendizado dos agentes e as condições para que uma tendência ao equilíbrio ocorra $^{21}$. O programa de pesquisa proposto por Hayek convida então a se investigar mais a fundo os processos de aprendizado descentralizados que ocorrem nos mercados, que resultam na 'divisão do conhecimento' identificada por Mises:

The problem which we pretend to solve is how the spontaneous interaction of a number of people, each possessing only bits of knowledge, brings about a state of affairs in which prices correspond to costs, etc., and which could be brought about by deliberate direction only by some body who possessed the combined knowledge of all those individuals. (Hayek, 1937:50)

Deve-se lembrar de que na resposta direta aos socialistas de mercado Hayek defende a tese de que os esquemas como os de Lange ou Durbin, aparentemente descentralizados, acabam por requerer ação centralizada que pressupõe conhecimento sobre todo o sistema econômico. Na resposta indireta, contudo, Hayek por vezes ignora a tentativa de propor esquemas descentralizados e contrasta diretamente os processos de aprendizado descentralizados que ocorrem nos mercados com a centralização sob uma economia planificada. Assume então que para os socialistas o conhecimento seria 'dado' centralmente, enquanto, na verdade, alguns desses socialistas procuram precisamente fazer uso do conhecimento descentralizado, embora de fato acabem apelando em última instância para o conhecimento superior dos planejadores, como aponta o próprio Hayek. Sendo assim, apesar dessa incorreção da parte desse autor, as objeções desenvolvidas na crítica indireta continuam aplicáveis ao socialismo de mercado.

O programa sugerido na citação acima é retomado no artigo seguinte - The Use of Knowledge in Society [1945] - tanto no aspecto positivo (como ocorre o aprendizado nos mercados) quanto no aspecto crítico (como esse processo de aprendizado é barrado no socialismo). Hayek inicia o artigo reafirmando que o problema fundamental da economia não é o problema lógico da alocação de recursos dados a fins alternativos conhecidos, mas sim o problema de assegurar o melhor uso dos recursos quando o conhecimento for disperso entre os membros da sociedade. A eficiência com que o

\footnotetext{
${ }^{21}$ No próximo capítulo estudaremos como isso pode ser feito.
} 
conhecimento disperso é utilizado e transmitido na economia, por sua vez, depende de como a sociedade seja organizada, por planejamento central ou planejamento descentralizado no mercado.

A comparação entre essas duas formas de organização, para o autor, depende da natureza do conhecimento relevante para a solução do problema alocativo. Em relação a isso Hayek (1945:81) chama a atenção para a importância em se distinguir entre conhecimento científico do economista e conhecimento prático do agente. Enquanto o primeiro consiste em simplificações teóricas que pretendem ser válidas em todas as circunstâncias, o segundo tem relevância circunscrita a cada situação. Hayek (pág. 80) denomina este último de 'conhecimento das circunstâncias particulares no tempo e lugar'. Esse tipo de conhecimento é composto em grande parte por regras de conduta e habilidades adquiridas ao longo da vida que sequer são conscientes. Tal conhecimento é utilizado para explorar oportunidades de ganho que dependem dos detalhes particulares de cada situação, enquanto o primeiro, por sua natureza, ignora tais detalhes.

Para Hayek, a falha em reconhecer esta distinção leva a uma opinião errônea sobre a capacidade do economista de intervir no mercado. O tipo de conhecimento possuído pelos agentes, sendo do segundo tipo, não pode ser resumido em estatísticas, pois cada detalhe, e não médias ou agregados, importa na exploração das oportunidades econômicas locais, além, é claro, da natureza tácita de boa parte desse conhecimento impedir que seja coletado na forma de dados objetivos.

Os economistas, por sua vez, parecem ter em mente o primeiro tipo de conhecimento científico - quando, por exemplo, supõem conhecimento dado ou então quando condenam a irracionalidade dos mercados por não disponibilizarem o conhecimento para todos os agentes, em uma referência indireta que Hayek faz às 'paredes de vidro' de Dickinson. Para Hayek, a própria natureza do conhecimento relevante para o mercado impede que este seja transmitido da mesma forma como se faz com o conhecimento científico.

A argumentação de Hayek, embora neste ponto não mencione o debate do cálculo, é claramente inspirada por esse. De fato, os proponentes do socialismo de mercado supõem tecnologias dadas para cada setor e curvas de custo conhecidas e razoavelmente estáveis. Para Hayek, as curvas de custo da teoria econômica, criadas como instrumento de compreensão dos princípios de funcionamento dos mercados, são confundidas com os custos do mundo real. Neste, o exercício de minimização dos custos, devido a grande 
complexidade das situações de escolhas reais, deve ser feito continuamente e não uma única vez, à luz de uma curva de custo bem definida e dada claramente ao agente:

How easy it is for an inefficient manager to dissipate the differentials on which profitability rests and that it is possible, with the same technical facilities, to produce with a great variety of costs are among the commonplaces of business experience which do not seem to be equally familiar in the study of the economist. (Hayek, 1945:82)

Segundo Hayek, a desconsideração das complexidades das escolhas reais se relaciona estreitamente com a pouca atenção que se dá às mudanças no ambiente econômico, como já apontara Mises em sua crítica aos socialistas de mercado:

Indeed, there are few points on which the assumptions made (usually only implicitly) by the "planners" differ from those of their opponents as much as with regard to the significance and frequency of changes which will make substantial alterations of production plans necessary. (Hayek, 1945:81)

Se o mundo fosse razoavelmente estático, com mudanças ocorrendo a intervalos longos, a aplicação direta do aparato teórico ao planejamento da economia não envolveria grandes dificuldades. De fato, vimos como Durbin acredita que os exercícios de estática comparativa (mudança na demanda e tecnologia) poderiam lidar com as questões dinâmicas postas por Hayek: quando lemos Durbin, temos a impressão de que de tempos em tempos a demanda ou os custos se alteram e essas mudanças são pronta e claramente observadas por todas. Lange e Dickinson, por sua vez, dão a entender com o seu emprego da teoria de equilíbrio geral que um vetor de equilíbrio pode operar por períodos razoáveis e portanto a mudança ocorreria esporadicamente.

Para Hayek (1945:83), em contraste, dada a complexidade da realidade e de sua mutabilidade constante, o problema econômico consiste na rápida adaptação a mudanças nas condições de tempo e local. Essa adaptabilidade, necessária diante da complexidade do problema, requer uma solução descentralizada. Em outra referência indireta à Lange, Hayek (pág. 84) afirma que não é possível que se comuniquem todas as mudanças a um órgão central que posteriormente emita ordens (no caso, preços).

Hayek passa a descrever então como o problema é resolvido de forma emergente pela 'ordem espontânea' dos mercados, sem que haja um mecanismo criado e dirigido conscientemente para resolvê-lo. O conhecimento limitado dos agentes não seria capaz de realizar tal feito. O sistema real de preços, por outro lado, permite que haja a divisão do conhecimento de Mises: os agentes não precisam dominar os detalhes de cada mercado, mas apenas agir com base em seu conhecimento local. A escassez relativa dos outros bens, sejam insumos ou produtos, é comunicada a eles de forma indireta, via 
alterações nos preços. Os agentes, ao buscarem lucros, substituem recursos ou alteram a quantidade produzida sem ter conhecimento das causas da maior ou menor escassez em outros mercados. Há, assim, uma espécie de 'economia de conhecimento', uma adaptação de cada agente à situação econômica cambiante sem que nenhum deles domine o conhecimento sobre todo o sistema econômico. Os preços funcionam, nas palavras de Hayek (1945:87), como um sistema de telecomunicação entre os agentes, sistema este que opera continuamente ${ }^{22}$.

A complexidade e o dinamismo do problema, dessa forma, requerem uma solução que possa transcender a capacidade cognitiva dos agentes. O sistema de preços fornece então um mecanismo de feedback negativo descentralizado que resulta na adaptação das ações dos agentes ao fluxo de alterações na economia, de forma a surgir uma ordem que coordena as ações de agentes com conhecimeto limitado.

Ao criticar a visão de que o progresso depende de maior controle consciente da produção com o auxílio de métodos científicos, Hayek antecipa em várias décadas o interesse moderno pela complexidade que surgiu em diversas ciências: um problema de complexidade elevada é resolvido não de forma consciente, mas pela emergência de um sistema de feedback negativo que encontra uma solução por tentativas e erros. Hayek (pág. 88) cita aprovativamente Whitehead quando este diz que 'a civilização avança através do aumento do número de operações importantes que podemos realizar sem pensar nelas'.

A crítica que Hayek faz ao mecanicismo presente nos modelos de socialismo de mercado é também estendida à prática de julgar a competição nos mercados segundo o critério de optimalidade presente no modelo de competição perfeita. Isto foi desenvolvido no ano seguinte (Hayek, 1946), em um artigo intitulado The Meaning of Competition e também mais tarde em Competition as a Discovery Process (Hayek, 1978), artigos estes que investigam o significado do conceito de competição.

\footnotetext{
${ }^{22}$ É importante notar, devido a interpretações errôneas do argumento feitas em uma fase posterior do debate (em especial por Hurwicz e Stiglitz), que Hayek não quer dizer nem que os preços sejam as únicas informações necessárias para alocar recursos, nem que a coordenação via sistema de preços seja perfeita. De fato, Hayek (1945:87) critica textualmente o uso de critérios de eficiência (optimalidade de Pareto) para julgar os resultados do mercado. A comparação relevante não seria entre o mercado real e uma situação teórica que pressupõe conhecimento perfeito dos agentes, mas entre o mercado, com o seu mecanismo de alocação descentralizado e a alocação via 'controle consciente', que requer omnisciência por parte dos planejadores ou ainda o sistema de preços artificiais proposto por Lange.
} 
No contexto do debate do cálculo, o fato dos mercados reais não se aproximarem do modelo ideal da competição perfeita e portanto do esgotamento das oportunidades de ganho mútuo presente nesse modelo foi, como vimos, um dos argumentos a favor do socialismo utilizados pelos socialistas de mercado, que pretendiam reproduzir o modelo ideal nas suas propostas de solução do problema do cálculo. Por sua vez, ao criticar o conceito de competição inerente a esse modelo, Hayek critica indiretamente as propostas de socialismo baseadas no mesmo ${ }^{23}$.

Para Hayek, a teoria da competição, como parte da lógica da escolha, se concentra na descrição do estado final de equilíbrio no qual se esgotam os ganhos de troca, pressupondo entre outros requisitos o conhecimento perfeito por parte dos agentes. Não explica assim o processo pelo qual o conhecimento destes converge para a realidade, possivelmente assumindo que este processo já ocorrera (Hayek, 1946:93). Ao adotar o modelo da competição perfeita como norma a ser imposta pelo estado, contudo, impedese que esse processo de aprendizado ocorra. Isso porque, na descrição do estado final de equilíbrio, todas as atividades tidas como competitivas, que fazem parte do processo de aprendizado, são excluídas por definição.

Em contraste com a noção de competição perfeita dos economistas, Hayek chama a atenção para a noção de competição relacionada à rivalidade, típica dos leigos e dos homens de negócio e coincidente com o uso do termo feito pelos economistas clássicos $^{24}$. Este último significado do termo trata não de um estado final de equilíbrio mas das atividades competitivas, como por exemplo publicidade, experimentação com qualidade, competição de preços ou formação de reputação.

O conhecimento dos 'dados' postulados pelos economistas seria, então, na verdade, obtido como fruto dessas atividades competitivas e portanto não se pode assumir a existência desses dados sem explicar a sua obtenção por algo como a atividade competitiva (atividade empresarial, na terminologia de Mises). O autor defende a tese de que a competição, no sentido relevante, seria importante mesmo que não estejam presentes as condições postuladas pelo modelo de competição perfeita. Mesmo com poucas firmas atuando em um mercado, a competição pode ser acirrada. A prevenção da competição por barreiras legais seria mais importante para a competição do que a

\footnotetext{
${ }^{23}$ Como vimos, Lerner também criticara o uso do modelo da competição perfeita no socialismo de mercado, embora em bases diferentes da crítica que veremos em seguida.

${ }^{24}$ Ver Machovec (1995).
} 
contagem do número de firmas em um mercado. O fundamental seria a presença da atividade competitiva que resultaria na descoberta dos dados.

Hayek (1978:256) traça um paralelo entre o aprendizado nos mercados e o progresso científico: nas duas esferas temos pessoas (agentes, cientistas) que buscam entender seu objeto de interesse: enquanto na ciência se investigam leis gerais, no mercado se busca descobrir fatos mercadológicos particulares a cada situação. Podemos interpretar o argumento de Hayek em termos popperianos, dizendo que a crítica e a competição oferecem, na ciência e no mercado, mecanismos de correção de hipóteses (dados) conjecturais. No processo de mercado, para Hayek, já que o conhecimento prático dos agentes também é conjectural, é inevitável que ocorra a frustração de algumas expectativas diante da realização dos lucros, o que induz alterações nas conjecturas, de maneira a ocorrer um aprendizado por tentativas e erros ${ }^{25}$.

Para Hayek (1978:256), a verdadeira função desempenhada pela competição, que descrevemos acima, tende a ser ignorada pelos economistas quando, na formulação do problema alocativo, parte-se de um estoque 'dado' de bens:

The real problem in all this is not whether we will get given commodities or services at given marginal costs but mainly by what commodities and services the needs of the people can be most cheaply satisfied. The solution of the economic problem of society is in this respect always a voyage of exploration into the unknown, an attempt to discover new ways of doing things better than they have been done before (Hayek, [1946]1980:101).

O valor dos mercados residiria no fato de que a competição resulta na descoberta de dados desconhecidos, que não viriam à luz sem a atividade competitiva. A visão da competição como um mecanismo de descoberta traria então consigo conseqüências fundamentais sobre a relevância do uso do critério de Pareto para se avaliar o desempenho dos mercados:

a) mais fundamental do que garantir que ganhos de troca sejam esgotados é descobrir a existência da possibilidade de tais ganhos. A possibilidade de explorá-los em algum grau, mesmo que não seja de forma completa, como ocorre nos mercados reais, deve ser comparada não com um ideal 'inatingível e irrelevante' (Hayek, 1946:100), como é o caso do critério de optimalidade, que para ser preenchido requer conhecimento completo dos dados, mas sim com outra alternativa concreta, como um arranjo institucional no qual os preços sejam fixados centralmente e a entrada em um mercado

\footnotetext{
${ }^{25}$ De fato, Hayek será considerado juntamente com Popper um dos fundadores da Epistemologia Evolucionária, que estuda os mecanismos de correção de erros presentes em diversos contextos. Ver Bartley (1990).
} 
dependa de permissão do estado. Além das constantes referências ao 'data given', aqui mais uma vez Hayek revela que tem em mente o modelo de Lange em seu artigo.

b) além de criticar a comparação entre mercados reais e um padrão inatingível em vez de um outro arranjo institucional possível - prática que Demsetz (1969) denominou de 'nirvana approach' - Hayek chama a atenção para o fato de que não se pode testar de antemão a importância da competição nos casos verdadeiramente interessantes. Dado que a competição seria um mecanismo de descoberta, não se pode saber hoje o que será descoberto pelo processo no futuro. Como nos esportes, a competição só vale a pena se o resultado final não for conhecido a priori. Para o autor (1978:255), em contraste, se os dados da economia fossem de fato conhecidos, o uso dos mercados como mecanismo de alocação seria um desperdício.

No contexto do debate, as observações de Hayek apontam para a incorreção em se querer reproduzir na realidade um modelo que exiba optimalidade, já que os dados aos quais a teoria se refere são fruto da atividade competitiva, atividade esta ausente na teoria da competição perfeita. Assim, se a competição for um processo de descoberta, partir do pressuposto de dados conhecidos se assemelha a uma petição de princípio. Esse problema pode ser ilustrado pelos exemplos do palácio (Sraffa) e pelo cão que corre atrás da bicicleta de seu dono de (Dobb).

A crítica indireta de Hayek ao socialismo de mercado teve como alvo a interpretação que seus proponentes faziam da teoria neoclássica. Hayek partilhava com Dickinson e Lange a crença na teoria do valor subjetivo, no problema da escolha diante da escassez e assim por diante. Entretanto, a formalização da teoria, cujas simplificações tinham como propósito explicar o princípio de funcionamento dos mercados, levou os economistas a enxergar o problema econômico de forma algo esquemática. Ao usar a teoria para construir na realidade mercados artificiais, houve uma tendência a se esquecer as complexidades do problema real. A importância da crítica de Hayek consiste, nas palavras do próprio autor, em frisar que 'de tempos em tempos é necessário se distanciar dos aspectos técnicos dos argumentos e se perguntar ingenuamente a que problema tudo isso se refere' (Hayek, 1937:56).

Dessa maneira, somos levados a ver que o problema econômico não é estritamente o problema mecânico da alocação de recursos dados a fins alternativos conhecidos de forma a se obter um equilíbrio no qual se esgotam as possibilidades de ganho, mas sim 
o problema sobre como agentes perseguem seus fins através da interação em um ambiente complexo e em constante mudança, de forma que suas ações sejam coordenadas de forma satisfatória mesmo que o conhecimento de cada um seja limitado e falível.

As diferenças analíticas apontadas por Hayek surgem a partir do reconhecimento da complexidade do problema econômico real. Em especial, o subjetivismo introduzido na Revolução Marginalista não se deve limitar ao ordenamento de preferências dos consumidores, mas deve ser estendido à apreciação da importância da atividade empresarial fora do equilíbrio - ambiente no qual as atividades econômicas de fato ocorrem. Nesse ambiente toda ação é especulativa e as alternativas sujeitas a escolha não estão claramente disponíveis. A competição real se refere mais a identificação empresarial de alternativas não pensadas pelos rivais e teste de conjecturas mercadológicas diversas do que com a tarefa rotineira de selecionar a mais adequada dentre as opções conhecidas.

Procuramos mostrar acima que a resposta de Hayek ao socialismo de mercado pode ser dividida em uma resposta direta e outra indireta. Consideramos que as várias citações feitas acima tenham sido suficientes para mostrar que os artigos discutidos na segunda categoria são de fato uma resposta ao socialismo de mercado, embora tenham relevância mais ampla e não façam referências diretas ao debate. Estabelecido isso, podemos avaliar a reação às críticas austríacas.

O leitor esperaria que, após a exposição das críticas de Mises, Robbins e Hayek, apresentaríamos uma seção ou capítulo que tratasse da reação dos socialistas de mercado às mesmas críticas. No entanto, as críticas austríacas foram quase por completo ignoradas. Podemos buscar uma explicação para tal nos seguintes fatores.

Em primeiro lugar, a própria estratégia adotada por Hayek em sua resposta pode ser responsável por isso. Como já mencionamos, Hayek não explicitou na resposta direta as diferenças entre as abordagens em questão. Assim, a crítica direta soou quase como uma crítica interna. E assim pareceu aos socialistas de mercado. De fato, Lange interpretou a crítica de Hayek não como uma visão teórica alternativa sobre o funcionamento dos mercados, mas sim como uma relação de obstáculos práticos a solução do problema, 
enquanto Durbin pretendeu responder as objeções com exercícios de estática comparativa, da mesma maneira que Kaldor analisara a teoria de ciclos de Hayek.

A crítica indireta, por sua vez, além de quase não mencionar a controvérsia do cálculo, foi escrita em um período de tempo mais longo, o que diminuiu o seu impacto no que diz respeito à controvérsia.

A falta de uma resposta mais completa aos argumentos austríacos, contudo, não pode ser explicada satisfatoriamente apenas dessa maneira. De fato, as críticas de Robbins e Mises deixam bem clara a necessidade de atividade empresarial e mercados financeiros já na época em que os socialistas de mercado escreviam. Adicionalmente, os economistas defensores do socialismo que retomaram o debate décadas mais tarde, por sua vez, aceitaram apenas parte das críticas diretas, também ignorando, com raríssimas exceções, as objeções mais fundamentais de Hayek. Nas ocasiões em que levaram tais argumentos em consideração, quase invariavelmente distorceram a posição de Hayek, reduzindo-a a termos neoclássicos convencionais, como veremos nos capítulos posteriores.

A falta de respostas às objeções de Hayek pode ser vista na verdade como um sintoma do cisma que ocorreu na escola marginalista a partir do debate: a economia austríaca deixou de ser vista como uma vertente verbal da teoria para se tornar explicitamente um programa de pesquisa próprio, embora comungue boa parte dos pressupostos da teoria tradicional. As críticas ao socialismo de mercado atingiram elementos do núcleo do programa de pesquisa neoclássico, e este, conforme a caracterização lakatosiana, fica fora do que é legitimamente passível de crítica segundo os defensores de um programa de pesquisa. Então, as críticas de Hayek ou foram traduzidas em termos neoclássicos de maneira que se possa lidar com elas no cinturão protetor ou foram simplesmente ignoradas.

\section{Extensão da Crítica Hayekiana: a regra dos custos}

Terminamos a discussão da reação austríaca às propostas dos socialistas de mercado notando que estes últimos não levaram em consideração as objeções desenvolvidas nessa reação. Hayek, por sua vez, também não levou a discussão adiante, no sentido de utilizar a crítica indireta para discutir novamente, agora de forma explícita, as propostas 
de socialismo de mercado. Isso foi feito apenas na década de oitenta, com o ressurgimento do interesse pela Escola Austríaca, conforme veremos no próximo capítulo. Podemos encontrar na época, contudo, um exemplo de crítica hayekiana ao socialismo de mercado, referente ao emprego da regra do custo marginal de Lerner, com o qual concluiremos este capítulo.

No capítulo anterior estudamos como Lerner defende o uso da regra do custo marginal, criticando as preocupações de Durbin e Lange com o custo médio e com a possibilidade de haver prejuízo nas firmas. Na esfera da teoria do equilíbrio, afirmou Lerner, a optimalidade na distribuição dos recursos requer que se produza algo até que a sua importância marginal se iguale ao custo de oportunidade dado pela importância do uso alternativo dos recursos empregados.

Entretanto, quando voltamos à questão informados pela crítica de Hayek, a instrução para que as firmas produzam até que tal igualdade seja obtida tem sua aplicabilidade contestada. Essa contestação foi feita por Thilby [1946] em um artigo intitulado "The Ruler", no qual seu autor nega que o custo seja uma entidade objetiva, cuja magnitude possa ser determinada e verificada por observador externo (the ruler) que dite regras. Sendo assim, questiona a aplicabilidade de qualquer regra que procure igualar preços a custos. Tal crítica foi mais tarde aplicada diretamente ao debate do cálculo por Wiseman [1953].

Nesse último artigo, seu autor compara o significado da igualdade $\mathrm{p}=\mathrm{CMg}$ no modelo da competição perfeita e no socialismo de mercado, denominado por Wiseman (1981:229) de 'economia coletivista liberal'. No primeiro caso, no qual se supõe que os agentes conhecem os dados, o custo de oportunidade subjetivo, definido como a expectativa sobre a receita alternativa que poderia ser obtida caso os recursos fossem aplicados em outra parte, encontra um equivalente objetivo, dado pelos preços conhecidos dos fatores. No modelo, adicionalmente, a igualdade entre preço e custo marginal é consequiência do comportamento maximizador de lucros sob as condições de competição perfeita. No socialismo de mercado, por sua vez, esse resultado, que não figura entre os propósitos dos agentes nos mercados reais, passará a ser um princípio administrativo a ser explicitamente buscado. O ponto do autor consiste na afirmação de que, uma vez que se admita a existência de incerteza inerente à passagem do tempo, a regra do custo marginal não fornece um guia claro que norteie as ações dos administradores das firmas socialistas. 
No modelo competitivo, como se pressupõe conhecimento perfeito, qualquer um que se depare como as mesmas circunstâncias tomaria a mesma decisão sobre o uso dos recursos. O custo de oportunidade nesse contexto reflete simplesmente a escassez desses recursos. Porém, quando levamos em conta a incerteza, o conceito de custo de oportunidade, além da escassez, necessariamente envolve o elemento de avaliação subjetiva. Diante das mesmas circunstâncias, diferentes agentes tomariam decisões diferentes, avaliariam de forma desigual a receita obtida a partir do uso alternativo dos recursos; assim, o custo de oportunidade perde sua pretensa objetividade existente no modelo anterior. A noção de custo estaria então intimamente associada à escolha ${ }^{26}$, através da avaliação de planos alternativos de ação no momento em que a escolha é feita.

A aceitação de que os verdadeiros custos de oportunidades não podem ser medidos de forma objetiva fora do equilíbrio competitivo traz consigo consequiências diversas quando temos em mente a comparação entre os mercados reais e o socialismo de mercado. Nos dois casos, não se pode verificar empiricamente a relação entre preços e o custo de oportunidade. Nos mercados reais, além disso, uma diferença entre receita e gastos pode tanto ser resultado de monopolização quanto de capacidade superior de prever as condições futuras do mercado. Embora não se possa distinguir com facilidade qual desses dois casos ocorre em cada situação, em última análise o elemento que aproxima a realidade da descrição teórica de um mercado competitivo (de forma imperfeita) é o mecanismo de lucros e perdas em um mercado com livre entrada, como veremos a pouco.

No socialismo de mercado, contudo, como a identidade $\mathrm{p}=\mathrm{CMg}$ assume o caráter de regra de conduta, a natureza subjetiva dos custos rouba a utilidade da regra como guia claro para a ação. Como apontara Thierlby (1981), ecoando a crítica de Hayek, a aplicação da regra resultaria na absorção das atividades do administrador pelo planejador central, visto que não há como verificar o seguimento da regra sem auditar em detalhes cada empreendimento em busca de uma opinião mais acurada sobre a

\footnotetext{
${ }^{26}$ Buchanan (1981 e 1993) associa o custo à escolha e como tal salienta a natureza subjetiva do mesmo: custo de oportunidade seria uma grandeza medida em utilidade - a avaliação da importância de um bem que se deixa de obter ao se optar por uma linha alternativa de ação. Da concepção de custo relacionado a escolha, Buchanan deriva algumas conclusões: os custos são subjetivos; portanto, não podem ser medidos por outra pessoa; nunca se realiza, pois o ato de escolha exclui a possibilidade da via alternativa ocorrer e são conceitos ex-ante, por se basear em expectativas.
} 
magnitude dos custos de oportunidade. Na prática, portanto, a regra seria substituída por um esquema centralizador.

Wiseman (1981:236) discute então a reformulação da regra de forma que esta lide não com o verdadeiro custo de oportunidade, mas com as receitas esperadas, expressas em orçamento, de planos diversos de emprego de um recurso. Tal reformulação traria por sua vez alguns problemas, como o fato de que apenas um desses orçamentos será realizado, sendo assim impossível comparar as duas vias de ação, ou ainda a formulação de um critério para escolher quais orçamentos alternativos seriam os relevantes ${ }^{27}$.

A alternativa com menos problema, para Wiseman, seria a adoção de uma regra de maximização de receita líquida - lucro - da mesma forma que ocorre nos mercados reais, assistida por regulações centrais que inibam comportamentos anticompetitivos, a fim de que se aproxime um pouco mais do resultado eficiente encontrado no modelo da competição perfeita.

Embora tanto as curvas de custo marginal quanto as de custo médio não possam ser traçadas de forma objetiva, a discussão de Wiseman recupera o valor da abordagem mais pragmática de Durbin frente à de Lerner, na medida em que o primeiro se preocupava com a solvência das firmas e o último lidava apenas com os custos marginais.

Buchanan (1981, 1993) agrupa as contribuições de Hayek, Thierlby, Wiseman e de outros autores em uma tradição austríaca-londrina de custos marginais subjetivos. Para ele, toda a controvérsia do cálculo se resolve com o reconhecimento da natureza subjetiva dos custos: é evidente que é possível calcular magnitudes objetivas, como fizeram os socialistas de mercado; entretanto, o problema do cálculo não envolve a manipulação de magnitudes objetivas dadas. Mesmo Hayek teria falhado no debate em explicitar a natureza subjetiva dos custos, o que teria tornado mais clara a natureza da objeção ao socialismo de mercado.

O reconhecimento da subjetividade dos custos, porém, não basta para resolver a questão. Tanto Mises quanto Knight ou Lerner também partiam de uma noção subjetiva de custos, não deixando porém clara a maneira como essas variáveis subjetivas se relacionavam com o mundo externo. A contribuição fundamental de Hayek, por sua

\footnotetext{
${ }^{27}$ Thielby (1981:169) ilustra a natureza cambiante dos custos: se um recurso aplicado em A ou em B gera $\$ 100$ e $\$ 150$ no projeto C, o custo de oportunidade da escolha de A será \$100 ou \$150 conforme a alternativa $\mathrm{C}$ seja ignorada ou desconhecida para o administrador que tenha escolhido $\mathrm{A}$.
} 
vez, investiga como as avaliações subjetivas convergem para uma realidade objetiva composta pelas ações dos demais agentes e pelo ambiente físico - através de um processo de aprendizado por tentativas e erros dado pelo mecanismo de lucros e perdas, que corrige as hipóteses empresariais a respeito do estado dos mercados em certo tempo e lugar.

Não se pode, dessa forma, dispensar o mecanismo de lucros em favor da adoção de critérios que façam referência direta aos custos marginais ou médios, a menos que se assuma - ilegitimamente - que as avaliações subjetivas correspondam automaticamente à realidade subjacente.

Já na década de cinquienta, algumas discussões metodológicas que ocorreram a respeito da natureza do instrumental da teoria econômica, semelhantes à crítica de Hayek, teriam sido esclarecedoras para a controvérsia do cálculo. Alchian [1950], de maneira análoga a Hayek, Thierlby e Wiseman, afirma que a hipótese de maximização de lucros não fornece um guia descritivo da ação dos agentes. A adoção da hipótese de maximização, porém, pode ser justificada na medida em que haja um processo evolutivo, de seleção natural, cujo resultado seja igual àquele descrito pela teoria de equilíbrio. Mesmo partindo de uma situação na qual os agentes determinam suas escolhas de forma arbitrária, o mecanismo de perdas e ganhos selecionaria aquelas que tendem a gerar mais valor do que subtrair recursos para outros fins (preço acima do custo). A seleção por falência ou a correção de hipóteses empresariais na forma de imitação daquelas firmas mais bem sucedidas constitui um mecanismo de seleção natural, tal como o requerido no processo de aprendizado descrito por Hayek. Em Alchian tal mecanismo é explicitamente comparado com a teoria da evolução:

The economic counterparts of genetic heredity, mutations, and natural selection are imitation, innovation, and positive profits. (1950:32)

A tradução da teoria econômica para o linguajar evolucionário se encaixa perfeitamente no programa de pesquisa de Hayek, na medida em que este preconizava a investigação sobre as condições necessárias para que haja adaptabilidade nos mercados. A tendência ao equilíbrio, por exemplo, dependeria da estabilidade do ambiente externo, que permite que o mesmo comportamento seja recompensado ou punido durante um período satisfatório de tempo. A liberdade para testar hipóteses empresariais diferentes, por sua vez, permite que haja a diversidade necessária para que o mecanismo de seleção funcione. 
É importante frisar que o uso da metáfora evolucionária não implica na garantia de que os resultados da teoria microeconômica sempre sejam válidos, e que portanto pode-se dispensar o estudo do mecanismo seletivo (ou processo de mercado), como parece sugerir o uso do argumento "as if" pelo instrumentalismo friedmaniano. Pelo contrário, convida a investigar a natureza desses mecanismos seletivos para que se possa identificar as ocasiões em que é possível justificar o uso do aparato teórico usual. Nessa ótica, o uso da teoria de equilíbrio pelos socialistas de mercado, porém, ao mesmo tempo que retém a igualdade $\mathrm{p}=\mathrm{CMg}$ ou a hipótese de minimização de custos, descarta o mecanismo que permite que esses resultados sejam justificados. Neste caso, o uso da teoria não foi fundamentado por uma explicação evolucionária que daria suporte à mesma.

Esse ponto, pela sua importância, deve ser enfatizado por meio de um exemplo. Considere o resultado teórico que afirma que uma firma maximizadora de lucros contrata um recurso de forma a igualar o valor do seu produto marginal ao preço de tal recurso. Interpretado literalmente, como quando aplicado ao socialismo de mercado, tal resultado exige que exista de fato uma função de produção bem definida e conhecida e que o administrador possa conhecer o produto marginal de um fator, além de expectativas acuradas sobre os preços futuros do insumo e do produto.

Quando aplicado à descrição de mecanismos de mercado reais, entretanto, não é necessário pressupor a existência ou conhecimento dessas simplificações teóricas. Ainda assim pode-se argumentar que as firmas que contratem uma determinada quantidade de um recurso de tal forma a aproximar esse resultado, baseadas em opiniões impressionistas sobre tais magnitudes, ou ainda baseando-se em critérios totalmente diferentes, obtenham lucros maiores do que firmas que contratem quantidades muito diferentes.

Assim, a firma que aproxima o resultado teórico prospera e é imitada. Nem o economista nem o agente, entretanto, tem conhecimento dos 'dados' do problema. Naturalmente, quanto mais acurada a opinião do agente, maior a chance de que este prospere. O socialismo de mercado, por outro lado, depende de uma interpretação extremamente literal da teoria: se não for possível determinar conscientemente o produto marginal de um fator, as regras não são aplicáveis, já que não existe o mecanismo de seleção de erros. 
Em conclusão, voltando à regra de Lerner, a discussão das mencionadas contribuições de Weiseman e Alchian é ilustrativa do tipo de crítica feita por Mises e Hayek ao uso da teoria efetuada pelos socialistas de mercado. Embora a regra do custo marginal seja adequada tendo em vista a teoria de equilíbrio competitivo, fora deste sua relevância se perde devido ao fato de que entre os mecanismos de descoberta e correção de erros a respeito de conjecturas subjetivas sobre o estado de um mercado, o mecanismo de lucros e perdas é o único mecanismo de seleção impessoal, externo, que não depende de definições maleáveis sobre quais foram os custos incorridos. Adotado um mecanismo de seleção artificial, baseado na identificação direta dos custos, abre-se espaço para manipulações arbitrárias da magnitude dos custos. Se a avaliação subjetiva dos custos de uma firma no socialismo de mercado for irreal, a firma continua a sobreviver. Se a avaliação dos custos de uma firma em um mercado real for irreal, cedo ou tarde isso afetará a lucratividade dessa firma. 


\section{A Batalha das Interpretações}

Nos dois últimos capítulos estudamos separadamente as propostas dos socialistas de mercado e as críticas austríacas a essas propostas. Os textos discutidos nesses capítulos, que compõem o núcleo do debate do cálculo econômico socialista, foram escritos em sua maioria entre 1935 e 1940, com desdobramentos realizados ao longo da década de quarenta. Depois disso, embora os protagonistas do debate tenham continuado a pesquisar sobre o tema do socialismo, a partir da década de cinqüenta não encontramos, salvo esporádicas menções ao debate, novas discussões diretas entre os mesmos autores. Até que ressurja na década de noventa, o debate fica relativamente dormente entre 1950 e 1990. Nesse período, a controvérsia é pobre em termos de geração de novas propostas de solução do problema do cálculo, girando mais em torno das diferentes interpretações sobre quem teria 'vencido' o debate das décadas de trinta e quarenta.

Essas décadas são então marcadas por trabalhos de História do Pensamento Econômico que procuram elucidar e interpretar as diferentes posições em conflito. Ao longo desse período surgiram diferentes versões do debate, que serão mais ou menos aceitas em cada instante do tempo conforme ocorria a evolução da teoria econômica e variava a aceitação do ideal socialista. Logo após o arrefecimento do debate, quando a teoria do equilíbrio geral ainda se desenvolvia e inspirava confiança entre economistas e o bloco soviético se expandia no pós-guerra, os economistas eram quase unânimes em afirmar que Lange havia vencido Hayek. A partir da década de oitenta, porém, com a maturidade da teoria, que vem acompanhada pelo aumento das críticas à mesma, e o ressurgimento do interesse por temas austríacos, além da crescente perda de confiança na capacidade de crescimento econômico da URSS, até o seu colapso final, o debate foi reinterpretado de forma favorável a Hayek. O ressurgimento da Escola Austríaca, por sua vez, gerou um debate interno que contrapôs as posições de Mises e Hayek. Além disso, já na década de noventa, alguns desenvolvimentos teóricos como a Economia da Informação e a teoria da Escolha Pública deram origem a novas propostas de socialismo de mercado e respectivas críticas, o que resultou em ainda outra interpretação da controvérsia original.

O propósito deste capítulo é estudar as diferentes interpretações feitas até a década de oitenta, além de construir uma interpretação própria sobre o significado da controvérsia. 
No capítulo seguinte, estudaremos a retomada do debate na década de noventa à luz da nossa interpretação.

\section{As Interpretações do Debate}

A interpretação predominante até 1985, denominada por Lavoie de 'versão padrão' do debate, repetida até hoje em boa parte dos livros textos de História do Pensamento Econômico e Sistemas Econômicos Comparados, pode ser sintetizada nos seguintes pontos ${ }^{1}$ :

i) Antes de Mises os socialistas não desenvolveram um modelo sobre o funcionamento econômico de uma comunidade socialista.

ii) $\mathrm{O}$ artigo de Mises, que teve o mérito de chamar a atenção para o problema, defende a tese de que é impossível sem propriedade privada e portanto sem preços de mercado alocar os recursos de forma racional; isto é, de forma que se obtenha uma alocação ótima de Pareto. O socialismo seria então teoricamente impossível.

iii) Antes mesmo da publicação do artigo de Mises, a tese da impossibilidade teórica foi refutada por Enrico Barone, que mostrou que uma economia socialista (sem propriedade privada) poderia resolver o problema através da solução de um conjunto de equações que descrevam o equilíbrio geral da economia. Dickinson, em resposta a Mises, repete a tese de Barone.

iv) Hayek e Robbins aceitam a possibilidade teórica do socialismo, recuando a uma segunda linha de defesa que afirma a sua impossibilidade prática, visto que não seria possível resolver efetivamente milhares de equações, nem obter os dados que as alimentem. Nota-se ainda que o argumento de Hayek é anterior à era dos computadores.

v) Lange, por sua vez, refuta a posição de Hayek, mostrando que o sistema de equações não precisa ser resolvido diretamente se o órgão planejador estabelecer diferentes preços até que um equilíbrio seja obtido por tentativas e erros.

\footnotetext{
${ }^{1}$ Na síntese da 'versão padrão' feita por Lavoie (1985a:10), cada ponto é fartamente ilustrado por citações retiradas de diversas fontes secundárias que ilustram essa versão do debate.
} 
Fica evidente pela leitura dos tópicos que tal interpretação é derivada da versão dos fatos elaborada em 1936 pelo próprio Lange. Portanto, em termos históricos, pelo menos até a década de oitenta, podemos dizer que Lange venceu o debate.

A interpretação de Lange foi difundida na profissão por vários autores, entre os quais se destacam Lippincott, Schumpeter e Bergson ${ }^{2}$. Esses três autores tiveram papel especial nesse processo, dado que o relato de tais autores foi a base a partir da qual se desenvolveu vasta literatura secundária sobre o assunto.

Um grande impulso na difusão da 'versão padrão' do debate foi dado pela publicação em 1938 dos artigos de Lange e de Taylor na forma de livro, editados com uma introdução por Lippincott. Nessa introdução, Lippincott repete a versão langeana do debate de forma mais didática, despida de complicações técnicas do argumento e das questões ainda por resolver que podemos encontrar nos artigos acadêmicos de Taylor e Lange que compõem o livro.

Apesar de que a introdução de Lippincott fosse muitas vezes a referência básica para a familiarização com o problema do cálculo, o maior responsável pela popularização da versão em questão do debate foi Schumpeter ${ }^{3}$, dada a influência que as idéias deste autor geralmente exerce sobre a opinião dos economistas no que diz respeito a história da disciplina. A controvérsia do cálculo é discutida por Schumpeter tanto em Capitalismo, Socialismo e Democracia [1947] quanto em History of Economic Analysis $[1954]^{4}$.

$\mathrm{Na}$ primeira obra, Schumpeter inicia dois capítulos que tratam da economia do socialismo com afirmações confiantes sobre a sua viabilidade:

Será viável o socialismo? Claro que é. (pág. 215)

Antes de mais nada, precisamos ver se existe ou não algo de errado com a lógica pura da economia socialista. ... Nada há de errado com a lógica pura do socialismo. E isso é tão óbvio que não me ocorreria insistir, não fosse pelo fato de que houve quem negasse, ... (Schumpeter, 1984:221)

\footnotetext{
${ }^{2}$ Lavoie (1981b) examina ainda a apreciação do debate dada por Ward (The Socialist Economy: A Study of Organizational Alternatives), Sweezy (The Economist in a Socialist Economy) e Dobb (Welfare Economics and the Economics of Socialism). Todas essas narrativas, inclusive a de Dobb, repetem em essência a versão langeana.

3 Hayek (1984:59) atribui a Schumpeter o que denomina mito de que Barone teria resolvido a controvérsia.

${ }^{4}$ É importante notar que Schumpeter orientou Klaire Tisch em sua tese de doutorado sobre o cálculo econômico.
} 
Nota-se que o autor coloca a questão em termos da consistência lógica do socialismo, distinguindo logo no primeiro parágrafo do capítulo XVI entre prova lógica (teórica) e viabilidade prática do socialismo. Schumpeter afirma que Mises, a autoridade negadora da credencial lógica do socialismo, não teria obtido resposta dos socialistas ortodoxos, pois estes não dominavam a teoria necessária para tal. A resposta definitiva, porém, teria sido dada por Barone, que mostrou que a 'lógica fundamental' da solução é a mesma tanto nas sociedades comerciais quanto no socialismo.

Schumpeter se propõe então a esboçar a tese de Barone despida do formalismo. O que segue, porém, não enfatiza a descrição do equilíbrio geral e do mecanismo de tentativas e erros, mas sim o comportamento das firmas individuais: descreve-se um esquema de distribuição de renda em dólares, a serem gastos pelos consumidores em indústrias cujas administrações devam minimizar custos, adquirir os recursos (dados) com os dólares obtidos através das vendas e produzir de forma a igualar o custo marginal ao preço estabelecido centralmente. O autor (pág. 226) continua sua exposição afirmando que 'a tarefa de cada comitê industrial é, então, determinada de maneira única, como, hoje em dia, todas as firmas de uma indústria em concorrência perfeita sabem o que, como e quanto produzir - desde que sejam dadas as possibilidades técnicas, as reações dos consumidores ... e os preços dos meios de produção'.

Percebe-se a identificação imediata da realidade dos mercados competitivos com a teoria da competição perfeita, da mesma maneira como fizera Lange anteriormente. De fato, alguns parágrafos mais adiante (pág. 228), Schumpeter revela que para funcionar na prática a transição para o socialismo deve ser feita de forma que o capitalismo esteja próximo do estado estacionário, já tendo vivido 'as loucuras da mocidade'. Pela análise dos dois trechos mencionados, mais uma vez podemos verificar a crença, também presente entre os socialistas de mercado, na capacidade da teoria de descrever a essência do funcionamento das economias reais, que de fato estariam próximas a um estado de equilíbrio. Ausentes grandes inovações, os agentes se comportam como tomadores de preços em um ambiente com tecnologias dadas. A falta de discussões metodológicas sobre a natureza das simplificações teóricas leva o autor a crer em um estado estacionário real e que a tarefa dos administradores socialistas seja unicamente determinada pelos fundamentos (dados) da economia, segundo a descrição teórica desses fundamentos. 
Para o autor, a transição de uma economia estacionária (que, como vimos, não é apenas um recurso teórico, mas algo que possa ser aproximado na prática) para uma na qual ocorra 'mudança industrial' não envolveria dificuldades substanciais para os planejadores. Schumpeter discute então o que fazer com o lucro advindo da mudança. As questões 'dinâmicas' que preocupam Schumpeter são, porém, claramente distintas daquelas levantadas por Mises e Hayek. Enquanto para o primeiro o empresário aparece de vez em quando para perturbar um equilíbrio estático, para os últimos a atividade empresarial seria necessária em todo instante para que se possa esperar uma tendência ao equilíbrio. Para estes autores, o estado estacionário seria apenas um útil instrumento analítico sem contrapartida na realidade.

Em History of Economic Analysis, Schumpeter (1994:985-990) volta ao tema do cálculo econômico socialista, repetindo a tese knightiana de que o argumento de similitude formal de Wieser, Pareto e Barone constitui uma prova da possibilidade lógica (teórica) do socialismo:

But all this amounts to saying that any attempt to develop a general logic of economic behavior will automatically yield a theory of the socialist economy as a by-product. (Schumpeter, 1994:987)

Barone, ao mostrar que existe para uma economia socialista um sistema de equações que possua um conjunto determinado de soluções que apresente propriedades de optimalidade, refuta também, em termos lógicos (pág. 989) a tese de que o socialismo seria irracional. $\mathrm{O}$ argumento de Mises e Hayek a respeito da impossibilidade em termos puramente teóricos (pág. 989, n.r. 12) seria então 'definitivamente errado'.

Note-se o uso alternado dos termos lógico e teórico, o que indica a sua equivalência, no entender do autor. Em relação a isso, devemos ter em mente o contraste com a opinião de Hayek expressa no artigo de 1937, no qual argumenta que a teoria econômica não deveria se limitar ao aspecto lógico, buscando um elemento empírico no estudo da tendência ao equilíbrio. A identificação exclusiva de argumento teórico com a pura lógica da escolha leva Schumpeter a ter dificuldades em interpretar os argumentos de Mises e Hayek. De fato, Schumpeter (1994:989) considera difícil determinar se tais autores negam de fato a validade do resultado de Barone.

A posição de Schumpeter no debate é em muitos aspectos surpreendente. Keizer (1997) dedica um artigo à tarefa de entender os paradoxos envolvidos nessa posição. Dada a antipatia de Schumpeter pelo socialismo, sua formação austríaca e sua própria teoria sobre a destruição criativa inerente à competição empresarial, deveríamos esperar que o 
autor se posicionasse contrário ao socialismo de mercado, moldado na teoria do equilíbrio estático. Além de indicar o gosto por paradoxos e polêmicas do autor, Keizer aponta para a admiração e respeito que Schumpeter devotava à teoria do equilíbrio geral e à formalização matemática, embora não fosse ele mesmo muito versado em matemática e não tivesse utilizado tal ferramenta em suas contribuições. Em History of Economic Analysis tal admiração pode ser constatada na afirmação de que Walras teria sido o maior economista de todos os tempos e a teoria do EG o maior feito teórico da disciplina.

Hayek, por sua vez, atribui a posição de Schumpeter a crenças metodológicas. Em "The Uses of Knowledge in Society" Hayek (1981:89-91) critica a afirmação encontrada em Capitalismo, Socialismo e Democracia (pág. 225) de que "os consumidores, ao avaliarem bens de consumo, ipso facto avaliam também os meios de produção que entram em sua produção". Para Hayek, a afirmação revela a adoção de "um certo ramo do positivismo" da parte de Schumpeter. O 'ipso facto' sugere que a avaliação dos fatores de produção seria uma implicação lógica da avaliação dos consumidores, como se uma única mente na posse dos dados objetivos calculasse todas as alternativas e escolhesse a melhor, como em um problema de engenharia. A posição de Schumpeter ignoraria então que entre os dados objetivos do problema e as ações estão as interpretações dos agentes sobre essas realidades, interpretações essas sujeitas a um processo de aprendizado. A objetivização dos dados ${ }^{5}$, inerente à formulação matemática do modelo, esconderia o fato de que 'a inevitável imperfeição do conhecimento humano' não permite concluir que o resultado da interação no mercado seja determinado a priori a partir de fundamentos objetivos da economia. Cada agente, com base em opiniões distintas sobre a realidade, escolheria uma linha de ação própria e portanto avaliaria os meios (os fatores de produção) de forma diversa.

Chegamos agora ao terceiro autor cuja contribuição solidificou a aceitação da versão padrão. Em 1948 Bergson escreve um artigo avaliando o debate. Nas décadas seguintes, esse artigo foi visto como a principal referência acadêmica ${ }^{6}$ sobre o assunto. Embora quase a totalidade do artigo seja dedicada à discussão da natureza de uma alocação ótima que deva ser obtida no socialismo, o que revela a primazia da pura lógica da

\footnotetext{
${ }^{5}$ Ver ponto análogo na discussão levantada por James Buchanan, no final do capítulo anterior.

${ }^{6}$ Ver Lavoie (1981b:49)
} 
escolha no pensamento do autor, Bergson também opina sobre o debate em si e examina algumas objeções ao modelo de Lange.

Bergson apresenta duas interpretações sobre o significado da tese de Mises. Segundo a primeira, mesmo um Órgão de Planejamento Central onisciente não poderia alocar recursos racionalmente:

Let us imagine a Board of Superman, with unlimited logical faculties, with a complete scale of values for the different consumers' goods and present and future consumption, and a detailed knowledge of production techniques. Even such a Board would be unable to evaluate rationally the means of production. (Bergson, 1948: 446)

Essa interpretação a respeito do que Mises teria dito seria defendida por Lange e Schumpeter, que indicaram que o argumento foi refutado por Pareto e Barone. A outra interpretação, que Bergson atribui a Hayek, afirma que o socialismo não seria logicamente impossível, mas não haveria maneira prática de realizá-lo. Quanto a essa segunda interpretação, Bergson contrasta a opinião de Lange, segundo a qual ele próprio teria refutado essa segunda tese, com a opinião de Hayek, que não acredita nessa solução. Bergson deixa ao leitor a decisão sobre qual interpretação seria a correta.

A inclinação do autor sobre a viabilidade do socialismo de mercado, entretanto, se revela na apreciação que Bergson (1948: 434-440) faz de algumas objeções levantadas contra o modelo de Lange. Entre estas, vejamos três relacionadas à crítica de Hayek.

Em primeiro lugar, Bergson investiga a questão do controle e incentivos no modelo. Deve-se notar que entre os autores simpáticos ao socialismo de mercado, Bergson foi provavelmente o primeiro a considerar legítima a discussão sobre incentivos, questão essa que só será abordada na retomada moderna do debate na década de noventa. Para Bergson, o teste ótimo de desempenho administrativo seria o lucro obtido pela firma. Entretanto, como já discutimos, a maximização de lucros, se seguida pelas firmas, violaria as regras de custo que levam à eficiência naquelas ocasiões em que temos condições diferentes das de competição perfeita.

Bergson cita então a objeção de Hayek de que o CPB teria que auditar minuciosamente os registros de custos das firmas ${ }^{7}$. Para Bergson (1948: 435), Hayek teria exagerado o problema: "provided the question of controls could be disposed of satisfactorily, our impression is that the question of managerial incentives would not present any serious difficulties". Acredita o autor que seria viável a construção de um clima no qual se

\footnotetext{
${ }^{7}$ Devemos lembrar, porém, que a objeção de Hayek não se relacionava a incentivos, mas sim ao fato de que os custos de oportunidades não são entidades objetivas fora do equilíbrio.
} 
avalie corretamente o risco dos empreendimentos. Sugere então esquemas como prêmio por lucros como incentivo, quando a maximização de lucros for adequada.

Em segundo lugar, mesmo ausentes problemas de incentivos, os agentes terão que prever as condições futuras do mercado. Para Bergson, entretanto, isso seria minimizado pela existência de um 'serviço de informação abrangente para o benefício dos gerentes'. Contrário à distinção de Hayek entre conhecimento do cientista e conhecimento localizado, Bergson acredita, da mesma forma que Dickinson, que dados colhidos em forma estatística são suficientes para gerenciar firmas.

Em terceiro lugar, Bergson (1948: 436) enfrenta o argumento de Hayek de que o esquema de Lange seria rígido porque não reajusta preços continuamente e trata produtos diferenciados de forma homogênea. Embora reconheça o problema do conhecimento disperso, inclusive citando o artigo de Hayek de 1945, novamente Bergson minimiza as dificuldades, acreditando que o CPB poderia construir um aparato elaborado para fixar preços, descentralizado geográfica e funcionalmente.

O artigo de Bergson, embora seja o único na literatura do socialismo de mercado até então a tratar de algumas das objeções feitas por Hayek e a reconhecer a existência de tais problemas, tende a minimizar a sua importância, contribuindo na difusão da opinião padrão do debate. Mais tarde, em um artigo menos conhecido, de 1967, Bergson aumenta seu ceticismo a respeito da viabilidade do socialismo de mercado, considerando com mais atenção algumas críticas de Hayek e levantando objeções a respeito da motivação dos agentes que só serão consideradas pelos socialistas na retomada do debate na década de noventa.

A partir das contribuições de Lange, Schumpeter, Bergson e de vários outros economistas, a versão padrão do debate é estabelecida definitivamente na literatura. A partir daí tal versão se espalhou para os livros-textos. Samuelson (1958:336), por exemplo, em uma nota de rodapé da Introdução à Análise Econômica resume o debate nas mesmas linhas. Sugere que Mises talvez desconhecesse a prova de Pareto quando aquele teria afirmado a impossibilidade lógica do socialismo. Em livros-texto de HPE traduzidos para o português, Fusfeld (2001:192), por exemplo, repete com detalhes a versão padrão, notando ainda que o argumento prático de Hayek foi escrito em uma época em que os computadores não eram conhecidos. 
A interpretação dominante da controvérsia, como vimos, teve sua origem no artigo de Lange de 1936-7. Seria interessante investigar então como evoluiu a opinião do autor depois dessa data. Os escritos posteriores de Lange sobre o socialismo, porém, versam mais sobre os problemas a serem enfrentados pelas reformas na Polônia e outros países do que sobre novas teorias ou controvérsias a respeito dos modelos de socialismo de mercado $^{8}$. Contudo, mencionaremos dois documentos que tratam de sua polêmica com Hayek.

Em uma cordial carta de 31 de julho de 1940, Lange ${ }^{9}$ escreve a Hayek agradecendo por este ter enviado uma cópia da crítica que este autor (Hayek, 1940) fizera ao seu artigo. $\mathrm{Na}$ carta, podemos encontrar uma adição de Lange a sua interpretação do debate:

I hope you won't be cross if I should characterize your position as taking a third line of defense, this time shifting the issue from the purely static to the dynamic aspects. (Lange, citado em Kovalik, 1994:298)

Impressionado com o artigo, Lange afirma que a 'mudança' para questões dinâmicas traz à tona as questões que realmente importam para o problema:

You certainly have succeeded in raising an important issue and pointing out the loopholes in a purely static solution as the one given by myself. (Lange, em Kovalik, 1994:298)

Lange escreve que planeja escrever um artigo em resposta a essas objeções a ser submetido à Economica - revista editada por Hayek - no outono daquele ano. Tal resposta, porém, nunca foi escrita.

Talvez sob o impacto do artigo de Hayek, Lange faz nessa carta uma surpreendente declaração, incompatível com os escritos anteriores e posteriores do autor sobre o tema. Afirma Lange que a sugestão da fixação de preços pelo CPB não seria uma solução prática, mas um 'recurso metodológico' para mostrar que se podem encontrar preços de equilíbrio por um processo de tentativas e erros sem fazer o uso de mercados reais. Lange esclarece que quando o número de agentes for grande, deve-se deixar que os preços sejam determinados pelos mercados e não seria necessária a socialização. Apenas em casos de competição imperfeita a fixação central de preços seria uma sugestão prática de uso do mecanismo descrito no artigo.

Em outra ocasião o autor revela dúvidas sobre o significado prático de seu modelo. Em um artigo de 1947 (Kovalik, 1994:169), Lange afirma que a análise marginal requer

\footnotetext{
${ }^{8}$ Ver Kovalik (1994).

${ }^{9}$ A Carta está transcrita no apêndice da coletânea de artigos editados por Kovalik (1994:298).
} 
muito mais elaboração em termos operacionais até que sirva como base para decisões práticas.

A aceitação da validade da crítica de Hayek e as dúvidas sobre o significado prático de seu resultado, contudo, voltam a desaparecer no último artigo escrito por Lange, no qual o autor reafirma sua confiança na simulação dos mercados através da teoria do equilíbrio geral. Nesse artigo, seguindo o caminho inverso ao de Dickinson, Lange migra da solução por tentativas e erros para a solução matemática:

Were I to rewrite my essay today my task would be much simpler. My answer to Hayek and Robbins would be: so what's the trouble? Let us put the simultaneous equations on an electronic computer and we shall obtain the solution in less than a second. The market process with its cumbersome tâtonnements appears old-fashioned. Indeed, it may be considered as a computing device of the pre-electronic age. (Lange, 1969:158) ${ }^{10}$

Nessa passagem Lange reafirma sua crença de que a essência da tarefa exercida pelos mercados é descrita pelo mecanismo de tâtonnement do modelo de equilíbrio geral.

A partir da década de oitenta, com o ressurgimento do interesse pela escola austríaca ${ }^{11}$, tomou corpo a literatura que contesta a interpretação dominante descrita acima. Embora esta última ainda predomine até hoje nos livros-textos, os trabalhos acadêmicos a respeito do debate feitos a partir de então foram em grande parte revisionistas. Veremos agora a formação dessa segunda versão do debate, desde sua formação até seu ápice na década de oitenta.

Da mesma forma que a opinião predominante teve sua origem em Lange, as interpretações contrárias se apoiaram em Hayek. A versão hayekiana dos fatos pode ser inferida a partir do livro de 1935 e do artigo de 1940. No primeiro, a história de Hayek é incompleta devido à data na qual foi escrita. No segundo, Hayek (1940:125-6) identifica três fases do debate, em cada uma delas havendo uma derrota da posição socialista. Podemos colocar a história de Hayek na forma de tópicos, como foi feito com a versão padrão:

1 a etapa: a tese de que o socialismo poderia dispensar o cálculo em termos de valor em favor de algo como cálculo em espécie foi refutada pelos teóricos de similitude formal e por Mises.

$\underline{2^{a}}$ etapa: a tese de que o cálculo econômico no socialismo poderia dispensar os mercados em favor da solução matemática foi refutada (por antecipação) por Pareto,

\footnotetext{
${ }^{10}$ Ver também "From Accounting to Mathematics" reproduzido em Kowalik (1994).

${ }^{11}$ Minha dissertação de mestrado trata da história desse ressurgimento.
} 
que argumenta que o único modo de resolver as equações é por observação dos mercados reais.

3 3apa: $^{\text {a }}$ a tese de que a solução para o sistema de equações poderia ser obtida por tentativas e erros foi criticada pelo artigo de 1940 do próprio Hayek.

Além de enfatizar as alterações na posição socialista, Hayek combate as alegações de Lange sobre o recuo austríaco a uma segunda linha de defesa:

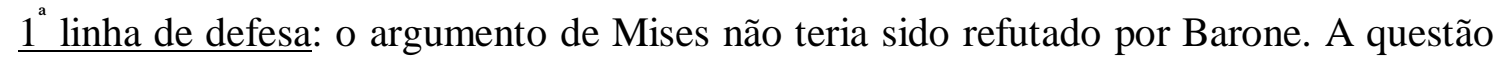
de Mises não seria sobre se as categorias econômicas devam ser aplicadas, o que seria óbvio desde Wieser, mas sim como de fato poderiam ser aplicadas sem mercados.

$\underline{2^{a}}$ linha de defesa: Hayek não abandonou o argumento de Mises em favor do argumento da impossibilidade prática. A diferença no argumento dos dois autores reside no tipo de idéias às quais se contrapõem. Enquanto os socialistas aos quais Mises se opôs partem de outra teoria, Hayek nega não a consistência lógica da teoria empregada pelos socialistas de mercado, mas sim sua relevância para resolver o problema.

A opinião de Hayek sobre o tema, ignorada durante o debate, passou a ser recuperada por alguns autores desde então, até que, nas mãos de Lavoie, se solidifique em uma interpretação alternativa - austríaca - do debate. Um das primeiras contestações da versão padrão foi feita por Michael Polanyi, irmão de Karl Polanyi. Ao contrário deste, que respondeu ao desafio de Mises por meio de uma das primeiras propostas de socialismo de mercado ${ }^{12}$, M. Polanyi [1950] se alinha com a posição contrária ao socialismo.

Em sua apreciação do debate, M. Polanyi enfatiza a posição socialista original contra a qual o argumento de Mises foi dirigido, posição essa que pretende eliminar os mercados em favor do controle consciente da produção. Esse objetivo, central para o socialismo, teria sido esquecido no desenrolar do debate. O socialismo de mercado, ao confiar aos mercados a alocação dos recursos, de fato teria abandonado a pretensão de planejamento central:

Sem que os críticos e os defensores percebessem, a teoria socialista moderna, ao adotar os princípios do comércio, tinha abandonado silenciosamente o pleito cardeal do socialismo: a direção central da produção industrial. (M. Polanyi, 2003:198-9)

\footnotetext{
${ }^{12}$ A proposta de K. Polanyi é mencionada no capítulo 2.
} 
A acusação de Polanyi é dirigida tanto aos defensores quando aos críticos do socialismo de mercado, lembrando que Dobb foi o único a protestar contra o abandono do ideal de planejamento central. Devemos recordar, porém, que Mises, Robbins e Hayek não deixaram de notar esse recuo em suas críticas ${ }^{13}$. Samuelson, (1958:336), em nota de rodapé na qual resume o debate, parece concordar com a visão de Polanyi quando descreve o CPB como 'deliberadamente planejando não planejar'.

Roberts [1971], vinte anos mais tarde que Polanyi, insistirá na tarefa de colocar o argumento de Mises em perspectiva histórica, contrapondo-o com as idéias socialistas originais. Roberts acredita que a essência do socialismo seria a abolição do sistema de produção de mercadorias. Neste sistema, as relações sociais entre as pessoas são determinadas segundo as relações entre mercadorias e a exploração do trabalho não é explícita, mas escondida sob a forma do pagamento de salários. Portanto, o fím da alienação dos trabalhadores, no socialismo, seria obtido pela abolição da produção de mercadorias. Os homens, assistidos pela ciência, dominariam o processo produtivo em vez de se ajustarem ao mecanismo dos mercados: as relações produtivas autônomas dos mercados seriam eliminadas em favor da organização racional da produção, cuja execução seria feita como se fosse em uma única fábrica.

Tendo em vista a natureza da oposição marxista aos mercados, a proposta de solução do problema de Mises oferecida por Lange teria, para Roberts (1971:265), obscurecido e posto fora de contexto o problema do planejamento. Como Mises combatia a proposta de eliminação das relações de mercado, uma teoria do socialismo baseada nas mesmas relações de troca não consistiria então em uma resposta ao problema do cálculo. Além de não responder a Mises, o modelo de Lange, ao ignorar a essência do socialismo, cria um socialismo em que nenhum socialista acreditou ou lutou por ele ${ }^{14}$. O debate, que procura investigar se os mercados poderiam ser simulados, só interessaria aos economistas teóricos.

A solução proposta por Lange, entretanto, fala em planejamento central. Mas quando se examina o funcionamento do modelo, observa-se que o papel do CPB é em essência ratificar os desejos dos agentes isolados e não dirigir a produção. O uso da

\footnotetext{
${ }^{13}$ Hayek nota que os socialistas de mercado invocam o planejamento central quando defendem a superioridade do socialismo, mas quando estão diante de qualquer problema concreto apelam para os mercados.

${ }^{14} \mathrm{Na}$ mesma linha opina Steele (1991:192): “'Market socialism' or factor market socialism means factor markets without financial markets. It has two problems: it is too capitalist to appeal to most socialists, and not capitalist enough to work."
} 
nomenclatura de planejamento e o apelo à alocação via mercados, para Roberts, consiste em uma contradição no modelo de Lange:

The contradictory dualism of the Lange model has been upheld by the willingness to overlook the logical inconsistency in assigning it a dual status. With this inconsistent duality, the Lange model was able to establish the theoretical possibility of socialist planning on the basis of the very market principles that socialist planning was supposed to replace. (Roberts, 1971:566)

O CPB, para Roberts, se limita a um papel passivo de reajustar preços determinados externamente pelos agentes isolados e portanto não consiste em um esquema de planejamento central ${ }^{15}$.

A ilusão de planejamento central existente na proposta de Lange, para Roberts [1971:572], teria sido perpetuada pela crítica de Hayek (1940), que concedeu à proposta uma não merecida credibilidade ao criticá-la em seus próprios termos. Mises, por sua vez, teria contribuído com isso ao apresentar ao mesmo tempo o argumento sobre a impossibilidade do planejamento e a defesa da propriedade privada, dando a entender que o problema se refere à alocação de bens de capital sem propriedade privada.

Embora de fato a versão padrão do debate ignore o contexto da argumentação de Mises e consista em um recuo em relação à possibilidade de planejamento central pleno, o artigo de Roberts peca por distorções na direção inversa. Em primeiro lugar, o CPB não é tão passivo como quer o autor. Especialmente na segunda parte do artigo, Lange apela para o conhecimento superior do CPB em relação aos agentes privados a fim de corrigir imperfeições do mercado ou dirigir o investimento. Hayek, por sua vez, criticou justamente as bases da alegação a respeito desse conhecimento superior. Em segundo lugar, a questão da propriedade em Mises não consiste em um argumento à parte, mas faz parte do ponto central. De fato, Mises define socialismo como ausência de propriedade privada de bens de produção. Finalmente, a discussão sobre qual é a definição correta de socialismo, que apresentamos no primeiro capítulo, é estéril. Devese em vez disso avaliar a capacidade de se obter o fim almejado (seja qual for) a partir do esquema proposto e, no máximo, indicar em que medida esse fim se altera ao longo do debate.

A partir da década de oitenta as apreciações do debate contrárias à versão padrão terão o seu foco deslocado da discussão da relação entre o socialismo marxista e o socialismo

\footnotetext{
${ }^{15}$ Além de criticar esse aspecto do modelo, Roberts repete as críticas que estudamos no capítulo anterior a respeito da aplicabilidade das regras de custo. $\mathrm{O}$ autor nota não só que a igualdade de custo marginal e preço é resultado do comportamento de busca de lucros e não uma regra consciente a ser seguida, mas também repete a tese de Wiseman de que a regra do custo não é aplicável sob incerteza.
} 
de mercado para a crítica da interpretação neoclássica da teoria dos preços. Isso é natural na medida em que a partir dessa década ressurge nos EUA o interesse pela economia austríaca. A nova versão do debate que surge nesse período, informada pelos recentes desenvolvimentos da teoria austríaca de processo de mercado ${ }^{16}$, irá enfatizar as diferenças entre as abordagens austríaca e a tradicional, criticando o desvio para questões estáticas promovido pelos socialistas de mercado.

A primeira história do debate sob esse ponto de vista foi feita por Karen Vaughn, ativa participante do ressurgimento da Escola Austríaca. Em 1980 a autora apresenta sua versão na introdução do livro de Hoff e em um artigo sobre a história da controvérsia. Neste último, Vaughn [1980] identifica as duas percepções sobre o problema em questão - austríaca e neoclássica - e conclui que as diferenças teóricas entre as mesmas impediram desde o início a resolução da controvérsia. Assim, os austríacos divergiram do mainstream a respeito da relevância e aplicabilidade dos modelos de equilíbrio estático nos quais o conhecimento é considerado como dado, os agentes reagem mecanicamente a esses dados e os incentivos fornecidos pelas diferentes instituições não influem no comportamento desses agentes. Com a teoria econômica se limitando ao modelo teórico convencional, a tese de Mises parece ser de fato refutada por Barone e as objeções teóricas de Hayek soam como objeções práticas.

Contudo, para Vaughn, a crítica de Hayek refletiria os aspectos dos mercados que o modelo deixa de fora, em especial a atenção ao processo de ajustamento ao equilíbrio, as conseqüências da incerteza, como a necessidade de atividade empresarial, a natureza da informação ou a questão dos incentivos ${ }^{17}$.

A partir do fato de que existem importantes diferenças entre os programas de pesquisa austríaco e neoclássico, Vaughn explica o silêncio dos socialistas de mercado em relação aos argumentos de Hayek. A autora nota (pág. 536) que nos jornais ingleses de fato não houve debate entre defensores e críticos do socialismo, mas sim apenas entre os primeiros. As críticas de Hayek, por sua vez, foram ignoradas e podem ser consideradas como críticas à parte (pág. 543). Além disso, para a autora (pág. 537), os economistas

\footnotetext{
${ }^{16}$ Em especial os estudos sobre a atividade empresarial de Israel Kirzner. A referência clássica é Competição e Atividade Empresarial (Kirzner, 1985).

17 Sob o tópico 'incentivos' a autora se refere a discussão de Hayek sobre a atitude dos investidores socialistas diante do risco. Devemos lembrar que Hayek, para fins de argumentação, assume que os agentes socialistas não têm problemas de motivação.
} 
favoráveis ao socialismo tentaram refutar os argumentos de Mises, o que parecia fácil, e ignoraram as 'questões mais difíceis' levantadas por Hayek.

Entretanto, Vaughn não explora as diferenças entre Mises e Hayek a fim de fundamentar sua opinião de que os argumentos de Hayek seriam diferentes dos de Mises $^{18}$. Contrapondo-se a essa opinião, o próximo artigo revisionista sobre a história do debate, publicado por Murrell em 1983, afirma que a maioria dos argumentos contrários ao socialismo de mercado foi exposta por Mises de forma mais clara do que Hayek e defende então a tese de que o socialismo de mercado não consiste em resposta legítima ao argumento de Mises.

Da mesma forma que Vaughn, Murrell busca nas diferenças entre as teorias austríaca e neoclássica o fundamento dessa última tese. Murrell expõe então o desafio de Mises em termos austríacos e mostra que a resposta neoclássica ignora os problemas levantados por Mises. Usando citações da edição alemã de Socialism de 1932, anterior aos trabalhos dos socialistas de mercado, Murrell mostra que o problema da alocação eficiente dos recursos para Mises requer adaptação à mudança. Toda a ação é voltada para um futuro incerto e é portanto especulativa. A atividade empresarial consiste essencialmente em abrir, modificar, expandir ou fechar empresas com base em especulações particulares sobre o futuro incerto. Por isso, na teoria de Mises, especial importância é dada aos mercados financeiros. A presença de lucros, por outro lado, premia aqueles especuladores que melhor anteciparam as necessidades futuras dos consumidores. O processo seletivo dado pelos lucros ou perdas, para Murrell (1983:95), estaria no coração da teoria de Mises.

A presença de fatores como atividade empresarial diante da mudança contínua e o mecanismo de seleção dado pelos lucros (em especial nos mercados financeiros) resultam na eficiência econômica que Mises relaciona com as economias de mercado. Dessa maneira, a eficiência exigiria adaptação à mudança. No socialismo de mercado, por sua vez, todos esses fatores estão ausentes. A não ser por alguns breves comentários de Lerner sobre expectativas, não existe no socialismo de mercado ação especulativa, voltada para o futuro. No modelo de Lange, os agentes são tomadores de preços e não se fala em expectativas. Murrell conclui então que o socialismo de mercado, ao ignorar a mudança, não seria então uma resposta ao desafio de Mises.

\footnotetext{
${ }^{18}$ Dedicamos a última seção deste capítulo para a discussão da relação entre as contribuições de Mises e Hayek.
} 
A desconsideração dos argumentos de Mises por parte dos socialistas de mercado, conclui Murrell (1983:100), não pode ser atribuída ao desconhecimento desses argumentos, já que a reconstrução de Murrell do argumento misesiano foi feita com base em edições de Socialism anteriores a 1936. Como Vaughn, Murrell atribui às diferenças entre os paradigmas austríaco e neoclássico a falta de uma resolução do debate:

The debate ended with two theories, resting on different assumptions and emphasizing different properties of economies. (Murrell, 1983:93)

A tarefa de explicitar as tais diferenças e restabelecer o argumento de Mises em termos dessas diferenças chega ao seu ápice com as contribuições de Lavoie. Em 1981 este autor organiza uma edição especial do Journal of Libertarian Studies dedicado ao problema do cálculo, com trabalhos teóricos que questionam a versão padrão (Lavoie, Steele e Bradley) e trabalhos históricos que aplicam o argumento do cálculo no estudo da história da União Soviética (Steele, Richman). A contribuição mais significativa de Lavoie ao problema, contudo, foi sua história do debate intitulada Rivarly and Central Planning de 1985. Tal livro se tornou a referência moderna mais importante sobre o debate, estabelecendo 'a' versão austríaca alternativa sobre o assunto. O próprio Lavoie (1985a:20-22) coloca essa nova versão na forma de tópicos, que podemos resumir da seguinte forma:

i) Embora não tenha dito como funcionaria a economia socialista, a literatura marxista dá indicações do que essa economia não seria, pois rejeita os mercados, o sistema de preços e o uso de moeda.

ii) $\mathrm{O}$ desafio de Mises seria dirigido contra a visão marxista do socialismo; não negaria a validade da lógica da escolha para o socialismo e também não seria um argumento de equilíbrio estático.

iii) $\mathrm{O}$ argumento de Barone seria similar ao de Mises (a lógica da escolha deve ser aplicada). Enquanto para Mises o sistema de equações não seria aplicável ao mundo real, para Dickinson seria a base de uma solução concreta.

iv) Os argumentos de Robbins e Hayek não são recuos, mas clarificação do argumento de Mises, dado que o argumento socialista se modificou.

v) $\mathrm{O}$ modelo de Lange não responde a Hayek por se basear na analogia com o modelo de competição perfeita e ignorar o problema de adaptação a mudanças no mundo real. 
vi) A teoria econômica não é neutra a respeito dos méritos relativos do socialismo e capitalismo. Isso só seria verdade se por 'teoria' entende-se exclusivamente a teoria neoclássica de equilíbrio de mercado.

A fim de justificar sua versão, Lavoie procura explicitar de forma sistemática as diferenças entre as teorias austríaca e neoclássica que Vaughn e Murrell já haviam mencionado. O autor (págs. 100-113) faz isso a partir da listagem do que considera 'as limitações da análise estática' derivada da segunda teoria: a) o limitado papel do subjetivismo, b) a desconsideração dos aspectos da escolha ligados à passagem do tempo e ação empresarial em favor unicamente do aspecto maximizador, c) a concentração no estudo do equilíbrio em vez do processo de obtenção do equilíbrio e finalmente d) a exclusão do estudo da influência de diferentes instituições no comportamento dos agentes. Essa lista deixa clara, quase cinqüenta anos após o ápice do debate, a distinção entre os programas de pesquisa envolvidos na disputa e portanto a natureza do desafio. Levando- se em conta tais aspectos desconsiderados pela teoria convencional, as críticas de Mises e Hayek devem ser vistas como argumentos teóricos (e não meramente práticos) sob o ponto de vista da teoria austríaca de processo de mercado.

O conceito que norteia todo o livro de Lavoie (1985a:22) é a noção de rivalidade: 'the clash of human purposes'. O autor distingue entre o conceito neoclássico de competição perfeita e o conceito clássico de competição, próximo ao austríaco, segundo o qual a competição consiste em um processo que envolve rivalidade ${ }^{19}$. Enquanto que o programa marxista condena a luta competitiva inerente aos mercados, e o programa neoclássico (e também o socialismo de mercado) por sua vez a ignore, o desafio austríaco de Mises, segundo Lavoie, aponta para a necessidade da rivalidade econômica para que se mantenha a complexidade da produção atual. $\mathrm{O}$ autor liga a rivalidade com a solução do problema do conhecimento de Hayek, segundo o qual, podemos lembrar, dever-se-ia estudar como os agentes adquirem o conhecimento postulado pela teoria neoclássica. A rivalidade entre competidores seria responsável, para Lavoie (págs. 26 e 102), pela própria criação do conhecimento a respeito das funções de produção, o que inviabilizaria a solução do modelo de Lange:

...the key point of the calculation argument is that the required knowledge of objective production possibilities would be unavailable without the competitive market process. (Lavoie, 1985a:102).

${ }^{19}$ Ver Machovec (1995). 
O problema do conhecimento é corretamente colocado por Lavoie no centro da objeção hayekiana ao planejamento. A maneira como o autor lida com esse problema, por sua vez, pode ser encontrada em seu outro livro, publicado no mesmo ano. Em National Economic Planning: what is left? (Lavoie, 1985b) temos a crítica ao planejamento central estendida a formas distintas de planejamento, como o uso das tabelas imputoutput de Leontief. A base da crítica, calcada no problema do conhecimento, é tomada a partir das contribuições à filosofia da ciência feitas por Michael Polanyi $(2003,1962)$ e, segundo Lavoie, pelo próprio Hayek.

O problema do conhecimento de Hayek, segundo Lavoie (pág. 52), consiste na afirmação de que um órgão planejador bem intencionado não pode alocar recursos de forma adequada devido à impossibilidade de obter o conhecimento necessário para isso. Por sua vez, a crença no planejamento central seria atribuível a uma concepção errônea sobre a natureza do conhecimento:

In short, the whole case against planning that is being developed here is rooted in a critique of objectivist theories of knowledge. (Lavoie, 1985b:57)

O termo 'objetivista' é usado no sentido desenvolvido por M. Polanyi e corresponde aproximadamente à concepção positivista da ciência, segundo a qual a ciência consiste na aquisição acumulativa de conhecimento objetivo empiricamente demostrado.

Os defensores do planejamento, ao esposarem tal concepção, crêem que a barreira à obtenção do sucesso de seus planos remonta à limitação na capacidade de obter dados, entendidos como informação explícita, não ambígua, objetiva e portanto comunicável (págs. 5-6). Entretanto, o que guia as decisões econômicas, para Lavoie, é o conhecimento dos agentes. Ao contrário dos dados, o conhecimento dos agentes tem natureza tácita e pessoal, composto muitas vezes de habilidades que seu detentor não é capaz de articular e transmitir. Polanyi dá o exemplo do ciclista que não conhece as leis físicas que mantém sua bicicleta em pé e no entanto as usa em seu proveito. A mesma idéia é expressa pela distinção de Gilbert Ryle entre knowing that and knowing how. Embora os órgãos de planejamento central possam colher 'montanhas de dados' (pág. 56), o conhecimento dos agentes é forçosamente disperso entre os agentes individuais, já que não pode ser expresso como dados.

A adoção da epistemologia subjetivista de Polanyi leva Lavoie não só a rejeitar a possibilidade de centralização de um conhecimento objetivo no socialismo, mas também a defender a rivalidade inerente à competição, a partir da qual se desenvolvem 
as habilidades e conhecimentos pessoais de cada agente, necessários para que se resolva o problema econômico nos mercados. Ao invés de defender a reconstrução racional (positivista) da sociedade a partir do centro, Lavoie crê que o entendimento da filosofia da ciência, tal como desenvolvida por Polanyi e Hayek, sustentaria a posição de que um sistema econômico complexo só é mantido pela emergência da ordem espontânea (Hayek) descentralizada dos mercados. Tal como uma colônia de formigas (cada uma delas limitada cognitivamente) que se organiza a partir de comunicação via feromônios, o conhecimento e habilidade pessoal de cada agente econômico só podem ser aproveitados por um sistema descentralizado no qual a comunicação é feita através dos preços.

O processo de diferenciação do programa de pesquisa austríaco do tradicional, que conforme pudemos apurar deveu muito ao envolvimento de Mises e Hayek na controvérsia do cálculo, foi completado na década de setenta com as obras de Lachmann e Kirzner. A versão alternativa do debate, de Vaughn a Lavoie, calcada na clara distinção entre os programas de pesquisa, representa então a retomada do problema original de Mises que havia se perdido com a preocupação neoclássica com questões de equilíbrio estático.

A partir da consolidação da versão alternativa do debate, temos desde a década de oitenta várias outras menções ao debate que divergem da versão padrão. Em particular devemos citar De Soto (1992) e Steele (1992), que escreveram histórias da controvérsia em forma de livro, ambos críticos das soluções do problema do cálculo apresentadas até então.

Da mesma maneira que fizemos ao final da exposição da versão padrão, quando relatamos os comentários de Lange feitos depois do debate, será interessante aqui fazermos o mesmo com Hayek. Ao contrário do primeiro autor, este não altera sua posição. Em um artigo escrito em 1982, Hayek (1984) novamente rejeita a afirmação da versão padrão de que ele teria recuado em relação à posição de Mises. Nesse artigo, Hayek reafirma sua objeção de que o conhecimento necessário para o planejamento central não pode ser transmitido a um órgão central e sequer existiria sem o processo competitivo de descoberta. Diferentemente da serenidade com que debatera na década de trinta, na citação abaixo o autor mostra visível impaciência com a versão padrão:

The illiterate expression 'given data' constantly recurs in Lange. It appears to have an irresistible attraction to mathematical economists because it doubly assures them that they know what they do not know. (Hayek, 1984:54) 
Em sua crítica ao modelo de Lange, porém, encontramos o mesmo engano da parte do autor que detectamos no artigo de 1940. Em vez de criticar o mecanismo de tentativas e erros, como fizera naquele artigo, Hayek parece atribuir a Lange a crença de que toda a informação necessária para o planejamento estaria disponível para o CPB. Talvez por escrever muito tempo depois do debate original, Hayek é levado ao erro quando lê no artigo de Lange a afirmação de que 'os administradores da economia socialista terão exatamente o mesmo conhecimento ou falta de conhecimento das funções de produção do que os empresários capitalistas.' Por 'administradores' Hayek entende o CPB, enquanto na verdade Lange se refere aos administradores descentralizados das plantas.

Embora Lange identifique ilegitimamente o conhecimento dado para o economista com aquele dado para o agente e em seu último artigo de fato demostra crer que o CPB possa de fato obter todos os dados, o novo artigo de Hayek distorce o significado do modelo original e esquece a crítica apropriada que fizera quarenta anos antes a respeito desse ponto específico do modelo: o mecanismo de tentativas e erros proposto, embora busque a descentralização, para funcionar requer que o CPB deva em última análise ter conhecimento sobre cada detalhe da economia, dado que as regras que as firmas devam seguir não são guias à ação claras e objetivas, como quer o autor da proposta.

\section{O Problema do Cálculo Reformulado}

Após expor ao longo do trabalho as contribuições dos autores envolvidos no debate e as diferentes opiniões na literatura secundária sobre o significado dessas contribuições, podemos agora retomar a discussão metodológica desenvolvida no primeiro capítulo, a luz da qual organizamos a nossa própria interpretação sobre a controvérsia e que orientará a maneira como em seguida reformularemos o problema original.

Como podemos lembrar, no primeiro capítulo discutimos as implicações metodológicas do estudo de fenômenos complexos. Vimos que para tais fenômenos as relações entre os seus diversos elementos individuais formam uma estrutura organizada cujo funcionamento não é captado pela mensuração estatística de médias e que o conhecimento sobre o estado desses elementos, necessário para que se possa prever ou construir peça por peça tais estruturas, supera em muito a capacidade cognitiva de 
qualquer elemento isolado. Uma forma de superar essa limitação é por meio da atuação dos mecanismos de tentativas e erros, como a seleção natural ou o mecanismo de lucros e perdas, responsáveis pela organização desses sistemas. As simplificações teóricas que descrevem o princípio de funcionamento desses mecanismos são úteis então para explicar ocorrências passadas e fazer previsões de padrão sobre algumas características gerais de um fenômeno complexo, não para a previsão de seus detalhes e a construção consciente de seus elementos de forma centralizada.

As implicações metodológicas da assimetria entre explicação e previsão que discutimos aparecem por trás das estratégias adotadas ao longo da controvérsia do cálculo por seus protagonistas. $\mathrm{O}$ artigo original de Mises pode de fato ser lido como um convite para se lidar com a complexidade da alocação de recursos. Tal complexidade, que podemos claramente ver na exposição do autor do problema alocativo, só seria preservada através das instituições que geram o mecanismo de tentativas e correção de erros dado pelos lucros e perdas.

Tal mecanismo permite abdicar da onisciência necessária para planejar o problema alocativo complexo em favor da 'divisão intelectual do trabalho' de que fala o autor. Teríamos então, a partir da ação de agentes cujo conhecimento é meramente especulativo, um sistema de alocação capaz de se adaptar às mudanças contínuas do ambiente econômico. Para Mises, o socialismo seria 'impossível' na medida em que exclui por definição o que identificamos como o mecanismo seletivo necessário para que haja tal adaptação.

$\mathrm{Na}$ verdade, o argumento não pode ser visto como uma 'prova' da impossibilidade do socialismo. O que seu autor faz é mostrar que o problema deve ser resolvido (argumento da similitude), explicar como este é resolvido pelos mercados e notar que não se pode contar com essa solução no socialismo, dada a intenção socialista de eliminar as relações de mercado. O desafio do cálculo consiste na verdade em notar que nenhuma solução alternativa foi formulada até então e convida para que isso seja feito.

A maneira mais simples de lidar com o desafio é negar a complexidade do problema. Vimos que a tradição marxista ignora essa complexidade por causa da influência ricardiana ${ }^{20}$. As decisões de produção são determinadas tecnicamente. Em autores mais recentes, porém, podemos encontrar a crença de que o problema alocativo não é tão

\footnotetext{
${ }^{20}$ Ver, como um exemplo representativo, citação de Engels no segundo capítulo.
} 
complexo como querem os proponentes da revolução marginalista. Dobb explicitamente negou a existência de uma complexidade inerente ao problema. Com ele, vários outros autores crêem que a complexidade seja aparente, fruto precisamente do sistema de produção de mercadorias. Eliminada a rivalidade que se manifesta em segredos industriais ou no planejamento descentralizado, a complexidade em si desapareceria. A mesma crença também surge com freqüência nos escritos dos socialistas de mercado.

A outra maneira de resolver o problema é aceitar a complexidade, mas limitando-a ao que descreve a teoria do equilíbrio geral. Como afirmamos no primeiro capítulo, quando o uso das simplificações da teoria é transferido da explicação para a construção dos mercados, a simplicidade da teoria é imposta à realidade. $\mathrm{O}$ socialismo de mercado rejeita então a postura clássica dos defensores do planejamento, mas se limita à descrição de um equilíbrio sem se preocupar com os outros fatores presentes nos mercados reais que possam desempenhar um papel significativo na alocação de recursos. A estratégia adotada é então excluir tais aspectos do conjunto de questões consideradas legítimas sob o ponto de vista da análise econômica, como ilustra o zelo extremo mostrado por Lerner em relegar tais questões aos campos da sociologia e psicologia.

As ambigüidades inerentes ao uso indiscriminado da teoria para tanto descrever quanto simular mercados estão presentes desde o artigo de Barone. Além de sua ambigüidade, o próprio silêncio desse autor sobre o significado de seu conjunto de equações possibilitou que seu artigo fosse utilizado tanto para sustentar a tese de que o socialismo seria impossível (Hayek) quanto para demostrar a sua possibilidade teórica (Lange). O modelo de EG desenvolvido por Barone, quanto visto como teoria meramente explicativa, mostra apenas a complexidade do problema, o que conspira contra o planejamento central; visto de forma literal, reduz tal complexidade de forma a que a solução do sistema seja vista como a base viável para uma resposta a Mises.

Os eventos do debate que ilustram essa nossa interpretação da estratégia dos socialistas de mercado são obscurecidos na visão padrão. Isto porque a visão padrão ficou excessivamente marcada pelas peculiaridades do artigo de Lange e pela época em que este foi escrito. A versão de Lange diminui a importância da solução de Dickinson e ignora tanto a outra solução proposta simultaneamente, desenvolvida por Durbin, quanto as críticas feitas por Hayek depois de 1936, data da publicação do texto de 
Lange. Sendo assim, salientaremos em seguida os episódios da controvérsia que ilustram nossa interpretação.

Tendo em vista as críticas que foram feitas aos modelos de socialismo de mercado, a estratégia de restringir a complexidade do problema aos elementos destacados pela teoria foi marcada por uma série de recuos, progressivamente abandonando elementos de planejamento central e reincorporando elementos de mercado conforme essa complexidade era introduzida novamente.

Inicialmente, Dickinson preserva o planejamento central através do uso de uma interpretação bastante literal da teoria. O S.E.C., por meio da coleta de estatísticas, traçaria curvas de demanda e custos e resolveria centralmente o sistema de equações do equilíbrio geral, sem auxílio de mercados. Todas as ações econômicas dos agentes seriam então satisfatoriamente 'comprimidas' em tais curvas.

A reação de Mises e de Hayek e essa proposta consistiu essencialmente em criticar a relevância do esquema para resolver o problema real. Para Mises, a teoria de equilíbrio é apenas uma construção auxiliar no processo de explicação do mundo, que abstrai da necessidade de lidar com o problema da ação empresarial diante da mudança. A descrição do equilíbrio não seria um guia para a ação no contexto relevante das escolhas concretas. Hayek, da mesma forma, identifica na proposta os erros originários do uso da teoria explicativa para dirigir uma economia. A distinção de Hayek entre conhecimento teórico do economista e conhecimento prático do agente deveria alertar Dickinson de que, para que tenhamos uma explicação, é legítimo o uso de abstrações que estilizam os dados sobre preferência, recursos e tecnologias. No mundo real, contudo, essas entidades simplificadoras se dissolvem em uma variedade enorme de detalhes, refletidos no conhecimento disperso entre todos os agentes sobre cada situação local. Tudo isso desaparece, por exemplo, quando se interpreta muito literalmente a noção de função de produção como uma relação constante e pouco mutável entre produtos homogêneos e insumos genéricos.

Durbin e Lange, porém, não se impressionaram com a distinção entre conhecimento teórico, fruto de simplificações, e conhecimento prático, extremamente rico em detalhes. Se o fizessem, teriam que lidar com os pro blemas da assimetria entre explicação e previsão. $\mathrm{O}$ aspecto da crítica de Hayek que os marcou, conseqüentemente, se restringiu ao ponto também levantado por Robbins de que a coleta e processamento dos dados para preencher as equações da teoria não seriam viáveis 'na prática'. A 
natureza dos dados, por sua vez, permanece em suas respostas como no modelo de Dickinson.

A consideração da objeção prática, por sua vez, foi suficiente para que o socialismo de mercado, na proposta de Lange, recuasse significativamente, abdicando do planejamento estritamente central em favor da adoção parcial do mecanismo de alocação descentralizado. A solução de Lange, sob o ponto de vista que defendemos, sem dúvida, representa um passo na direção correta, na medida em que propõe um mecanismo seletivo que em princípio dispensa a necessidade de planejadores oniscientes, já que os dados sobre os fundamentos da economia não mais são coletados pelo CPB.

Embora utilize o princípio correto, o mecanismo seletivo proposto por Lange é ainda bastante rudimentar. Como Dickinson, Lange vê a teoria de forma literal, o que simplifica sobremaneira a visão que o autor tem a respeito da tarefa que deve ser realizada por um mecanismo de correção de erros no mercado. A crítica de Hayek irá justamente salientar essa extrema simplificação. Para Lange, a economia requer poucas adaptações, os produtos são homogêneos, as alternativas produtivas conhecidas pelos agentes, as expectativas não desempenham função alguma e o papel dos administradores se limita a reagir mecanicamente a preços dados. De fato, como vimos, este último autor acredita que os agentes nos mercados atuam da mesma forma que descreve a teoria da competição perfeita. Nessa interpretação literal da teoria, o processo de mercado se reduz efetivamente a uma espécie de mecanismo primitivo de computação de dados, como de fato afirmou Lange (1969).

O esquema de Lange, porém, retém elementos centralizadores. Não só o processo de fixação de preços depende do CPB e os agentes atuam passivamente segundo as ordens centrais, mas também podemos ver na segunda parte do artigo que o autor deixa de apelar aos mercados artificiais e defende intervenções centrais com base no conhecimento superior dos planejadores. É curioso notar que Hayek não dá atenção a essa parte do artigo, mais facilmente exposta a sua crítica baseada na limitação do conhecimento.

Parte da centralização ainda presente no modelo de Lange é abandonada na proposta de Durbin. Nesta última, a fixação centralizada de preços é abandonada em favor da fixação realizada pelos administradores dos monopólios nacionalizados, ainda que a fixação obedeça a regras impostas sobre custos. O modelo evita assim a rigidez na 
periodicidade dos reajustes de preços ou a hipótese de existência de muitas firmas por mercado existente no primeiro modelo. É interessante notar que a proposta não obteve a atenção que mereceu no debate. Na versão padrão a proposta não aparece, pois foi publicada no mesmo ano que o artigo de Lange. Hayek, por sua vez, discutiu uma proposta análoga no seu artigo de 1935, surpreendentemente ignorando em seus artigos posteriores à proposta de Durbin, que ilustraria mais um recuo em relação à postura centralista. O descaso com a proposta, de qualquer maneira, deve ser reavaliado em trabalhos históricos como este, já que na retomada do debate a partir da década de noventa, as novas propostas de socialismo de mercado se aproximam em espírito muito mais de Durbin do que de Lange, na medida em que utilizam mercados reais e não simulados.

Esta proposta, porém, como as demais, se atém ao universo da teoria convencional e ignora elementos fundamentais dos mercados reais. Em uma crítica válida também para a proposta de Lange, Hayek aponta em seu artigo de 1935 que em um mundo fora do equilíbrio, com a incerteza inerente ao mesmo, as alternativas não são dadas e os custos de oportunidade existentes sob competição não existem sem que haja competição propriamente dita. Instruir as firmas a igualar preço a custo marginal pressupõe conhecimento sobre custos que só existe na presença do processo competitivo abstraído pela teoria. Para que a aplicação das regras seja efetiva, o órgão central deveria então, a fim de avaliar as alternativas, conhecer os detalhes de cada empreendimento, o que resultaria no abandono da descentralização pretendida.

Ao explorar as assimetrias entre previsão e explicação na teoria econômica, apontando para elementos dos mercados que vão além da descrição da lógica da escolha em equilíbrio, a crítica austríaca ao socialismo de mercado deu origem a uma teoria alternativa sobre a competição, teoria essa que enfatiza a rivalidade entre empresários e o processo de descoberta de conhecimento que daí resulta. A teoria austríaca moderna do processo de mercado, como vimos, deveu muito de sua formação ao próprio debate do cálculo. Contudo, outros desenvolvimentos teóricos que ocorreram no séc. XX, como as teorias de direito de propriedade, escolha pública e economia da informação, ou mesmo os próprios desenvolvimentos posteriores da teoria de equilíbrio geral, poderiam ter acrescentado aspectos novos ao problema do cálculo.

Tais desenvolvimentos resultarão de fato na retomada do debate na década de noventa, como veremos no próximo capítulo. Aqui, porém, apenas ilustraremos como um desses 
elementos deixados de fora, a questão dos incentivos, teve sua discussão ora legitimada ora não ao longo do debate original. Os primeiros críticos do socialismo apontavam para a falta de motivação para o trabalho que existiria naquele sistema. Mises e Hayek, por sua vez, queriam mostrar que sem propriedade privada, independente dessa crítica, escolhas racionais não seriam possíveis. Assumiram então essa motivação como dada, pois pretendiam apontar outro problema com o socialismo. Isso não implica naturalmente que consideravam os problemas de incentivo irrelevantes. Os socialistas de mercado, por outro lado, rejeitaram a análise dessas questões porque as consideravam fora do escopo da teoria econômica. Na resposta ao socialismo de mercado, Mises e Hayek introduzem um segundo tipo de incentivo, diverso daquele discutido pelos primeiros críticos: a propriedade privada estaria ligada com a atividade empresarial, a postura diante do risco e a rivalidade necessária para a descoberta de alternativas. Finalmente, como veremos no próximo capítulo, os socialistas de mercado modernos, ao incorporarem a teoria de informação assimétrica em seus modelos, voltarão a considerar legítimas as observações sobre motivação postas pelos primeiros críticos e interpretarão as observações austríacas sobre o segundo tipo de motivação como se fossem do primeiro, ignorando os problemas levantados por Mises e Hayek. Irão então procurar desenhar mecanismos de incentivos para o controle da administração das firmas socialistas que sejam capazes de induzir os administradores a se esforçar mesmo sem que seus superiores os observem.

Entretanto, sob o ponto de vista austríaco, a questão fundamental que emergiu do debate foi o problema do conhecimento proposto por Hayek. Além da complexidade encontrada em fenômenos físicos, o estudo das relações de mercado adiciona ainda as complicações inerentes aos fenômenos mentais e sociais. Em vez de apenas relações estruturais entre objetos inanimados, temos também a interação de agentes cujos planos de ação para atingir seus propósitos levam em conta as crenças de cada um, tanto a respeito de objetos inanimados quanto a respeito dos planos de outros agentes. $\mathrm{O}$ subjetivismo austríaco, que se estende além do reconhecimento das preferências como a base do valor, nas mãos de Hayek dissocia o conhecimento estilizado postulado pelos economistas do conhecimento de cada agente sobre os detalhes de seu entorno. Mais ainda, questiona a correspondência automática entre esse último tipo de conhecimento (ou crença) e a realidade que pretende refletir, correspondência essa que figura na definição de equilíbrio do autor. A Economia, para este, deveria então investigar o 
processo de aprendizado pelo qual o conhecimento dos agentes se aproxima ou não dessa realidade:

Thus one might describe economics (what I now prefer to call catallactics) as a metatheory, a theory about the theories people have developed to explain how most effectively to discover and use different means for diverse purposes. (Hayek, 1988:98, ênfase no original)

A interpretação de Lavoie do debate corretamente coloca o problema do conhecimento no centro da objeção hayekiana ao planejamento central. Como Hayek apenas formula o problema e não deixa explícita qual 'metateoria' ou abordagem de metodologia da ciência pretende usar para resolvê-lo, Lavoie utiliza em sua discussão do debate as idéias de Michael Polanyi sobre o conhecimento pessoal. O uso dessa abordagem leva Lavoie a enfatizar a natureza tácita do conhecimento dos agentes, de modo que o uso centralizado do mesmo seria barrado pela impossibilidade de articulá-lo e portanto comunicá-lo diretamente a um órgão diretor. O desenvolvimento dessas habilidades tácitas seria por sua vez fruto da rivalidade inerente ao processo de mercado.

Contudo, em nossa opinião, existe uma outra abordagem metodológica mais adequada para lidar com o problema do conhecimento e portanto também com a interpretação da controvérsia do cálculo. Reinterpretaremos aqui o debate a partir de uma postura popperiana a respeito do problema do conhecimento ${ }^{21}$. Esta abordagem, aliás, se aproxima mais das crenças metodológicas do próprio Hayek, bastante influenciadas pelas idéias seu amigo Karl Popper ${ }^{22}$.

O grande mérito do artigo de Hayek de 1937 foi enfatizar tanto a importância do conhecimento falível dos agentes quanto postular a existência de uma realidade independente desse conhecimento, realidade essa a qual o agente deve se adaptar com o auxílio do mecanismo competitivo de descoberta. Os mesmos elementos podem ser encontrados na obra de Popper, como pode ser visto através do breve esboço de sua versão da Epistemologia Evolucionária que apresentamos em seguida ${ }^{23}$.

Popper contraria a posição positivista que crê que a ciência progride através do acúmulo de dados empíricos objetivos, independentes de crenças pessoais. Como a ciência sempre parte de problemas, a coleta de dados é sempre condicionada pelas concepções

\footnotetext{
${ }^{21}$ Não nos referimos ao popperianismo de livro-texto que se limita a descrever um falsificacionismo ingênuo, mas ao falibilismo do autor que pode ser visto em obras como Conhecimento Objetivo. Para a distinção entre o Popper popular e o Popper relevante, ver Boland, (1990, 1994). e também o primeiro e último capítulos de minha dissertação de mestrado (Barbieri, 2001).

${ }^{22}$ Bartley, em (Bartley e Radnitszky (ed.), 1987), discute a grande aproximação entre as idéias dos dois autores, agrupadas sob a mesma categoria denominada epistemologia evolucionária.

${ }^{23}$ Este esboço se baseia em Popper (1975).
} 
prévias, além das disposições inatas do cientista. Não existiriam dados independentes de teoria; aqueles são impregnados por estas ${ }^{24}$. A ciência partiria então da tentativa de resolver problemas através da formulação de hipóteses explicativas de natureza conjectural. Embora creia que a ciência não parta dos fatos, mas sim de idéias, Popper é realista: existe uma realidade externa à qual as teorias pretendem se referir. Esta realidade, por sua vez, nunca é captada de forma perfeita pelas hipóteses: o conhecimento humano é sempre falível.

A racionalidade da ciência não dependeria da capacidade de justificar (provar) as teorias - isto seria impossível - mas sim da postura crítica, da disposição para submeter as hipóteses a testes. A impossibilidade de se saber com certeza se uma hipótese foi refutada ou não, por sua vez, não altera a essência de sua filosofia. O racionalismo crítico de Popper pode ser ampliado de forma a estender o falibilismo ao próprio processo de crítica, o que Bartley denomina racionalismo pan-crítico ${ }^{25}$.

Para essa vertente de defesa do racionalismo, independente de conhecermos os detalhes de funcionamento do processo seletivo, independente de sabermos se em cada caso a crítica teria sido conclusiva ou não, ainda assim o progresso do conhecimento humano depende da existência do espírito crítico. Suspensa a atitude crítica, necessária para que o conhecimento falível se aproxime da realidade inatingível, cessa a competição entre idéias e reina o dogmatismo.

O desenvolvimento do conhecimento por meio de 'conjecturas e refutações', como descreve Popper, é apenas uma variante do mecanismo geral de seleção por tentativas e erros que encontramos tanto na biologia de Darwin, na filosofia da ciência de Popper ou na teoria da competição de Hayek. Uma das linhas de pesquisa da Epistemologia Evolucionária explora justamente as semelhanças e diferenças entre esses processos seletivos. Na ciência, para que haja efetivamente a 'seleção' de idéias, estas precisam ser passíveis de crítica. Para isso, devem ser vistas como entidades objetivas, dissociadas de seus criadores. O casamento indissociável entre o criador e sua idéia, como é feito em epistemologias subjetivistas, limita o processo de crítica à seleção (morte) do próprio indivíduo. A articulação da idéia por meio de uma linguagem que possa ser entendida intersubjetivamente 'objetifica' a teoria de modo que possamos analisá-la pelo seu mérito próprio, independente de seu criador. Assim, podemos 'deixar

\footnotetext{
${ }^{24}$ Ver também Hayek (1952).

${ }^{25}$ Ver Bartley e Radnitsky (1987).
} 
que as idéias morram em nosso lugar', como coloca Popper, o que aceleraria o processo de correção de erros.

O 'conhecimento objetivo', dissociado dos aspectos sociológicos e psicológicos de sua criação, se torna autônomo, na medida em que existem implicações lógicas desse conhecimento que podem revelar novos problemas, problemas que estavam lá, de forma independente da percepção prévia dos analistas. Abre-se caminho então para um processo de descoberta, de exploração das consequiências das idéias, processo esse cujo resultado revela alternativas surpreendentes e insuspeitas.

O falibilismo, o caráter conjectural das hipóteses, o realismo, o mecanismo de correção de erros e a natureza indeterminista do processo de evolução que, como indicamos em nosso esboço acima, caracterizam a filosofia de Popper, são elementos - também presentes na obra de Hayek - utilizados em nossa reformulação do problema do cálculo.

A dificuldade com a solução de Lavoie ao problema reside no fato de que, ao se refugiar em uma postura estritamente subjetivista a respeito do conhecimento, impede-se o desenvolvimento do programa de pesquisa proposto por Hayek. Por um lado, considerar que o conhecimento disperso seja tácito e inarticulável permite que se critique o tipo de planejamento que pressupõe o conhecimento dos dados objetivos do problema e que reduz o problema à capacidade de processamento desses dados. Por outro, restringe-se sobremodo o que se pode dizer a respeito do processo de aprendizado dos agentes, de como o conhecimento subjetivo se aproxima ou não da realidade externa.

Sem dúvida grande parte do conhecimento dos agentes é tácito, o que implica em uma objeção válida ao planejamento central enfatizada por Lavoie; entretanto, isso não revela a principal dificuldade que esse planejamento encontra ao lidar com o problema do conhecimento de Hayek, a saber, como o conhecimento se relaciona com a realidade subjacente. Sob um ponto de vista popperiano, porém, essa dificuldade figura no centro do problema ${ }^{26}$.

Sob esse ponto de vista, o problema dos agentes econômicos é o mesmo que o dos cientistas, a não ser pela natureza da realidade que se investiga (geral no caso dos cientistas ou local no caso dos empresários). O conhecimento dos agentes econômicos,

\footnotetext{
${ }^{26}$ Harper (1996), de um ponto de vista ligeiramente diferente, também trata a competição entre empresários no mercado como um processo popperiano de conjecturas e refutações, como faremos agora.
} 
como o dos cientistas, é conjectural e falível. O comportamento futuro dos consumidores, as alternativas tecnológicas, os usos alternativos dos recursos são muito complexos para que se tenha conhecimento imediato a seu respeito. Cada empresário formula então uma hipótese sobre quais são as condições dos mercados que lhe interessa e estabelece um plano de ação baseado nessa conjectura. Mais ainda, dentro de cada firma podemos encontrar teorias diferentes, defendidas por grupos diferentes de executivos, que procuram explicar, por exemplo, por que as vendas de certa firma estariam caindo. As ações baseadas nas conjecturas são implementadas e sujeitas então a teste: se a causa for a renda baixa da população, a adoção de produtos mais baratos pode resolver o problema, se for a falta de conhecimento dos consumidores sobre a existência do produto, publicidade poderia ser a solução.

Cada hipótese empresarial enseja a análise de dados diferentes e o mesmo conjunto de dados é interpretado de forma diferente por indivíduos diferentes. As ações dos indivíduos não são portanto determinadas pelo conjunto de dados objetivos conhecidos pelos agentes. Podemos então modificar a distinção entre informação e conhecimento proposta por Lavoie ${ }^{27}$. Informação seria um fluxo de dados e conhecimento seria um estoque de teorias que compõem a 'visão de mundo' do indivíduo ${ }^{28}$.

Fransman (1987) coloca a distinção de forma clara no que chama de 'paradoxo da IBM': se o que diferencia as firmas são conjuntos de informação, pode-se perguntar como a IBM - processadora de informação por excelência - pôde cometer tamanho erro na década de sessenta ao privilegiar os mercados de mainframes em detrimento dos mercados de microcomputadores, enquanto pequenos empresários, sem a mesma capacidade de processamento de informação, tomaram a decisão empresarial correta? A resposta do autor coincide com a nossa: mais importante que 'informação' é o conjunto de crenças (o conhecimento) que gera hipóteses diferentes sobre a realidade.

A essência do processo competitivo reside no teste dessas hipóteses, na medida em estas são a base dos planos de ação implementados. Lucros indicam que a hipótese empresarial não foi refutada até então e prejuízos indicam que pelo menos alguma hipótese deve ser abandonada ou reformulada. As bolsas de valores e as demais modalidades de investimento são arenas nas quais opiniões diferentes sobre os mercados entram em conflito. Por tratar da condição dos mercados no futuro mais

\footnotetext{
${ }^{27}$ Para este autor, conhecimento seria subjetivo e pessoal e informação seria objetiva.

${ }^{28}$ Lachmann (1986) adota esta postura.
} 
distante, a respeito do qual o conhecimento é mais incerto, nas bolsas e demais mercados de investimento é importante que haja conjecturas diferentes.

Nos termos da Epistemologia Evolucionária, o aprendizado não depende apenas do processo de correção, mas também das 'mutações' ou variabilidade de hipóteses. Quanto se reconhece que o conhecimento é falível, a diversidade é bem vinda. Porém, quando se pressupõe que os agentes já conheçam a realidade, como faz a teoria neoclássica, a diversidade pode representar uma ineficiência: a diversificação nas características dos produtos é vista não como uma tentativa de descobrir as preferências dos consumidores, mas como uma tentativa de gerar poder de monopólio.

O próprio Lavoie acaba reconhecendo a importância do esquema de competição popperiano (hayekiano) entre hipóteses conjecturais, embora essa idéia não possa ser derivada da metodologia Kuhniana que defende:

Market participants are not and could not be price taker any more than scientists could be theory takers. In both cases a background of unquestioned prices or theories is relied upon subsidiary by the entrepreneur or scientist, but the focus of the activity is on disagreeing with certain market prices or scientific theories. Entrepreneurs (or scientists) actively disagree with existing prices (or theories) and commit themselves to their own projects (or ideas) by bidding prices up or down (or by criticizing existing theories). (Lavoie, 1985b:83-4)

Podemos a partir da postura falibilista rever a crença dos socialistas de mercado de que o planejamento do investimento reduziria ou eliminaria as flutuações econômicas. Se o conjunto das atividades econômicas for determinado segundo as hipóteses sobre a realidade econômica concebidas pelo planejador, embora não haja neste caso desperdício advindo das decisões contráditórias por parte de agentes isolados (as paredes seriam de vidro), será quase certo que o sistema como um todo sofrerá flutuações ainda maiores após um certo tempo, depois que a conjectura que baseou todas as decisões se revelar errônea.

O sistema de correção de erros existente nos mercados, por outro lado, a todo instante elimina erros, o que é seguido de imitação das estratégias que se revelaram corretas. $\mathrm{O}$ processo de encontrar a hipótese mais correta pressupõe a diversidade de tentativas e o conseqüente desperdício representado pelos erros.

Esse problema surge também, em menor grau, no planejamento indicativo. Na medida em que o comando central for de fato efetivo, subtrai-se a capacidade do sistema de testar alternativas. $\mathrm{O} \mathrm{MITI}^{29}$ japonês, ao qual freqüentemente se associa o sucesso

\footnotetext{
${ }^{29}$ MITI: ministério do comércio internacional e indústria.
} 
econômico do Japão, acreditava na década de sessenta que o país não comportava mais do que uma única fábrica de automóveis, que não se deveria investir em software e inicialmente negou à Sony o licenciamento da tecnologia americana de transistors porque acreditava que tal tecnologia não tinha futuro (Henderson, 1993:744). Tivesse o MITI autoridade de fato para planejar o investimento, o processo de descoberta do mercado teria sido barrado e o progresso tecnológico seria provavelmente menor. A publicação dos dados setoriais, por sua vez, não eliminaria o problema, na medida em que estes seriam interpretados de formas diferentes pelos empresários.

Tendo em vista a forma como colocamos o problema do conhecimento, podemos agora reformular o desafio do cálculo econômico posto por Mises.

A alocação de recursos em uma sociedade desenvolvida é tarefa extremamente complexa, devido ao enorme número de inter-relações entre indivíduos interagindo com elevado grau de divisão do trabalho e a existência de um contínuo fluxo de mudanças às quais deve haver adaptação. Nenhum indivíduo ou grupo é capaz de descobrir e dominar o conhecimento necessário para dirigir tal tarefa alocativa centralmente. Em economias de mercado, a alocação de recursos é feita através de um sistema de correção de conjecturas empresarias falíveis dado pelo mecanismo de lucros e perdas. A competição entre empresários gera novas conjecturas cujas consequiências são desconhecidas e que serão por sua vez testadas e darão origem a novas oportunidades de lucros. A diversidade de hipóteses (concorrência de idéias) submetidas à teste aumenta as chances de aprendizado e descoberta dessas novas possibilidades, em comparação com uma situação na qual todos os planos sejam baseados no mesmo conjunto de hipóteses (monopólio de idéias). A falibilidade do conhecimento e a presença das mudanças no ambiente econômico requerem que o processo de correção de erros seja contínuo. O mercado não chega a um estado estacionário de equilíbrio ótimo. Gera adaptação, mas não esgota as possibilidades de troca.

A rejeição dos mercados exige então que ou se explique como o problema do conhecimento deixa de ser relevante em um sistema alternativo ou se explicite qual seria o mecanismo que substituiria o processo de seleção de mercado e ainda assim resolveria o mesmo problema, ou seja, de forma que haja um processo de descoberta que sirva como base para a alocação de recursos que pelo menos preserve a complexidade e a capacidade de adaptação presentes no mecanismo seletivo dos mercados (ou que de fato o supere e gere um resultado ótimo). 
As soluções apresentadas pelos socialistas de mercado até então falharam pelos seguintes motivos:

a) Seus autores pressupõem nos modelos a solução do problema exposto acima (petitio principii), na medida em que postulam que os agentes e os planejadores possuam o conhecimento que é gerado pelo mecanismo de descoberta substituído;

b) Seus autores ao mesmo tempo reconhecem a complexidade do problema (quando utilizam a teoria para explicar o mercado) e ignoram essa complexidade em suas respostas (quando transferem a simplicidade do modelo explicativo para a realidade, na medida em que o utilizam para simular os mercados).

O caminho mais promissor para resolver a questão, em nossa opinião, requer que se investiguem mais a fundo as características dos processos de correção de erros. A representação desses processos por meio de um modelo de seleção por tentativas e erros, como o de Lange, ignora a diversidade de dimensões competitivas e depende da formulação de critérios a priori sobre o que consiste sucesso ou fracasso ${ }^{30}$.

A questão central é colocada pelo próprio Mises quando este afirma que seria necessário para a economia um mecanismo de seleção automático, pois do contrário teríamos que postular o conhecimento da solução, caso a seleção fosse consciente. O rigor analítico mostrado por Lerner ao defender o abandono da 'regra' do lucro em favor do apelo direto aos custos e receitas marginais, quando visto à luz do problema do conhecimento de Hayek, na verdade se dissolve na falácia apontada no item (a).

\footnotetext{
${ }^{30}$ Este aspecto será melhor explorado quando fizermos a distinção no último capítulo entre seleção natural e seleção artificial.
} 


\section{Mises x Hayek: O Debate Interno Austríaco}

Defendemos na seção anterior que o resultado mais importante da controvérsia do cálculo foi a formulação do problema do conhecimento. Contudo, a solução popperiana que sugerimos, compatível com as idéias de Hayek, se choca diretamente com as crenças metodológicas de Mises ${ }^{31}$, crenças estas defendidas até hoje por um grupo de economistas austríacos. Como resultado disso temos na década de noventa um debate entre economistas austríacos a respeito da questão do cálculo econômico socialista. Esse debate, que gira em torno das diferenças entre as contribuições de Mises e Hayek, ilustra a maneira como as diferentes posturas metodológicas envolvidas são compatíveis ou não com o problema do conhecimento.

A distinção hayekiana entre conhecimento teórico e conhecimento prático dos agentes trouxe consigo a dissociação entre o conhecimento subjetivo desses últimos e a realidade externa à qual este conhecimento pretende se referir. A introdução do realismo e do falibilismo no que diz respeito ao conhecimento dos agentes, por sua vez, implica que a explicação econômica deve ir além da lógica da escolha baseada somente nas decisões subjetivas dos agentes. Os agentes econômicos erram e a teoria econômica deveria justamente investigar como a alocação econômica dos recursos depende de um processo de correção desses erros. O programa de pesquisa proposto por Hayek - a formulação de teorias sobre aprendizado -rouba então da economia a pretensão de estabelecer a validade de seus resultados apenas a partir do exame das implicações lógicas do conceito de ação humana proposital, como quer a metodologia misesiana. Isto porque o estudo da ação proposital se limita ao estudo da lógica da ação de cada agente, enquanto a garantia de que haja coordenação no mercado depende de considerações intersubjetivas. Por causa disso, o confinamento da análise à pura lógica da escolha levou o referido grupo de economistas austríacos a rejeitar a contribuição de Hayek ao debate, refugiando-se em uma postura por vezes denominada "subjetivismo radical".

Os defensores do apriorismo misesiano irão então desferir um ataque simultâneo ao programa de pesquisa hayekiano, em duas frentes: Selgin (1990), sob um ponto de vista estritamente subjetivista, irá criticar as idéias de Lachmann e Kirzner derivadas do

\footnotetext{
${ }^{31}$ No capítulo 3 aludimos à metodologia defendida por Mises, a praxeologia, segundo a qual a teoria econômica seria toda derivada logicamente do pressuposto da ação humana, pressuposto esse válido $a$ priori. A praxeologia não seria assim passível de confirmação ou refutação empírica.
} 
problema do conhecimento de Hayek e Salerno $(1990,1993)$ procurará dissociar as idéias de Mises das de Hayek, rejeitando as contribuições do segundo.

Esse ataque deu origem ao debate interno a respeito das contribuições de Mises e Hayek à controvérsia do cálculo. Yeager (1994, 1996, 1997) e Kirzner (1996) defendem a relevância das objeções de Hayek ao socialismo, enquanto Salerno (1994, 1996), Rothbard (1991), Hoppe (1996) e Herbener (1996) defendem a tese de que o problema do cálculo de Mises é diferente do problema do conhecimento de Hayek, sendo este último um desvio do argumento relevante:

In particular, he [Salerno, 1990] has shown that their [Mises and Hayek] views on socialism are distinctly different, and he has argued in effect that Mises's original argument in the so-called socialist calculation debate was correct all along and was also the final word, whereas Hayek's distinct contribution to the debate was fallacious from the outset, and merely added confusion. (Hoppe, 1996: 143)

A rejeição da contribuição de Hayek, como sugerimos acima, é derivada da crença deste autor no realismo e falibilismo popperiano (modificado pelas considerações sobre complexidade do fenômeno social). A veracidade dessa afirmação é ilustrada de forma mais clara pelo texto de Selgin (1990). Para este autor (1990:28), a investigação sobre o conhecimento dos agentes introduz na análise hipóteses auxiliares não provadas que invalidariam a certeza obtida através do conhecimento praxeológico. $\mathrm{O}$ falsificacionismo que Hayek introduz em seu artigo de 1937, interpretado por Selgin, diria respeito à possibilidade de refutação da teoria a partir da observação concreta das 'motivações particulares e estímulos' que dariam origem às escolhas reais dos agentes. Para Selgin, porém, a observação do aprendizado dos agentes seria relevante apenas para estudos históricos, não teóricos. Segundo a praxeologia, observações sobre eventos históricos apenas ilustram a teoria, cuja validade seria determinada a priori.

Contudo, essa interpretação do significado do artigo de Hayek de 1937, repetida por seus demais oponentes, não se sustenta. Como mencionamos no capítulo anterior, quando estudamos o referido artigo, Hayek deixa claro que está sugerindo uma teoria sobre aprendizado e não a coleta de dados empíricos sobre aprendizados reais dos agentes. Esta interpretação é reforçada pela citação do autor que fizemos há pouco sobre a Economia como metateoria.

Em Hayek, o subjetivismo e o realismo convivem e são representados respectivamente pelas conjecturas empresariais e pelo mecanismo impessoal de seleção por lucros e perdas. Selgin, por sua vez, procura defender a praxeologia através de uma postura 
radicalmente subjetivista. Para este autor (1990:39), os conceitos de lucro ou perda "são fenômenos subjetivos, não tendo uma base 'objetiva' externa à mente dos participantes dos mercados". Para Selgin, a imaginação das vias alternativas de ação define a oportunidade de lucros. Não existiriam, como quer Kirzner, oportunidades de lucros objetivas, não percebidas, passíveis de serem descobertas ${ }^{32}$. Selgin (pág. 43) procura então 'esconder' a realidade externa através da justificação da seguinte afirmativa: não existem oportunidades objetivas de lucro porque não existem preferências dos consumidores independentes da reação destes às ofertas empresariais.

Nas obras de Hayek e de Mises, além do elemento empresarial subjetivo, temos também o mecanismo de lucros e perdas reais influenciando o comportamento subjetivo dos agentes. Neste ponto a fraqueza da postura estritamente subjetivista de Selgin se torna explícita, tanto que ele próprio não deixa de apelar para esse segundo elemento. Quando saímos da esfera da praxeologia, afirma este autor, e investigamos processos de mercados reais, históricos, temos que a realização de lucro (distinto do conceito praxeológico de lucro empresarial) é sintoma de que 'a compreensão e imaginação' do empresário se mostraram corretas.

De maneira hayekiana (e misesiana), Selgin afirma que nesse caso as conjecturas empresariais 'não foram baseadas em ilusão ou antecipação incorreta do futuro' (pág. 49) ou ainda que 'os preços de mercado transmitiram informação refletindo a compreensão derivada do contínuo processo de trocas' (pág. 51). Sem o cálculo monetário, continua o autor, seria impossível julgar se as conjecturas empresariais foram corretas.

Dessa maneira, depois de descrever com outras palavras o próprio processo de aprendizado hayekiano, necessário para que se obtenha a coordenação nos mercados, e que não depende apenas dos aspectos subjetivos dos agentes, mas também do mecanismo de correção de erros, Selgin subitamente atribui à praxeologia a garantia de que haverá coordenação no mercado. Para tal o autor apela para a necessidade dos preços para que se faça o cálculo econômico, sendo estes preços um conceito praxeológico:

\footnotetext{
${ }^{32}$ Selgin nota (pág. 44) que a postulação de uma oportunidade objetiva a ser descoberta rouba o caráter inovador da atividade empresarial. Uma crítica semelhante a esta aparece em minha dissertação de mestrado. Lá, notamos todavia que, sob o ponto de vista popperiano, o reconhecimento da realidade objetiva não elimina o caráter imaginativo das conjecturas sobre essa realidade.
} 
The existence of market prices, which itself depends upon private ownership and exchange of the means of production, is therefore a necessary prerequisite to economic calculation. This is the fundamental conclusion of praxeological critique of socialism. The necessity (not sufficiency) of market prices for entrepreneurial success, including entrepreneurial calculation and understanding, can be ascertained without appeal to other, necessary assumptions regarding the use and dissemination of knowledge. Its truth does not depended on the 'alertness' of entrepreneurs in the unhampered market. It derives from consideration of the pure logic of the equilibration process:... (Selgin, 1990:51)

É curioso notar que a descrição do funcionamento dos mercados não diverge significativamente daquela apresentada por Hayek. Apenas as conseqüências metodológicas da contribuição deste último são impalatáveis para os defensores da metodologia de Mises.

Entretanto, isto bastou para que as idéias de Hayek em geral, e em particular sua contribuição ao debate do cálculo fosse sistematicamente criticada e mal compreendida por esse grupo de economistas. Salerno (1990:39), por exemplo, ataca o conceito de ordem espontânea através de uma falácia da composição: a racionalidade da ação individual implica, para o autor, a racionalidade das instituições sociais. Os mercados seriam então criados propositadamente, de forma racional.

Nesse mesmo artigo, Salerno rejeita a contribuição de Hayek ao debate, afirmando que o problema do socialismo se refere ao cálculo, não ao conhecimento. A fim de suportar a sua rejeição das considerações sobre conhecimento, Salerno cita trechos dos capítulos 25 e 26 do Human Action de Mises (1998:692-696). Nesses trechos, Mises introduz o problema do cálculo. Argumentando contra a visão de que o cálculo dispensa preços (em favor do cálculo em espécie), o autor assume que os fins sejam dados (a construção de um prédio) e que as alternativas tecnológicas sejam conhecidas pelo diretor socialista que toma a decisão.

Argumenta então que mesmo na posse desse conhecimento, a decisão sobre a construção não pode ser feita racionalmente porque é impossível sem moeda atribuir valor aos diferentes bens de capital, já que não se podem somar recursos heterogêneos. Citado fora do contexto, o pressuposto de que as tecnologias, recursos e preferências sejam conhecidos pelo diretor consiste para Salerno (pág. 45) em uma 'prova' de que mesmo com conhecimento perfeito o problema do cálculo ainda persistiria.

A hostilidade de Salerno em relação à obra de Hayek suscitou uma resposta da parte de Yeager (1994), que marcou o início do debate propriamente dito entre os dois autores. O artigo de Yeager defende a continuidade entre os argumentos de Mises e Hayek e 
convida Salerno a indicar claramente qual é o aspecto fundamental do problema do cálculo que não faz referência ao conhecimento dos agentes.

Salerno (1990), antes do desafio de Yeager, já indicara que o elemento relevante à questão do cálculo seria o conceito de avaliação (appraisement). Para Salerno, a avaliação empresarial consiste na antecipação do estado futuro do mercado com o auxílio dos preços passados. A posição de Hayek, por sua vez, é interpretada por Salerno (1994:116) de maneira a sugerir que a avaliação empresarial para este último seria dispensável. O argumento de Hayek seria do tipo 'próximo do equilíbrio', de forma que os preços passados transmitiriam automaticamente informação relevante sobre o conhecimento disperso entre os agentes. Salerno repete ao longo do debate sua interpretação do argumento de Hayek:

... Yeager now abandons his original hayekian position that the price system, i.e., past prices, automatically conveys to all passive producers all the knowledge that is relevant to their business decision. (Salerno, 1996:142)

Pela nossa discussão da participação de Hayek no debate que vimos ao longo do capítulo anterior, contudo, esta interpretação é claramente errônea. Na interpretação de Hayek, os agentes jamais seriam passivos. Justamente porque existe uma realidade exterior, realidade esta muito complexa para ser apreendida imediatamente, cada empresário deve imaginar e descobrir maneiras melhores de satisfazer os consumidor por meio de suas conjecturas.

O teste no mercado dessas conjecturas empresarias está no centro da concepção do autor sobre a atividade competitiva. A variabilidade de conjecturas empresarias sobre determinada realidade de mercado, juntamente com o mecanismo seletivo de mercado, são para o autor os elementos que explicam a tendência ao equilíbrio. O argumento é portanto de processo equilibrador e não uma análise pura de equilíbrio (ou na vizinhança do equilíbrio) como quer Salerno.

Em conclusão, a não ser por distorções no significado do argumento de Hayek, Salerno não é capaz de responder ao desafio de Yeager e separar o problema do conhecimento de Hayek de sua origem misesiana. Essa incapacidade se revela a todo instante através de repetições involuntárias das idéias de Hayek como se fossem argumentos contrários às mesmas:

Or, put another way, yesterday's prices do not 'economize knowledge' but save on the mental effort expended by the entrepreneur in striving to 'understand' the effects of anticipated change on tomorrow's price structure. (Salerno, 1990:43) 
Como corretamente aponta Yeager (1996) os conceitos de previsão empresarial e appraisement apontados por Salero são todos aspectos ligados à questão do conhecimento proposto por Hayek.

A reação de Salerno à crítica fundamental de Hayek à exclusividade da lógica da escolha, na verdade, o coloca ao lado da teoria neoclássica tradicional, em oposição à moderna teoria austríaca do processo de mercado. Isto porque, como veremos no próximo capítulo, também os intérpretes neoclássicos de Hayek se recusarão a reconhecer a natureza falível do conhecimento. Para estes intérpretes, a preocupação com o conhecimento de Hayek se dissolverá em uma questão puramente computacional a respeito da transmissão de informações objetivas. 


\section{Socialismo de Mercado Moderno: Informação e Incentivos}

Desde o arrefecimento das discussões na década de quarenta, ocorreram vários desenvolvimentos teóricos que poderiam fornecer munição para ambos os lados em conflito no debate, possivelmente causando a sua retomada. Entretanto, com a difusão da versão padrão, os economistas acreditavam que a disputa teria se encerrado com a vitória de Lange. A partir de então, defensores e críticos do socialismo desenvolviam seus argumentos sem menções significativas ao debate original.

Os defensores do socialismo desenvolviam, entre outras coisas, modelos de planejamento por programação linear, pelo uso de tabelas insumo-produto e estudos históricos sobre as economias do bloco soviético. Entre os defensores do liberalismo econômico surgiam estudos sobre os efeitos da propriedade privada, sobre a economia do rent-seeking e desenvolvimentos da teoria da atividade empresarial. No campo crítico, os opositores do liberalismo, utilizando o critério de optimalidade de Pareto, focavam sua atenção no estudo das falhas de mercado, enquanto os opositores do estatismo, introduzindo a hipótese de agentes públicos auto-interessados, investigavam as falhas de governo. Ao mesmo tempo, prevalecia entre economistas e na opinião pública a crença em alguma forma de economia mista.

Apesar da predominância da crença na 'terceira via', acompanhada pelo desinteresse das formas 'extremas' de organização social, os desenvolvimentos no campo da teoria, aliados à falência dos regimes do bloco soviético, criaram novamente um ambiente favorável à retomada do debate do cálculo econômico, o que de fato ocorreu na última década do século vinte.

Neste capítulo veremos como uma nova geração de propostas de socialismo de mercado surgiu em larga medida a partir de considerações sobre um desses desenvolvimentos teóricos, a Economia da Informação. Veremos também como essas propostas, bem como a noção geral de socialismo de mercado, foram criticadas sob o ponto de vista da escola da Escolha Pública. Constataremos que o aspecto marcante dessa nova fase do debate é a centralidade da questão dos incentivos, ponto este excluído do debate original. Antes de investigar como as alterações no cinto protetor da teoria neoclássica permitiram a legitimação do estudo dessas questões, e como estas resultaram em novos 
modelos de socialismo de mercado, nos debruçaremos na rejeição dos problemas levantados por Hayek no programa de pesquisa austríaco, na medida em que a aceitação desses problemas afeta o núcleo rígido do primeiro programa.

\section{Economia da Informação e o Debate: Hayek no Leito de Procusto}

Os capítulos anteriores mostraram como emergiu do debate a preocupação com o processo de mercado fora do equilíbrio e com o aprendizado dos agentes, o que para os austríacos fundamentaria a crença na capacidade coordenadora dos mercados. Na nossa interpretação do que poderíamos chamar de Economia do Conhecimento, Hayek nos convida a investigar a maneira como os agentes, em princípio ignorantes sobre a realidade econômica que os cercam, na busca pela melhor maneira de atingir seus propósitos, adquirem conhecimento sobre essa realidade. A atividade empresarial consiste em ações econômicas guiadas pelas concepções particulares (teorias empresariais) de cada um a respeito da existência de oportunidades de lucro. A exploração bem sucedida dessas oportunidades dependerá não apenas da acuidade do conhecimento individual a respeito da disponibilidade objetiva de recursos, das predisposições naturais dos consumidores a demandar certos bens ou serviços ou ainda das alternativas técnicas de produção, mas também da capacidade de descobrir e imaginar meios alternativos de satisfazer tais necessidades e dependerá ainda da compatibilidade da ação pretendida com os planos dos demais agentes.

Segundo essa concepção, a compatibilidade de planos, fruto do processo de aprendizado, não seria o ponto de partida da análise econômica, mas sim o próprio fenômeno a ser explicado. Na tradição austríaca, tal compatibilidade é aproximada a partir do confronto competitivo entre teorias empresariais falíveis. Um plano incompatível com as preferências, tecnologias, disponibilidade de recursos e com os planos dos demais tende a ser frustrado, o que suscita a sua modificação (por meio, por exemplo, da imitação de planos que se revelaram viáveis) ou ainda seu abandono. Fora do equilíbrio, os preços revelam oportunidades de lucro, guiam os agentes em suas escolhas e influenciam suas hipóteses sobre as condições dos mercados. 
Numa leitura popperiana (ou evolucionária) do problema de Hayek, para que haja adaptação das ações aos fins dos agentes, são necessárias tanto a diversidade de planos (mutação) quanto um mecanismo de correção de hipóteses refutadas (seleção). Entre os austríacos, a propriedade privada e o sistema de preços de mercado proveriam tanto a liberdade necessária para a diversidade de planos quanto um mecanismo automático de correção de erros que faltariam ao socialismo.

O socialismo, na visão hayekiana, falharia por não lidar satisfatoriamente com a inevitável limitação do conhecimento humano diante da complexidade do problema alocativo $^{1}$, na medida em que despreza o mecanismo descentralizado de descoberta inerente aos mercados em favor de esquemas que de uma forma ou outra apelam para o conhecimento superior do planejador. Como vimos, se o mundo estiver em constante mudança, mesmo o socialismo de mercado, que pretendia originalmente contornar essa limitação, acaba apelando para o centralismo quando se leva em conta a complexidade do problema alocativo real.

Em nosso entendimento, a crítica hayekiana ao socialismo é em última análise uma manifestação da epistemologia falibilista de Popper: a diversidade de opiniões - e não a imposição de uma concepção única sobre a realidade econômica - é requerida para que haja um processo de aprendizado e se mantenha a adaptabilidade das ações à realidade econômica.

O desenvolvimento moderno da Economia da Informação, ao abandonar o pressuposto de conhecimento perfeito em favor da hipótese de que os agentes possuem informação limitada, poderia levar ao reconhecimento do problema do conhecimento de Hayek. Essa era a esperança de alguns economistas que desafiaram a visão padrão do debate na década de oitenta, como Vaughn (1980:552) ou Murrell (1983). Este último acreditava que a economia da informação poderia lidar com o problema do cálculo em um mundo em mudança: 'Cinqüenta anos depois de que Mises apresentou seu desafio, a teoria econômica pode estar pronta para enfrentar as questões que ele levantou' (1983:104).

De fato, munidos com a Teoria da Informação Assimétrica, alguns economistas retomaram o debate do cálculo. As questões estudadas, porém, diferiram substancialmente do problema do conhecimento exposto acima. Em especial, na

\footnotetext{
${ }^{1}$ Não se trata, devemos enfatizar, de encontrar alternativas que coordenem perfeitamente as ações dos indivíduos de forma ótima, como requer o ideal inatingível de optimalidade de Pareto, mas sim de pelo menos replicar a adaptabilidade em relação às mudanças existente nos mercados.
} 
retomada do debate os problemas do socialismo continuarão sendo analisados sob o ponto de vista de teorias de equilíbrio, que pressupõem que o processo de competição já ocorreu, o que contraria a essência da crítica hayekiana. Entretanto, surpreendentemente, alguns dos participantes dessa retomada do debate vêem Hayek como um precursor de seus estudos. Vejamos então como as preocupações sobre conhecimento deste último autor foram interpretadas sob a ótica da Economia da Informação e como esta última trata do problema do socialismo.

Já antes do desenvolvimento da Economia da Informação, as idéias de Hayek sobre conhecimento foram 'traduzidas' nos termos da economia de equilíbrio por Hurwicz. Ao chamar a atenção para a necessidade de mecanismos de alocação de bens, em contraste com a mera enunciação das fórmulas que descrevem o equilíbrio ótimo (como as regras de custo discutidas no debate entre Lerner e Durbin), Hurwicz (1969:514) invoca a crítica de Hayek. Esta, segundo o autor, consistiria essencialmente na afirmação de que tais fórmulas não implicam na existência de mecanismos de processamento de informações descentralizadas de modo a que se tenha uma aproximação ao equilíbrio competitivo. Para Hayek, não seria possível no socialismo a transmissão de informações dispersas a um órgão central.

Hurwicz coloca então o problema do socialismo da seguinte forma: como desenhar mecanismos alocativos eficientes a partir de agentes que possuam conhecimento apenas de suas próprias preferências, dos recursos e trechos da função de produção, de forma a minimizar a transferência de informações entre as unidades da economia?

Para o autor, em uma economia competitiva ${ }^{2}$, a transmissão de informação se limita a vetores de quantidades ofertadas ou demandadas por agentes que reagem a vetores de preços paramétricos. O problema seria então encontrar mecanismos de alocação ótima que apresentem 'descentralização informacional' da mesma maneira que o modelo competitivo; ou seja, que minimizem a necessidade de transmissão de informações (Hurwicz, 1973:5).

Se todas as funções de produção forem Cobb-Douglas, por exemplo, as firmas poderiam transmitir ao CPB apenas os parâmetros particulares de suas funções. Hurwicz analisa então mecanismos diferentes nos quais o 'diálogo' informacional entre centro e periferia seja administrável: poderíamos, por exemplo, imaginar a transmissão pelo órgão central

\footnotetext{
${ }^{2}$ Como Barone ou Lange, Hurwicz não distingue o modelo competitivo de mercados reais.
} 
de metas quantitativas e feedback das firmas na forma de preços sombra, até que haja uma convergência ao equilíbrio.

Tais mecanismos, porém, são discutidos em ambientes altamente estilizados, como economias com um único consumidor, função de produção estritamente convexa e conhecida e assim por diante. A relevância desses modelos para o problema real do planejamento e a interpretação literal da teoria poderia ser discutida à luz da própria crítica de Hayek. Contudo, o que é importante notar é que nas mãos de Hurwicz a contribuição de Hayek foi despida de seu elemento essencial - a crítica do confinamento da análise à teoria de equilíbrio - e interpretada em termos da própria teoria neoclássica.

É significativo que tanto em Hurwicz quanto entre os economistas que retomaram o debate na década de noventa ${ }^{3}$ as citações de Hayek utilizadas são provenientes do The Uses of Knowlege in Society [1945] e não do Economics and Knowledge [1937], já que é neste último que temos a crítica fundamental à economia de equilíbrio, enquanto o argumento do primeiro, tomando-se passagens isoladas, pode ser interpretado em termos neoclássicos. O famoso exemplo do estanho que Hayek elabora neste texto é reconhecido por esses autores como o início da preocupação com o aspecto informacional dos preços. Hayek estaria argumentando que os preços seriam estatísticas suficientes; ou seja, a informação derivada através dos preços seria o bastante para se atingir uma alocação econômica eficiente. O conhecimento localizado de cada agente seria agregado nos preços e os agentes desinformados poderiam inferir conhecimento a partir das variações nos preços causadas por agentes informados.

A intuição de Hayek, segundo essa interpretação, poderia ser analisada rigorosamente a partir da teoria da informação ${ }^{4}$. Levando-se em conta que a obtenção de informação é custosa, Grossman e Stiglitz (1996) chegam à conclusão de que os preços não são capazes de transmitir e agregar informações de forma eficiente, como teria afirmado Hayek.

Os autores desenvolvem um modelo no qual um ativo financeiro com retorno $\mathrm{r}$ é demandando por agentes que podem ou não obter (a um certo custo) informações sobre

\footnotetext{
3 Hurwicz (1969:514; 1973:5), Makowski e Ostroy (1993:79), Roemer (1994), Gossman e Stiglitz (1996:253).

${ }^{4}$ Ver Grossman e Stiglitz (1996:253).
} 
um parâmetro $\eta$ que se relaciona com o retorno, que por sua vez depende também de uma variável não observável $\varepsilon$. Temos assim:

$$
r=\eta+\varepsilon
$$

sendo $\eta$ e $\varepsilon$ variáveis aleatórias independentes. A demanda per capita dos agentes informados depende tanto do preço p quanto do valor de $\eta$, enquanto a demanda dos desinformados depende apenas dos preços. Em equilíbrio, a demanda de mercado se iguala à oferta. Quando a oferta for fixa, variações nos preços de equilíbrio são causadas por variações na demanda dos agentes informados que observaram valores diferentes de eta. Os desinformados podem então inferir a partir de um aumento de preços o aumento de eta: os preços transmitiriam de forma perfeita informação dos informados para os desinformados. Quando o estoque do ativo varia aleatoriamente, porém, uma mudança nos preços pode ser devida tanto a alterações na demanda dos informados quanto a oscilações na oferta. Neste caso, os preços revelam alguma informação sobre eta, mas não informação completa.

Levando-se em conta o custo de obter informação, teríamos em equilíbrio que um indivíduo estaria indiferente entre obtê-la ou não. Quando o sistema de preços for informativo, porém, não vale a pena comprar informações sobre eta, pois pode-se inferir gratuitamente seu valor pelo preço. No extremo oposto, quando nenhum agente conhece eta, valeria a pena a compra da informação, pois o sistema de preços não informaria nada. Pode-se então chegar a uma fração dos indivíduos em equilíbrio comprando informação e outra não. Nesse modelo, a afirmação 'de Hayek' de que os preços transmitem informação de forma perfeita não se sustentaria.

Da mesma maneira, os autores chegam à conclusão de que o sistema de preços não agrega informação de forma perfeita: se o fizesse, um agente não basearia suas decisões em seu conhecimento particular, mas no preço. Neste caso, como poderia o preço agregar informações de todos os agentes? Nestes e em outros exemplos, as externalidades relacionadas à coleta de informação custosa impedem que se obtenha a quantidade ótima de informação.

Deve-se notar que tanto para Hurwicz quanto para Grossman e Stiglitz, os preços não exercem o papel de, fora do equilíbrio, auxiliar o processo de descoberta de conhecimento. No modelo, os agentes sabem exatamente quais informações são relevantes para a tomada de decisão e o valor dessa informação. Nenhuma informação 
causa surpresa, alterando o conhecimento que o agente tem sobre a realidade. Assumese que de algum modo os agentes conhecem a teoria correta sobre o mundo; só faltam osdados para tomar as decisões corretas.

Nos modelos desses autores investiga-se, pelo contrário, se em equilíbrio o sistema de preços é 'informacionalmente eficiente', transmitindo e agregando informações de maneira a termos alocações ótimas. A 'tradução' de Hayek para o referencial de equilíbrio neoclássico permitiu então que se ignorassem os problemas do socialismo que dizem respeito às questões levantadas por este autor. O socialismo de mercado será então analisado na década de noventa à luz daqueles aspectos dos mercados que são elucidados pela economia da informação. Especificamente, a questão dos incentivos, rejeitada pelos primeiros socialistas de mercado, passará a ocupar o primeiro plano tanto na formulação de propostas de socialismo quanto nas críticas à possibilidade de criar mecanismos adequados de incentivos aos agentes públicos a perseguirem os objetivos estabelecidos centralmente.

A retomada moderna do debate deve muito a dois economistas que publicaram livros sobre o problema em 1994. Entre aqueles que acreditam que a Economia da Informação pode gerar os elementos necessários para viabilizar o socialismo de mercado, destaca-se John Roemer, autor de A Future for Socialism. Entre os céticos, destaca-se Joseph Stiglitz, autor de Whither Socialism? Ambos os autores reavaliam o debate original e discutem a viabilidade do socialismo de mercado à luz da Economia da Informação.

Dos dois, apenas Roemer (1993:3-9; 1994:28-36) avalia o debate original com cuidado 5 . Em sua narrativa, Roemer segue o mesmo esquema em três fases proposto por Hayek: discussão da similitude formal, da solução matemática e da necessidade de mercados para utilizar informação descentralizada. Depois de expor o modelo de Lange, Roemer

\footnotetext{
${ }^{5}$ Os participantes do novo debate aprendem sobre o debate original a partir da narrativa de Roemer e da leitura do "The Uses of Knowledge in Society", além dos artigos de Grossman e Stiglitz. Makowski e Ostroy (1993:86 n.r.), por exemplo, embora dediquem uma seção de seu artigo a criticar os argumentos de Hayek contra o socialismo de mercado, reconhecem em nota de rodapé que não leram a crítica de Hayek (1940)! Isso não impede os autores de avaliar a crítica como difusa (fuzzy) por não enfatizar os problemas de incentivo. Caldwell (1987), em um protesto contra a falta de cuidado com a história das idéias e com a tradução de argumentos anteriores em termos da teoria atual (o que é algumas vezes chamado de whigg history), nota que no livro de Stiglitz dedicado ao socialismo de mercado não se encontra na bibliografia nenhuma referência aos textos de Mises, Dobb, Robbins ou Dickinson e apenas uma menção a Lange, Lerner e Hayek (de textos não relacionados diretamente ao debate). No entanto, temos citados 122 artigos do próprio Stiglitz. Como resultado disso, podemos encontrar em Whither Socialism? várias distorções das posições originais, como: 'under market socialism managers are instructed to maximize profits, ...' (pág.9) e discussões de questões já tratadas no debate na década de vinte como se tivessem sido trazidas à tona pela primeira vez pelo próprio Stiglitz: Innovation played no role in the markets/market socialism debate, ....' (pág 139).
} 
menciona as críticas internas que poderiam ser feitas ao mesmo, como investigações sobre convergência do processo de tâtonnement, problemas de acumulação de capital e formulação de regras quando houver retornos crescentes de escala. A crítica de Hayek, por outro lado, teria apontado para as simplificações da teoria que ignoram as complexidades da realidade: a) não há convergência devido ao constante fluxo de mudanças nos fundamentos da economia; b) os bens não são homogêneos, de modo que não seria possível sequer listar os preços que deveriam ser controlados; e, finalmente, c) administradores leais e capazes não poderiam encontrar os métodos de produção que minimizam custos.

Embora concorde com os dois primeiros pontos, Roemer (1993:5) contesta o terceiro. Como podemos lembrar, Hayek argumenta que se a prática de cortar preços não for permitida, não se pode encontrar os métodos mais baratos de produção. Neste ponto podemos perceber as diferenças entre as abordagens austríaca e neoclássica. Roemer lê o argumento de Hayek em termos dessa última: o argumento seria incorreto porque administradores competentes já operam com tecnologias eficientes e o processo de tentativas e erros de Lange converge para o único equilíbrio que minimiza custos, mesmo com agentes tomadores de preços (não há competição via corte de preços). Roemer argumenta que se o estímulo dado por mercados com cortes de preços não existisse, os agentes poderiam não ser estimulados a procurar técnicas de produção econômicas. Neste caso, porém, não se sustenta a hipótese de que os agentes sejam 'tão capazes e ansiosos para achar métodos eficientes quanto os capitalistas'.

O argumento de Hayek, interpretado no contexto austríaco, na verdade não assume que o conhecimento dos agentes (como por exemplo, o conhecimento técnico) seja dado: o conhecimento de tal técnica eficaz seria fruto do próprio processo competitivo de descoberta. Seria ilegítimo supor esse conhecimento como dado a princípio. Devem-se então separar os termos 'capaz' e 'ansioso' no parágrafo anterior. A motivação para se esforçar e fazer o melhor entre alternativas conhecidas (ao menos probabilisticamente) pode ser estudada no contexto da economia da informação ${ }^{6}$. Entre os administradores esforçados e ansiosos pelo sucesso, porém, a única maneira de selecionar aqueles capazes de descobrir os melhores métodos seria através do apelo à competição real, a menos que se suponha como conhecido aquilo que de fato é fruto do processo

\footnotetext{
${ }^{6}$ A discussão dessa motivação não era aceita pelos socialistas de mercados e tal motivação era assumida pelos austríacos, por fins de argumentação.
} 
competitivo. Se partirmos da hipótese hayekiana de ignorância inicial sobre a realidade econômica, a habilidade empresarial não pode ser reduzida a um fator com produtividade conhecida: o fruto da descoberta empresarial é, por definição, desconhecido antes do processo competitivo. O seu valor não pode ser estabelecido $a$ priori, nem seu uso planejado em doses ótimas.

Ao interpretar a crítica de Hayek em termos neoclássicos, Roemer não separa a questão da rivalidade empresarial da questão de como desenhar mecanismos de incentivo que motivem os agentes a seguir os objetivos dos planejadores, ou seja, mecanismos que os induzam a adotar as já conhecidas vias de ação que levam ao lucro máximo esperado. Este último seria então o verdadeiro problema a ser enfrentado pelo socialismo. De fato, o autor interpreta o fracasso das economias planejadas nesses termos:

I propose an explanation for why the centrally planned economies eventually failed: simply put, they were unable to solve principal-agent problems. (Roemer,1994:7)

Roemer (1993:91) identifica no socialismo problemas de agência em três esferas: nas relações entre administrador - trabalhador, planejador - administrador e público planejador.

Stiglitz, por sua vez, ao reduzir o problema fundamental tratado por Hayek (o problema do conhecimento) ao problema de transmitir e agregar informações dadas, mas dispersas entre os agentes, não vê como o primeiro possa trazer problemas para o modelo de Lange:

I am not sure that Hayek fully appreciated the range of information problems. If they were limited to the kinds of information problems that are at the center of the Arrow-Debreu model - consumers conveying their preferences to firms, and scarcity values being communicated both to firms and consumers - then market socialism would have worked. Lange would have been correct that by using prices, the socialist economy 'solve' [sic] the information problem just as well as the market could. But problems of information are broader. (Stiglitz, 1994:14)

Embora seja certo que Hayek não tenha abordado os problemas tratados pela economia da informação (parte deles foram considerados como resolvidos, por motivos de argumentação), mostraremos agora como a crítica de Stiglitz ao socialismo de mercado revela justamente o problema apontado por Hayek em sua crítica à teoria de equilíbrio ${ }^{7}$.

Em contraste com a opinião do autor exposta acima, a crítica de Stiglitz soa em princípio bastante hayekiana, como um ataque aos fundamentos da teoria neoclássica:

\footnotetext{
${ }^{7}$ Poderíamos parafrasear a última citação da seguinte forma: Não tenho certeza que Stiglitz reconheceu o escopo dos problemas de conhecimento. Se fossem limitados aos problemas de informação no centro do modelo de equilíbrio - como fazer com que se produza uma quantidade de informação adequada - então o socialismo de mercado teria funcionado (embora não de forma ótima). Mas os problemas de conhecimento limitado são mais amplos.
} 
In this essay I argue that the idea of market socialism is fundamentally flawed - and for many of the same reasons that the Arrow-Debreu model on which it is based is flawed as a description of the market economy. (Stiglitz, 1993:21)

Stiglitz (1993:22) ridiculariza a visão esquemática que os economistas têm da realidade econômica. Essa visão, denominada pelo autor de engeneering economics, refletida por exemplo no livro-texto de Samuelson, vê a economia apenas como composta por problemas de maximização de algumas funções, ignorando as complexidades do mundo real. Tanto a idéia de Joan Robinson de que a tarefa da administração se reduz a consultar a página do manual técnico referente aos preços dos fatores, quanto a idéia (encontrada, por exemplo, em Hurwicz) de que existiriam algoritmos computacionais alternativos ao sistema de preços são citados como exemplos dessa visão. Assim, Stiglitz observa que, dado o desprezo de Lange, Lerner e Taylor por mecanismos de incentivos gerenciais, os administradores poderiam ser facilmente substituídos por autômatos nos modelos dos socialistas de mercado.

No que diz respeito ao socialismo de mercado propriamente dito, Stiglitz repete, talvez sem saber disso, alguns dos argumentos desenvolvidos por Hayek no artigo de 1940. Como Hayek, Stiglitz aponta para a complexidade do espaço de bens: se um produto simples como uma camiseta tiver 10 características (como cor, tamanho, etc.), cada uma delas podendo assumir 10 valores diferentes (azul, verde, ..., pequeno, médio, ...) o CPB teria então que fixar 10 bilhões de preços $\left(10^{10}\right)$ ! Seria praticamente impossível especificar as características do produto e sempre que um preço fosse regulado as firmas poderiam compensar diminuindo a qualidade ou alterando outra característica qualquer. Como Hayek, Stiglitz também observa que essa complexidade impede que se suponha competição perfeita em todos os mercados.

Ao contrário da teoria tradicional, o contato entre firmas e entre estas e os consumidores (como a construção de reputação, por exemplo) exerce funções nos mercados reais. Os preços, embora por um lado não reflitam todas as informações, têm outras funções, como incentivos ou seleção, funções essas ignoradas pela teoria de equilíbrio geral.

Para o autor, o problema fundamental com a teoria econômica tradicional seria a ignorância dos problemas de informação assimétrica: não se pergunta naquela como os agentes são incentivados a coletar informações e não se avalia a eficiência com a qual se processam essas informações.

Embora a crítica de Stiglitz soe como um ataque à teoria tradicional, o que explica as semelhanças entre as observações desse autor e as de Hayek, na verdade o trabalho de 
Stiglitz preserva aqueles elementos centrais da teoria que foram criticados por Hayek; a saber, a exclusividade da preocupação com estados de equilíbrio e a preocupação correlata com a obtenção de alocações eficientes.

Para Stiglitz, a comparação entre socialismo de mercado e economias de mercados puras deve ser feita em termos de obtenção de equilíbrios que apresentem a propriedade de esgotar as oportunidades de trocas vantajosas. Como não é de surpreender, o autor chega à conclusão de que as duas formas de organização econômica falham em atingir equilíbrios ótimos de Pareto. A falta de mercados futuros completos, por exemplo, resulta na incapacidade dos mercados de alocar o investimento de forma eficiente.

O debate entre Hayek e Lange seria então inconclusivo. Para Grossman e Stiglitz (1996), Grossman teria formalizado a afirmação de Hayek de que preços agregam informações. Neste caso, se os preços forem estatísticas suficientes, o CPB não pode melhorar as alocações descentralizadas. Mas, se obter informações for custoso, essa afirmação 'de Hayek' não se sustenta, pelas razões já apontadas. Neste caso, um CPB com informações completas poderia melhorar o resultado dos mercados.

Embora seja difícil crer que os autores acreditem que o estado possa de fato adquirir toda a informação necessária (à luz das complexidades da realidade econômica revistas acima), somos levados pelos autores, como antes fizera o próprio Pareto, a comparar economias de mercado com geração não-ótima de informação com economias socialistas (de mercado) que têm apenas custos de monitoramento de funcionários:

Thus in out view the Lange-Lerner-Taylor-Hayek debate comes down to the fundamental distinction between economies where: (1) prices and hence allocations are the outcome of a competitive arbitrage process which will, of necessity, be imperfect because of the costs of arbitrage as discussed in this paper, and (2) economies where prices and hence allocations are the outcome of a centralized allocative mechanism which will, of necessity, be imperfect because of the costs of monitoring bureaucrats. (Grossman e Stiglitz, 1996:252)

A inconclusão a respeito da escolha institucional é resolvida na preferência do autor por uma forma de intervencionismo: Stiglitz (1993, 1994) crê que políticas antitruste, regulações de falhas de mercado e políticas keynesianas possam melhorar a eficiência dos mercados. Na defesa dessa postura se revelam de forma mais nítida os problemas discutidos por Hayek: ao mesmo tempo em que na citação anterior o autor se esquiva de mostrar como um órgão central possa obter conhecimento, em outro contexto, ao discutir a imposição de uma taxa/subsídio corretiva para eliminar moral hazard em seguros, Stiglitz (1994: 31) afirma que os custos e benefícios marginais relevantes a esta 
situação podem ser obtidos pela verificação de 'magnitudes observáveis', como elasticidades próprias e cruzadas.

Poderíamos indagar, tendo em vista as observações do próprio autor encontradas no mesmo livro sobre a complexidade do espaço de bens, se o número de elasticidades empiricamente observáveis que o estado precisaria conhecer não deveria então ser multiplicado por 10 bilhões (desconsiderando as elasticidades cruzadas). Na obra do autor, a assimetria entre a complexidade do problema enfrentado pelos agentes privados e pelo estado e portanto os diferentes requisitos cognitivos exigidos dos mesmos agentes revelam a postura que Demsetz denominou 'nirvana approach': a condenação da realidade do mercado com base na comparação com um ideal sem que se explique como esse ideal seria aproximado em um esquema alternativo concreto ${ }^{8}$.

A crença identificada por Hayek de que os fundamentos da economia são estáveis e facilmente reconhecíveis e que curvas de demanda e custos objetivas estão disponíveis para os agentes e o estado observar ${ }^{9}$ em última análise subsiste na análise de Stiglitz, o que impede que se reconheça o problema do conhecimento, de modo a se acreditar que os governos sejam dotados do conhecimento de tais curvas e possam, por conseguinte, utilizar seu poder para se obterem equilíbrios ótimos de Pareto. Dessa maneira, a obra de Stiglitz ilustra precisamente o tipo de crítica que Hayek fez ao planejamento central: a pretensão de conhecimento superior por parte dos governos.

Com isso chegamos às diferenças entre os núcleos dos programas de pesquisa austríaco e neoclássico. Sentindo o choque entre essas tradições, Stiglitz procura em Whither Socialism? criticar algumas idéias austríacas que servem como base das objeções a sua própria abordagem. Em uma seção do livro intitulada 'Hayek versus Stiglitz', o autor aceita o argumento 'de Hayek' de que o modelo que pressupõe conhecimento perfeito ignora a maneira como os preços transmitem e agregam preferências, mas rejeita a abordagem austríaca:

My concerns are two-fold: First, because Hayek (and his followers) failed to develop formal models of the market process, it is not possible to assess claims concerning the efficiency of that process, and second (and relatedly), in the absence of such modeling, it is not possible to address the central issues of concern here, the mix and design of public and private activities, including alternative

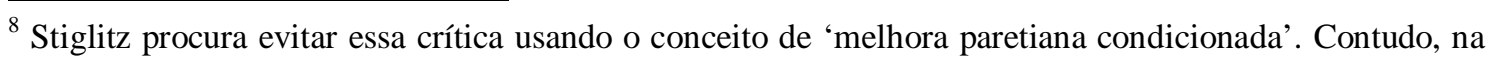
argumentação do autor, a complexidade dos mercados (causa das ineficiências) desaparece quando se analisam as ações corretivas do estado.

${ }^{9}$ Essas crenças tácitas são derivadas da falha em distinguir entre a natureza do conhecimento prático (detalhado e cambiante) e teórico (estável e simplificado para fins de explanação e não de previsão), como observado por Hayek.
} 
forms of regulations ... and the advantages of alternative policies toward decentralizationcentralization. (Stiglitz, 1994: 25)

A rejeição austríaca pela modelagem formal é atribuída por Stiglitz à observação de que a realidade é muito complexa para ser tratada por modelos simples. Essa complexidade, contudo, tornaria menos provável ainda a obtenção de equilíbrios ótimos nos mercados:

If markets do not work efficiently under these idealized circumstances, how can we be confident that they would work efficiently under more complicated circumstances? Only by and act of (and indeed a leap of) faith! (Stiglitz, 1994: 26)

Embora rejeite o critério paretiano, a análise austríaca seria, para o autor, altamente normativa. Stiglitz faz então referência à abordagem evolucionária encontrada entre os austríacos. Contudo, como as idéias combatidas são apresentadas na forma de insinuações, sem referências a autores ou textos específicos, a compreensão sobre exatamente o que está sendo criticado é dificultada ${ }^{10}$.

Para Stiglitz (1996:282, n.r.11), o apelo à teoria da evolução seria mal concebido, pois (pág. 25) a 'sobrevivência do mais apto' não define um critério a respeito do que é considerada uma aptidão e além disso os processos evolutivos não resultam sempre em optimalidade.

Aqui, novamente, as idéias austríacas (e evolucionárias) são distorcidas por Stiglitz. Em primeiro lugar, em parte alguma as abordagens evolucionárias pressupõem a desejabilidade de todo processo evolutivo. Em O Caminho da Servidão, por exemplo, Hayek mostra como processos seletivos na esfera política levam sempre os piores ao poder. Em segundo lugar, em vez de apenas apelar para a evolução, a epistemologia evolucionária examina a natureza dos processos seletivos diversos, de forma a comparar semelhanças e diferenças entre processos evolutivos nas esferas biológica, econômica ou epistemológica. Em terceiro lugar, embora a abordagem evolucionária seja utilizada para mostrar que processos evolutivos na economia não resultam em optimalidade, ao mesmo tempo convida a se avaliarem os processos em termos de capacidade de adaptação e não em termos da possibilidade de atingir a perfeição. Em quarto lugar, a teoria é propositadamente não específica no que refere aos critérios concretos de seleção que operam em cada caso. Isso ocorre precisamente porque em cada caso temos um enorme número de variáveis que afetam a capacidade de sobrevivência, variáveis essas que, devido a sua complexidade, só pode ser vislumbrado

\footnotetext{
${ }^{10} \mathrm{O}$ autor provavelmente se refere às idéias evolucionárias de Hayek desenvolvidas em The Fatal Conceit: the erros of socialism (1988), pois esta é a única referência deste autor citada na bibliografia do Whither Socialism?
} 
pela observação concreta de processo seletivos particulares, a menos que se suponha cientistas oniscientes.

Chegamos assim ao ponto principal da abordagem evolucionária de Hayek (e Popper). Embora seja certo que a complexidade conspira contra a optimalidade, como aponta Stiglitz, a conseqüência disso para a comparação institucional é outra, que escapa a este último autor. A complexidade da realidade econômica, como procuramos mostrar ao longo deste trabalho, também conspira contra a possibilidade de que qualquer agente ou grupo domine o conhecimento necessário para que supere a coordenação obtida nos mercados através de um mecanismo centralizado. O conhecimento necessário para a atividade coordenadora dependeria do processo seletivo de aprendizado por tentativas e erros (conjecturas e refutações) em que consiste a atividade competitiva entre empresários no mercado e não pode ser simplesmente assumido como dado.

As diferentes instituições podem ser comparadas em termos da capacidade de gerar aprendizado, conforme investigamos a natureza dos processos seletivos subjacentes. A incapacidade de gerar modelos formais que dêem conta de detalhes desse processo é, contudo, inerente ao problema. Como apontou Hayek, é logicamente impossível avaliar o fruto do processo de aprendizado antes que este ocorra. Por exemplo, não seria possível representar no modelo de aprendizado de Stiglitz esse problema: pressupor uma equação entre o retorno $r$ de um ativo e o valor de uma variável $\eta$ leva a crer que o processo de aprendizado já ocorreu. O mercado deve ser valorizado hoje, para Hayek, pelo fato de que sem rivalidade não se pode esperar que algum empresário descubra amanhã que surpreendentemente o retorno depende também de outra variável até então negligenciada, digamos, $\xi$. Nada garante hoje, contudo, que essa relação existe e será descoberta. A impossibilidade lógica de conhecer hoje o que será descoberto amanhã impõe limites à capacidade de representar o processo de aprendizado a não ser em suas características mais genéricas. Essa dificuldade, no entanto, não diz nada sobre a relevância do problema do conhecimento.

A retomada do debate do cálculo sob o ponto de vista da economia da informação suscitou reações entre os austríacos. Caldwell (1997), por exemplo, protesta contra as distorções da posição austríaca e procura recuperar o significado original do problema do conhecimento frente à interpretação de Stiglitz sobre o significado da contribuição de Hayek, enfatizando as diferenças entre conhecimento e informação ou ainda o significado da análise de processo frente à preocupação com o equilíbrio estático, entre 
outros aspectos. A desconsideração dos problemas do socialismo estudados pelos austríacos levou Caldwell (1997:1885) a parafrasear Hayek: enquanto este protestava contra o excesso e preocupação dos socialistas de mercado com as condições do 'hipotético estado de equilíbrio estacionário', Caldwell protesta contra a excessiva preocupação moderna com os problemas de informação.

Thomsen (1992: 61), por sua vez, procura clarificar a controvérsia identificando três diferentes funções informativas dos preços: (a) os preços permitem que os agentes tomem decisões como se possuíssem muito mais informação de que de fato possuem, segundo o argumento desenvolvido por Hayek em The Uses of Knowledge in Society; (b) os preços permitem que se façam inferências sobre conhecimento possuído por outros, conforme argumentam Grossman e Stiglitz e (c) preços em desequilíbrio fornecem oportunidades de lucros que induzem um processo de descoberta que produz conhecimento não antes imaginado, conforme desenvolvido pela moderna abordagem de processo de mercado austríaca.

Thomsen procura mostrar que esta última função não diz respeito à possibilidade de resumir nos preços as informações dispersas na sociedade, mas sim ao fato de que, como apontou Lavoie, os empresários aceitam alguns preços mas discordam de outros, apostando recursos na hipótese de que seu conhecimento sobre características locais do mercado revelem oportunidades de lucros não percebidas pelos demais agentes.

Para os austríacos, como vimos, o problema com o socialismo de mercado reside na desconsideração da função empresarial. Stiglitz, embora interprete o argumento de Hayek de forma neoclássica e rejeite a abordagem austríaca, acaba por apelar em Whither Socialism? para argumentos que resvalam nos problemas austríacos. Além dos problemas de incentivo e falta de mercados completos, Stiglitz (1994:66; 1993:27) critica o socialismo de mercado por ignorar o papel da inovação, descentralização e competição. Ironicamente, encontramos no livro do autor um destaque a esses argumentos, cuja apresentação não é formalizada, a despeito da rejeição anterior aos mesmos argumentos (expressos na literatura austríaca) justamente por não serem formalizados.

Roemer, do mesmo modo, reavalia sua opinião de que a causa do fracasso das economias do bloco soviético fosse devida a problemas de agência. Em A Future for Socialism, Roemer (1994:44) afirma que o problema central teria sido a falta de progresso técnico. Isso teria ocorrido não porque os agentes deixaram de seguir as 
ordens dos principais: ninguém deu ordens nesse sentido. Para Roemer, ao contrário, a inovação não ocorreu por falta de competição entre firmas nos mercados.

Embora o problema do conhecimento não seja reconhecido por Stiglitz e Roemer devido ao fato de que tal reconhecimento abalaria o núcleo duro do programa de pesquisa neoclássico, as interpretações históricas sobre os problemas do planejamento central não são derivadas dos modelos formais desenvolvidos por esses autores, mas sim precisamente da noção de competição como um processo rival que rejeitam em termos teóricos, noção essa comum às escolas clássica, austríaca e ao sentido leigo do termo.

Enquanto Stiglitz, repetindo a opinião de Gossen proferida 140 anos antes, é céptico em relação à possibilidade de resolver esses problemas no socialismo de mercado, Roemer liderará a busca por formas de socialismo de mercado que possam lidar tanto com o problema de incentivo do tipo agente-principal, como do problema de geração de inovações:

The question for socialists becomes, then, whether an economic mechanism can be designed under which technological innovation will take place but in which a characteristically capitalism distribution of income does not evolve. (Roemer, 1994:45)

A despeito dessa avaliação, os modelos desenvolvidos tratam do problema de agência identificado acima. A próxima seção é dedicada ao exame das propostas de socialismo de mercado que partem dos problemas discutidos aqui.

\section{A Nova Geração de Modelos de Socialismo de Mercado}

\section{O 'Socialismo de Mercado Real'}

Roemer (1993:6) adiciona mais duas fases ao debate do cálculo em relação às três já identificadas por Hayek. A quarta fase se refere à discussão dos processos de reforma das economias relativamente centralizadas, em especial no leste europeu ${ }^{11}$. A quinta fase, por sua vez, se relaciona às propostas de socialismo de mercado que lidam com o problema dos incentivos.

\footnotetext{
${ }^{11}$ Roemer cita Janos Kornai, Alec Nove e Wlodzimierz Brus como os principais representantes dessa fase.
} 
Embora a quarta fase de Roemer não seja um desdobramento direto da controvérsia do cálculo, dedicaremos algum espaço a ela porque os modelos desenvolvidos na retomada do debate propriamente dito (quinta fase de Roemer) foram bastante influenciados pela crítica que János Kornai fez às economias em transição na quarta fase. Além disso, na época em que ocorreram, as transformações ocorridas no leste europeu eram vistas como o surgimento de uma terceira via, uma síntese entre o capitalismo e a forma centralizadora do socialismo real existente até então. A possibilidade de transformar as economias desse último tipo em algo diferente estimulou a retomada do estudo teórico de formas de socialismo que incorporem elementos dos mercados, contribuindo com a retomada do debate do cálculo.

A expressão 'socialismo de mercado' foi então associada às economias desses países em transição, embora a realidade dessas economias pouco se assemelhasse aos modelos teóricos de socialismo de mercado desenvolvidos na década de trinta. A partir de 1950 alguns países com economias centralizadas, em especial Iugoslávia e Hungria, buscaram implementar reformas que introduziam alguns elementos das economias de mercado ${ }^{12}$. Mais tarde, países como China, União Soviética, Polônia, entre outros, seguiram, em graus diferentes, na mesma direção.

Na Iugoslávia, o centralismo soviético foi substituído por um sistema no qual as decisões das firmas e a alocação de capital passaram a ser feitas de forma descentralizada por firmas operando em mercados. As firmas que operam nesses mercados, porém, não são administradas por proprietários privados ou gestores apontados por estes, mas sim pelos próprios trabalhadores, que escolhem os gerentes via eleições. Uma firma maior pode ainda ser composta por diversos conjuntos menores de trabalhadores denominados 'Organizações Básicas de Trabalho Associado'.

No país, a alocação de fundos emprestáveis passou a ser feita por bancos e as próprias firmas escolhiam a parcela dos lucros a serem reinvestidas ou distribuídas. O comércio internacional aumentou e os preços passaram a guiar de forma mais significativa as decisões gerenciais.

A Hungria, por seu turno, também realizou um processo de reformas, adotando em 1968 o chamado 'novo mecanismo econômico'. Nesse sistema, as quotas físicas de produção foram substituídas por firmas que reagem a incentivos de lucro. Ao contrário da

\footnotetext{
${ }^{12}$ Ver Brus $(1998: 337,1992)$ e Kornai $(1986,1993)$.
} 
Iugoslávia, na Hungria as firmas permaneciam estatais, embora os mesmos processos de abertura comercial e liberalização de preços tenham ocorrido. Além disso, não se abandonou a alocação central de capital ou a idéia de que a economia deva seguir um plano central.

Enquanto o sistema iugoslavo, em termos da caracterização de Mises, se encaixa mais na categoria de sindicalismo do que de socialismo, o sistema húngaro se aproximava do socialismo de mercado idealizado pelos socialistas envolvidos na controvérsia do cálculo, na medida em que concilia propriedade pública com alocação de bens via mercado e alocação central do capital. A semelhança percebida entre essas duas economias e os modelos de socialismo de mercado resultou na incorporação do estudo dessas economias ao debate teórico do cálculo econômico.

Isso ocorreu a partir da análise que János Kornai realizou dessas economias, na medida em que o problema central do socialismo de mercado real identificado por este autor serviu de referência para os novos modelos teóricos de socialismo de mercado baseados na Economia da Informação.

O diagnóstico de Kornai (1986) a respeito dos problemas econômicos do socialismo de mercado real é centrado no conceito de 'restrição orçamentária tênue' (soft budget constraint). Nas economias modernas, nas quais o estado assume um caráter paternalista, e em especial nas economias socialistas, ocorre um relaxamento da disciplina financeira resultante da expectativa existente nas firmas de que, se fracassarem, serão socorridas pelo estado por meio de assistência financeira.

O autor ilustra metaforicamente o problema por meio da restrição orçamentária extraída dos manuais de microeconomia, representada na figura ao lado. Se uma firma adquire quantidades $\mathrm{P}_{1}$ de dois bens que se revelem acima da restrição orçamentária (representada pela linha cheia), o estado cobrirá o déficit e no período seguinte a firma consumirá $\mathrm{P}_{2}$, na expectativa de ser salva novamente. A restrição

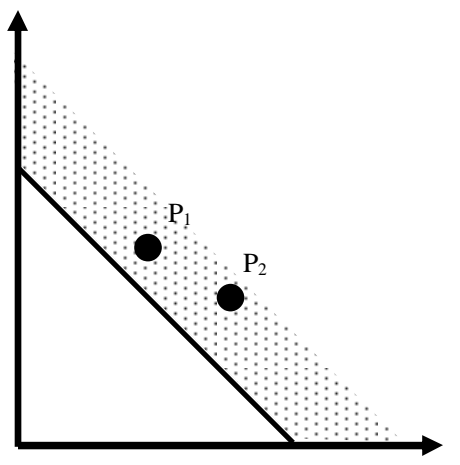
orçamentária não seria então representada por uma linha, mas pela faixa pontilhada da figura, que pode ser estendida para a direita. Quanto maior a expectativa de salvamento, mais tênue é a restrição orçamentária. 
O fenômeno, para Kornai (1986:6), assume várias formas, como subsídios com montantes negociáveis e sensíveis a pressões políticas; impostos com regras negociáveis; créditos concedidos sem que haja desincentivos a quebras de contrato e preços fixados centralmente, sensíveis aos aumentos de custos das firmas. Quando a restrição orçamentária for tênue, as firmas não reagem a variações nos preços dos insumos, como pode ser visto pela indefinição na inclinação da curva de restrição na figura. Isso resulta em ineficiência na alocação de recursos. As firmas, do mesmo modo, não têm incentivos para agir competitivamente, inovando ou cortando custos, havendo um desvio do foco da eficiência administrativa para a eficiência na capacidade de busca de rendas (rent-seeking) junto às autoridades. Finalmente, para Kornai, a restrição orçamentária tênue seria responsável pela persistente escassez de produtos nas economias socialistas, pois sem a restrição, a demanda por fatores não é limitada por considerações de custos.

Kornai investiga em que medida o problema da restrição orçamentária tênue ocorre no socialismo de mercado real. A respeito da Hungria, relata o autor que:

The State takes away money from a firm with one hand - and then gives money to another firm (or perhaps to the same firm, but with another 'entitlement') with its other hand. Or more precisely, the State has not only two hands but it is a Shiva with many more hands: there are in total 276 types of taxes and subsidies used by different tax-levying or subsidy-granting authorities. (Kornai, 1986:15)

O resultado disso é que não haveria naquele país relação alguma entre o desempenho de uma firma, medido pelo lucro antes dos impostos e subsídios, e a 'lucratividade' final, medida após a redistribuirão de recursos.

Embora seja marcante no socialismo de mercado, o autor observa que o fenômeno da restrição orçamentária tênue ocorre também, embora em menor grau, nos países não socialistas.

O diagnóstico de Kornai a respeito das dificuldades encontradas pelas economias que abandonaram o centralismo soviético influenciará não apenas a retomada moderna do debate do cálculo na década de noventa, mas também os autores da quarta fase identificada por Roemer, que buscam formas alternativas para o socialismo na década anterior.

Brus e Laski (1992:106), por exemplo, relacionam a persistência da restrição orçamentária tênue na Hungria com a adoção de mecanismos de mercado apenas para bens de consumo final, excluindo-se das reformas a introdução de mercados de capitais. Se se espera que as firmas sobrevivam intertemporalmente com seus próprios recursos, 
sem auxílio do estado, elas deveriam ter acesso a fontes independentes de financiamento, a fim de que se explorem as oportunidades de sobrevivência e desenvolvimento dessas firmas. A livre entrada, elemento crucial para que se mantenha a competitividade das firmas, também depende da existência de mercados de capital desenvolvidos. A descentralização da posse de capital, por sua vez, permite que se explorem as oportunidades de ganho empresarial. Sem mercados de capital, além disso, perde-se a capacidade de alocar recursos entre setores e entre regiões e as decisões sobre investimento e poupança permanecem centralizadas.

A proposta de socialismo de mercado desses autores será então caracterizada pela introdução de mercados de capital, além dos mercados de trabalho e bens de consumo já presentes nas demais propostas. Propõem então o desenvolvimento de bancos comerciais e empresas com capital aberto a fim de lidar com os problemas apontados acima. Para que se isole a administração das firmas da interferência estatal, defendem os autores uma 'separação do estado como proprietário do estado como administrador' (Brus e Laski, 1992:136): embora as firmas sejam autônomas na administração de seus ativos, o estado mantém o direito ao retorno do capital.

Nove (1983), por sua vez, também propõe um socialismo de mercado que evite os problemas encontrados na experiência iugoslava e húngara. A alocação de recursos seria feita por firmas administrativamente autônomas competindo em mercados. Haveria tanto firmas estatais quanto cooperativas administradas por trabalhadores ou ainda pequenas firmas privadas. $\mathrm{O}$ estado, além de regular a competição e fornecer serviços públicos, planejaria o investimento em áreas chaves.

As preocupações de autores como Kornai, Brus e Nove com o socialismo de mercado real antecederam a discussão de modelos teóricos de socialismo de mercado que incorporassem aspectos dos mercados negligenciados nas propostas da década de trinta. De fato, a obra desses autores não apenas antecipa as preocupações modernas com mecanismos de incentivo como também as críticas que serão feitas a esses novos modelos sob o ponto de vista da escola da escolha pública, como pode ser visto na seguinte avaliação do modelo de Lange:

... in our opinion the most important gap in the model is the omission of the problem of motivation of the economic actors, both central planners and managers. The CPB is presented as an embodiment of unity, public interest, and pure reason; its only concern is to implement the rules of market socialism - to adjust prices in order to avoid shortages or gluts - without using its enormous power for any other purpose. (Brus e Laski, 1992:56) 
$\mathrm{Na}$ próxima seção veremos como as preocupações teóricas com a informação assimétrica deram origem na década de noventa a novas propostas de socialismo de mercado, semelhantes àquelas esboçadas por Brus, Laski e Nove.

\section{As Novas Propostas}

A mistura entre instituições centralizadoras do socialismo real com regras de comportamento de firmas inerentes aos mercados dá origem ao problema de como fazer com que as empresas socialistas se comportem como se estivessem em uma economia competitiva, ou, nos termos de Mises, como fazer com que as firmas 'brinquem de competição'.

Para este último, como vimos, tal problema não tem solução, na medida em que o estímulo à atividade empresarial depende da existência da propriedade privada. Para os modernos socialistas de mercado da década de noventa, no entanto, o problema toma a forma do desenho de instituições que forneçam os incentivos para que os agentes sigam as instruções dos principais na presença de informação assimétrica. Para esses economistas, a 'síndrome da restrição orçamentária tênue' identificada por Kornai foi vista como uma manifestação desse problema de agência: sem um mecanismo crível de incentivo ou punição por meio dos lucros e perdas as firmas não seguem a ordem que as obrigaria a maximizar lucros. As propostas mais modernas de socialismo de mercado irão justamente buscar formas alternativas de lidar com o problema identificado por Kornai, sem que se apele para a restauração completa da propriedade privada.

Roemer (1993:7), comentando sobre o novo estágio do debate, nota que as novas propostas de socialismo de mercado irão abandonar não só a necessidade de fixação central de preços, presente no modelo de Lange, como também a própria noção de propriedade pública (estatal) dos fatores produtivos. O novo socialismo de mercado dá então um passo além da proposta de Durbin, que não fixava centralmente os preços mas retinha a propriedade pública dos fatores.

Com mais essa concessão, contudo, poucos estariam inclinados a conceder credenciais socialistas a essas propostas. De fato, como vimos, tanto defensores quanto oponentes do socialismo ao longo do debate consideraram a propriedade pública como o caráter central do socialismo. Roemer lida com esse problema notando que além da propriedade 
privada ou estatal pura, existem inúmeras formas de direitos de propriedade intermediárias. Em sua proposta, o autor irá buscar uma dessa formas que possa lidar com o problema de agência percebido como central ao socialismo. O socialismo seria então definido não pelos seus meios, como a propriedade pública dos bens de produção, mas pelos seus fins. Roemer (1994:11) identifica estes com a igualdade de oportunidades para 'auto-realização e bem estar, influência política e status social'.

A fim de atingir esses objetivos igualitaristas, o socialismo deve utilizar a capacidade dos mercados de induzir os administradores a maximizar lucros, de forma a gerar alocações eficientes. Isso, porém, deve ser dissociado da distribuição de reda desigual que caracteriza o capitalismo. A fim de extrair tal vantagem sem a consequiência distributiva indesejável, Roemer imagina o modelo de socialismo de mercado descrito em seguida ${ }^{13}$.

O problema central do socialismo de mercado é visto como o desenho de instituições que forneçam o incentivo para que os administradores maximizem lucros. Isso é resolvido, na proposta de Roemer, através da curiosa introdução de uma bolsa de valores no socialismo. Cada cidadão adulto teria direito a um conjunto de vales correspondentes a uma fração do capital de cada firma grande do país. Na prática, Roemer (1992:110; 1993:96; 1994:49) imagina uma série de fundos mútuos detentores de portfólios idênticos de ações de todas as firmas, e cada habitante adulto por sua vez possuiria ações dos fundos mútuos. Quando um indivíduo morre, suas ações voltam para o estado, que as distribui entre aqueles que adquirem maioridade.

A partir dessa situação inicial a bolsa de valores funcionaria de forma a equilibrar o valor das ações das firmas. A fim de que os pobres não vendam seus ativos aos ricos (devido à maior taxa de preferência temporal) ou aos mais informados, o que restabeleceria a desigualdade de direitos ao rendimento do capital, limitam-se os direitos de propriedade sobre os papéis: os indivíduos seriam proibidos de vender todos os seus ativos financeiros; as ações só podem ser trocadas por outras, não por dinheiro.

Tampouco poupanças acumuladas em dinheiro podem ser usadas para adquirir ações. Estabelece-se assim uma espécie de escambo de ações: a moeda corrente não serve como meio de troca nesses mercados. Embora não se possa obter ganhos com a troca de

\footnotetext{
${ }^{13}$ A descrição do modelo pode ser encontrada em Roemer (1994) ou Bardhan e Roemer (1992, 1993).
} 
ações por dinheiro, os detentores das ações teriam direito aos lucros do capital representados pela ação.

O financiamento de investimentos ocorreria via empréstimos bancários. Roemer se inspira no sistema bancário japonês, imaginando bancos ligados a um conjunto de firmas, de maneira semelhante aos keiretsus. As firmas teriam seu quadro de diretores formados por representantes dos fundos mútuos e do banco financiador.

As firmas menores poderiam ser criadas e operadas de forma tradicional, com propriedade privada plena, o que garante a continuidade das inovações (feitas também nos departamentos de pesquisa das firmas grandes). A partir de um certo tamanho, contudo, as firmas pequenas sobreviventes teriam que participar do esquema proposto acima, sendo nacionalizadas.

Retendo uma característica comum ao socialismo de mercado, propõe-se que o estado possa dirigir o investimento, seja de forma direta, seja manipulando taxas diferenciadas de juros. A intervenção no investimento é justificada pelas mesmas razões apontadas por Stiglitz: caso não houvesse externalidades nos investimentos e existissem mercados completos, o investimento poderia ser privado. Roemer acredita, por exemplo, que a falta de um seguro para o caso de que um futuro ciclo econômico inviabilize um investimento no longo prazo resulta na não obtenção de um equilíbrio ótimo de Pareto. Esse tipo de ineficiência justificaria a condução do investimento pelo estado.

Com a sua proposta, Roemer pretende ao mesmo tempo resolver o problema de agência e garantir uma distribuição igualitária no socialismo de mercado. Se os preços (expressos em vales) das ações de uma firma caírem, os fundos mútuos irão vender seus estoques. O banco financiador e os fundos mútuos terão então incentivos para monitorar o desempenho das firmas. Nas economias de mercado, a pressão para manter o desempenho econômico é acompanhanda por variações na riqueza dos agentes. No socialismo de mercado de Roemer, porém, pretende-se quebrar essa relação:

I am assuming that the mechanism of requiring citizens to hold shares of mutual funds, and not firms directly, would prevent the unworldly from losing their stock assets by making poor investments. There would have to be federal regulation of the mutual funds. (Roemer, 1993:97)

Como sugere a última frase da citação, na verdade o problema reaparece uma instância acima: como monitorar os monitores? Com isso chegamos aos problemas que foram o foco da análise de Kornai. Embora reconheça que não se possa fugir completamente do problema da restrição orçamentária tênue, Roemer acredita que os bancos e fundos 
mútuos formam uma camada protetora entre as firmas e o tesouro. O autor cita o sistema bancário japonês como um exemplo concreto de sucesso na monitoração das firmas pelos bancos. Os monitores teriam uma reputação a zelar:

The managerial labor market will not forget if a bank manager forgives bad loans or tolerates nonperforming firms too often. (Roemer, 1994:77)

Outras garantias são mencionadas, como o fato de que os funcionários dos bancos seriam pagos segundo o desempenho, a concorrência internacional seria permitida e os bancos teriam acionistas outros além do estado.

Além de resolver o problema do monitoramento das firmas e gerar distribuições mais igualitárias de renda, Roemer adiciona outro argumento a favor de sua proposta. Para ele, a alta concentração da propriedade de ativos resulta na geração de externalidades negativas advindas da capacidade que os ricos teriam de influenciar as políticas públicas. A indústria armamentista, por exemplo, teria poder para influenciar os governos a tomar decisões em seu favor, mesmo que isso se constitua um 'mal público' sob o ponto de vista da sociedade como um todo. Eliminando-se a concentração na posse do capital, esse problema de externalidades seria bastante reduzido.

A apresentação da proposta de Roemer foi acompanhada por uma variante defendida pelo seu co-autor, Pranab Bardhan. Este último interpreta o problema da restrição orçamentária tênue como constituído de duas partes: o problema de agência na administração das firmas e o problema político de compromisso crível por parte do estado de se ater às regras. Para resolver o primeiro problema, o autor propõe (Bardhan, 1993:147; Bardhan e Roemer, 1992:108) uma forma de socialismo de mercado na qual as firmas são sociedades de capital aberto com algumas ações pertencentes aos seus trabalhadores, instituições financeiras, fundos de pensão e governos locais, entre outros. A maioria das ações, porém, seria controlada pelas demais firmas pertencentes ao mesmo grupo e ao banco associado ao mesmo. Cada grupo de firmas estaria então associado a um banco principal.

O financiamento do capital das firmas seria feito pelos bancos principais, cujo sócio majoritário seria o governo central. Cada grupo não pode ser muito grande, de forma a que se perca a capacidade de monitoramento por parte do banco, mas também não pode ser pequeno, devido ao aumento do risco associado a um portfólio dependente de poucos empreendimentos. Como na proposta de Roemer, pequenos empresários seriam livres para criar e operar pequenas empresas de forma independente. 
O socialismo de mercado proposto por Bardhan difere do de Roemer essencialmente no que diz respeito às instituições responsáveis pelo monitoramento da administração das firmas. Enquanto na proposta deste último tal tarefa seria realizada através de uma bolsa de valores, na proposta do primeiro autor temos o controle centrado em bancos, inspirados no sistema financeiro japonês. Na opinião do autor, grupos financeiros como os keiretzus japoneses possibilitariam um monitoramento mais direto das firmas do que a ameaça de aquisição em uma bolsa de valores, pois a concentração da propriedade nos bancos resultaria no maior interesse da parte dos administradores do banco na fiscalização das firmas e na obtenção de informações sobre as mesmas do que acionistas dispersos.

O monitoramento das firmas assumiria a seguinte forma:

The shares of a large firm can be sold to the main bank. At the first signs of significant attempts by other firms at unloading the shares of a particular firm, and usually much earlier, the main bank will take measures to prod and discipline the management, renegotiate the debt contract if necessary, orchestrate financial rescue strategies, help the firm with an interest moratorium and emergency loans, an arrange for technological assistance from affiliated firms and for the (temporary) sale of the firm's stock assets (in other firms) to cover its operating losses. ... it [the bank] will even have the power to take over temporarily the management of the ailing firm, if necessary. (Bardhan, 1993:148)

Os bancos, além de sua capacidade de resolver o problema de agência das firmas, estariam menos sujeitos ao comportamento miópico encontrado nas bolsas, voltado para a lucratividade de curto prazo.

Comparando as duas propostas, Roemer considera que países capitalistas com um mercado de capitais desenvolvido poderiam adotar a sua proposta de socialismo de mercado, enquanto a proposta centrada em bancos seria mais adequada para países com pouca tradição nesses mercados.

Além daquelas desenvolvidas por Roemer e Bardhan, existem outras propostas de socialismo de mercado que levam em conta em maior ou menor grau os problemas de informação identificados no 'socialismo de mercado real'. Algumas delas retomam idéias defendidas desde a origem do socialismo e discutidas no início do debate, como a administração das firmas pelos trabalhadores. Esse tipo de proposta tem uma história própria, com vasta literatura desenvolvida de forma independente do debate do 
cálculo $^{14}$. Embora a revisão dessa literatura fuja ao escopo do presente trabalho, reportaremos o ressurgimento dessas idéias nesta fase do debate do cálculo.

Na mesma coletânea editada por Bardhan e Roemer podemos encontrar a idéia de socialismo de mercado com firmas administradas pelos trabalhadores como uma alternativa às propostas dos editores. Para Fleurbaey (1993: 274), as versões tradicionais de socialismo de mercado se concentram no objetivo de obter melhor distribuição de renda, negligenciando o objetivo socialista de atingir uma maior democracia no local de trabalho ${ }^{15}$, objetivo este perseguido em sua proposta.

Nesta, pretende-se alterar os direitos de propriedade de forma a separar três poderes que podem ser exercidos pelos mesmos agentes no sistema de propriedade privada: a decisão sobre a proporção entre consumo e investimento, a decisão sobre a alocação de capital para firmas e a decisão sobre o uso do capital dentro da firma.

Este último permaneceria sob a responsabilidade dos trabalhadores. As decisões administrativas seriam tomadas de forma democrática, via consulta aos trabalhadores. $\mathrm{O}$ autor, porém, não explicita em sua proposta a forma de participação adequada, que poderia variar desde o extremo no qual cada decisão administrativa deva ser votada pelos trabalhadores até a delegação da autoridade a administradores profissionais por períodos determinados de tempo via eleições, passando pela rotação dos trabalhadores nos cargos gerenciais.

As decisões do segundo tipo, por sua vez, seriam totalmente delegadas aos bancos. As famílias decidem a proporção de sua renda a ser poupada, depositam sua poupança nos bancos, que emprestam o capital às firmas interessadas. Todo o financiamento assume essa forma, sendo proibidos mercados de capital nos quais as famílias financiem diretamente as firmas via ações e outros títulos. Na proposta do autor, sequer as firmas poderiam se autofinanciar. Embora não seja discutido neste ponto o destino dos lucros

\footnotetext{
${ }^{14}$ Entre os defensores da idéia, destacamos Jaroslav Vanek: (1971) The Participatory Economy, Cornell University Press; (1977) The Labor-Managed Economy: Essays, Cornell University Press, David Ellerman (1990) The Democratic Worker-Owned Firm, Unwin e David Schweickart: (1980) Capitalism or Worker Control? An Ethical and Economic Appraisal. New York: Praeger. No campo crítico, salientamos Benjamin Ward: (1958) "The Firm in Illyria: Market Syndicalism" American Economic Review 48(3)

${ }^{15}$ Weisskopf (1993:120), cuja proposta discutiremos em seguida, lista quatro objetivos socialistas que o socialismo de mercado deva buscar: maior igualdade distributiva, mais democracia política e econômica (participação nas decisões produtivas), formação de senso comunitário e maior racionalidade em termos de eficiência.
} 
extraordinários, podemos inferir que estes seriam automaticamente distribuídos aos trabalhadores da firma.

Os bancos, por sua vez, poderiam ser firmas públicas ou privadas, todas elas administradas pelos trabalhadores. Pressupõe o autor que tais bancos competirão entre si na captação de recursos e financiamento das firmas, de forma intensa o bastante para que o problema de agência entre o público e os bancos (má administração dos portfólios) seja mitigado.

A redistribuição da renda, já que nesse esquema há a tendência de se afastar de uma distribuição igualitária, poderia ser realizada sem o uso de tributação, na mudança de gerações, impondo-se um limite ao montante que uma pessoa possa herdar, limite esse próximo da riqueza média per capita.

Finalmente, imagina o autor, haveria a adoção de planejamento indireto via impostos e subsídios para correção de externalidades ou para direcionamento do investimento em certas direções.

$\mathrm{Na}$ proposta descrita acima, Fleurbaey pretende, com o financiamento de firmas por bancos, contornar alguns problemas identificados com os modelos de economias com firmas geridas pelos trabalhadores. Sem financiamento externo, as firmas tenderiam a investir menos do que o ótimo, por uma série de razões: os horizontes de vida dos projetos são maiores do que o tempo de trabalho futuro dos trabalhadores atuais; os trabalhadores novos 'pegariam carona' nos investimentos antigos e os trabalhadores seriam muito expostos ao risco, porque investem seu capital e trabalho em um mesmo empreendimento. Ao apelar para o financiamento externo via uma rede de bancos, tais problemas seriam contornados: o pagamento dos empréstimos pode ser simultâneo com os retornos do projeto, os novos trabalhadores também pagam as amortizações dos empréstimos e os bancos funcionam como seguradoras para os trabalhadores, cujo capital financeiro é investido em uma carteira diversificada de ativos. Além de seu papel de seguradora, Fleurbaey acredita como Bardham que os bancos teriam capacidade superior de monitorar a administração das firmas do que acionistas.

Embora a proposta de Fleurbaey contemple em alguma medida os problemas de agência tratados por Bardham e incorpore o financiamento das firmas por uma rede de bancos, temos ainda na nova geração de modelos de socialismo de mercado uma proposta mista, que combina elementos do socialismo de mercado com mercado de capitais de Roemer 
e elementos do socialismo de mercado baseado em administração pelos trabalhadores. Weisskopf (1993) imagina um socialismo que evite os problemas tanto do socialismo de mercado tradicional (problemas de informação assimétrica) quanto da administração por trabalhadores (falta de investimentos, falta de mercados de trabalho desenvolvidos e risco elevado para os trabalhadores), preservando contudo suas respectivas vantagens (relativa igualdade de renda e democracia nas decisões econômicas, respectivamente).

Nesse modelo híbrido, as firmas com mais de dez trabalhadores elegem conselhos a partir de eleições, com um voto por trabalhador. O conselho, por sua vez, contrata administradores das firmas, responsáveis pela gestão das firmas. Firmas pequenas, por sua vez, podem existir sob o regime de propriedade privada convencional.

O financiamento das firmas administradas pelos trabalhadores é realizado por aluguel de ativos de outras firmas, por empréstimos bancários junto a instituições financeiras administradas pelos trabalhadores, por emissão de ações sem direito a voto ou reinvestindo os lucros retidos. Conseqüentemente, os ofertantes externos de capital teriam influência apenas indireta sobre as decisões das firmas, que ficam sob a responsabilidade dos administradores que respondem aos trabalhadores.

Ao contrário da proposta de Roemer, na qual os proprietários das ações podem influenciar diretamente as decisões das firmas, no modelo de Weisskopf existe um mercado de ações sem direito a voto e um mercado no qual ações de fundos mútuos são distribuídas equitativamente à população adulta, que não pode trocá-las por outras formas de ativos, da mesma forma como imaginado por Roemer. A diferença entre as duas propostas garantiria assim um maior controle da administração pelos trabalhadores.

A última proposta moderna de socialismo de mercado que destacaremos foi sugerida por Yunker $^{16}$, que a denomina 'socialismo de mercado pragmático'. Para seu autor, o modelo de Lange ou os modelos de administração por trabalhadores não seriam necessariamente inviáveis. Apenas a crença dos economistas na sua inviabilidade constituiria um obstáculo a sua adoção (Yunker, 1995). A sua própria proposta, ao

\footnotetext{
${ }^{16}$ O modelo foi desenvolvido por Yunker em um livro publicado em 1992 (Socialism Revised and Modernized: The Case for Pragmatic Market Socialism. Nova York: Praeger Publishers). Infelizmente, tivemos acesso apenas a um resumo da proposta, feito pelo próprio autor (Yunker, 1995). Além das propostas que apresentamos em nosso trabalho, existem algumas outras formas sugeridas de socialismo de mercado. Roemer (1003) cita o trabalho de Block (1992) e Cohen e Rogers (1992). Yunker (1995) cita ainda a proposta de Stauber (1977) "A proposal for a Democratic Market Economy". Journal of Comparative Economics 1(3):235-258
} 
incorporar o princípio da maximização de lucros, pragmaticamente aceita tal princípio não pela sua relevância para o funcionamento das economias, mas pela sua aceitação entre os economistas.

No 'socialismo de mercado pragmático', uma agência central denominada Bureau of Public Ownership (BPO) se apropriaria de todos os ativos financeiros previamente possuídos pelas famílias. Os ativos pertencentes a pessoas jurídicas, por outro lado, permaneceriam com seus donos. Entretanto, as ações com direito a voto seriam convertidas em títulos sem esses direitos, que seriam totalmente controlados pelo BPO.

O BPO nacional seria descentralizado em escritórios regionais, cada um deles contendo agentes recrutados entre administradores de empresas. A cada agente seriam atribuídas as funções dos acionistas de um conjunto de empresas de setores não relacionados entre si, para evitar conluios anticompetitivos. O agente do BPO não poderia interferir nas decisões administrativas, mas apenas aprovar o plano de pagamento dos executivos das firma, aprovar a nomeação do executivo chefe e decidir sobre a demissão ou manutenção desse executivo.

O salário do agente do BPO seria uma fração bem pequena dos lucros das firmas sob sua responsabilidade. Os ativos financeiros nessa economia seriam por sua vez indicadores de desempenho e não fonte de rendimento de capital. Pretende-se assim uma economia guiada por mercados, mas sem a concentração de renda derivada da posse de capital - combinação almejada por todas as formas de socialismo de mercado modernas.

Como nas propostas anteriores, firmas pequenas e profissionais liberais poderiam operar de forma independente. Yunker permitiria ainda a existência de firmas grandes livres do controle pelo BPO, desde que administradas pelos seus donos fundadores. Neste caso, seria cobrado um imposto sobre o capital igual à taxa normal de retorno do capital da economia.

Além do objetivo socialista de obter maior igualdade de renda, Yunker busca maior eficiência. A centralização do controle no BPO, para o autor, resolveria o problema de incentivo advindo da separação entre posse e controle dos ativos encontrada no capitalismo, pois o risco de demissão do executivo chefe seria maior. Além disso, os rendimentos do capital seriam distribuídos aos trabalhadores como um percentual fixo 
do salário. Para o autor, essa renda complementar aumentaria a oferta de trabalho, o que seria eficiente ${ }^{17}$.

\section{A Nova Geração de Críticas}

A primeira geração de socialistas de mercado foi criticada pelos austríacos em termos da incapacidade da teoria pura de equilíbrio de resolver o problema real do cálculo. Defensores e críticos, contudo, não discutiram os pressupostos sobre motivação dos agentes sob o socialismo de mercado. Com o desenvolvimento da teoria da informação assimétrica, conforme foi visto neste capítulo, uma nova geração de socialistas de mercado procurou lidar justamente com o problema da motivação, ainda sob o ponto de vista de teoria tradicional de equilíbrio. Porém, como veremos em seguida, a crítica a essa nova geração não será como antes feita sob o ponto de vista austríaco: os críticos comungarão com os defensores modernos do socialismo de mercado os pressupostos da teoria de equilíbrio e a preocupação com a motivação dos agentes.

De fato, antes de apresentar sua crítica ao socialismo de mercado moderno, Shleifer e Vishny (1994:166-167) resumem o debate do cálculo de forma idêntica a como isso é feito na versão padrão do capítulo anterior. No texto no qual propõem sua explicação própria para o fracasso do socialismo real, Shleifer e Vishny (1992:246) caracterizam o debate como uma discussão sobre a 'complexidade da tarefa computacional enfrentada pelo planejador benevolente'. Levy (1990), por sua vez, ao tentar buscar sem sucesso no artigo original de Mises o argumento sobre as reais intenções dos planejadores, interpreta de forma algo distorcida alguns trechos deste artigo de Mises a fim de reduzir a objeção deste autor ao socialismo à busca de preços de equilíbrio que melhor estimem os produtos marginais dos fatores.

Rejeitada a tese austríaca de que existe algum problema de cálculo econômico, os novos críticos avaliarão o socialismo de mercado (antigo e moderno) sob o ponto de vista da Escola da Escolha Pública, contestando o pressuposto de agentes públicos benevolentes.

\footnotetext{
${ }^{17}$ É importante lembrar a discussão entre Lange e Lerner sobre o mesmo ponto. Os autores chagaram à conclusão que o dividendo social deveria ser fixo e não proporcional aos salários para não distorcer a alocação de trabalho. Yunker, contudo, afirma que através de uma simulação feita com um modelo de equilíbrio geral o produto total aumentaria em $10,5 \%$ em relação a uma economia de mercado.
} 
Essa nova abordagem crítica não causa surpresa. Afinal, os socialistas de mercado antigos e modernos procuraram resolver um dos problemas atribuídos às economias de mercado - a monopolização - por meio de esquemas que apelam de uma forma ou de outra para a imposição de monopólios legais (seja de firmas, seja de órgãos de financiamento ou ainda de comitês centrais). Isso convida naturalmente ao questionamento sobre o que garantiria que os gerentes de um monopólio legal absoluto se comportem de forma superior aos gerentes em uma economia com apenas um certo grau de monopolização.

Para Shleifer e Vishny (1994:167), o argumento de Lange de que o socialismo de mercado poderia alocar recursos de forma mais eficiente do que os mercados reais dependeria do pressuposto de que os governos de fato buscam a obtenção de maior eficiência. Os objetivos distributivos, de internalização de externalidades e de eliminação do poder de monopólio só seriam buscados de fato se o governo se preocupasse com esses problemas.

Mas, apontam os autores, no socialismo real podemos observar que bens escassos não têm seus preços elevados, o grau de concentração industrial é maior do que nas economias de mercado, o grau de poluição também é maior e não ocorrem inovações advindas de mais competição.

Isso seria explicado pela hipótese de que os governantes não têm como objetivo a maximização do bem estar, mas sim do seu próprio interesse. Sendo esse o caso, as tentativas modernas de prover o socialismo de mecanismos de incentivos parecidos com os de mercado, como no sistema bancário proposto por Bardhan e Roemer, seriam fadadas ao fracasso. Os interesses dos políticos destruiriam qualquer esquema no qual firmas de fato obtivessem lucros.

Por isso, para os autores, mais importante do que os incentivos dos agentes são os objetivos dos principais:

... market socialists often obfuscate the importance of politician's intentions by imagining complex corporate governance structures. Thus Bardhan and Roemer imagine a system in which the government controls banks, which also have other shareholders, and that in turn control enterprises. Our view in this issue is simple, but realistic: no matter what smoke and mirrors are used, as long as the government remains in ultimate control of enterprises, which it does by definition in all market socialists' schemes, its objectives are going to be the ones that are maximized. Any manager who dares to stand up to the government, or to the bank controlled by the government, will be acting against personal interests. Similarly, no manager of a bank controlled by the government will refuse to lend money to a large state enterprise when the government that hired him "advises" in favor of the loan. (Shleifer e Vishny, 1994:170) 
Para os autores, um ditador de um país socialista totalitário, livre de pressões políticas, poderia em princípio agir de forma a garantir eficiência, visto que ele seria em última análise o proprietário de todos os ativos da economia e seu interesse seria então maximizar o produto total. Contudo, tal ditador não opera em um ambiente competitivo: o mais provável seria a manipulação de preços para a extração de ganhos de monopólio, e não a busca da eficiência econômica.

Por outro lado, se o ditador maximizador de riqueza sofresse pressões políticas, o resultado seria ainda menos eficiente. Neste caso predominaria a construção de monumentos, exércitos, concessão da administração das firmas a conhecidos em detrimento de especialistas, industrialização fracassada, com firmas gigantes e ineficientes, mas como grande poder propagandístico e assim por diante.

Se a hipótese de políticos auto-interessados for válida, como os preços seriam ajustados no socialismo? Enquanto o governo desinteressado de Lange ajustaria os preços de forma a igualar oferta e demanda, um governo maximizador de renda tenderia a fixar preços abaixo do equilíbrio, de forma a gerar escassez, como de fato seria observável no socialismo real. Enquanto Kornai explica a constante falta de produtos pelo fenômeno da restrição orçamentária tênue - as firmas adquirem todos os insumos que puderem, visto que não se importam com o custo - os economistas da escola da Escolha Pública explicam o mesmo fenômeno como uma maneira de coletar subornos.

Para Levy (1990:217), se o preço de um produto for fixado em $\mathrm{p}_{\mathrm{c}}$, a disposição a pagar pelo produto seria dada por $\mathrm{D}\left(\mathrm{Q}_{\mathrm{c}}\right)$, sendo $\mathrm{D}\left(\mathrm{Q}_{\mathrm{c}}\right)-\mathrm{P}_{\mathrm{c}} \mathrm{O}$ preço máximo que um consumidor estaria disposto a pagar 'por fora' para obter o produto (ou o preço do direito a comprá-lo) Assim, $\left[\mathrm{D}\left(\mathrm{Q}_{\mathrm{c}}\right)\right.$ - $\left.P_{c}\right] Q_{c}$ representa o volume de subornos

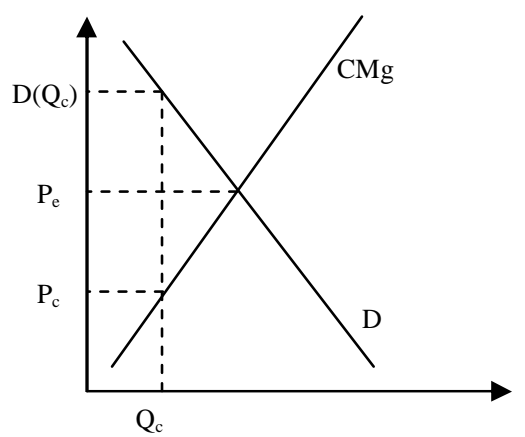
arrecadado no total.

O responsável por cada produto zelaria pela existência da escassez de seu produto, de forma a poder trocar o direito de compra pelos outros bens da economia. Teríamos então sistematicamente uma produção abaixo da quantidade eficiente prevista por Lange. 
Shleifer e Vishny (1992) desenvolvem essas idéias. Se os impostos sobre os lucros das firmas socialistas forem próximos de $100 \%$, como seria o caso nas economias socialistas, os gerentes das firmas não teriam interesse em vender ao preço de equilíbrio. Se uma escassez for mantida por meio de um preço baixo, a diferença apontada há pouco pode ser coletada como suborno, não sujeito a confisco. Os autores supõem que não há competição entre firmas, caso contrário poderia haver redução competitiva dos subornos a zero. No modelo, porém, as firmas em uma indústria seriam coordenadas pelos responsáveis pela indústria, que participariam dos ganhos com o suborno.

O objetivo das firmas seria então maximizar o suborno. Sendo P o preço oficial e $D(Q)$ a demanda inversa, esse objetivo é dado pela diferença entre o montante total pago pelos consumidores (preço oficial mais suborno) menos a receita oficial:

$$
\mathrm{D}(\mathrm{Q}) \cdot \mathrm{Q}-\mathrm{P} . \mathrm{Q}
$$

Como os insumos são pagos pelo estado de qualquer modo, os custos não aparecem na função. Para a firma os custos são representados pela própria arrecadação de receita oficial. Assim, o preço P representa os custos da firma. Esta irá então igualar sua receita marginal ao custo, isto é, ao preço P. Isso pode ser visto tomando a derivada da expressão acima em relação à quantidade, para se obter a condição de primeira ordem da maximização do suborno:

$$
D^{\prime}(Q) \cdot Q+D(Q)-P=0
$$

Representando a receita marginal por $\mathrm{RMg}$, temos:

$$
\mathrm{RMg}=\mathrm{P}
$$

Totalmente não restrita, a indústria gostaria de fixar o preço em zero e produzir enquanto a receita marginal for positiva. Isso, contudo, aumentaria os problemas orçamentários do estado. Este poderia então impor um limite mínimo para os lucros ou aumentar os preços. No primeiro caso, representando os custos por $\mathrm{C}(\mathrm{Q})$, teríamos o limite A para os lucros:

$$
\text { P.Q }-\mathrm{C}(\mathrm{Q}) \geq \mathrm{A}
$$

Admitindo que as firmas operarão com lucro mínimo, essa expressão se trasforma em uma igualdade. Isolando P.Q e substituindo na expressão do suborno, temos:

$$
D(Q) \cdot Q-C(Q)-A
$$


cuja maximização resulta na igualdade entre receita marginal e custo marginal. Teríamos então firmas produzindo a quantidade de monopólio, independente de A. Isso significa que deixar a restrição orçamentária menos tênue reduziria a escassez via aumento de preços, não produção.

No segundo caso, se os preços aumentarem, temos o curioso resultado de que a quantidade produzida diminui ainda mais. Como pode ser visto na figura em seguida, a elevação do preço de $\mathrm{P}$ para $\mathrm{P}$ ' equivale a um aumento de custos, o que reduz a quantidade ótima da firma (igualando-se a receita marginal ao 'custo' marginal) de $\mathrm{Q}$ para Q'.

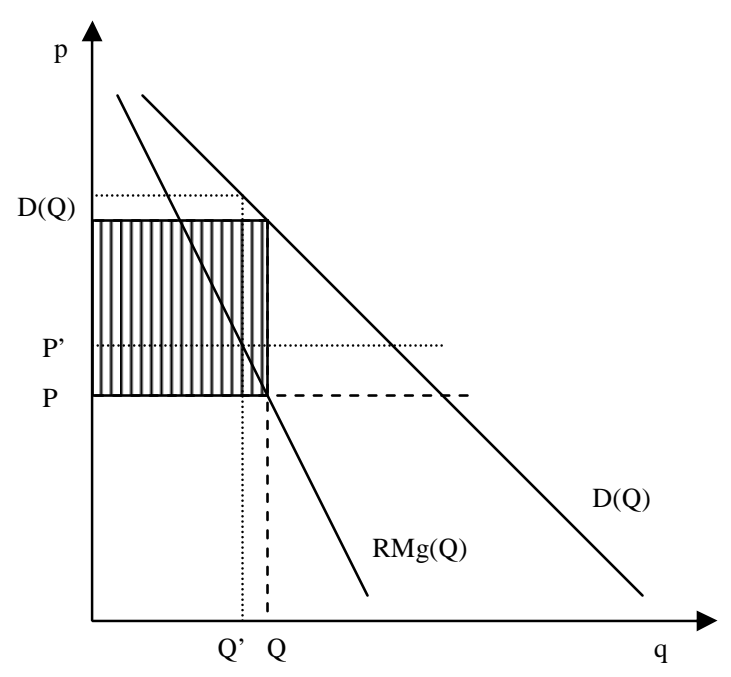

A conclusão mais importante extraída do modelo descrito acima é que o abandono da hipótese de que os dirigentes maximizariam o bem estar da população invalida o pressuposto de que o socialismo de mercado seria capaz de gerar um sistema de preços eficiente.

Os socialistas de mercado, por outro lado, acreditam que o fracasso do socialismo de mercado real deva ser atribuído à falta de democracia existente nessas experiências concretas. As propostas modernas de socialismo de mercado, porém, assumem democracia. Shleifer e Vishny (1994:169) investigam então como a democracia modifica as conclusões derivadas do modelo acima.

Para estes autores, não se pode esperar a busca de eficiência por parte de governos democráticos, tanto nas economias de mercado quanto no socialismo - admitindo que neste último a democracia seja possível. No modelo de voto majoritário, uma 
transferência da minoria para a maioria tende a ser aprovada mesmo que o ganho para a maioria seja menor do que o custo para a minoria. No modelo de grupos de interesse, por outro lado, os governos também não são pautados por preocupações sobre eficiência, a menos que não haja custos para organizar grupos e pressionar o parlamento. Se alguns grupos tiverem custos menores para se organizar, as decisões políticas refletirão os interesses desses grupos. Na realidade, de fato, é muito mais comum a formação de um grupo de pressão de produtores a favor de proteção comercial do que a de um grupo de consumidores a favor do comércio livre.

Embora a democracia não garanta a busca de eficiência nos dois regimes, as distorções seriam bem piores no socialismo (Shleifer e Vishny, 1994:173). Neste, pelo fato de que o estado é relativamente muito mais rico do que o estado capitalista, seria mais fácil bancar intervenções ineficientes com propósitos políticos.

A crítica ao socialismo de mercado de Shleifer e Vishny provocou uma reação de Bardhan e Roemer. Os argumentos de Escolha Pública foram vistos por Bardhan e Roemer (1994) como um exagero em uma direção oposta: embora não seja verdade que o governo seja completamente desinteressado, também não é verdade que seja exclusivamente composto de egoístas preocupados exclusivamente com dinheiro e carreiras. De qualquer modo, acreditam estes autores que suas propostas lidam satisfatoriamente com o problema de isolar as firmas de indevida interferência governamental. Os mecanismos que limitariam essa interferência, tal como imaginam os autores, poderiam inclusive ter o status de garantias constitucionais.

A crítica comportamental ao socialismo feita pela escola da escolha pública (os agentes do governo não são desinteressados), ao contrário da crítica epistemológica austríaca (os agentes do governo não são oniscientes), poderia ser contestada com base na observação de que nada garante que a hipótese de comportamento egoísta seja sempre válida. É possível imaginar sociedades não individualistas, nas quais os agentes se comportariam de outra maneira. De fato, em outra ocasião, Bardhan e Roemer sugerem exatamente isso:

Indeed, it may be the case that the culture of management in a market-socialist economy, with its Weltanschauung of egalitarianism, would be different, at least to some extent, from the culture of capitalist management. (Bardhan e Roemer, 1993:8)

Independentemente da controvérsia sobre se o egoísmo estaria calcado na natureza humana ou se a hipótese russeauniana do bom selvagem seria correta, cuja discussão fugiria ao escopo de nosso trabalho, uma observação pode ser feita a respeito da 
questão. Como observou Buchanan (1987), trabalhar com a hipótese de agentes egoístas não equivale a afirmar que os agentes de fato assim o sejam, mas sim indagar, como teria feito Adam Smith, sobre que conjunto de instituições impediria que o payoff de um único agente oportunista seja grande o bastante de maneira que seu comportamento passe a se espalhar e eventualmente dominar as relações sociais. Busca-se assim um conjunto de regras cujo bom funcionamento não dependa da perfeição moral de todos os agentes.

Deve-se então investigar a possibilidade de que uma sociedade inspirada em um modelo desenhado com o objetivo de evitar os problemas discutidos acima venha a evoluir na direção de suprimir as garantias estabelecidas contra o uso indevido do poder, visto que nessa sociedade existe um estado forte cujo poder poderia tentar um líder não desinteressado. Essa é justamente uma preocupação presente na crítica de Kornai (1993) ao socialismo de mercado moderno, para a qual nos voltaremos agora.

Kornai (1993:48), de fato, acredita que é impossível desenhar e fazer valer um contrato entre estado central (principal) e firmas (agentes) que garanta uma alocação eficiente de recursos, como querem os socialistas de mercado. Isso porque seria ingênuo esperar que o processo produtivo seja despolitizado, uma vez que a propriedade pública de fato coloca a economia nas mãos de políticos. Como Shleifer e Vishny, Kornai acredita que os objetivos destes, como crenças ideológicas ou brigas por poder, distorceriam as decisões econômicas. A tentação da burocracia de exercer o poder e não delegá-lo à gerência das firmas seria irresistível.

Kornai (1993:51) ataca também a crença fundamental dos socialistas de mercado de que o problema de agência advindo da separação entre propriedade e gerência no capitalismo seria análogo ao problema das firmas no socialismo de mercado. A analogia se revelaria falsa quando se observa que neste último: a) os objetivos do principal são políticos e não a maximização dos lucros, b) os principais utilizam como ameaça de penalidade polícias políticas e não penalidades financeiras e demissão e c) os agentes não podem trocar de empregador, uma vez que o estado é o único proprietário, mantendo o registro do funcionário em qualquer firma que este esteja. Se o administrador se opuser à burocracia central, suas chances de prosseguir carreiras em outra parte são bastante limitadas. Disso Kornai conclui, seguindo Mises, que seria impossível obter descentralização verdadeira sem propriedade privada. Adicionalmente, com propriedade pública, as firmas nunca seriam abandonadas a sua própria sorte. A 
propriedade privada seria então condição necessária para uma restrição orçamentária não tênue.

Além da discussão do papel da propriedade privada, Kornai retoma o conceito austríaco (e clássico) de competição, centrado na atividade rival. Kornai (1993: 54) acredita que no socialismo de mercado não haveria livre entrada e saída de firmas, ao contrário do que acreditam os seus defensores. Para Kornai as decisões de entrada e saída seriam tomadas em um ambiente político, não econômico. Sem livre entrada e saída, continua o autor, não ocorreria o processo de seleção natural e a ação competitiva das firmas no sentido de superarem umas às outras. Sem esse processo de seleção natural seria impossível estabelecer um 'contrato' entre o estado (principal) e as firmas (agentes), já que sem competição seria impossível comparar o desempenho das firmas e portanto avaliar se o contrato foi cumprido ou não.

Kornai resvala assim em um dos argumentos de Hayek contra o socialismo de mercado: não existem os 'dados' de forma independente do processo competitivo ${ }^{18}$. Embora reconheça a ligação entre suas críticas ao socialismo de mercado moderno e as críticas de Mises e Hayek ao socialismo de mercado antigo, Kornai (1993:63) considera essas últimas como 'palpites brilhantes', baseados na 'visão' dos autores. Heilbroner (1990), do mesmo modo, analisa o debate entre Hayek e Lange à luz dos acontecimentos históricos em termos das visões dos autores e não em termos do mérito de seus argumentos. Mesmo utilizando argumentos austríacos, Kornai não reconhece a teoria de processo de mercado como uma alternativa à luz da qual o socialismo de mercado moderno poderia ser analisado.

Contudo, um outro argumento austríaco foi empregado em uma discussão em torno do socialismo de mercado com firmas controladas pelos trabalhadores, o último tipo de proposta de socialismo de mercado que mencionaremos. Tal argumento foi empregado por Arnold (1987a, 1987b, 1987c) antes da retomada moderna dessa proposta por Fleurbaey e Weisskopf, tendo como referência as defesas de Vanek e Schweickart desse tipo de proposta.

\footnotetext{
${ }^{18}$ Convém lembrar que Lerner defendia a idéia de que seria possível comparar o desempenho de firmas através do exame de seus custos, enquanto que Hayek negava que curvas de custos fossem dadas independente do processo de mercado.
} 
De forma curiosa, Arnold estende o argumento de similitude formal para a atividade empresarial no socialismo de mercado, investigando a maneira como a função empresarial seria exercida pelos trabalhadores.

Retoricamente, Arnold busca apoio em Marx. Argumenta o autor que para Marx o socialismo exclui os mercados, pois existiria uma tendência inerente ao sistema de produção de mercadorias de desenvolver as relações sociais capitalistas, em especial a falta de controle dos meios de produção pelos trabalhadores, que apenas vendem sua força de trabalho como mercadoria.

No socialismo de mercado, da mesma maneira, essa tendência detectada por Marx também estaria operante. A propriedade e o controle das firmas, em princípio pertencentes aos trabalhadores, tenderiam a ser concentradas nas mãos de poucos administradores, na medida em que a atividade empresarial e administrativa requer talentos específicos. As firmas que profissionalizassem seus processos decisórios teriam vantagens competitivas sobre aquelas que não o fizessem. Para que essa tendência de fato ocorra, o autor assume que as firmas são de fato submetidas à pressão competitiva. Ou seja, não ocorre o problema de restrição orçamentária tênue identificado por Kornai. Nesse ambiente, progressivamente os trabalhadores abdicariam do controle dos ativos das firmas para se tornar meros vendedores de trabalho, à medida em que o sucesso empresarial fosse compensado com lucros e o insucesso com prejuízos:

As was the case with the rise of capitalism, competition would be the acid which dissolves the relations of production which predominate under market socialism. (Arnold:1987:32)

Schweickart (1987a, 1987b) reagiu à crítica de Arnold, reação esta que ilustra perfeitamente as incompreensões resultantes do contraste entre programas de pesquisa diferentes. Para Schweickart (1987a:310), a tese de Arnold dependeria da hipótese de que 'people willing and able to innovate and to manage effectively are normally in short supply', hipótese esta que explicaria os altos salários dos administradores pela escassez da habilidade administrativa vista como um fator de produção. Para Schweickart, no entanto, os salários são altos porque os próprios administradores fixam seus rendimentos, e a habilidade administrativa não seria escassa em absoluto.

Em sua réplica, Arnold (1987b) enfatiza a diferença entre administração e atividade empresarial, sendo esta última não redutível a um fator produtivo com produtividade conhecida. Sob condições de incerteza, como vimos, não bastam a motivação e 
habilidade para administrar. A habilidade empresarial só é testada no próprio processo competitivo, sendo dependente da rivalidade entre as firmas.

A discussão entre Arnold e Schwickart nos traz de volta ao contraste que fizemos no início do capítulo entre a preocupação austríaca com a economia do conhecimento e a preocupação neoclássica com a economia da informação. A leitura da contribuição de Hayek ao debate sob óculos da segunda abordagem direcionou a discussão para o desenho de mecanismos de incentivos que motivem os agentes a seguir as ordens dos principais. Por outro lado, assumindo-se tal motivação, o problema de saber $o$ que deve ser feito sob condições de incerteza não recebeu devida atenção. Em seguida, no início do próximo capítulo, iremos avaliar os modelos da nova geração de socialismo de mercado sob o ponto de vista da crítica de Hayek. 


\section{Informação, Conhecimento e Complexidade do Problema Econômico}

Descrevemos ao longo deste trabalho como no debate do cálculo a teoria econômica foi interpretada e empregada de maneiras diferentes e como isso contribuiu com o desenvolvimento da abordagem austríaca vista como um programa de pesquisa próprio. A retomada do debate na década de noventa, por sua vez, não consistiu em um choque direto entre essas abordagens, mas sim em uma tentativa de reduzir os argumentos austríacos de Hayek a uma manifestação precoce da economia da informação, o que permitiu que se visse o problema do socialismo de mercado exclusivamente como uma questão de informação assimétrica.

No início do capítulo anterior, mostramos como essa redução não se sustenta: Hayek discute o problema da geração de conhecimento e não apenas de assimetria de informação. Embora possa valer a pena investigar este último, o primeiro também coloca desafios fundamentais ao problema do cálculo, não sendo legítima a sua desconsideração. Iremos então analisar no início deste capítulo as propostas modernas de socialismo de mercado à luz do problema do conhecimento proposto por Hayek.

Em seguida, veremos como alguns autores modernos procuraram levar em conta explicitamente algumas objeções austríacas, sob o impacto da interpretação revisionista do debate feita por Lavoie. Argumentaremos que a desconsideração da complexidade do problema econômico está na base da falha dos autores desses textos de apreciar a verdadeira natureza da objeção hayekiana ao planejamento.

Encerraremos o capítulo com um resumo das conclusões a que chegamos ao longo deste trabalho. 


\section{O Problema do Socialismo de Mercado: Informação ou Conhecimento?}

No final do sexto capítulo reformulamos o problema do conhecimento de Hayek em termos da Epistemologia Evolucionária: para que possamos supor um processo de aprendizado em um sistema econômico complexo, devemos explicar como são geradas as diferentes hipóteses sobre as cambiantes condições econômicas locais (variação), como se dá o processo de correção de hipóteses erradas (seleção), como o conhecimento adquirido é preservado e transmitido (hereditariedade) e como esses elementos se relacionam. Em uma proposta de modelo econômico alternativo, o processo de aprendizado composto por esses elementos deve pelo menos replicar a complexidade e a riqueza de detalhes encontradas nos mercados reais. Examinemos agora os modelos modernos de socialismo de mercado propostos por Roemer e Bardhan sob o ponto de vista do problema do conhecimento.

Em relação à geração de hipóteses empresariais rivais, os modelos dos autores em questão limitam a capacidade empreendedora em vários aspectos. Empresas com mais de alguns poucos funcionários não podem unir capacidades para lançar novos projetos em conjunto. Para financiar projetos, uma firma depende exclusivamente de seu banco principal, o que limita a sua capacidade de inovação: os administradores, caso queiram exercer atividade empresarial, devem convencer os funcionários desse único banco de que a idéia é viável ou abandonar o projeto, pois é ilegal convencer poupadores independentes a investir no projeto. Como os bancos são em última análise estatais, é provável que uma concepção central prévia sobre a realidade econômica venha a direcionar a aprovação de crédito em projetos compatíveis com essa concepção. A atividade empresarial nas firmas médias e grandes é então limitada a decisões sobre o uso da quantidade de capital já investida nas mesmas.

Um empresário independente, por sua vez, só pode pôr em prática sua hipótese empresarial se esta for aplicada em pequena escala, já que o esquema permite apenas a livre iniciativa em firmas com um número reduzido de funcionários. Idéias empresariais que dependam de uma escala mínima maior seriam barradas. Essa restrição da proposta, além de limitar a geração de hipóteses empresariais, provavelmente teria um efeito distorcivo na alocação de recursos: caso a avaliação do banco sobre o valor presente dos rendimentos futuros da firma seja superior à do empresário, este tentará artificialmente expandir o seu empreendimento a fim de vendê-lo para o setor estatal a esse valor. Se o 
estado avaliar o empreendimento na outra direção, a firma irá deter a expansão a fim de evitar a perda de seus ativos.

Como a teoria que orienta as propostas se concentra em problemas de informação e não na falibilidade do conhecimento dos agentes, o problema da atividade empresarial é subestimado. Roemer e Bardhan acreditam que a liberdade de estabelecimento de pequenas firmas e o financiamento de laboratórios de pesquisa bastariam para manter a capacidade inovadora na economia. As inovações não dependeriam significativamente do processo de rivalidade entre firmas que se manifesta, por exemplo, em mercados de capital desenvolvidos.

O tratamento exógeno da função empresarial aparece de forma explícita em Yunker (1995), que imagina em sua proposta de 'socialismo de mercado pragmático' uma agência denominada National Entrepreneurial Investiment Board encarregada de 'estabelecer novas firmas viáveis e lucrativas'. A atividade empresarial, infere-se dessa sugestão, novamente nada deve à existência de diversidade de opiniões de agentes independentes que possam ter alguma liberdade de apostar em suas idéias.

O outro aspecto das propostas modernas de socialismo de mercado que devemos considerar é a natureza do processo seletivo. Embora seja suposto o mesmo mecanismo de lucros e perdas das economias de mercado, as diferenças entre as instituições destas economias e dos modelos propostos restringem na prática a efetividade desse mecanismo seletivo, visto que se subestima a necessidade do aprendizado empresarial.

$\mathrm{Na}$ abordagem austríaca, a bolsa de valores funciona como uma arena na qual se debatem os planos rivais dos empresários. Estes empenham seus recursos em projetos compatíveis com ou dirigidos por tais planos. A lucratividade passada das firmas (com ações em bolsa ou não), por sua vez, reflete ao mesmo tempo a sorte e a habilidade do empresário de antever as condições futuras dos mercados, servindo como um teste das ações empresariais de seus dirigentes.

Já na visão de Roemer e Bardhan, a existência de bolsas de valores serve para disciplinar o comportamento dos administradores caso estes não desejem maximizar lucros. O prejuízo funciona como uma ameaça contra comportamentos tais como esforço insuficiente (shirking), e não como uma conseqüência de erros empresariais. Como o problema do socialismo de mercado é visto em termos de informação assimétrica em relação ao comportamento dos administradores e não em termos de 
geração de conhecimento empresarial, desaparece de cena o processo de eliminação de erros e a conseqüente variação de renda decorrente disso, como se as ações adequadas a serem tomadas pelas firmas já fossem conhecidas e a economia estivesse automaticamente perto de um equilíbrio estático e tudo o que resta é convencer as pessoas a implementar essas ações.

Mas, a menos que se suponha conhecimento perfeito, os erros são inevitáveis. Nos modelos dos autores, contudo, os agentes nunca fracassam de fato. Um poupador privado nunca perde seus recursos em aplicações erradas, pois administradores profissionais dos fundos mútuos administram seus portfólios. Os fundos mútuos, por sua vez, ao mesmo tempo controlam indiretamente um conjunto pequeno de firmas de modo a conseguir monitorá-las e diversificado o bastante para não depender da sorte de qualquer dessas firmas. Caso uma firma dê sinais de fracassar, o fundo mútuo e os bancos atuam prontamente sobre os administradores das firmas de forma a rapidamente corrigir o erro.

Mas, se o erro não for devido a administradores não vigiados o bastante, mas sim fruto da adoção de planos errados, incompatíveis com a realidade econômica do mercado em questão, estamos simplesmente deslocando a atividade empresarial da firma para os fundos mútuos. Estes estarão então sujeitos ao fracasso e o estarão de forma mais intensa, pois esse deslocamento da atividade empresarial apresenta o problema de menor uso de informação dispersa e de menor diversidade de opiniões empresarias, já que a atividade empresarial é mais centralizada.

Mas, se os fundos mútuos e os bancos fracassarem, a perda de capital é muito concentrada, o que torna improvável que isso seja politicamente viável. Entra então em cena o que Kornai chama de síndrome de restrição orçamentária tênue: os fundos mútuos seriam salvos pelo governo central e provavelmente haveria grande expansão de crédito como resultado da tentativa de salvá-los. Esse resultado não seria devido à falta de democracia (o que Roemer e Bardhan consideram o problema de agência do público em relação ao estado), mas sim inerente ao regresso infinito existente no modelo: não se pode ter um processo de tentativas e erros sem erros, e eliminar a variação na renda dos agentes econômicos transferindo a responsabilidade para instâncias anteriores torna os erros mais graves e de maior magnitude. Como a diminuição de renda advinda do erro é deslocada para instâncias mais amplas, a competição entre os agentes se transfere da esfera econômica para a política, na disputa para se livrar do ônus de arcar com o 
prejuízo. Neste ponto a análise da escola de escolha pública complementa a análise austríaca.

É curioso notar que Roemer e Bardhan, escrevendo na primeira metade da década de noventa, tomam como modelo o sistema bancário japonês, que, ironicamente, viria a entrar em crise logo em seguida, em grande medida devido ao excesso de créditos concedidos indiscriminadamente. A incapacidade do sistema de monitorar os investimentos das firmas japonesas, aliás, provavelmente esteja relacionado com o arrefecimento no interesse pelas propostas de socialismo de mercado aqui discutidas.

Embora o modelo não dê conta de gerar um processo de aprendizado empresarial como nos mercados reais, a análise de Roemer é a proposta de socialismo de mercado que mais perto chega de levar em conta as complexidades dos mercados, tanto em relação às propostas antigas quanto em relação à maioria das análises posteriores sobre o debate do cálculo.

É curioso notar que na nossa análise 'hayekiana' do socialismo de mercado moderno, devido à postura falibilista em relação ao conhecimento humano que marca o pensamento desse autor, o fracasso do modelo é visto como uma conseqüência não intencional da ação do cientista que propõe tal modelo. A proposta fracassaria por desconsiderar um aspecto real dos mercados que está fora da análise de equilíbrio tradicional : o processo empresarial de descoberta.

É interessante comparar essa postura com a crítica baseada na escola da escolha pública. Como esta última compartilha com a teoria neoclássica os postulados sobre racionalidade, não apenas os agentes não têm problemas relacionados à atividade empresarial, como também os planejadores não têm problemas de imaginar todas as consequiências de um esquema proposto de socialismo, de modo que, para Shleifer e Vishny, se alguém defende o socialismo de mercado moderno, defende também a atividade de rent-seeking que resultaria da implementação do modelo:

In this context, it is instructive to keep in mind who the supporters of 'market socialism' in eastern Europe are. The supporters, who inevitably talk about Sweden, tend to be former communist officials and managers of doomed state enterprises - the people who stand to personally benefit the most from continued government ownership. It is unfortunate that, like the Soviet communists in the 1930s, these advocates of market socialism are getting support from idealists in the West. (Shleifer e Vishny, 1994:175)

Bardhan e Roemer (1994:181) protestam contra essa afirmação, que seria equiparável a uma acusação de que os defensores do capitalismo seriam na verdade defensores dos mafiosos que dominam as economias da Europa Oriental. 


\section{Complexidade e Planejamento}

Chegamos agora ao último grupo de contribuições ao debate. A controvérsia do cálculo em si talvez não tenha um término, dado o perene interesse em formas diversas de organização social. A análise desse último grupo de autores, porém, fornece um bom ponto para encerrarmos o nosso trabalho, pois com ele chegamos a um círculo completo: a releitura austríaca do debate foi criticada sob o ponto de vista marxista original. $\mathrm{O}$ exame dessa crítica é interessante porque nela aparecem os pontos centrais do problema do cálculo; a saber, a complexidade do problema econômico e a natureza do conhecimento necessário para lidar com ela.

Iniciaremos mais esse desdobramento do debate a partir de um artigo de O’Neill (1989). Nesse artigo, seu autor examina o problema do cálculo em termos marxistas, criticando tanto Hayek quanto os socialistas de mercado. O’Neill contesta a leitura destes últimos de que a objeção aos mercados feita por Marx repousa no fato de que a coordenação nos mercados seria ex post e no socialismo deveria ser ex ante: aponta o autor que não só nos mercados ocorre planejamento individual para o futuro quanto no socialismo deve haver coordenação ex post, dado que aí também ocorrem mudanças.

A objeção genuína de Marx se referiria à incapacidade de coordenação dos agentes justamente devido ao processo competitivo que Hayek afirma que levaria à coordenação. À maneira de Stiglitz, O’Neill utiliza o exemplo do estanho de Hayek para afirmar que este último autor teria dito que o sistema de preços comunica toda a informação necessária para coordenar os mercados. Além de discordar essa afirmativa 'de Hayek', o autor questiona a afirmação de que a informação contida nos preços seja suficiente para coordenar os mercados. Para que isso ocorra, os agentes deveriam estar cientes dos planos de ação dos demais, caso contrário haveria excesso de produção causado pela reação de produtores isolados a uma variação de preços sem levar em conta a mesma reação dos demais. Essa ignorância mútua estaria na base da explicação marxista das crises.

Para o autor, a natureza competitiva dos mercados bloquearia a possibilidade de existir um mecanismo para transmitir essas informações, não havendo assim coordenação perfeita entre planos. A partir disso O’Neill pula para a conclusão de que não existe 
complexidade inerente ao problema econômico, já que a aparente complexidade é devida à falta das 'paredes de vidro' de Dickinson:

The market in virtue of its competitive nature blocks the communication of the information and fails to coordinate plans for economic action. That feature of the market is specific to the market as a system of independent producers in competition with one another for the sale of goods. It is not a consequence of complexity or change. (O'Neill, 1989:209, ênfase no original)

Para o autor (1989:210), esse problema de impossibilidade de coordenação persistiria no socialismo de mercado, pois cooperativas de trabalhadores não implicariam em cooperação entre firmas ${ }^{1}$.

Eliminada a competição dos mercados, presume-se, desapareceria a falsa complexidade do problema econômico, abrindo espaço para uma economia 'cooperativa', na qual existe um mecanismo de transmissão de informações entre os agentes. A natureza desse mecanismo e as instituições existentes no socialismo para lidar com esse mecanismo, porém, não são discutidas pelo autor. Temos apenas em uma nota de rodapé a sugestão de que a solução seria próxima à proposta de Otto Neurath.

Partindo do mesmo diagnóstico de que o principal problema de coordenação repousaria na independência das decisões dos produtores isolados, Adaman e Devine (1996) procuram construir um modelo do que O'Neill chama de economia cooperativa. A proposta é denominada pelos autores de 'planejamento participatório democrático'.

O modelo pretende combinar as contribuições ao debate feitas por Dobb com as feitas por Lavoie. De Dobb, Adaman e Devine extraem a idéia de que o socialismo deva coordenar ex ante as decisões de investimento das firmas, levando em conta as relações intersetoriais, os possíveis gargalos no que se refere à produção futura, externalidades no consumo e assim por diante. A visão de Dobb sobre o socialismo, porém, seria incompleta, pois este autor acredita que a coordenação entre os setores da economia possa ser feita com base em dados objetivos sobre a economia.

Da interpretação que Lavoie faz do problema do conhecimento de Hayek, Adaman e Devine extraem o reconhecimento da importância do conhecimento tácito. Se boa parte do conhecimento relevante para as decisões econômicas fosse tácita, o planejamento proposto por Dobb não seria possível.

\footnotetext{
${ }^{1}$ Aparentemente o autor identifica a proposta de administração participativa com o socialismo de mercado em geral, dado que não discute outras formas de socialismo de mercado nas quais, por exemplo, o estado coordena o investimento.
} 
Por outro lado, os autores não crêem que a única forma de descobrir e utilizar conhecimento tácito seja através da rivalidade entre empresários competindo nos mercados. A atividade empresarial, dessa maneira, não estaria associada necessariamente com a existência de propriedade privada.

No modelo de 'planejamento participatório democrático', Adaman e Devine pretendem então combinar os pontos fortes de Dobb e Lavoie, complementares entre si:

In our view, the lesson for socialists from the calculation debate is that attention should be focused on the possibility of combining planning with the articulation of tacit knowledge. (Adaman e Devine, 1996:529)

Isso seria feito a partir da implementação da 'propriedade social', distinta tanto da idéia de propriedade privada quanto da propriedade pública estatal. O conceito de propriedade social atribui direito de participação nas decisões sobre o uso de um conjunto de ativos a todos aqueles que são afetados por essas decisões.

No que diz respeito à propriedade social das firmas, as decisões devem ser tomadas em conjunto pelos trabalhadores, consumidores, comunidades locais e regionais onde as firmas se situam, órgãos de planejamento central e regional, grupos defensores do meio ambiente e grupos voltados para a defesa de oportunidades iguais para grupos de interesse específicos.

Embora não detalhem como, acreditam os autores que o conhecimento tácito desses agentes seria articulado no processo de negociação:

...this tacit knowledge would be mobilized through a process of negotiation among all the beneficial interests and hence principal-agent problems would be minimized. (Adaman e Devine, 1996:533)

Desse diálogo entre os detentores do capital social da firma são decididos os usos dos recursos dessa firma.

Por outro lado, os autores afirmam que as firmas fixariam seus preços com base nos custos médios de longo prazo, calculados com base na quantidade de trabalho empregada na produção dos bens. Adicionalmente, a observação dos estoques ou encomendas forneceria informações sobre a necessidade de expansão ou contração da produção.

As indústrias, por sua vez, decidiriam o montante de expansão na sua capacidade produtiva através da discussão nos chamados 'corpos de coordenação negociada', que reuniriam os consumidores, as firmas do setor, as firmas fornecedoras de insumos e as firmas consumidoras de produtos, comissões de planejamento global, nacional e 
regional preocupadas com inovações, desenvolvimento regional ou relações entre indústrias, além de outros grupos interessados no setor.

Os corpos de coordenação decidiriam sobre os investimentos a partir de informações sobre o desempenho das firmas, estimativas de mudanças, custos e demanda com a capacidade atual e com a adoção de inovações, além de opiniões sobre as causas das diferenças de desempenho e também sobre as condições econômicas e sociais das diversas localidades.

Os autores não discutem como essas informações são obtidas, como são estabelecidos os preços e custos ou ainda em que medida os órgãos decisórios devem ou não se ater a regras de custos e ajustar a produção à demanda. Embora a alusão a essas regras implique que a coordenação no final das contas seria ex post, os autores afirmam que as transações de mercado seriam mantidas, mas as forças de mercados seriam substituídas pelo planejamento ex ante através das discussões. Entretanto, não temos um detalhamento mais preciso de como a coordenação ex ante, via planejamento, interage com a coordenação ex post, via preços, de forma a haver um mecanismo de seleção de hipóteses empresariais erradas.

A moderna reação de inspiração marxista aos desenvolvimentos do debate do cálculo que apresentamos acima nos servirá para ilustrar o ponto essencial que separa os defensores dos críticos do planejamento ao longo da controvérsia.

O ponto original do desafio de Mises, retomado por Hayek, foi apontar para a incapacidade da mente humana de lidar com a complexidade do problema alocativo. Em Mises, o reconhecimento dessa complexidade tem origem na teoria austríaca do capital e se manifesta na enorme variedade de combinações que os bens de produção podem tomar ao longo do processo temporal de produção. Sem a 'divisão intelectual do trabalho' possibilitada pelo cálculo baseado nos preços de mercado, seria impossível conceber quais dessas combinações seriam as mais econômicas.

Reagindo à solução estática do socialismo de mercado, que simplifica sobremodo a natureza do problema, tanto Mises quanto Hayek enfatizaram o fluxo contínuo de alterações na realidade econômica e a riqueza de detalhes locais que devem ser levados em conta no problema real. A fim de preservar a produtividade de um sistema econômico moderno, com a alta especialização e complexas e cambiantes relações entre seus elementos, ou fazemos uso de um sistema indireto de correção de erros, que 
transcende ao controle consciente do planejador, ou devemos esperar que este seja onisciente.

Já por trás tanto do trabalho de O’Neill quanto do de Adaman e Devine, podemos encontrar uma opinião (ora explícita ora tácita) sobre a complexidade do problema econômico e sobre a natureza do conhecimento necessário para lidar com ele. $\mathrm{O}$ primeiro nega claramente que haja a complexidade mencionada acima, sendo a incapacidade de conhecer o sistema como um todo tributável aos segredos industriais mantidos pelas firmas, rivais entre si. O texto de Adaman e Devine, por sua vez, procura imaginar uma proposta concreta para organizar a produção de forma transparente. Reduzida a complexidade do problema econômico, a mente humana passa a dar conta da sua solução de forma consciente. Os três autores consideram o problema econômico simples o bastante de modo a ser possível agregar e processar informações sobre os diferentes setores da economia, viabilizando o controle consciente do processo produtivo como um todo.

No texto de O’Neill, temos uma concepção sobre a natureza do conhecimento relevante para a solução do problema econômico próxima à de Dickinson: deve-se imaginar um sistema de coleta de informações objetivas (e acuradas) sobre a realidade econômica. Difere O'Neill deste último autor apenas no que se refere à natureza desses dados necessários, já que este acredita na teoria do equilíbrio geral enquanto aquele, na doutrina marxista.

Já Adaman e Devine, sob a influência de Lavoie, reconhecem a natureza tácita de grande parte do conhecimento dos agentes e que, portanto, não seria possível tratar os dados de forma objetiva. Entretanto, este problema poderia ser superado pela conversa entre todos aqueles que se relacionam economicamente. Isso tornaria possível transformar o conhecimento tácito em objetivo.

Examinando essa afirmação sob o ponto de vista austríaco, contudo, isso não seria possível, precisamente por causa da crença na complexidade do problema alocativo. Se um sistema econômico se limitar ao uso de conhecimento articulado, o grau de complexidade que esse sistema poderia atingir seria limitado pela capacidade cognitiva de seus agentes. Para Hayek, a humanidade transcendeu esse limite através da evolução de instituições, como o sistema de preços, que forneceram mecanismos de correção de erros impessoais, que dispensam o controle consciente imaginado pelos marxistas. 
Por isso, na concepção hayekiana de Lavoie, boa parte do conhecimento relevante economicamente será necessariamente tácito, não articulável. Os agentes atuam boa parte do tempo não por meio de cálculo racional consciente, mas sim segundo regras, tradições que evoluíram ao longo do tempo e que foram capazes de garantir algum sucesso aos agentes. A idéia de Adaman e Devine de que o conhecimento tácito seria articulado ao longo do processo de discussão pecaria então por ignorar dois elementos: a) os agentes não têm consciência de boa parte dessas regras e b) o conhecimento tácito se forma a partir de tentativas e erros durante o processo de competição entre rivais nos mercados.

Paralelamente à discussão sobre as conseqüências do reconhecimento da natureza tácita do conhecimento em relação à capacidade (ou não) de se controlar conscientemente o processo produtivo, podemos examinar as idéias de O'Neill, Adaman e Devine sob o ponto de vista da reinterpretação do problema que efetuamos no sexto capítulo.

A complexidade do problema alocativo na qual acredita Hayek implica que o conhecimento dos agentes econômicos é falível, sempre conjectural. Isso nos traz de volta a preocupação com o conhecimento dos agentes e não apenas com a capacidade de processamento de informações. Se as hipóteses dos agentes sobre as variáveis econômicas locais forem conjecturais, a diversidade de opiniões (e um mecanismo de correção de erros) se faz necessária. Assim, mesmo supondo plena publicidade dos dados, como quer O’Neill, não teríamos a coordenação entre os agentes: ou as mesmas informações seriam interpretadas de forma diferente por diversas firmas e não teríamos um plano coerente ou o conjunto de todas as firmas coordenariam suas ações, caso em que cedo ou tarde teríamos o desencontro entre a única opinião que informa os planos e a realidade subjacente, causando crises de proporções significativas.

Da mesma maneira, na proposta de Devine, a despeito dos desacordos no processo de diálogo entre os agentes, teríamos uma única opinião sendo eleita democraticamente. Seria então impossível apostar em uma linha de ação diversa e provar que a maioria estava errada.

O controle consciente do processo produtivo sugerido nos dois textos, para que represente um ganho de eficiência em relação à competição nos mercados, deve em última análise pressupor infalibilidade do conhecimento. Evitam-se com isso os desperdícios da competição; mas, se o conhecimento for falível, o plano fracassa como um todo. 
A tendência entre os economistas de adotar uma concepção positivista sobre o progresso do conhecimento (visto como um acúmulo de informações objetivas, livres de préconcepções, coletadas empiricamente e passíveis de generalização indutiva) sempre esteve presente no debate. Adicionalmente, a falha em distinguir entre o conhecimento estilizado do economista e o conhecimento prático dos agentes econômicos resultou na transferência da simplicidade do primeiro para o segundo, o que levou os economistas a acharem que o planejamento econômico deve envolver a coleta de dados imutáveis sobre simplificações como funções de produção, preços de produtos homogêneos e portanto curvas objetivas de custos.

As tendências descritas acima permitiram que, de Barone a Stiglitz, o problema do cálculo fosse visto meramente como uma questão de coleta e processamento de dados. A última proposta de solução ao problema do cálculo que discutiremos, formulada por Cotrell e Cockshot (1993), ilustra mais uma vez essa concepção. O interesse da proposta, também pertencente ao conjunto de críticas marxistas à revisão do debate feita por Lavoie, consiste em tocar no ponto que consideramos central ao debate: a complexidade do problema e o conhecimento necessário para lidar com essa complexidade.

Cottrell e Cockshott (1993:246), em sua interpretação do debate, reconhecem que a questão da complexidade do problema econômico está na base do argumento de Mises. Como fizemos no terceiro capítulo, citam em suporte desta tese a passagem de Mises a respeito da 'divisão intelectual do trabalho', que sugere que o planejamento de sistemas complexos estaria limitado pelas capacidades da mente humana.

Contudo, os autores disputam a tese misesiana de que a única maneira de realizar esse controle seria via cálculo aritmético em termos de lucros e perdas. Uma borboleta, por exemplo, ao controlar os movimentos de seus músculos, dirige seu corpo em direção a fontes de alimento. A borboleta teria então que computar os benefícios e os custos de cada tipo de movimento a fim de atingir seu objetivo, a obtenção de néctar. Esse cálculo, entretanto, não seria aritmético.

A partir desse exemplo, cuja fonte de ordem é a seleção natural, os autores sugerem que desenvolvimentos na ciência da computação, como inteligência artificial e redes neurais, podem então dizer algo sobre a tese de Mises. 
Cottrell e Cockshott desenvolvem então um modelo de economia socialista na qual pretende utilizar os métodos aludidos de computação para superar a complexidade do problema econômico.

A proposta de solução ao problema do cálculo dos autores é baseada na teoria do valor trabalho e combina a matriz insumo-produto de Leontieff com um mecanismo de tâtonnement semelhante ao idealizado por Lange. $\mathrm{O}$ valor $v_{\mathrm{i}}$ de uma unidade do bem $\mathrm{i}$, medido em termos de quantidade de trabalho empregada em sua produção, é dado pela quantidade de trabalho diretamente empregada $\lambda_{\mathrm{i}}$ acrescido do valor dos bens de capital usados na produção do bem. Esse valor é dado pelo valor $v_{j}$ de cada insumo multiplicado pelo coeficiente técnico $a_{\mathrm{ij}}$ que diz quantas unidades do bem $\mathrm{j}$ devem ser utilizadas na produção do bem i. O valor de um bem então é dado por:

$v_{i}=\lambda_{i}+a_{i 1} v_{1}+a_{i 2} v_{2}+\ldots+a_{i n} v_{n}$

Essa formulação é acompanhada da reafirmação dos autores da crença marxista de que o trabalho de agentes diferentes pode ser reduzido a um denominador comum.

Tomando todos os i produtos na economia, temos uma matriz V (nx1) dos seus valores, dados pelo vetor $\Lambda$ (nx1) de trabalho direto mais a matriz A (nxn) de coeficientes técnicos multiplicada pelo valor de cada bem, vistos agora como insumos:

$\mathrm{V}=\Lambda+\mathrm{AV}$

$\mathrm{O}$ vetor $\mathrm{V}$, que representa a solução para os valores dos bens em termos de quantidade de trabalho, é então dado pela inversão da matriz $(\mathrm{I}-\mathrm{A})^{-1}$ :

$\mathrm{V}=(\mathrm{I}-\mathrm{A})^{-1} \Lambda$

Calculado o valor dos bens em termos de horas de trabalho, os consumidores, de posse de seus vales ${ }^{2}$, cujo valor é equivalente ao número de horas trabalhadas por eles, demandam os bens que quiserem. No curto prazo, a autoridade responsável pelos preços efetua reajustes de preços de forma a obter um equilíbrio entre oferta e demanda. No próximo período, a produção daqueles bens cujo valor de equilíbrio esteja acima (abaixo) do valor do trabalho é aumentada (diminuída), até que a razão entre esses dois valores seja igual à unidade no longo prazo. Em cada período são então efetuados ajustes na matriz de coeficientes. Obtém-se assim um plano coerente para a economia.

\footnotetext{
${ }^{2}$ Ver no segundo capítulo a discussão do uso desses vales feita por Marx em Critic of Gotha Program.
} 
Contudo, a possibilidade de implementação desse modelo, entre outras críticas, estaria sujeita à objeção computacional levantada por Robbins e Hayek contra a proposta de Dickinson. Cottrel e Cockshott, que vêem o problema do cálculo como uma questão puramente computacional, afirmam que essa objeção seria válida apenas na época do debate original. A modelagem moderna de fenômenos complexos teria resultado no desenvolvimento de algoritmos capazes de lidar com o problema. Estimando que a economia soviética possuía 10 milhões de produtos, a inversão de uma matriz $10^{7} \times 10^{7}$ seria viável com o auxílio desses algoritmos e pelo fato de que grande parte da matriz de fato seria composta por zeros (cada produto utiliza um número relativamente pequeno de insumos).

Quanto à coleta dos dados, Cotrell e Cockshott (1993:103) imaginam uma rede de computadores interligando as firmas, cada uma delas apresentando uma planilha na qual são reportadas as condições atuais da produção, em termos da quantidade de insumos e produtos, codificados de forma padronizada.

Os autores, que de início mencionam a complexidade do problema, acabam acreditando que este seria afinal tratável. Repetem então a opinião final de Lange (1969) de que o futuro do socialismo estaria na maior capacidade de processamento de dados que resulta do progresso da ciência da computação.

Tendo em vista a proposta de Cotrell e Cockshott, poderíamos perguntar como, também partindo de considerações sobre complexidade, os seus autores chegam a conclusões diretamente opostas a nossa interpretação do debate. Na verdade, isso pode ser explicado pelo fato de que a complexidade é reconhecida apenas no modelo, no modo como os dados são tratados, e minimizada no que se refere à complexidade do problema em si. Isso pode ser visto a partir da crítica que os autores fazem à reinterpretação do debate feita por Lavoie.

Cotrell e Cockshott (1993:90) identificam corretamente que a leitura de Lavoie se baseia no fato de que os socialistas de mercado ignoraram o problema econômico real dinâmico - para se concentrar na solução estática, irrelevante para o primeiro. Porém, em vez de argumentar contra a necessidade de uma teoria de processo de mercado, os autores interpretam a crítica austríaca como se esta tratasse de computação de dados para se obter um novo equilíbrio estático: 
To the extent that such claims are based on the limitations of communications and data-storage facilities, they are now simply out of date, but is there a further basis? Lavoie suggests that the problem lies not so much in data-collection, as in the creation of relevant data. (Cotrell e Cockshott, 1993:90, ênfase no original.)

Desconsiderando o falibilismo inerente ao conhecimento dos agentes, testado no processo competitivo, os autores, como Yunker, acreditam que a atividade empresarial poderia ser substituída por um fundo criado com o propósito de gerar inovações ${ }^{3}$. Os problemas gerados pela possibilidade de conhecimento falível, dessa forma, passam despercebidos pelos autores:

The valid point that a dynamic economy must be constantly in search of new methods and products, and hence 'production function' information is not given once and for all, tends to shade over, in Mises and Hayek, into what one might call a 'mysticism of the entrepreneur' - a radical subjectivism for which we can see no scientific justification. (Cotrell e Cockshott, 1993:90, n.r.)

A dificuldade em interpretar corretamente o significado da objeção austríaca, segundo a nossa tese, pode ser buscada em considerações sobre conhecimento: se a complexidade do problema econômico for plenamente reconhecida, o conhecimento dos agentes se torna conjectural e falível, o que requer diversidade de opiniões e um mecanismo de teste. Se essa complexidade for ignorada, o conhecimento se reduz a dados, cuja única dificuldade consiste em serem coletados e processados a tempo.

O artigo de Cotrell e Cockshott resultou em uma resposta de um economista austríaco. Horwitz (1996), da mesma forma que fizemos acima, também considera que o problema da proposta dos autores consiste em tratar uma questão epistemológica como se fosse computacional. Entretanto, a crítica de Horwitz difere da nossa em relação às idéias epistemológicas utilizadas. Em vez do falibilismo popperiano que utilizamos, Horwitz emprega as observações de Lavoie sobre conhecimento tácito.

Cottrel e Cockshott, ao buscar algoritmos que resolvam o problema computacional de seu modelo, citam o Organization of Behavior de Hebb como uma obra pioneira na área de redes neurais. Horwitz (1996:71) chama a atenção para uma ironia relacionada a essa citação. O The Sensory Order de Hayek, publicado na mesma época que o livro de Hebb e que desenvolve os mesmos temas deste último, conteria a crítica à proposta de Cottrel e Cockshott. Uma das principais conclusões do trabalho de Hayek afirma que a complexidade da mente impede que ela entenda o seu próprio funcionamento e que esta só pode entender completamente algo que tenha um grau de complexidade menor. Em

\footnotetext{
${ }^{3}$ Confunde-se aqui o sentido da atividade empresarial de Schumpeter com o sentido austríaco de Mises e Kirzner. Para estes, como vimos, a atividade empresarial é necessária em todos os mercados, o tempo todo, a fim de que se explique a convergência ao equilíbrio, e não apenas para implementar inovações esporádicas.
} 
vez de entender seus detalhes, a mente poderia apenas explicar os princípios de seu funcionamento e realizar previsões de padrão.

O limite ao conhecimento explícito dos agentes que pode ser derivado dessas idéias, para Horwitz (1996:71), mostra o defeito do modelo dos autores: não é possível transmitir conhecimento tácito que não existiria sem o processo competitivo.

Horwitz nota que se por um lado as observações sobre complexidade, aplicadas a modelos, podem ajudar a solução de um problema computacional, por outro, quando aplicadas ao próprio fenômeno estudado, conspiram contra a relevância de tal solução ${ }^{4}$. Essa idéia pode ser melhor entendida através da distinção retirada na biologia evolucionária entre seleção natural e seleção artificial. Como podemos lembrar, Cottrell e Cockshott tomam o vôo de uma borboleta para ilustrar um mecanismo de controle de um sistema complexo. Dawkins (1998) ao utilizar um exemplo semelhante, a alimentação de aranhas, introduz a distinção entre seleção natural e artificial, relevante para o nosso problema.

A adaptação evolutiva dos seres vivos pode ser descrita como um processo de resolução de problemas ${ }^{5}$. Dawkins (1998, capítulo 2) considera o problema particular de achar um método eficiente de capturar insetos. Na solução encontrada pelas aranhas, utilizar redes de seda, temos a vantagem do grande alcance das teias e também de seus baixos custos em comparação com o deslocamento direto do predador. Mas, se por um lado teias maiores e mais densas capturam mais insetos, os seus custos de fabricação e manutenção são maiores. Teias mais esparsas, do contrário, têm custo pequeno mas quase não capturam insetos.

A seleção natural, dessa maneira, favorece as teias que capturam o alimento de forma relativamente eficiente. Como firmas maximizadoras de lucros, aranhas que constroem teias cujo benefício marginal da seda e do trabalho se iguala ao seu custo marginal tendem a sobreviver e reproduzir. Como em Alchian, tudo ocorre 'como se' a aranha fosse capaz de realizar o cálculo econômico de custos e benefícios.

\footnotetext{
${ }^{4} \mathrm{O}$ autor apresenta o seu ponto através de uma analogia entre o uso de preços de mercado e o uso da linguagem. Da mesma forma que uma palavra só tem significado no contexto fornecido pelas demais palavras, também os preços não são entidades objetivas, mas só têm significado se forem parte do processo de competição. Embora pouco clara, a analogia pode ser entendida através da discussão que se segue.

${ }^{5}$ Popper (1975).
} 
Esse processo de seleção natural foi simulado artificialmente. Krink e Vollrath (1997) desenvolveram um programa denominado NetSpinner, no qual a seleção de teias de aranha é modelada com o auxílio de um algoritmo genético. Considere aranhas artificiais que constroem teias na tela de um computador. $\mathrm{O}$ formato das teias é dado por regras de construção representadas por 'genes', que controlam, por exemplo, o ângulo entre os fios radiais ou dos fios espiralados. Cada aranha dá origem a descendentes com mutações. Esses descendentes são submetidos à seleção, conforme o seguinte critério: cada teia é bombardeada aleatoriamente por pontos, que representam insetos, e computam-se os 'lucros' da aranha. Quanto mais densa a teia, maior é o número de insetos capturados, maior portanto a 'receita' obtida. Isto, porém, tem um custo, determinado em termos do comprimento do fio utilizado, já que a seda e a energia da aranha são recursos escassos. Uma teia pouco custosa, no entanto, não é capaz de capturar muitos insetos. O descendente com maior retorno (que não é máximo) é selecionado para procriar na próxima geração e assim repete-se o procedimento. Depois de várias gerações, o processo de evolução das teias no NetSpinner chega a resultados semelhantes a teias reais.

Apesar do sucesso em explicar o princípio de funcionamento da seleção natural, o modelo de seleção artificial não duplica o processo de seleção natural. Dawkins nota que o NetSpinner é um programa que dá conta de apenas alguns aspectos do processo evolutivo real. Por isso, os dados que alimentam o sistema têm necessariamente algo de arbitrário:

O programador tem que tomar uma decisão acerca de quanto custará uma dada extensão de "seda", na mesma moeda em que determina o valor de um "inseto". O programador poderia alterar à vontade a taxa de conversão de moeda. Ele poderia, vamos dizer, duplicar o "preço" da seda.... A taxa pela qual a "carne" de inseto é convertida em filhotes de aranha também é decidida pelo programador. A decisão é arbitrária e, se alterada, produzirá um resultado evolucionário diferente. (Dawkins, 1998:78)

O processo de seleção natural em geral leva em conta uma infinidade de características dos animais que interagem de forma complexa, como agilidade, dureza do couro, tamanho de dentes e assim por diante. Para podermos avaliar em um modelo a eficácia desses instrumentos para a caça de uma presa, precisaríamos recriar no computador toda a biologia e a física. Não há como obter sucesso nessa tarefa, por mais complexos que sejam nossos programas:

Mas parece não haver algum modo natural e não arbitrário de decidir que características [dos seres artificiais] os tornarão bons ou não no que diz respeito a caçar presas ou escapar de predadores. ... Os dentes e a pele são apenas padrões de pontos numa tela fluorescente bidimensional. Agudeza e dureza, fragilidade e venenosidade, estas quantidades não têm significado algum em um tela de 
computador além do definido por números, arbitrariamente escolhidos pelo programador. Você pode programar um jogo de computador no qual números lutem contra outros números, mas as vestimentas gráficas dos números são meras maquiagens supérfluas. "Arbitrário" e "planejado" soam para o jogador como eufemismos. (Dawkins, 1998:71)

Ainda que de forma muito imperfeita, conseguimos simular o processo de seleção natural na construção de teias de aranhas, pois lidamos com teias bidimensionais, mais facilmente reproduzidas em uma tela plana. O comprimento do fio e a representação pontual de insetos são simplificações razoáveis. Conhecem-se, além disso, os processos naturais de construção de teias reais ${ }^{6}$. Mas mesmo nesse caso, aponta Dawkins, o modelo nem esbarra na complexidade do problema. Poderíamos levar em conta uma infinidade de complicações, como por exemplo a utilidade marginal decrescente de apanhar um inseto adicional, ou os diferentes valores nutritivos dos insetos, os complicados fatores físicos da construção da teia. As soluções encontradas nas teias de aranha reais são de fato muito mais complexas do que aquilo que poderíamos gerar no computador. A adição de detalhes dessa natureza aos 'preços' ainda envolveria decisões arbitrárias do programador:

A decisão é arbitrária e, se alterada, produziria um resultado evolucionário diferente. Na vida real, nenhuma dessas decisões é arbitrária. Nenhuma delas é, de fato, uma decisão e nenhum maquinário computacional é usado para que sejam tomadas. Elas apenas acontecem, naturalmente e sem alardes....A conversão acontece automaticamente, a despeito de alguém registrá-la em termos matemático-econômicos ou não. (Dawkins, 1998:78)

É grande a semelhança do argumento de Dawkins com a tese de Mises e Hayek sobre a impossibilidade de calculo econômico no socialismo sem um sistema de preços de mercado. Preços paramétricos podem dar conta de um aspecto muito limitado da complexa realidade econômica, pois fazem parte de um sistema de seleção artificial. A vantagem do sistema de seleção natural do mercado é justamente lidar com essa complexidade. No mecanismo seletivo dado pelos lucros e perdas, não impomos $a$ priori o que poderia levar a uma vantagem competitiva. No processo evolutiovo surgem soluções criativas e inovadoras para gerar tais vantagens. Na competição econômica, a mesma idéia aparece quando Hayek vê o mercado como um processo de descoberta.

Já os modelos de Lange e Cockshott são exemplos de seleção artificial: os fundamentos da economia que entram no modelo não representam a riqueza do processo de seleção

\footnotetext{
${ }^{6}$ No mesmo capítulo em que trata da seleção artificial do NetSpinner, Dawkins descreve os intrincados problemas e criativas soluções encontradas na história da seleção natural de teias de aranha de verdade. $\mathrm{O}$ autor pode fazer isso porque é capaz de observar a história passada das soluções já existentes. Cada solução tentativa para um problema evolutivo leva a uma nova gama de problemas num processo incessante de tentativas e erros.
} 
dos mercados reais. A substituição deste pelo modelo de seleção artificial acarretaria então na diminuição da efetividade do mecanismo de resolução de problemas.

A contribuição hayekiana ao debate, por outro lado, pode ser resumida da seguinte forma: só conseguimos expandir a complexidade da cooperação social, por meio de maior divisão do trabalho, com o auxílio de instituições, como o sistema de preços, que realizem a tarefa de economizar informações. As partes de um sistema se coordenam por um sistema de feedback (lucros e perdas) que não requer onisciência por parte dos agentes, pois os detalhes do processo de seleção não precisam ser conhecidos (não se trata de seleção artificial). A mesma idéia pode ser encontrada em Dawkins:

O ponto que desejo esclarecer é tão óbvio que mal precisa ser explicado. No entanto, é importante demais para passar em branco. A toda hora incorpora-se um ponto adicional e complicado ao NetSpinner e páginas extras de difícil linguagem de computação têm que ser escritas por um programador humano inteligente. Entretanto, na vida real existe uma ausência marcante de computações explícitas. $\mathrm{O}$ fator de conversão de valores/moedas entre a proteína do inseto e a proteína da seda simplesmente existe automaticamente. (Dawkins, 1998:79)

Esse argumento articula a ênfase misesiana na formação de preços de mercado, resultante da participação de inúmeros indivíduos e que portanto contêm mais informações do que um preço paramétrico, na medida em que o processo competitivo real não se limita àquilo que é descrito pela teoria da competição perfeita.

Embora em economia os agentes individuais planejem conscientemente, façam cálculos econômicos, suas tentativas ainda são cegas em relação ao problema da coordenação como um todo: os agentes têm que descobrir, em um processo de tentativa e erros de outra ordem, quais são as realidades às quais suas ações têm que se adaptar. Mas, novamente, tanto em biologia quanto em economia, o processo seletivo gera um padrão complexo que não exige o conhecimento dos detalhes do sistema:

A seleção natural é um processo extremamente simples, no sentido de que necessita muito pouco maquinário para funcionar. É claro que os efeitos e consequiências da seleção natural são extremamente complexos. ((Dawkins, 1998:pág. 82)

Vimos que para Dawkins (Hayek), o programador (o planejador central) tem em seu modelo uma representação bastante pobre da realidade estudada e mais especificamente dos processos seletivos envolvidos. Por isso, a necessidade imposta pela modelagem de se especificar explicitamente o critério seletivo envolve a desconsideração de uma característica essencial dos processos evolutivos, qual seja, a complexidade dos elementos que entram no processo de seleção. Pode ocorrer que a competição em mercados artificiais cesse levando-se em conta o critério arbitrário postulado pelo programador, mas a competição real prosseguiria, tendo em vista aspectos insuspeitos, 
não contemplados pelo programa. Ou ainda em outros termos, a capacidade de adaptação de um sistema evolutivo é grandemente reduzida, por hipótese, nesse tipo de modelagem.

Com base nessa discussão, podemos afirmar que o ponto fraco dos modelos de socialismo de mercado, de Taylor a Cottrell e Cockshott, consiste em ignorar as diferenças entre seleção natural e artificial no que diz respeito à superação da limitação cognitiva no problema da coordenação de agentes que interagem em sistemas complexos.

Esse resultado 'naturalista' substancia o triunfo da tese de Mises? Não existiriam então outros meios de coordenação das atividades econômicas a não ser pelo uso do sistema de preços existentes nos mercados? A tese da impossibilidade, para ser válida, precisaria provar que não é possível que evolua um mecanismo seletivo alternativo que, talvez com o auxílio da informática, possa lidar com a complexidade do problema alocativo. Isso não foi mostrado. Entretanto, entre as tentativas de solução ao desafio de Mises apresentadas até aqui, nenhuma chega perto de replicar a complexidade alcançada com o sistema de preços.

Apesar dessa inconclusão, o estudo do debate do cálculo mantém seu interesse. Para os defensores do socialismo, deve estimular a imaginação na tarefa de especular sobre sistemas econômicos alternativos. Para os economistas em geral, por outro lado, ajuda a compreender a natureza da tarefa executada nos mercados, por meio do experimento mental de imaginar o funcionamento de uma economia sem mercados. 


\section{Conclusão}

Este trabalho teve como objetivo estudar o debate sobre o cálculo econômico socialista. Além do interesse do próprio assunto discutido, o seu estudo tem interesse metodológico. Como o problema discutido no debate tem sido investigado por mais de um século, de 1850 até hoje, os economistas que participaram das controvérsias se filiam a várias abordagens teóricas diferentes. Isso cria um ambiente propício para contrastar os diferentes pressupostos adotados por cada programa de pesquisa, em especial aqueles implícitos. A compreensão do problema em si, dessa maneira, se enriquece pela multiplicidade de pontos de vista com que esse problema foi tratado e a discussão das diferenças entre os programas de pesquisa nos ajuda a compreender melhor o significado dos postulados da teoria com a qual trabalhamos.

Por causa dessa multiplicidade de pontos de vista, boa parte das discussões foi gerada pelas traduções dos argumentos de autores filiados a uma abordagem por autores formados em outra teoria. Em termos da História do Pensamento Econômico, o nosso trabalho procurou situar cada argumento no seu devido contexto teórico, recuperando assim o sentido original de cada argumento.

No diagrama abaixo, ilustramos algumas semelhanças e diferenças entre os principais programas de pesquisa envolvidos na controvérsia no que se refere ao problema do cálculo. Características no interior do triângulo indicam acordo e fora do mesmo desacordo.

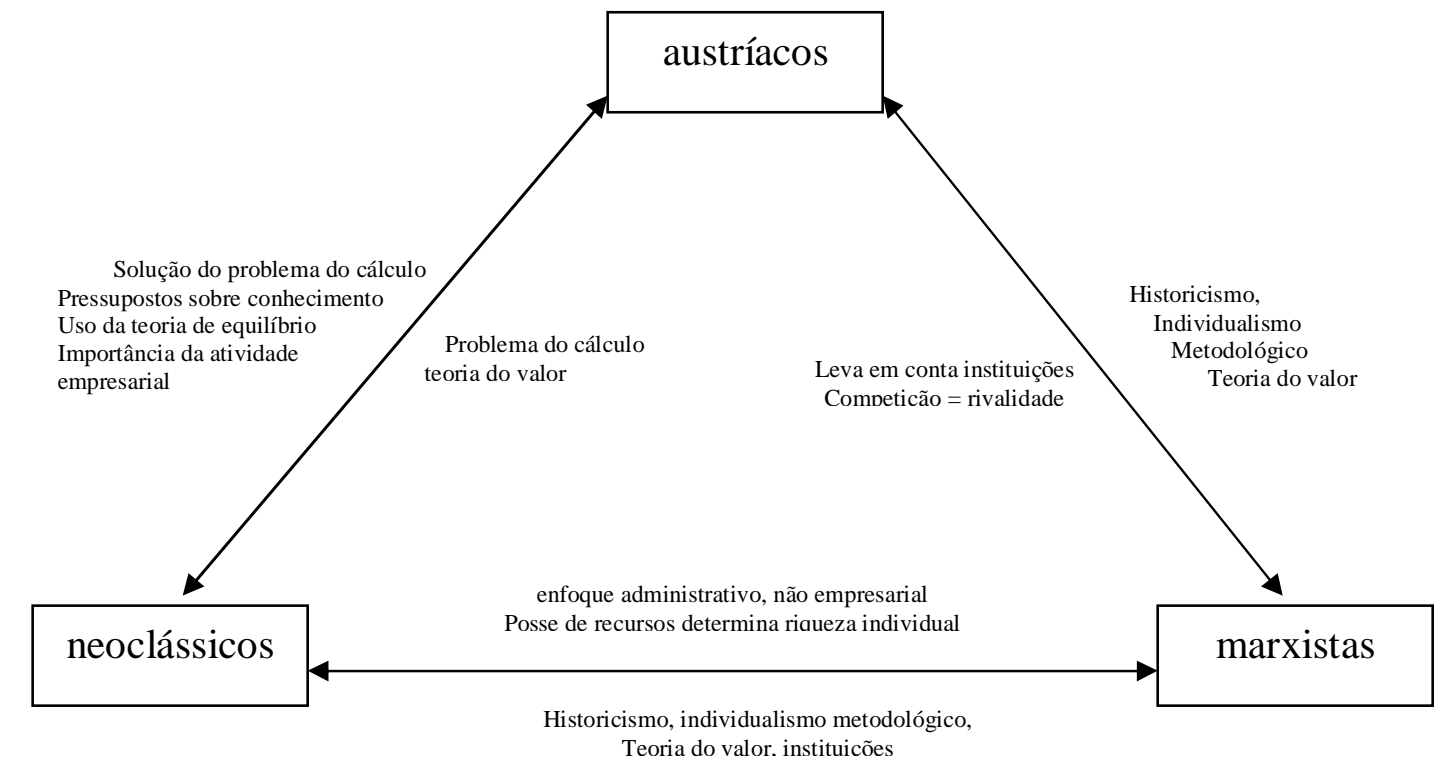

O ideal, naturalmente, seria uma sucessão de esquemas, como em um filme, já que os próprios programas de pesquisa foram mudando, em parte devido ao próprio trascorrer 
do debate. A Escola Austríaca, em especial, articulou explicitamente suas diferenças com a Escola Neoclássica a partir das discussões do debate (cap. 5). Os economistas filiados a esta última, por sua vez, com a incorporação dos temas relacionados à assimetria de informação e com a maturação da teoria de equilíbrio geral, alteram suas opiniões sobre o problema do socialismo de mercado. Deixamos ainda de lado as diferenças entre correntes austríacas, marxistas ou mesmo de escolha pública que enriquecem mais ainda o debate.

Passando dos programas de pesquisa para os autores propriamente ditos, temos que o debate se constituiu de uma série de trocas entre autores específicos, com Mises, Hayek e Lange ocupando posição central. Na tabela em seguida, indicamos algumas dessas trocas. Na tabela, o autor da primeira coluna iniciou cada disputa, o símbolo ' $\Rightarrow$ ' indica que o autor da primeira coluna criticou o da segunda e ' $\Leftrightarrow$ ' indica que houve resposta à crítica por parte do segundo. A última coluna indica o capítulo do nosso trabalho no qual a disputa é tratada:

\begin{tabular}{|l|l|l|c|}
\hline \multicolumn{1}{|c|}{ Autor } & \multicolumn{1}{c|}{ A } & \multicolumn{1}{c|}{ Cator } & 2 \\
\hline Pierson & $\Leftrightarrow$ & Kautsky & 3 \\
\hline Weber & $\Rightarrow$ & Neurath & 4 \\
\hline Heinman, K. Polanyi & $\Leftrightarrow$ & Mises & 4 \\
\hline Tisch, Zassenhaus, Marshak & $\Rightarrow$ & Mises & 3 \\
\hline Mises & $\Rightarrow$ & Marx & 5 \\
\hline Mises & $\Leftrightarrow$ & Heinman & 5 \\
\hline Mises & $\Leftrightarrow$ & Karl Polanyi & $4,5,6$ \\
\hline Lange & $\Leftrightarrow$ & Hayek & 4,5 \\
\hline Lange & $\Leftrightarrow$ & Mises & 4 \\
\hline Lerner & $\Leftrightarrow$ & Dobb & 4 \\
\hline Lerner & $\Leftrightarrow$ & Dickinson & 4 \\
\hline Lerner & $\Leftrightarrow$ & Durbin & 4 \\
\hline Lerner & $\Leftrightarrow$ & Lange & 6 \\
\hline Roberts & $\Leftrightarrow$ & Drewnowski & 6 \\
\hline Salerno, Hoppe e Rothbard & $\Rightarrow$ & Hayek & 6 \\
\hline Yeager & $\Leftrightarrow$ & Salerno & 8 \\
\hline Arnold & $\Leftrightarrow$ & Schweickart & 7 \\
\hline Lavoie & $\Rightarrow$ & Stiglitz & 7 \\
\hline Shleifer e Vishny & $\Leftrightarrow$ & Bardhan e Roemer & 8 \\
\hline Cotrell e Cockshot & $\Rightarrow$ & Hayek & 8 \\
\hline Horwitz & $\Rightarrow$ & Cotrell e Cockshot & \\
\hline
\end{tabular}

Devemos salientar que o núcleo do debate na verdade foi uma discussão entre autores neoclássicos (cap. 4) que ignoraram ou traduziram para o próprio referencial as críticas austríacas. 
Em seguida, apresentamos uma linha do tempo do debate, para que possamos situar as contribuições dos autores em seus contextos históricos.

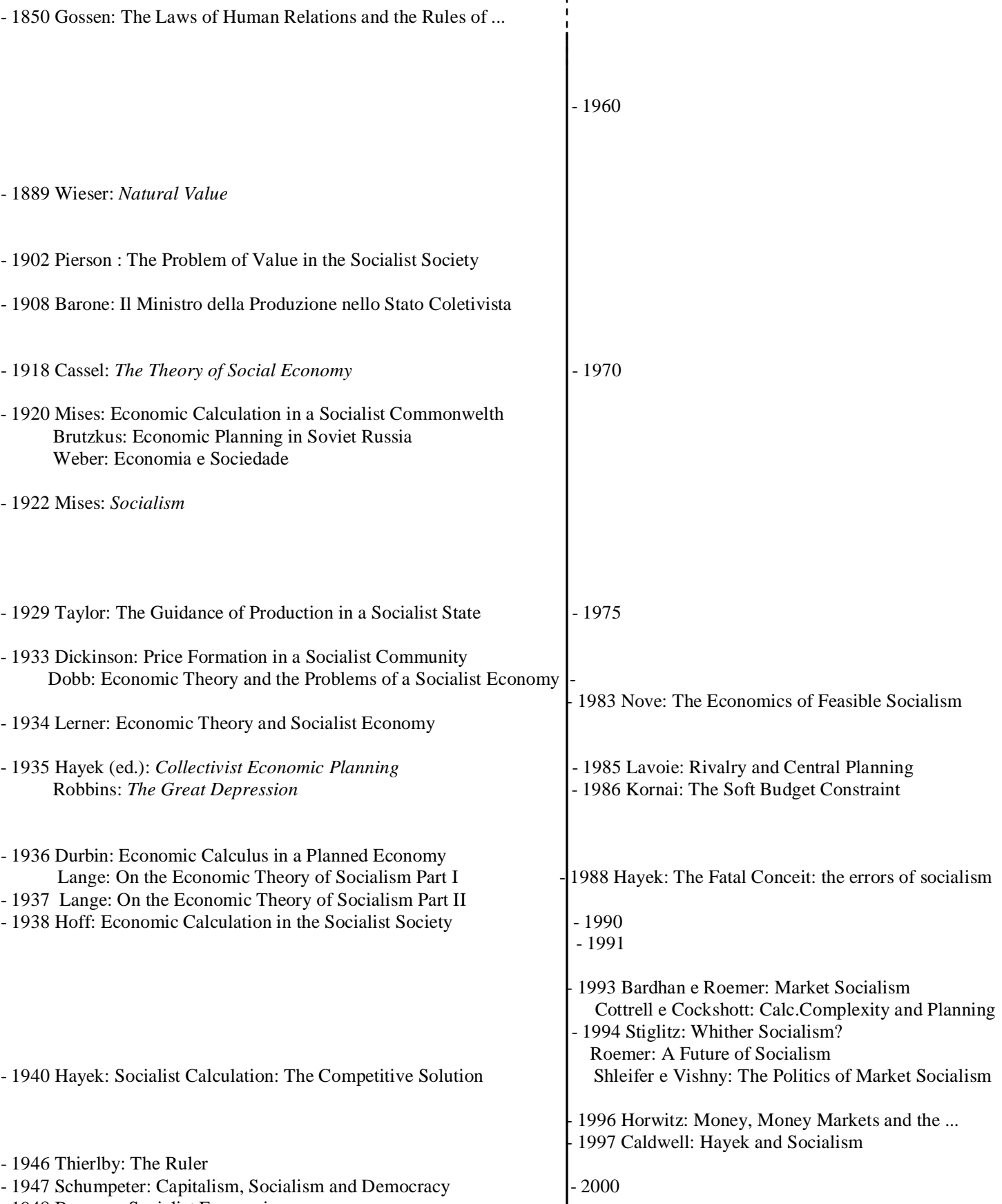

1993 Bardhan e Roemer: Market Socialism

Cottrell e Cockshott: Calc.Complexity and Planning - 1994 Stiglitz: Whither Socialism?

Roemer: A Future of Socialism

Shleifer e Vishny: The Politics of Market Socialism

1996 Horwitz: Money, Money Markets and the ...

1997 Caldwell: Hayek and Socialism 
Como mostra o diagrama, o problema já era discutido antes do texto de Mises (cap.2) e, depois do artigo deste (cap.3), o debate propriamente dito se concentrou na década de trinta do século vinte (cap. 4 e 5). Até que seja retomado na década de noventa (cap. 7), o período entre 1940 e 1990 foi marcado pela controvérsia em HPE sobre quem teria vencido o debate (cap. 6).

No que diz respeito às tentativas de refutar a tese de Mises, foram imaginados vários modelos nos quais o cálculo econômico seria realizável no socialismo. O debate do cálculo, além das discussões sobre a natureza do problema em si e das interpretações dos argumentos utilizados, girou em torno da viabilidade dessas propostas.

Embora tenhamos diferenças entre as propostas dos diversos autores, podemos agrupalas em categorias. Na tabela abaixo, listamos, em ordem cronológica, as mais importantes, bem como seus defensores e críticos e características que as distinguem:

\begin{tabular}{|c|c|c|c|}
\hline Proposta de Solução & Defensores & Críticos & Características \\
\hline Cálculo em espécie & Neurath, Tchayanov & Mises, Brutzkus & $\begin{array}{l}\text { Planejamento central com cálculo em unidades } \\
\text { de produtos e insumos, sem uso de moeda. }\end{array}$ \\
\hline Cálculo em horas de trabalho & Engels Leichter & Mises & $\begin{array}{l}\text { Observação da quantidade de trabalho necessária } \\
\text { para a produção dos bens provê medida de valor } \\
\text { dos bens. }\end{array}$ \\
\hline Solução matemática & $\begin{array}{l}\text { Tisch, Zassenhaus, } \\
\text { Dickinson }\end{array}$ & $\begin{array}{l}\text { Mises, Hayek, } \\
\text { Robbins, Lerner }\end{array}$ & $\begin{array}{l}\text { Formulação das equações de equilíbrio geral } \\
\text { com o auxílio de estatísticas. Solução algébrica } \\
\text { das equações. }\end{array}$ \\
\hline Tentativas e erros & $\begin{array}{l}\text { Taylor, } \\
\text { Dickinson }\end{array}$ & Mises, Hayek & $\begin{array}{l}\text { Solução do EG a partir de vetor de preços } \\
\text { aleatórios corrigidos conforme os excessos de } \\
\text { demanda ou oferta de firmas que atuam segundo } \\
\text { as regras } \mathrm{p}=\mathrm{CMg} \text { e min } \mathrm{CMe} \text {. }\end{array}$ \\
\hline $\begin{array}{l}\text { Monopólios setoriais } \text { ou } \\
\text { quase mercados }\end{array}$ & Heiman, Durbin & Mises, Hayek & $\begin{array}{l}\text { Firmas estatais que atuam em mercados e } \\
\text { seguem ordem de igualar preço a custo marginal } \\
\text { e médio de produção }\end{array}$ \\
\hline $\begin{array}{l}\text { Supressão da soberania do } \\
\text { consumidor }\end{array}$ & Dobb & Lerner & $\begin{array}{l}\text { Planejar diretamente a produção sem levar em } \\
\text { conta as preferências do consumidor. Sem } \\
\text { mercados, mesmo artificiais. }\end{array}$ \\
\hline $\begin{array}{l}\text { Desenho de mecanismos } \\
\text { alocativos diversos }\end{array}$ & Hurwicz & & $\begin{array}{l}\text { Semelhante a Lange, com outros mecanismos } \\
\text { para se atingir equilíbrios. }\end{array}$ \\
\hline $\begin{array}{l}\text { Socialismo de mercado com } \\
\text { keitetzu }\end{array}$ & Bardhan & Shleifer e Vishny & $\begin{array}{l}\text { Fiscalização de firmas através de bancos que } \\
\text { financiam grupos de empresas correlatas }\end{array}$ \\
\hline $\begin{array}{l}\text { Socialismo de mercado com } \\
\text { bolsa de valores }\end{array}$ & Roemer & Shleifer e Vishny & $\begin{array}{l}\text { Distribuição igualitária de ações de firmas que } \\
\text { não podem ser trocadas por dinheiro. }\end{array}$ \\
\hline $\begin{array}{l}\text { Socialismo de mercado com } \\
\text { firmas auto-administradas } \\
\text { pelos trabalhadores }\end{array}$ & $\begin{array}{l}\text { Schweickart, Drèze, } \\
\text { Fleurbaey }\end{array}$ & Arnold & $\begin{array}{l}\text { Firmas administradas pelos trabalhadores, sem } \\
\text { propriedade pública, financiamento por bancos } \\
\text { independentes. }\end{array}$ \\
\hline $\begin{array}{l}\text { Auto-administração } \\
\text { bolsa de valores }\end{array}$ & Weisskopf & & $\begin{array}{l}\text { Mistura propostas de Roemer e Bardhan com } \\
\text { firmas geridas pelos trabalhadores }\end{array}$ \\
\hline $\begin{array}{l}\text { Planejamento com o auxílio } \\
\text { de computadores }\end{array}$ & $\begin{array}{l}\text { Cottrell e Cockshott, } \\
\text { Lange }\end{array}$ & Horwitz & $\begin{array}{l}\text { Marx+Lange+Leontieff Solução com o auxílio } \\
\text { de computadores. Cálculo em termos de } \\
\text { quantidade de trabalho }\end{array}$ \\
\hline
\end{tabular}

Defendemos ao longo deste trabalho a tese de que a sucessão de propostas e suas críticas nos ajudam a compreender o significado da teoria microeconômica e suas limitações. A teoria de equilíbrio de mercado originalmente pretendia descrever a solução do problema alocativo nos mercados. As hipóteses simplificadoras da teoria, como argumentamos, são legítimas na medida em que são utilizadas para explicar parte 
do fenômeno estudado. Quando o conjunto de simplificações teóricas foi utilizado pelos socialistas de mercado para construir um mecanismo alocativo, entretanto, as complexidades do mundo real deixadas de fora do modelo fizeram com que os mecanismos propostos não desempenhassem adequadamente sua função. $\mathrm{Na}$ tabela abaixo, poderemos ver que cada solução proposta ignora aspectos dos mercados reais. Como os críticos chamaram a atenção para esses aspectos, alguns deles eram incorporados na proposta seguinte. Conseqüentemente, em cada passo algum aspecto do planejamento cental foi abandonado em favor da reintrodução de mecanismos de mercado, com o propósito de lidar com as objeções:

\begin{tabular}{|c|c|}
\hline Solução: & cálculo em espécie (Neurath) \\
\hline Método de Cálculo: & $\begin{array}{l}\text { tratar o problema econômico como um grande problema de } \\
\text { engenharia, comparando alternativas em termos de quantidades } \\
\text { de bens utilizados. }\end{array}$ \\
\hline Crítica: & $\begin{array}{l}\text { não é possível expressar o valor dos bens em termos físicos; o } \\
\text { problema é extremamente complexo. }\end{array}$ \\
\hline Solução: & em quantidade de trabalho (Leichter) \\
\hline Método de Cálculo: & $\begin{array}{l}\text { o valor deve ser estabelecido em termos da quantidade de } \\
\text { trabalho empregada na produção dos bens. }\end{array}$ \\
\hline Crítica: & $\begin{array}{l}\text { não há como levar em conta a importância dos bens e portanto } \\
\text { não há como saber a priori a quantidade de trabalho socialmente } \\
\text { necessária em cada caso. }\end{array}$ \\
\hline
\end{tabular}

\begin{tabular}{|l|l|}
\hline Solução: & $\begin{array}{l}\text { solução matemática (Dickinson) } \\
\text { os preços devem ser calculados a partir do conjunto de equações } \\
\text { que estabeleçam o equilíbrio geral na economia. }\end{array}$ \\
\hline Crítica: & $\begin{array}{l}\text { não há como coletar e processar as informações, solução } \\
\text { estática, não lida com os problemas da atividade empresarial } \\
\text { (ação especulativa que pretende descobrir quais seriam os os } \\
\text { fundamentos da economia) }\end{array}$ \\
\hline
\end{tabular}

\begin{tabular}{|l|l|}
\hline Solução: & solução por tentativas e erros (Lange) \\
\hline Método de Cálculo: & $\begin{array}{l}\text { os preços no modelo de Dickinson são estabelecidos por um } \\
\text { órgão de planejamento que faz o papel de leiloeiro walrasiano. }\end{array}$ \\
\hline Crítica: & $\begin{array}{l}\text { solução estática, não lida com os problemas da atividade } \\
\text { empresarial. }\end{array}$ \\
\hline
\end{tabular}

\begin{tabular}{|l|l|}
\hline Solução: & $\begin{array}{l}\text { competição entre monopólios setoriais (Durbin) } \\
\text { os preços são obtidos em mercados nos quais interagem firmas } \\
\text { estatais que seguem regras sobre custos. }\end{array}$ \\
\hline Crítica: & $\begin{array}{l}\text { solução estática, não lida com os problemas da atividade } \\
\text { empresarial. }\end{array}$ \\
\hline
\end{tabular}

\begin{tabular}{|l|l|}
\hline Solução: & competição com mercados de capitais (Roemer) \\
\hline Método de Cálculo: & $\begin{array}{l}\text { os preços são obtidos em mercados com firmas controladas } \\
\text { indiretamente por bancos ou acionistas. }\end{array}$ \\
\hline Crítica: & $\begin{array}{l}\text { não lida com os problemas da atividade empresarial, ignora } \\
\text { motivação do governo. }\end{array}$ \\
\hline
\end{tabular}


Nessa seqüência, sucessivamente foram introduzidas preocupações com valor, com um sistema de preços, com a sua fixação por tentativas e erros, com a sua fixação de forma livre e, finalmente, com a introdução parcial de mercados de capital. Como a crítica austríaca a respeito da atividade empresarial que ocorre no processo de mercado foi ignorada em todas as fases, outros elementos não foram adicionados.

A introdução progressiva de elementos dos mercados nas propostas de socialismo nos informa então a relação entre a competição real nos mercados e as hipóteses da teoria que descreve essa competição, de forma a termos uma visão mais clara das limitações metodológicas do uso da teoria e dos limites explicativos da mesma.

Do estudo da sucessão de propostas e críticas às mesmas extraímos o ponto central da nossa tese: as diferentes posturas a respeito da possibilidade de realizar cálculo econômico no socialismo variam conforme as diferentes concepções adotadas sobre a complexidade do problema econômico e sobre a natureza do conhecimento utilizado na solução do mesmo.

Se o problema for complexo e os seres humanos não forem oniscientes, o conhecimento sobre os detalhes que compõem os cambiantes fundamentos da economia é disperso entre os agentes e ao mesmo tempo falível. Se o conhecimento dos agentes for falível, precisamos de um mecanismo impessoal de seleção de hipóteses conjecturais e da liberdade para experimentar essas hipóteses. Os mecanismos de seleção artificial propostos no debate, por outro lado, transferem a simplicidade do modelo para a realidade, reduzindo então a complexidade desta. Se não distinguirmos a natureza do conhecimento do cientista e do agente, corremos o risco de adotar uma visão positivista sobre o conhecimento dos agentes: o problema do cálculo se reduziria então à discussão sobre a capacidade de processar e coletar dados objetivos sobre funções de produção, demanda e quantidades de recursos.

Paralelamente a essa tese principal, o estudo de cada fase do debate mereceu interpretações sobre o seu significado. Alguns dos pontos desenvolvidos ao longo dos capítulos são listados em seguida.

No primeiro capítulo emendamos a distinção entre ciência normativa e positiva de forma a incorporar na última o estudo teórico de sistemas alocativos alternativos. 
Mostramos também como as evidências empíricas sobre o socialismo real não dão julgamentos definitivos sobre as teses discutidas no debate teórico.

No segundo capítulo, vimos como a preocupação com o problema do cálculo se inicia com a própria criação da teoria marginalista. Desde Gossen, a definição do problema econômico muda, de modo que a utilização dos fatores na produção de cada bem não mais é vista como dependendo puramente de decisões técnicas, mas também de considerações sobre variações nos custos de oportunidades desses fatores. Independente da organização social, o problema alocativo deve ser resolvido. O argumento de similitude formal, além disso, já contém o germe da discórdia entre neoclássicos e austríacos, conforme a exposição do problema seja verbal ou formal.

O terceiro capítulo mostrou como a tese da impossibilidade do cálculo foi formulada simultaneamente por Brutzkus, Mises e Weber. Nos três autores está claramente presente a noção de que o problema alocativo é muito complexo para ser resolvido de forma direta, sem o auxílio dos preços.

No capítulo seguinte defendemos a tese de que os socialistas de mercado, ao interpretarem o desafio de Mises em termos walrasianos, ignoram o problema proposto por esse e transferem a simplicidade do modelo para a teoria, o que permitiu a sua solução no contexto da teoria de equilíbrio. Vimos no quarto capítulo o debate em torno das regras a serem seguidas: enquanto a regra 'correta' dos custos marginais pressupõe o conhecimento e fácil identificação das curvas de custo, a regra dos custos médios tinha seu apelo na independência financeira das firmas, consideração esta excluída por definição do escopo da teoria pelos economistas do período.

O capítulo sobre a reação austríaca mostrou como Robbins, Mises e Hayek criticaram a legitimidade da solução estática. Embora os dois primeiros tenham inicialmente deixado mais claras as diferenças entre as abordagens austríaca e neoclássica, advogando a necessidade da atividade empresarial e mercados financeiros, o último estabeleceu em sua tentativa de criticar o socialismo de mercado o que denominamos Economia do Conhecimento, pertencente ao núcleo do programa de pesquisa austríaco moderno: a Economia deve explicar como o conhecimento converge para a realidade e não assumir a correspondência automática entre dados e realidade.

No sexto capítulo contrastamos a versão predominante sobre o debate, baseada no texto de Lange de 1936 com a versão revisionista austríaca, representada por Lavoie, além de 
estudar o debate entre os austríacos a respeito das diferenças entre os argumentos de Mises e Hayek. Essas diferenças foram atribuídas à rejeição do falibilismo popperiano por parte dos austríacos que defendiam o apriorismo misesiano. Consideramos também que a proposta de Durbin, ignorada na versão langeana do debate, merece mais atenção por ser mais próxima ao socialismo de mercado moderno. Nesse capítulo, demos ainda a nossa interpretação do debate em termos de uma solução popperiana ao problema do conhecimento de Hayek, em contraste com a solução de Lavoie.

No sétimo capítulo vimos como a preocupação com a Economia do Conhecimento de Hayek foi interpretada em termos da Economia da Informação. Essa tradução do argumento fez com que a objeção austríaca ao socialismo de mercado continuasse ignorada, pois esta afronta o núcleo duro do programa de pesquisa neoclássico. Em vez de lidar com os problemas do conhecimento falível, os novos socialistas de mercado buscaram modelos que tratassem do problema de informação assimétrica entre planejadores e administradores. Esta fase do debate aborda assim as questões consideradas ilegítimas por Lerner e Knight, o que reflete a alteração no cinto protetor da teoria neoclássica.

No último capítulo vimos como a reação à interpretação de Lavoie por parte de autores marxistas reforça a nossa crença na centralidade da complexidade e da natureza do processo de aprendizagem dos agentes. 


\section{Índice de Nomes}

\section{$\boldsymbol{A}$}

Adaman $258,259,261,262,283$ Arnold.......... 249, 250, 251, 273, 275, 283, 292

$\boldsymbol{B}$

Bardhan.234, 236, 237, 238, 243, 247, 253, 254, 255, 256, 273, 274, 275, 283, 286, 289, 293

Barone 42, 45, 46, 49, 50, 51, 52, 53, 54, 56, 62 , $63,70,88,99,102,131,143,153,175,176$, $177,178,180,184,187,189,195,216,263$, 274, 283

Bartley $164,200,201,283$

Bastiat 39,142

Bergson...... 15, 16, 17, 176, 179, 180, 181, 274, 283, 284

Blaug 20,284

Boettke...............15, 17, 27, 71, 283, 284, 293

Böhm-Bawerk...42, 43, 44, 45, 62, 72, 102, 111, 112,284

Boland 200,284

Bradley 189,284

Brus $19,228,229,231,232,233,284$

Brutzkus... 10, 16, 24, 31, 34, 38, 63, 64, 65, 66, $67,68,69,70,81,123,127,274,275,278$, 284

Buchanan ..... 169, 170, 179, 248, 284, 292, 293

Bukharin ............... 32, 34, 35, 36, 37, 83, 285

C

Caldwell. $219,226,274,285$

Cassel 12, 55, 56, 87, 88, 95, 102, 136, 274, 285

Ch

Chaloupek $83,84,285$

C

Cockshott.... 263, 264, 265, 266, 267, 269, 271, 274, 275, 285

Cottrell.........263, 264, 267, 271, 274, 275, 285

D

Darwin .201

Dawkins $267,268,269,270,285$

Demsetz $165,224,285$

Devine $258,259,261,262,283$

Dickinson 14, 15, 41, 89, 99, 100, 101, 102, 103, 104, 106, 107, 108, 110, 111, 112, 115, 123, $124,126,128,130,137,139,143,151,152$, $153,155,160,161,165,175,181,183,189$, $195,196,197,219,258,261,265,273,274$, 275, 276, 285

Dobb...14, 82, 90, 123, 124, 125, 126, 127, 128, $147,165,176,185,195,219,258,259,273$, $274,275,285$

Drewnowski $273,285,291$
Durbin ....5, 90, 91, 92, 100, 110, 111, 112, 113, $114,115,117,118,119,120,121,122,123$, $130,135,137,139,140,147,149,150,159$, $161,167,168,170,195,196,197,216,233$, $273,274,275,276,279,285,286$

\section{$\boldsymbol{E}$}

Ebeling $57,58,286$ Engels $30,34,61,68,77,194,275,286$

\section{$\boldsymbol{F}$}

Feijó 20,286

Fransman ......................................... 203, 286 Fusfeld.............................................. 181, 286

G

Gossen.....12, 24, 58, 59, 60, 228, 274, 278, 286 Grossman............217, 218, 219, 223, 227, 286

H

Halm. $83,86,87,102,143,286$

Harper 202,286

Hayek . 5, 7, 8, 17, 18, 20, 21, 22, 23, 24, 27, 40, $43,49,53,54,58,60,63,65,66,69,74,82$, $83,88,90,96,98,99,102,103,107,112$, $126,130,131,132,133,139,143,144,145$, $146,147,148,149,150,151,152,153,154$, $155,156,157,158,159,160,161,162,163$, $164,165,166,167,168,169,170,171,173$, $174,175,176,178,179,180,181,182,183$, $184,185,186,187,188,189,190,191,192$, 193, 195, 196, 197, 198, 199, 200, 201, 202, 206, 207, 208, 209, 210, 211, 212, 214, 215, $216,217,218,219,220,221,222,223,224$, $225,226,227,228,249,251,252,253,257$, $258,260,261,262,265,266,269,270,273$, $274,275,278,279,283,285,286,287,290$, 291, 292, 293

Heilbroner. 249,287

Henderson 205,287

Herbener 208, 286, 287

Hicks 27,287

Hoff... 38, 83, 85, 87, 88, 89, 187, 274, 287, 293

Hoppe $208,273,287$

Horwitz 266, 267, 273, 274, 275, 287

Hurwicz $162,216,217,218,222,275,287$

I

Ikeda. 17,287

$J$

Junker 287

K

Kautsky $35,37,60,83,108,273,287$

Keizer 178,288 
Keynes $18,22,109,288$

Kirzner..144, 150, 187, 192, 207, 208, 209, 266, 288

Knight..........44, 94, 95, 96, 115, 170, 279, 288

Kornai.... 17, 228, 229, 230, 231, 232, 233, 235, 244, 248, 249, 250, 255, 274, 288

Kowalik

183,288

Krink. 268,288

$L$

Lachmann $134,192,203,207,288$

Lange.. 11, 17, 18, 49, 53, 54, 88, 89, 91, 95, 96, 97, 99, 102, 103, 104, 105, 106, 107, 108, $109,110,111,112,113,115,116,117,122$, $123,130,133,137,138,139,142,143,144$, $145,146,147,151,152,153,155,157,159$, $161,162,165,166,168,174,175,176,177$, $180,181,182,183,184,185,186,188,189$, 190, 192, 193, 195, 196, 197, 198, 206, 213, $216,219,220,221,222,223,232,233,240$, 242, 243, 244, 249, 264, 265, 269, 273, 274, 275, 276, 278, 288, 292, 293

Lavoie.31, 54, 75, 130, 175, 176, 179, 184, 189, 190, 191, 192, 200, 202, 203, 204, 227, 252, $258,259,261,262,263,265,266,273,274$, $278,279,288,289$

Lenin. $33,79,137,289$

Lerner ...14, 18, 90, 91, 106, 110, 113, 115, 116, $117,118,119,120,121,122,123,126,127$, $128,130,132,137,141,142,143,147,150$, $153,163,168,170,173,188,195,206,216$, $219,222,242,249,273,274,275,279,285$, 289

Levin 289

Levy..... $242,244,289$

Lippincott. $15,176,289$

M

Machovec $163,190,289$

Makovski ...289

Marx ... 17, 19, 27, 30, 31, 32, 33, 39, 41, 44, 56, $71,75,76,78,88,100,108,250,257,264$, 273, 275, 283, 284, 290, 292

Menger.

$43,70,71,72$

Mill. 29, 290

Mises 7, 8, 10, 11, 12, 13, 14, 16, 17, 19, 22, 24, $26,27,30,37,38,42,43,49,54,56,57,58$, $59,60,62,63,64,70,71,72,73,74,75,76$, $77,78,79,80,81,82,83,84,85,86,87,88$, $89,93,94,95,96,99,102,103,110,111$, $115,122,123,125,127,129,130,131,132$, $133,134,135,136,137,138,139,140,141$, $143,145,146,147,151,152,155,157,159$, $161,163,166,167,170,173,174,175,177$, $178,180,181,183,184,185,186,187,188$, 189, 190, 192, 194, 195, 196, 199, 205, 206, 207, 208, 209, 210, 215, 219, 230, 233, 242, $248,249,260,263,266,269,271,273,274$, $275,278,279,286,287,288,290,291,292$, 293
Murrell $188,189,190,215,290$

$N$

Neurath. 38, 39, 40, 41, 64, 65, 83, 85, 125, 258, $273,275,276,290$

Nove. $16,228,232,233,274,290$

$O$

Ostroy........ $217,219,289$

$\boldsymbol{P}$

Pareto . 12, 24, 38, 42, 45, 46, 47, 48, 49, 51, 54, $62,63,140,145,146,162,164,175,178$, $180,181,183,213,215,223,224,235,290$

Pierson....35, 60, 61, 62, 70, 102, 127, 143, 273, 274, 290

Platão.. 13

Polanyi ... 16, 22, 85, 86, 87, 111, 184, 185, 191, 200, 273, 291

Popper ..13, 16, 20, 21, 134, 164, 200, 201, 202, 215, 226, 267, 284, 291

$\boldsymbol{R}$

Radnitsky 201

Richman 189,291

Robbins ..16, 28, 29, 63, 90, 102, 107, 112, 123, 130, 132, 133, 139, 140, 141, 142, 143, 144, $147,148,149,151,152,155,166,167,175$, $183,185,189,196,219,265,274,275,278$, 291

Roberts $185,186,273,285,291$

Roemer .....14, 15, 217, 219, 220, 221, 227, 228, 229, 231, 233, 234, 235, 236, 237, 238, 239, 240, 243, 247, 253, 254, 255, 256, 273, 274, 275, 276, 283, 286, 288, 289, 291, 292, 293

Rothbard 208, 273, 291

$S$

Salerno ........ 208, 210, 211, 212, 273, 291, 293 Samuelson ......................... 181, 185, 222, 291 Say ................................................28, 29, 291

Schumpeter..... 69, 88, 176, 177, 178, 179, 180, 181, 266, 274, 288, 292

Schweickart .. 238, 249, 250, 273, 275, 283, 292

Shapiro ................................................. 292

Shleifer.242, 243, 245, 246, 247, 248, 256, 273, 274, 275, 292

Soto . $15,54,130,192,292$

Steele.. 19, 34, 35, 60, 68, 71, 95, 100, 103, 110, $185,189,192,292$

Stiebler 57,292

Stiglitz...49, 162, 217, 218, 219, 221, 222, 223, $224,225,226,227,228,235,257,263,273$, 274, 286, 292

Sztyber 292

$T$

Taylor.....89, 96, 97, 98, 99, 101, 103, 107, 108, $110,138,147,151,176,222,271,274,275$, 292 
Thirlby 284, 292, 293

Thomsen 227,292

Tisch. $57,88,89,99,176,273,275$

V

Vaughn ........ 187, 188, 189, 190, 192, 215, 293

Vishny ..242, 243, 245, 246, 247, 248, 256, 273 , 274, 275, 292

Vollrath. 268,288

W

Walras. $46,70,102,106,111,179,293$
Weber. 16, 24, 38, 63, 64, 65, 81, 127, 273, 274, 278, 293

Weisskopf............. 14, 238, 240, 249, 275, 293

Wieser .. 12, 24, 38, 42, 43, 44, 45, 97, 102, 131, $152,178,184,274,293$

Wiseman............. 168, 170, 171, 186, 274, 293

$Y$

Yeager 208, 210, 211, 212, 273, 291, 293

Yunker. 240, 241, 242, 254, 266, 293 


\section{Bibliografia}

Observações:

Algumas das principais contribuições ao debate do cálculo foram publicadas em 2000 pela Routledge em uma coletânea composta por nove volumes intitulada Socialism and the Market: The Socialist Calculation Debate Revisited, editada por Peter Boettke. Nas referências bibliográficas que seguem, quando se tratar de um texto contido na coletânea, indicaremos a edição original do texto seguida da indicação S\&M V n, em que $\mathrm{n}$ indica o volume no qual o texto se encontra. As citações se referem aos números de páginas da edição original, não da coletânea.

Seguiremos a convenção segundo a qual a data original da publicação de um trabalho (quando importante por razões históricas) aparece entre chaves e a data da edição que tivemos acesso se encontra entre parênteses.

Adaman, F. e Devine, P. (1996) "The Economic Calculation Debate; Lessons for Socialists", Cambridge Journal of Economics, Vol. 20, No.5. S\&M V 9.

Arnold, N. S. (1987a) "Marx and the Disequilibrium in Market Socialist Relations of Production", Economics and Philosophy, Vol. 3, No. 1. S\&M V 9.

Arnold, N. S. (1987b) "Further Thoughts on the Degeneration of Market Socialism: A Reply to Schweickart”, Economics and Philosophy, Vol. 3, No. 2.S\&M V 9.

Arnold, N. S. (1987c) "Final Reply to Professor Schweickart", Economics and Philosophy, Vol. 3, No. 2. S\&M V 9.

Arnold, N. S. (1988) "Marx and Disequilibrium in Market Socialist Relations of Production: Reply", Economics and Philosophy, Vol. 3, No. 1. S\&M V 9.

Bartley III, W.W. e Radnitzky, G. (eds.) (1987) Evolutionary Epistemology, Rationality and the Sociology of Science. La Salle: Open Court.

Bardhan, P. e Roemer, J.E. (1992) "Market Socialism: A Case for Rejuvenation", Journal of Economic Perspectives, Vol. 6, No. 3. S\&M V 9.

Bardhan, P. e Roemer, J.E. (1993) (ed.) Market Socialism: The Current Debate. Oxford: Oxford University Press

Bardhan, P. e Roemer, J.E. (1994) "On the Workability of Market Socialism", Journal of Economic Perspectives, Vol. 8, No. 2. S\&M V 9.

Barone, E. (1935) "The Ministry of Production in the Collectivist State", em Hayek (ed.). Collectivist Economic Planning. S\&M V 2.

Bergson, A. (1948) "Socialist Economics", em Ellis, H.S. (ed.) A Survey of Contemporary Economics, vol. 1. Homewood: Richard D. Irwin Inc. 
Bergson, A. (1967) "Market Socialism Revisited", The Journal of Political Economy Vol. 75, No.5. S\&M V 5.

Blaug, M. (1980) Metodologia da Economia. São Paulo: Edusp.

Boettke, P.J. (1998) "Economic Calculation: the austrian contribution to political economy". Advances in Austrian Economics, Vol. 5. Reproduzido em Boettke (2001).

Boettke, P.J. (1990) The Political Economy of Soviet Socialism: The Formative Years. Boston: Kluwer Academic Publishers S\&M V 7.

Boettke, P.J. (2000a) (ed.) Socialism and the Market: The Socialist Calculation Debate Revisited. Londres: Routledge

Boettke, P.J. (2000b) "Introduction: The Theory and Practice of Economic Planning", em Boettke, 2000.

Boettke, P.J. (2001) Calculation and Coordination. Londres: Routledge

Böhm-Bawerk, E. (1959) [1889] Capital and Interest. 3 volumes em 1. South Holland: Libertarian Press

Boland, L.A. (1990) "Understanding the Popperian Legacy in Economics", Research in the History of Economic Thought and Methodology, 7, 1990-92.

Boland, L.A. (1994) "Scientific thinking without scientific method: two views of Popper", in Roger Backhouse (ed.) New Directions in Economic Methodology. Londres: Routledge

Bradley Jr., R. (1981) "Market Socialism: a Subjective Evaluation", Journal of Libertarian Studies, Vol V, No.1

Brus, W. (1972) The Market in a Socialist Economy. Londres: Routledge.

Brus, W (1998) "Market Socialism" em Eatwell, J., Milgate, M. e Newman, P. (eds.) The New Palgrave: a dictionary of economics. Vol 3. Nova York.

Brus, W. e Laski, K (1992) From Marx to the Market: socialism in search of an economic system. Oxford: Oxford University Press e Clarendon Press

Brutzkus, B. (1935) Economic Planning in Soviet Russia. Londres: Routledge. S\&M V3.

Buchanan, J.M. e Thirlby, G. F. (ed.) (1981) L.S.E. Essays on Cost. Nova York: NYU Press.

Buchanan, J.M. (1987) Economics: between predictive science and moral philosophy. Texas A\&M University Press.

Buchanan, J.M. (1993) Custo e Escolha. São Paulo: Instituto Libera1/Inconfidentes. 
Bukharin, N. (1979) The Politics and Economics of the Transition Period, London: Routledge. S\&M V1.

Bukharin, N. (1982) Concerning the New Economic Policy and Our Task, em Selected Writings on the State and the Transition of Socialism, Armonk: M.E. Sharpe Inc. S\&M V 1 .

Bukharin, N. e Preobrazensky, E. (1922) The ABC of Communism. The Communist Party of Great Britain. S\&M V1.

Caldwell, B. (1997) "Hayek and Socialism", Journal of Economic Literature. Vol. 35, No. 4. S\&M V9.

Cassel, G. (1967) [1918] The Theory of Social Economy. New York: Augustus M. Kelley.

Chaloupek, G. K. (1990) "The Austrian Debate on Economic Calculation in a Socialist Economy", History of Political Economy. Vol. 22, No. 4. S\&M V5.

Cottrell, A. e Cockshott, W. P. (1993) "Calculation, Complexity and Planning: The Socialist Calculation debate Once Again", Review of Political Economy. Vol.5, No. 1. S\&M V9.

Dawkins, R. (1998) A Escalada do Monte Improvável. São Paulo: Cia. das Letras.

Demsetz, H. (1969) "Information and Efficiency: another viewpoint", The Journal of Law and Economics. Vol. 12.

Dickinson, H.D. (1933) "Price Formation in a Socialist Economy", The Economic Journal. Vol.43, No. 170. S\&M V4.

Dickinson, H.D. (1939) Economics of Socialism. Oxford University Press

Dobb, M. (1933) "Economic Theory and the Problems of a Socialist Economy", The Economic Journal. Vol.43, No. 172. S\&M V4.

Dobb, M. (1934-5) "Economic Theory and Socialist Economy: A Reply". The Review of Economic Studies, Vol. 2. S\&M V 4.

Drewnowski, J. (1961) "The Economic Theory of Socialism: A Suggestion for Reconsideration", The Journal of Political Economy, Vol. 69, No. 4. S\&M V 5.

Drewnowski, J. (1971) "Drewnowski's Economic Theory of Socialism by Paul Craig Roberts: A Reply", The Journal of Political Economy, Vol. 79, No. 1. S\&M V 5.

Durbin, E.F.M. (1936) "Economic Calculus in a Planned Economy", The Economic Journal. Vol.46, No. 184. S\&M V 4.

Durbin, E.F.M. (1937) “A Note on Mr Lerner's Dynamical Propositions", The Economic Journal. Vol.47, No. 187. S\&M V 4. 
Durbin, E.F.M. (1940) The Politics of Democratic Socialism: An Essay on Social Policy. Londres: Routledge \& Kegan Paul Ltd.

Durbin, E.F.M. (1949) Problems of Economic Planning. Londres: Routledge.

Ebeling, R. (1993) "Economic Calculation under Socialism: Ludwig von Mises and his predecessors", in Herbener, J.M. (ed.) The Meaning of Ludwig von Mises. Auburn: Ludwig von Mises Institute.

Engels, F. (1935) Socialism: Utopian and Scientific. Chicago: Charles H. Kerr \& Co. S\&M V 1.

Feijó, R. (2003) Metodologia e Fisolofia da Ciência. São Paulo: Atlas.

Fleurbaey, M. (1993) "Economic Democracy and Equality: A Proposal", em Bardhan e Roemer (eds.), 1993.

Fransman, M. (1998) "Information, Knowledge, Vision and Theories of the Firm", in Dosi et all, Technology, Organization and Competitiveness. Oxford University Press.

Fusfeld, D.R. (2001) A Era do Economista. São Paulo: Saraiva.

Gossen, H. H. (1983) [1853] The Laws of Human Relations and the Rules of Human Action Derived Therefrom. Cambridge: The MIT Press.

Grossman, S.J. e Stiglitz, J.E. (1996) "Information and Competitive Price Systems", American Economic Review Vol. 66, No. 2

Halm, G. (1935.) "Further Considerations on the Possibility of Adequate Calculation in a Socialist Community", em Hayek (ed.), Collectivist Economic Planning, S\&M V 2.

Harper, D. (1996) Entrepreneuship and the Market Process - An inquiry into the growth of knowledge. Londres: Routledge.

Hayek, F.A. (ed.) (1935) Collectivist Economic Planning. Londres: Routledge. S\&M V 2.

Hayek, F.A. [1937] "Economics and Knowledge”, em Hayek ,1980.

Hayek, F.A. (1940) "Socialist Calculation: The Competitive Solution", Economica, Vol. 7, No. 26. $S \& M V 5$.

Hayek, F.A. [1945] "The Use of Knowledge in Society" em Hayek, 1980.

Hayek, F.A. [1946] "The Meaning of Competition” em: Hayek, 1980.

Hayek, F.A. (1952) The Sensory Order. Chicago: The University of Chicago Press.

Hayek, F.A. (1967) "The Theory of Complex Phenomena", em Studies in Philosophy, Politics and Economics. Londres: Routledge.

Hayek, F.A. (1978) "Competition as a Discovery Procedure", em New Studies in Philosophy, Politics and Economics. Londres: Routledge. 
Hayek, F.A. (1979) [1952] The Counter-Revolution of Science, Indianapolis: Liberty Press.

Hayek, F.A. (1980) Individualism and Economic Order, Chicago: Chicago University Press.

Hayek, F.A. (1982) Law, Legislation and Liberty. Londres: Routledge.

Hayek, F.A (1984) Two Pages of Fiction: The Impossibility of Socialist Calculation. Em Nishiyama, C. e Leube, K.R. (eds.) The Essence of Hayek Hoover Institution Press.

Hayek, F.A (1988) The Fatal Conceit: the errors of socialism, Chicago: Univ. of Chicago Press

Heilbroner, H. (1990) "Analysis and Vision in the History of Modern Economic Thought", Journal of Economic Literature, vol XXVIII.

Henderson, D.R. (1993) "Japan and the Myth of MITI". Em Henderson, D.R. (ed.) The Fortune Encyclopedia of Economics. Nova York: Warner Books Inc.

Herbener, J.M. (1996) "Calculation and the Question of Arithmetic", Review of Austrian Economics, vol 9, no 1.

Hicks, J. (1976) “'Revolutions' in Economics", em S. Latsis (ed.) Method and Appraisal in Economics. Cambridge University Press.

Hoff, T.J.B. [1938] (1981) Economic Calculation in the Socialist Society, Indianapolis: Liberty Press.

Hoppe, H. (1996) "Socialism: A Property or Knowledge Problem?", Review of Austrian Economics, Vol 9, No 1.

Horwitz, S. (1996) "Money, Money prices and the Socialist Calculation Debate", Advances in Austrian Economics, Vol. 3. S\&M V 9.

Horwitz, S. (1998) "Monetary Calculation and Mises's Critique of Planning", History of Political Economy, Vol 30, No. 3.

Hurwicz. L. (1969) "On the Concept and Possibility of Informational Decentralization", The American Economic Review, Vol.59, Issue 2. S\&M V 8.

Hurwicz. L. (1973) "The Design Mechanisms for Resource Allocation", The American Economic Review S\&M V 8.

Ikeda, S. (1997) Dynamics of the Mixed Economy: toward a theory of interventionism, Londres: Routledge.

Junker, J.A. (1995) "Post-Lange Market Socialism: an evaluation of profit-oriented proposals", Journal of Economic Issues. Setembro.

Kautsky, K. (1902) The Social Revolution and On the Day After the Social Revolution. Texto disponível na internet: http://www.marxists.org/archive/kautsky/1902/socrev/index.htm . 
Keizer, W. (1997) "Schumpeter's Walrasian Stand in the Socialist Calculation Debate", in Keizer, W.,Tieben, B. e Zijp, R. (ed.) Austrian Economics in Debate. Londres: Routledge.

Keynes, J.M. (1994) [1938] "Carta a Roy”, em Hausman, D.M. (ed.) The Philosophy of Economics: an anthology. Cambridge: Cambridge University Press.

Kirzner, I. (1976) "Ludwig von Mises and the Economic Calculation under Socialism", em Moss, L (ed.) The Economics of Ludwig von Mises: toward a critical reappraisal. Kansas: Sheed and Ward, Inc.

Kirzner, I. (1985) Competição e Atividade Empresarial, Rio de Janeiro: Instituto Liberal.

Knight, F.H. (1936) "The Place of Marginalist Economics in a Collectivist System", American Economic Review, Vol. 26, No. 1. S\&M V 4.

Kornai, J. (1986) “The Soft Budget Constraint”, Kyklos, Vol 39, No. 1 S\&M V 5.

Kornai, J. (1993) “Market Socialism Revisited”, em Bardham e Roemer (ed.), 1993.

Kowalik, T. (ed) (1994) Economic Theory and Market Socialism. Selected Essays of Oskar Lange. Aldershot:Edward Elgar.

Krink, T. e Vollrath, F. (1997) "Analysing Spider Web-building with Rule-based Simulations and Genetic Algorithms", Journal of Theoretical Biology, vol. 185.

Lachmann, L. (1986) The Market as an Economic Process. Oxford: Basil Blackwell.

Lange, O. (1936-7a) "Mr Lerners Note on Socialist Economics", The Review of Economic Studies, Vol.4, p.143-144 S\&M V 4.

Lange, O. (1936-7b) "On the Economic Theory of Socialism: Part One" The Review of Economic Studies, Vol.4, p.53-71 S\&M V 4.

Lange, O. (1936-7c) "On the Economic Theory of Socialism Part Two", The Review of Economic Studies, Vol.4, p.123-142 S\&M V 4.

Lange, O. (1969) "The Computer and the Market" en Feinstein, C.H. (ed.) Socialism, Capitalism and Economic Growth. Cambridge: Cambridge Unversity Press S\&M V 8.

Lange, O. (1994a) Economic Theory and Market Socialism. Selected Essays of Oskar Lange. Aldershot: Edward Elgar.

Lange, O. (1994b) "The Economic Operation of a Socialist Society: I \& II" em Lange, 1994.

Lange, O. (1994c) "The Practice of Economic Planning and the Optimum Allocation of Resources”. Em Lange, 1994.

Lange, O. (1994d) "From Accounting to Mathematics". Em Lange, 1994

Lavoie, D. (1981a) "Introduction”. Journal of Libertarian Studies. Vol. 5, No.1 
Lavoie, D. (1981b) "A Critique of the Standard Account of the Socialist Calculation Debate", Journal of Libertarian Studies, Vol. 5, No.1.

Lavoie, D. (1985a) Rivalry and Central Planning, Cambridge: Cambridge Economic Press. S\&M V 6

Lavoie, D. (1985b) National Economic Planning: What is Left. Cambridge: Ballinger Publishing Company

Lavoie, D. (1986) "The Market as a Procedure for Discovery and Conveyance of Inarticulate Knowledge", Comparative Economic Studies, Vol. 28, No. 1. S\&M V 8.

Lavoie, D. (1990) "Computation, Incentives and Discovery: The Cognitive Function of Markets in Market Socialism" Annals of the American Academy of Political and Social Science, vol. 507, pág. 72-79. S\&M V 8.

Lenin, V.I. (1920) State and Revolution. Sidney: Australian Socialist Party. S\&M V 1.

Lerner, A.P. (1934) "Economic Theory and Socialist Economy", The Review of Economic Studies, Vol 2, pág. 51-61 S\&M V 4.

Lerner, A.P.(1934-5) “A Rejoinder”, The Review of Economic Studies, Vol 2, pág. $152-$ $154 \mathrm{~S} \& \mathrm{M} \mathrm{V} 4$.

Lerner, A.P. (1936-7) "A Note on Socialist Economics", The Review of Economic Studies Vol. 4 pág. 72-76. S\&M V 4.

Lerner, A.P. (1937) "Statics and Dynamics in a Planned Economy", The Economic Journal, Vol. 47, Issue 186, pág. 253-270. S\&M V 4.

Lerner, A.P. (1938) "Theory and Practise in Socialist Economics" The Revies of Economic Studies, Vol. 6, p’sh. 71-75. S\&M V 4.

Lerner, A.P. (1944) The Economics of Control: Principles of Welfare Economics. Nova York: Macmillan.

Levin, P. (1998) "The Firm, Money and Economic Calculation: Considering the Institutional Nexus of Market Production", American Journal of Economics and Sociology, vol 57:4.

Levy, D. (1999) "The Bias in Centrally Planned Prices", Public Choice, Vol. 67, pág. 213-226. S\&M V 9.

Lippincott, B.E. (1965) [1938] "Introduction" em Lippincott, B.E. (ed) On The Economic Theory of Socialism. Nova York: McGraw-Hill.

Machovec, F.M. (1995) Perfect Competition and the Transformation of Economics. Londres: Routledge.

Makovski, L. e Ostroy, J.M. (1993) "General Equilibrium and Market Socialism: Clarifying the Logic of Competitive Markets", em Bardhan e Roemer (ed.) (1993). 
Marx, K. (1989) Critique of the Gotha Programme. Nova York: International Publishers, pág. 3-23. S\&M V 1.

Mill, J. S. (1996) Princípios de Economia Política, Vol. 1, São Paulo: Nova Cultural.

Mises, L (1935) [1920] "Economic Calculation in a Socialist Commonwealth" em Hayek (ed.) Collectivism Economic Planning, S\&M V 2.

Mises, L (1957) Theory and History: An Interpreation of Social and Economic Evolution. New Haven: Yele University Press.

Mises, L. (1981) [1922] Socialism: An Economic and Sociological Analysis Indianapolis: Liberty Fund.

Mises, L (1993) Bureaucracy. Grove City: Libertarian Press.

Mises, L. (1998) [1949] Human Action: A Treatise on Economics. The Scholar's Edition Auburn: Ludwig von Mises Institute.

Mises, L. (2000) [1938] "The Equations of Mathematical Economics and the Problem of Economic Calculation in a Socialist State". The Quarterly Journal of Austrian Economics, vol 3, No.1.

Mises, L. (2002) [1923] "New Contributions to the Problem of Socialist Economic Calculation”, em Selected Writings of Ludwig von Mises. Indianapolis: Liberty Fund.

Mises, L. (2002) [1928] "Recent Writings Concerning the Problem of Economic Calculation under Socialism, em Selected Writings of Ludwig von Mises. Indianapolis: Liberty Fund.

Mises, L. (s.d.) Uma Crítica ao Intervencionismo, Rio de Janeiro: Nórdica/IL.

Murrell, P. (1983) "Did the Theory of Market Socialism Answer the Challenge of Ludwig von Mises? A Reinterpretation of the Socialist Controversy" History of Political Economy, Vol. 15, No. 1. S\&M V 5.

Neurath, O. (1973) 'Through War Economy to Economy in Kind", Empiricism and Sociology. Dordrecht e Boston: Reidel Publishing C. S\&M V 1.

Nove, A. (1983) The Economics of Feasible Socialism. Londres: George Allen and Unwin.

O'Neill, J. (1989) "Markets, Socialism, and Information: A Reformulation of a Marxian Objection to the Market", Social Philosophy and Policy, Vol. 6, Issue 2, pág. 200-210 S\&M V 9.

Pareto, V. (1984) Manual de Economia Política. São Paulo: Abril Cultural.

Pareto, V. (1949) [1896] Corso di Economia Politica. Giulio Einaudi editore.

Pierson, N.G. (1902) "The Problem of Value in the Socialist Society", em Hayek (ed.). Collectivist Economic Planning, S\&M V 2. 
Polanyi, M. (1962) [1958] Personal Knowledge: Towards a Post-Critical Philosophy. Chicago: The Chicago University Press.

Polanyi, M. (2003) [1951] A Lógica da Liberdade. Rio de Janeiro: Topbooks.

Popper, K.R. (1975) Conhecimento Objetivo: uma abordagem evolucionária. Belo Horizonte/São Paulo: Itatiaia/EDUSP.

Popper, K.R. (s.d.) A Miséria do Historicismo. São Paulo: Cultrix.

Robbins, L. (1932) An Essay on the Nature and Significance of Economic Science. Londres: Macmillan \&Co.

Robbins, L. (1935) The Great Depression. Londres: Macmillian \&Co. S\&M V 5.

Robbins, L. (1937) Economic Planning and International Order. Londres: Macmillian \&Co. S\&M V 5.

Richman, S.L. (1981) "War Communism to NEP: The Road from Serfdom", Journal of Libertarian Studies. Vol. 5, No.1.

Roberts, P.C. (1968) "Drewnowski's Economic Theory of Socialism", The Journal of Political Economy, Vol. 76, Issue 4, Part I. S\&M V 5.

Roberts, P.C. (1971) "Oskar Langes Theory of Economic Planning", The Journal of Political Economy, Vol. 79, Issue 3. S\&M V 5.

Roberts, P.C. (1972) "Revealed Planners Preferences Once Again: A Rebuttal to Drewnowski” The Journal of Political Economy, Vol 80, Issue 3. S\&M V 5.

Roemer. J. E. (1994) A Future for Socialism. Cambridge: Harvard University Press.

Rothbard, M. (1991) "The End of Socialism and the Calculation Debate Revisited", Review of Austrian Economics, vol 5, no 2.

Salerno, J. (1990) "Ludwig von Mises as Social Rationalist", Review of Austrian Economics, vol 4.

Salerno, J. (1993) "Mises and Hayek Dehomogenized", Review of Austrian Economics, vol 6 , no 2 .

Salerno, J. (1994) "Reply to Leland B. Yeager on 'Mises and Hayek on Calculation and Knowledge", Review of Austrian Economics, vol 7, no 2.

Salerno, J. (1996) “A Final Word: Calculation, Knowledge, and Appraisement”, Review of Austrian Economics, S\&M V 9, no 1.

Samuelson, P.A. (1958) Introdução à Análise Econômica. Rio de Janeiro: Agir.

Say, J.B. (1983) Tratado de Economia Política. Os Economistas. São Paulo: Abril Cultural. 
Schumpeter, J.A. (1984) [1947] Capitalismo, Socialismo e Democracia. Rio de Janeiro: Zahar Editores S.A.

Schumpeter, J.A. (1994) [1954] History of Economic Analysis. New York: Oxford University Press.

Schweickart, D. (1987a) "Market Socialist Capitalist Roaders: A Comment on Arnold" Economics and Philosophy, Vol. 3, No. 2. S\&M V 9.

Schweickart, D. (1987b) "A Reply to Arnolds Reply", Economics and Philosophy, Vol. 3, No. 2. S\&M V 9.

Shapiro, D. (1989) "Reviving the Socialist Calculation Debate: A Defence of Hayek Against Lange", Social Philosophy and Policy, Vol. 6, Issue 2. S\&M V 9.

Shleifer, A. e Vishny, W. (1994) "The Politics of Market Socialism", RAND Journal of Economics, Vol. 23, No. 2. S\&M V 9.

Soto, J.H. (1992) Socialismo, Cálculo Económico y Función Empresarial. Madri: Unión Editorial.

Soto, J.H. (1995) "Entrepreneurship and the Economic Analysis of Socialism", in Meijer, G. (ed.) New Perspectives on Austrian Economics. Londres: Routledge.

Steele, D.R. (1981a) "Posing the Problem: the impossibility of economic calculation under socialism", Journal of Libertarian Studies, Vol V, No 1.

Steele, D.R. (1981b) "The Failure of Bolchevism and its Aftermath" Journal of Libertarian Studies. Vol. 5, No.1.

Steele, D.R. (1992) From Marx to Mises: post-capitalist society and the challenge of economic calculation. La Salle: Open Court.

Stiebler, R. (1999) "A Pre-History Of Misesian Calculation: The Contribution Of Adolphe Thiers", The Quarterly Journal of Austrian Economics S\&M V 2, no. 4 (Winter 1999): 41-47.

Stiglitz, J. (1993) "Market Socialism and Neoclassical Economics". em Bardham e Roemer (ed.), 1993.

Stiglitz, J. (1994) Whither Socialism? Cambridge: The MIT Press.

Sztyber, W. (1995) "Early Views on the Socialist Economy". in Meijer, G. (ed.) New Perspectives on Austrian Economics. Londres: Routledge.

Taylor, F.M. (1929) "The Guidance of Production in a Socialist State", The American Economic Review, Vol. 19, Issue 1. S\&M V 4.

Thirlby, J. (1981) [1946] “The Ruler”, em Buchanan. J. M. e Thirlby, G. F. (ed.) L.S.E. Essays on Cost. Nova York: NYU Press.

Thomsen, E. (1992) Prices and Knowledge. Londres: Routledge. 
Vaughn, K. (1980) "Economic Calculation Under Socialism: The Austrian Contribution", Economic Inquiry, Vol. 18. S\&M V 5.

Vaughn, K. (1981) "Introduction", in Hoff, Economic Calculation in the Socialist Society. Indianapolis: Liberty Press.

Vaughn, K. (1994) "The Socialist Calculation Debate". in Boettke (ed.), The Elgar Companion to Austrian Economics. Cheltenhan: Edward Elgar.

Walras, L. M.E. (1983) Compêndio dos Elementos de Economia Política Pura. Os Economistas. São Paulo: Abril Cultural.

Weber, M. (1997) [1922] Economia y Sociedad, México: Fondo de Cultura Económica.

Weisskopf, T.E. (1993) "A Democratic Enterprise-Based Market Socialism”, em Bardhan e Roemer (eds.), 1993.

Wieser, F. (1889) Natural Value. Texto eletrônico disponível em: http://www.socserv.socsci.mcmaster.ca/ econ/ugcm/3113/index.html .

Wiseman, J. (1981) [1953] "Uncertainty, Costs, and Collectivist Economic Planning", in Buchanan. J. M. e Thirlby, G. F. (ed.) L.S.E. Essays on Cost, Nova York: NYU Press. Reimpresso em S\&M V 5.

Yeager, L. (1994) "Mises and Hayek on Calculation and Knowledge", Review of Austrian Economics. vol 7 no 2.

Yeager, L. (1996) "Rejoinder: Salerno on Calculation, Knowledge and Appraisement", Review of Austrian Economics, vol 9, no 1.

Yeager, L. (1997) "Calculation and Knowledge: Let's Write Finis", Review of Austrian Economics, Vol 10, No. 1.

Yunker, J.A. (1995) "Post Lange Market Socialism: an evaluation of profit-oriented proposals", Journal of Economic Issues, September. 